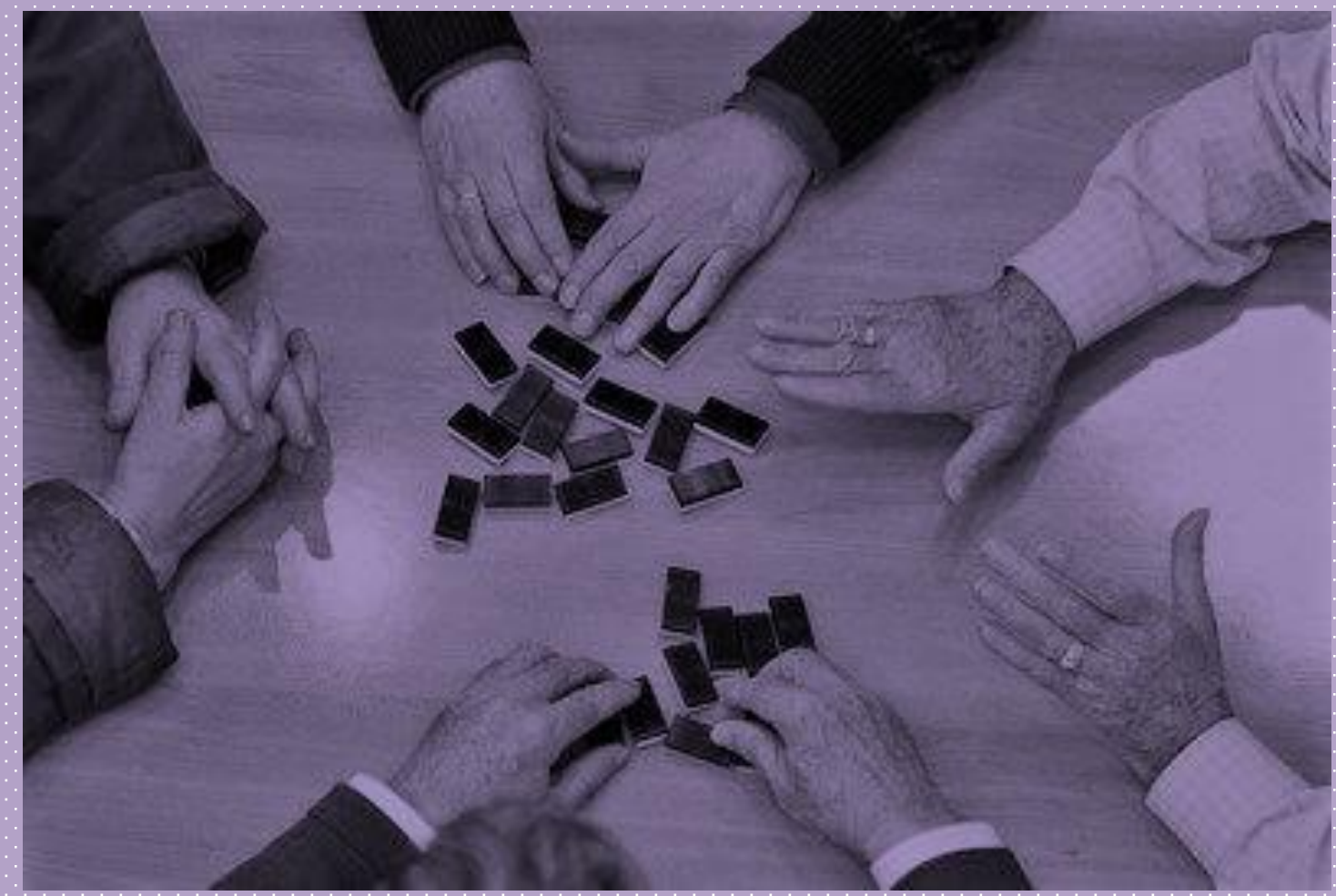

Análisis de las relaciones sociales y la fragilidad en mayores de 75 años residentes en Castellón de la Plana

Antonia López Martínez

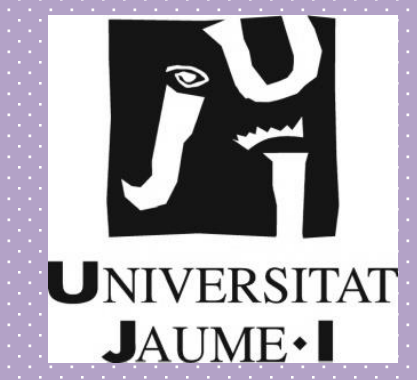

Tesis Doctoral

Castellón, 2017 
Tesis Doctoral

\title{
Análisis de las relaciones sociales y la fragilidad en mayores de 75 años residentes en Castellón de la Plana
}

\author{
Antonia López Martínez \\ Programa de doctorado en Ciencias de la Salud
}

Dirección:

Dra. María Pilar Molés Julio

Castellón, 2017 



\section{Mitos y estereotipos de las relaciones sociales}

Las personas mayores son el grupo de población con mayor variabilidad interindividual, con diferencias biológicas, en las características psicológicas, sociales, culturales.

Las personas mayores están enfermas, tienen dependencia funcional y son frágiles Si bien es cierto que las personas mayores padecen un número elevado de patologías crónicas, cuando se les pregunta acerca de la percepción que tienen sobre su salud, tres de cada cuatro personas dicen tener buen estado de salud; además, a pesar de estas patologías, mantienen un buen nivel funcional para la realización de las actividades de la vida diaria, pueden vivir solos y tener una vida totalmente autónoma.

Los mayores están solos y aislados. Está muy extendida la idea de que las personas mayores no tienen relaciones sociales, que están aisladas y por tanto deprimidas. Sin embargo, las personas mayores, en general, mantienen buenas relaciones y apoyos sociales, con una red social menos extensa (dado que fallecen muchas de sus amistades, e incluso la pareja) que en la juventud, pero más gratificante y más leal, principalmente con sus familias y sus hijos. Los fallos de memoria son la queja subjetiva más frecuente entre las personas mayores, lo que provoca un mayor temor al posible padecimiento de la demencia y la percepción de deterioro y envejecimiento que no se evidencia mediante pruebas diagnósticas.

Los mayores son algo rígidos pero se van adaptando a los cambios Los rasgos de personalidad se mantienen a lo largo de toda la vida. 



\section{Mitos}

- El mito de "la improductividad". El jubilado es considerado como no productivo, no consumista, no útil y es soportado como una carga para la Sociedad.

- El mito del "descompromiso o desvinculación social". Se le considera como una persona retirada de los intereses vitales, como si estuviera fuera de la circulación.

- El mito del "aislamiento social". Se suele considerar a la persona mayor como alguien aislado de su familia y un recluido de la Sociedad.

- También se cree que las personas mayores sienten menos interés por "El sexo". Cuando es justamente en esta etapa cuando aumenta la aptitud emocional y la capacidad de amar.

- El mito sobre "la incapacidad de aprender". Hoy es sabido el deseo que tienen las personas mayores por aprender cosas que quizá no pudieron aprender en su juventud y de ahí la proliferación de Escuelas de aprendizaje para la Tercera Edad y de los cursos para el Aprendizaje permanente de Adultos.

- El mito de "la inflexibilidad". Se le considera incapaz de cambiar y de adaptarse a las nuevas situaciones. Cuando hoy más que nunca las Personas Mayores buscan el aprendizaje y la cultura en todos los sentidos para estar más acordes con los cambios que aporta esta sociedad tecnológica y cambiante.

- El mito del "conservadurismo". Es verdad, que la persona mayor es conservadora en el buen sentido de la palabra porque es la depositaria de las tradiciones y del saber hacer, pero también sabe adaptarse a los nuevos tiempos con una gran apertura de espíritu. 



\section{AGRADECIMIENTOS}

Quiero mencionar a todas aquellas personas que de una forma u otra han estado ahí apoyándome en la realización de esta tesis.

A la Dra. María Loreto Masía que siempre estuvo ahí, con sus consejos, observaciones, orientaciones me ha ido formando durante la tesis.

A la Dra. Pilar Moles que me ha ayudado guiado como una buena compañera durante la tesis, a la que sin ella este proyecto no se hubiese podido llevar a cabo.

A Pilar, Esperanza, Yolanda, Joan, Martín y Julián por ser parte de este proyecto y porque continuemos trabajando en él. También a todos esos compañeros que nos han facilitado que nuestro trabajo de campo se pudiera llevar a cabo de la mejor manera posible. Y a esas personas "Mayores" que tan amablemente han querido formar parte de este proyecto, sin ellas no se podría haber llevado a cabo.

Agradecer a mi familia su apoyo y paciencia pero en especial a mi marido por la paciencia, apoyo y comprensión que ha tenido durante este tiempo, a mis hijas y nietos para por haberles robado un poco de su tiempo y que sepan que nunca es tarde cuando una persona quiere conseguir una meta que con esfuerzo podrán conseguir todo lo que se propongan. 

RESUMEN

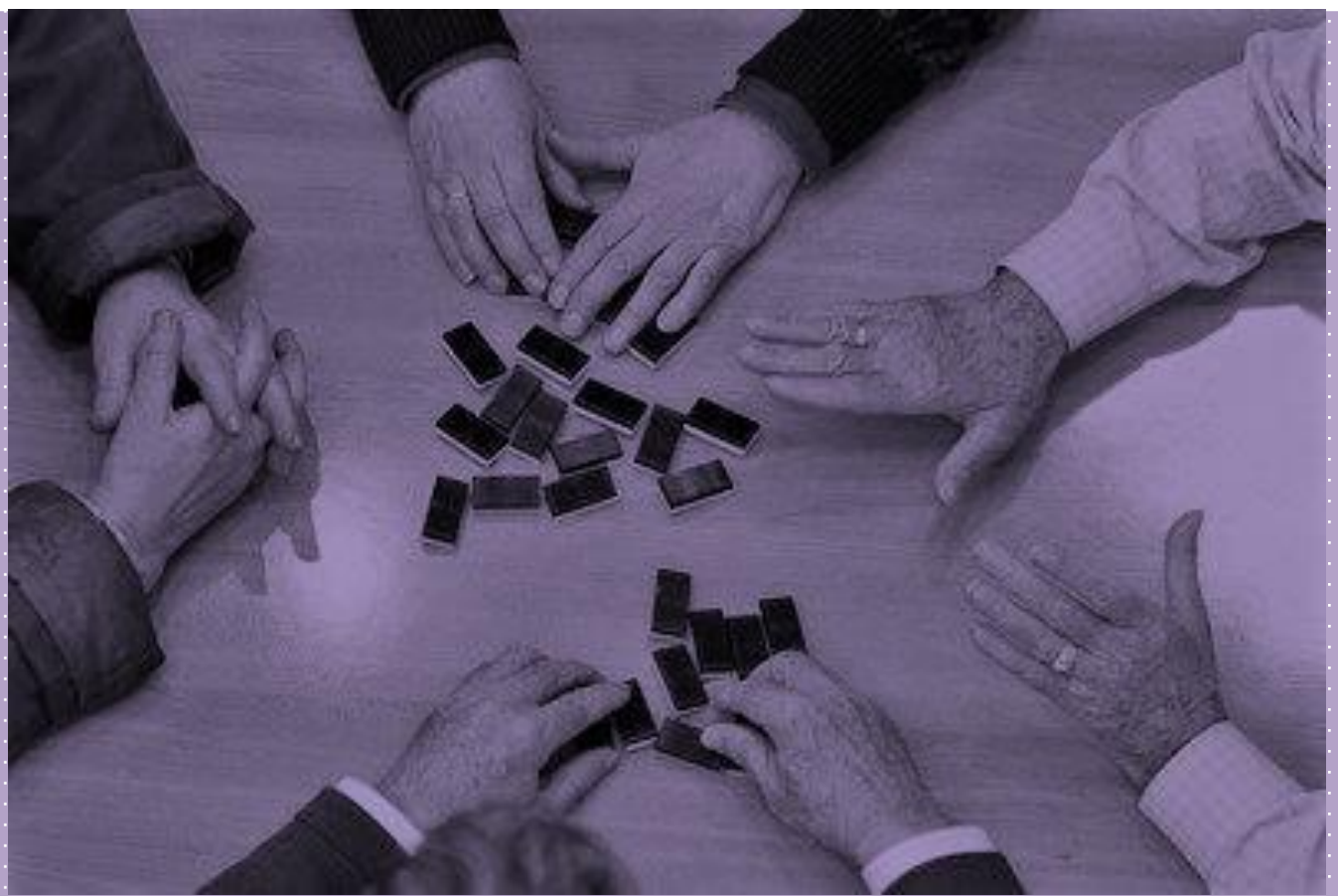





\section{RESUMEN}

Título: Análisis de las relaciones sociales y la fragilidad de las personas mayores de 75 años residentes en Castellón de la Plana.

Objetivos: Describir y Analizar la influencia de las relaciones sociales con la fragilidad y las características sociodemográficas, hábitos y estado de salud de la población mayor.

Metodología: Estudio observacional de corte transversal basado en la recogida de datos individual. La muestra total fue de 326 personas mayores de 75 años de edad, residentes en Castellón de la Plana. Se estudian todas las variables recogidas en las diferentes dimensiones del cuestionario. Como variables dependientes encontramos los mecanismos psicosociales y las relaciones sociales. Entre las variables independientes están los factores sociodemográficos, el estado de salud y los hábitos de salud. Para la recogida de información se han utilizado instrumentos de medida validados, incluidos en la encuesta FRALLE (fragilidad Castellón).

Resultados: Sobre la relación entre las redes sociales y la fragilidad podemos destacar que todos los índices son significativos con una media de 2,41 para vínculos familiares, 1,45 para actividades comunitarias y 4,39 para la diversidad de la red .En la regresión logística encontramos Odds Ratio (OR) de 0,073 en el apoyo emocional recibido y la fragilidad.

Conclusiones: Parece pertinente potenciar las relaciones sociales y psicosociales que afectan al estado de salud de los mayores, y en particular lo que afecta a los más frágiles y prefrágiles, a través de intervenciones por grupos de población que mejoren la fragilidad a partir de la mejora de las relaciones sociales.

Palabras Clave: Anciano, Comunidad, Relaciones, Fragilidad, Familia. 

ABSTRACT

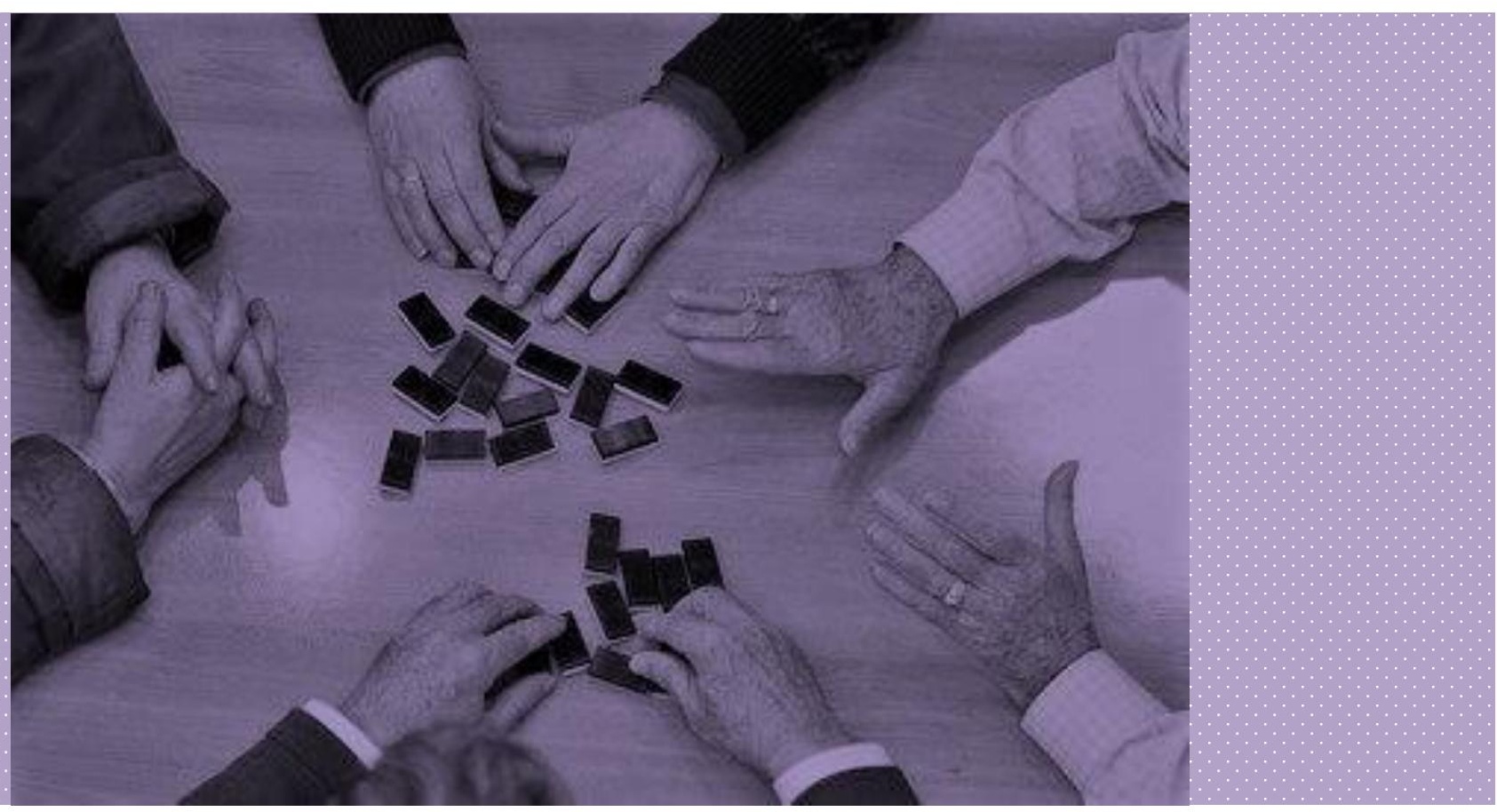





\section{ABSTRACT}

Title: Analysis of social relationships and fragility of people over the age of 75 living in Castellón de la Plana.

Objectives: Describing and analyzing the influence of social relationships with fragility and sociodemographic characteristics, habits and health conditions of the elderly population.

Method: Transversal observational study based on individual data collection. The total sample is composed of 326 elderly people over the age of 75 living in Castellón de la Plana. All variables encompassed in the dimensions of the questionnaire are studied. Dependent variables include psychosocial mechanisms and social relationships. Independent variables include sociodemographic factors as well as health status and health habits. Validated measurement instruments included in the FRALLE questionnaire (fragility Castellón) were used to gather information.

Results: Concerning the connection between social relationships and fragility, it is worth noting that all rates are significant, with an average of 2.41 for family ties, 1.45 for community activities, and 4.39 for the diversity of social ties. Logistic regression shows Odds Ratio (OR) 0.073 related to the emotional support received and fragility.

Conclusions: It seems appropriate to foster social and psychosocial relationships affecting the health condition of the elderly, especially those affecting fragile and pre-fragile subjects, by conducting interventions according to population groups improving fragility on the basis of social relationship improvement.

Keywords: Elderly, Community, Relations, Fragility, Family 



\section{Índice}

Introducción

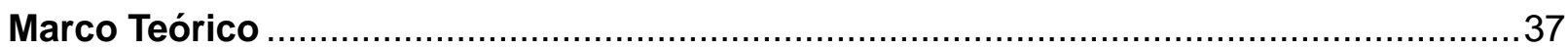

2.1. Definición y características propias de la persona mayor .........................................37

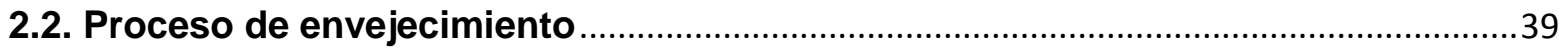

2.3. Definición de envejecimiento con éxito, saludable y activo .....................................4

2.4. Determinantes del envejecimiento con éxito, saludable, activo y competente .....43

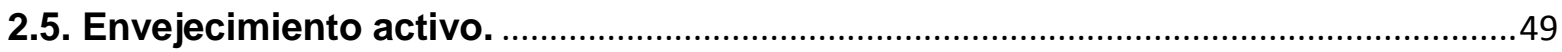

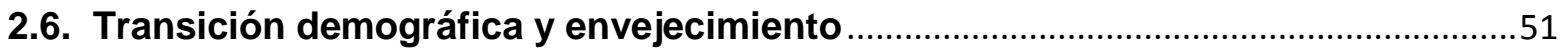

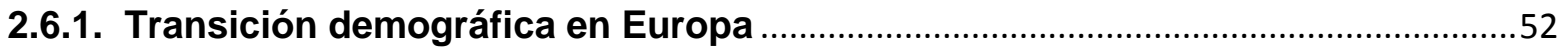

2.6.2. Transición demográfica en la Comunidad Valenciana ...........................................55

2.7 Conceptos generales de geriatría, gerontología y su aplicación en el ambito de la

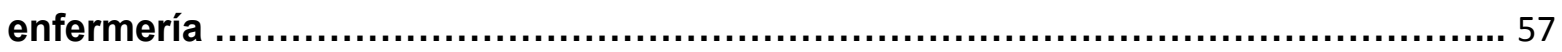

2.8. Envejecimiento normal y personas mayores frágiles (dependencia) ....................60

2.9. Hábitos de Salud de las Personas Mayores ............................................................62

2.10. Las relaciones sociales, red social y apoyo social ...............................................63

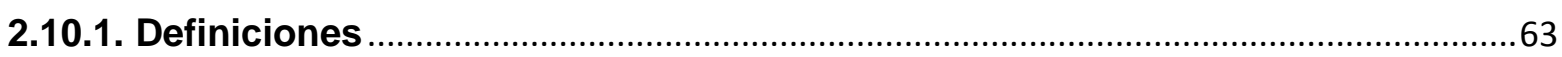

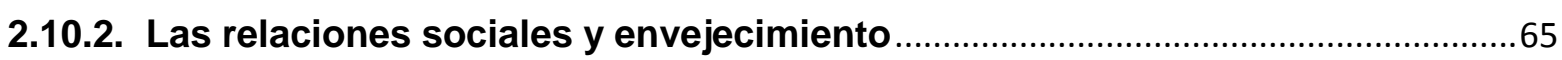

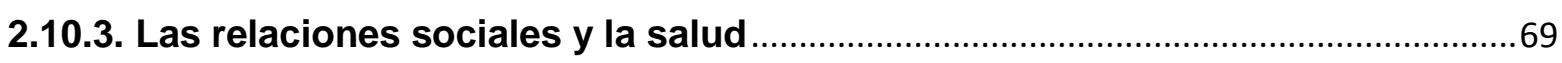

2.10.4. Factores asociados a las relaciones sociales...................................................... 75

2.10.5. Instrumentos para analizar las relaciones sociales.............................................. 84

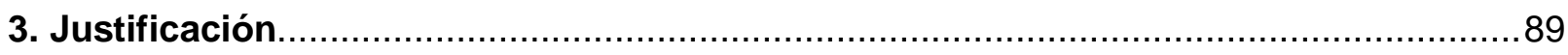

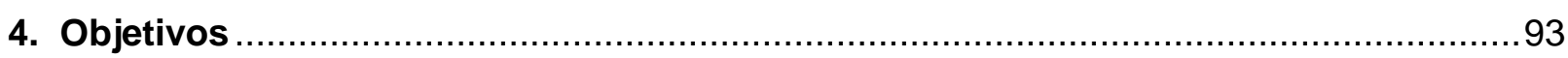

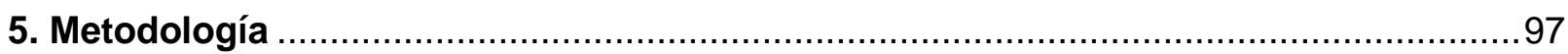

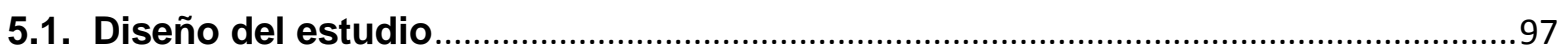

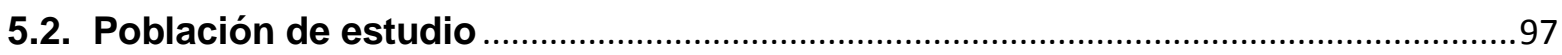

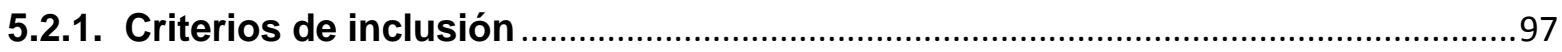

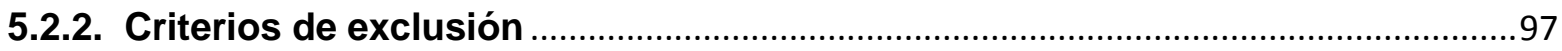

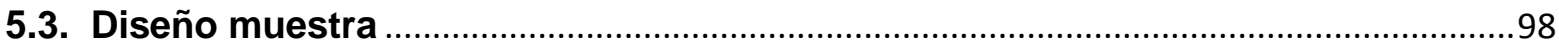

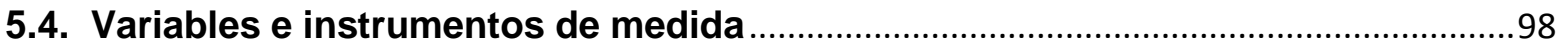

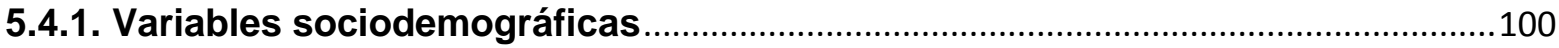

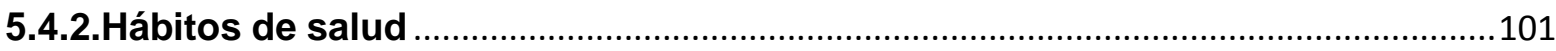


5.4.5. Relaciones sociales

5.5. Recogida de datos 107

5.6. Consideraciones éticas. 108

5.7. Análisis estadístico 108

6. Resultados

6.1. Características sociodemográficas globales de la población estudiada por sexo

6.2. Resultados de los hábitos de salud por sexo

6.3. Características del estado de salud de la población separada por sexo

6.4. Resultados del análisis descriptivo de las relaciones sociales y los mecanismos psicosociales separado por sexo.

6.4.1. Estructura de la red social de los encuestados en cuanto la cantidad de personas con las que mantiene relación

6.4.2. Estructura de la red social de los encuestados en cuanto la frecuencia de relación en términos de contacto a modo de vistas con otras personas

6.4.3. Estructura de la red social de los encuestados en cuanto la frecuencia de relación en términos de contacto a modo de vistas con otras personas

6.4.4. Estructura de la red social de los encuestados en cuanto a la distancia de la persona más cercana conocida o familiar.

6.4.5. Presencia de confidente y tipo de relación de los encuestados.

6.4.6 Participación en actividades comunitarias de los encuestados.

6.4.7. Relaciones sociales en forma de redes sociales. Mecanismos psicosociales de los encuestados. Resultados separados por sexo

6.4.8. Índices globales de las redes sociales de los encuestados según las características sociodemográficas.

6.4.9. Resultados de los índices globales de la dimensión Mecanismos psicosociales y su relación con las características sociodemográficas

6.4.10. Resultados del análisis de las redes sociales (índices globales) relacionados con hábitos de la salud

6.4.11. Redes sociales (índices globales) y su relación con enfermedades o problemas de salud más severos

6.4.12. Mecanismos psicosociales (índices globales) y su relación con hábitos de salud

6.4.13. Mecanismos psicosociales (índices globales) relacionados con estado de salud. 
6.5. Resultados del análisis de asociación entre las relaciones sociales de la población estudiada y su grado de fragilidad, separado por características sociodemográficas y su relación con hábitos y estado de salud.

6.5.1. Características del grado de fragilidad en función de las relaciones sociales 134

6.6. Asociación entre las relaciones sociales y la fragilidad en presencia de características sociodemográficas, estado y hábitos de salud.

7.Discusión

7.1. Características sociodemográficas globales de la población estudiada por sexo

7.2. Características de los hábitos de salud por sexo

7.3. Características del estado de salud de la población separado por sexos 149

7.4. Características del grado de fragilidad en función de las relaciones sociales

jError! Marcador no definido.

7.5. Asociación entre las relaciones sociales y la fragilidad en presencia de características sociodemográficas estado y hábitos de salud jError! Marcador no definido.

7.5.1. Estructura de la red social de los encuestados en cuanto a la frecuencia de relación visual y oral con otra personas

7.5.2. Estructura de la red social de los encuestados en cuanto a la distancia de la persona más cercana

7.5.3. Participación en actividades comunitarias de los encuestados.

7.5.4. Relaciones sociales en forma de redes sociales. Mecanismos psicosociales de los encuestados. Resultados separados por sexo.

7.6. Características de las relaciones sociales y los mecanismos psicosociales......155

7.6.1. Redes sociales y mecanismos psicosociales según características sociodemográficas de la población a estudio

7.6.2. Resultados de los índices globales de la dimensión mecanismos psicosociales y su relación con las características sociodemográficas

7.6.3. Resultados del análisis de las redes sociales (índices globales) relacionados con los hábitos de salud.

7.6.4. Mecanismos psicosociales (índices globales) y su relación con hábitos de salud. 160

7.6.5. Redes sociales (índices globales) y su relación con el estado de salud 160

7.6.6. Mecanismos psicosociales (índices globales ) relacionados con estados de salud. 161

7.7. Características del grado de fragilidad en función de las relaciones sociales ...162

7.8. Asociación entre las relaciones sociales y la fragilidad en presencia de características sociodemográficas estado y hábitos de salud

7.9. Limitaciones del estudio. 165 
7.10 Futuras líneas de investigación. 166

8. Conclusiones 170

9. Bibliografía 173

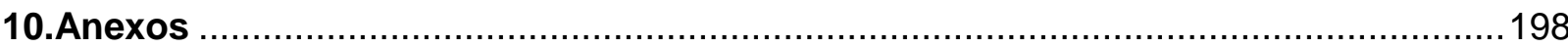

ANEXO 1.

ANEXO 2.

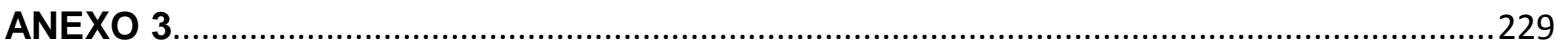

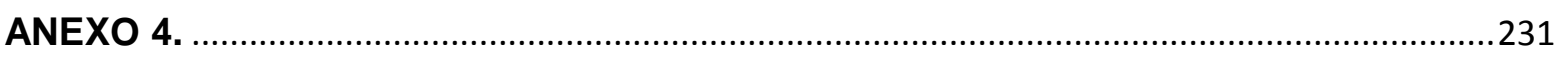

ANEXO 5. 


\section{INDICE DE FIGURAS}

Figura 1: Modelo conceptual de Berckman y Glass en el que se inscribe la tesis.... .47

Figura 2. Determinantes de envejecimiento activo. 49

Figura 3. Determinantes de salud según Lalonde. .51

Figura 4. Población de 65 y más años en la Unión Europea (18,4\%), 2014. .52

Figura 5. Diferencia entre la población de hombres y mujeres por franja de edad, 2015 .54

Figura 6. Pirámide de la población total de la Comunidad Valenciana. .55

Figura 7. Pirámide de la población de Castellón de la Plana. .55

Figura 8. Componentes de la red social. .72 


\section{INDICE DE TABLAS}

Tabla 1. Evolución de la población mayor, 1900-2061 ......................................53

Tabla 2. Factores que influyen en la fragilidad.........................................60

Tabla 3. Distribución de la muestra estudiada por centro de salud: recuento (n) y frecuencia (\%)

Tabla 4. Características sociodemográficas globales por sexo: recuento $(n)$ y frecuencia (\%)

Tabla 5. Características de hábitos de salud por sexo: recuento (n) y frecuencia (\%)...114

Tabla 6. Características del estado de salud por sexo: recuento (n) y frecuencia (\%)...115

Tabla 7. Estructura de la red social sexo: recuento (n) y frecuencia (\%). 120

Tabla 8. Estructura de la red social respecto al contacto visual por sexo: recuento (n) y frecuencia $(\%)$.

Tabla 9. Estructura de la red social y frecuencia de los contactos por sexo: recuento (n) y frecuencia (\%)

Tabla 10. Estructura de la red social distancia a la que viven los contactos por sexo: recuento $(n)$ y frecuencia $(\%)$

Tabla 11. Características de la presencia de confidente y tipo de relación de los encuestados por sexo: recuento $(n)$ y frecuencia $(\%)$.

Tabla 12. Características de la participación en actividades comunitarias de los encuestados por sexo: recuento $(n)$ y frecuencia $(\%)$.

Tabla 13. Redes sociales de los encuestados por sexo: Media y Deviación estándar (DE)

Tabla14. Mecanismos psicosociales de los encuestados por sexo: Media y Deviación estándar (DE).....

Tabla 15. Las redes sociales (índices globales) según las características sociodemográficas: media y desviación estándar (DE). 128

Tabla 16. Los mecanismos psicosociales (índices globales) según las características socioeconómicas: media y desviación estándar (DE). 
Tabla 17. Las redes sociales (índices globales) según los hábitos de salud: media y desviación estándar (DE).

Tabla 18. Redes sociales (índices globales) según el estado de salud: media y desviación estándar (DE)....

Tabla19. Los mecanismos psicosociales (índices globales) según los hábitos de salud: media y desviación estándar (DE).

Tabla 20. Mecanismos psicosociales (índices globales) según el estado de salud: media y desviación estándar (DE)

Tabla 21. Grado de fragilidad en de la red social con respecto al número de familiares: recuento $(\mathrm{n})$ y frecuencia $(\%)$ 133

Tabla 22. Grado de fragilidad en la estructura de la red social respecto al contacto visual: recuento $(\mathrm{n})$ y frecuencia $(\%)$. 134

Tabla 23. Grado de fragilidad en la estructura de la red social respecto a frecuencia de los contactos: recuento $(\mathrm{n})$ y frecuencia $(\%)$ 136

Tabla 24. Grado de fragilidad en la estructura de la red social respecto a la distancia a la que viven los contactos: recuento (n) y frecuencia (\%).... 137

Tabla 25. Grado de fragilidad en la estructura de la red social respecto a las características de la presencia de confidente y tipo de relación de los encuestados: recuento $(\mathrm{n})$ y frecuencia $(\%)$. 138

Tabla 26. Grado de fragilidad en la estructura de la red social respecto a las características de la participación en actividades comunitarias de los encuestados: recuento $(\mathrm{n})$ y frecuencia $(\%)$ 139

Tabla 27. Las redes sociales (índices globales) según la fragilidad: media y desviación estándar (DE)

Tabla 28. Mecanismos psicosociales (índices globales) según la fragilidad: media y desviación estándar (DE)

Tabla 29. Odds Ratio (OR) e intervalos de confianza al 95\% (IC95\%) del modelo de regresión logística binaria que analiza la posibilidad de presentar fragilidad 


\section{LISTADO DE SIGLAS Y ABREVIATURAS}

ABVD: Actividades Básicas de la Vida Diaria

AIVD: Actividades Instrumentales de la Vida Diaria

ALSA: Australian Longitudinal Study of Ageing

AVD: Actividades de la Vida Diaria

CASP-19: Teoría de la satisfacción de la vida

CES-D: Center for Epidemiological Studies-Depression

CHS: Estudio de Salud Cardiovascular

CLESA: Determinantes internacionales de calidad de vida y servicios sanitarios para las personas mayores

DCL: Demencia cognitiva leve

DSM: Demencia severa de memoria

DSM y VI: Demencia severa de memoria y deterioro cognitivo ligero

ENS: Encuesta Nacional de Salud

EPESE: Established Populations for Epidemiology Studies of the Elderly

ESB92: Encuesta de Salud de Barcelona, 1992

FRAGILIDAD: Fragilidad y Dependencia en Albacete

IC: Intervalo de confianza IF: Índice de fragilidad

IMC: Índice de Masa Corporal 
INE: Instituto Nacional de Estadística

LASA: Longitudinal Aging Study Amsterdam

MNA-SF: Test Mini Nutritional Assessment Short Form

NHP: Nuttingham Health Profile

OMS: Organización Mundial de la Salud

OR: Odds Ratio

OARS-MFAQ: Older Americans Resources and Services Multidimensional Functional Assessment Questionnaire

PASE: Physical Activity Scale for the Elderly

SEEGG: Sociedad Española de Enfermería de Geriatría y Gerontología

SOC: Selección, Optimización y Compensación

USA: United States of America 
INTRODUCCIÓN

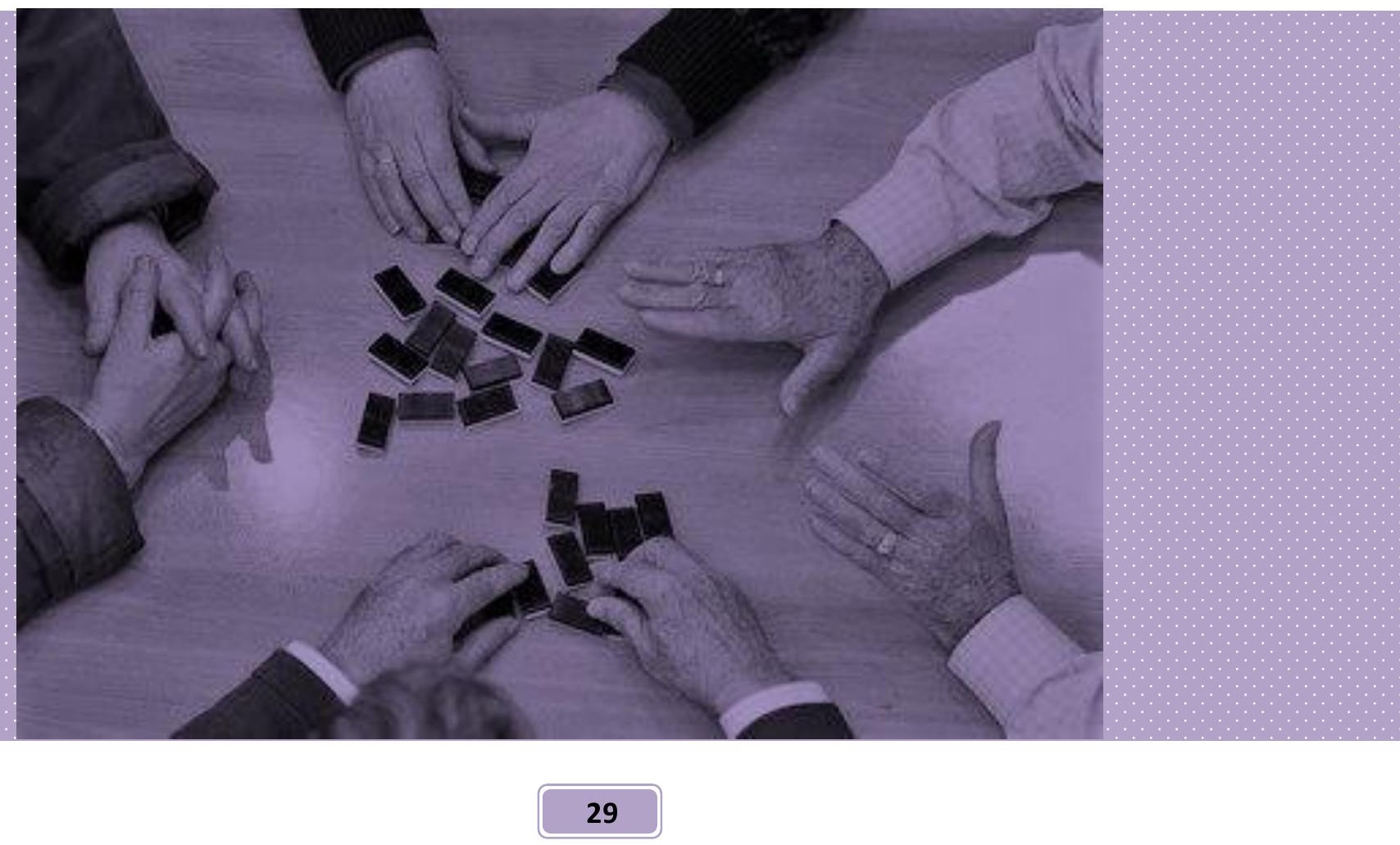





\section{Introducción}

El aumento de la población mayor en el mundo es ya un hecho contrastado. Según la Organización mundial de la salud (OMS) (1) en la mayoría de países la proporción de personas mayores está aumentando más rápido que los otros grupos de edad. La población mayor del mundo (personas de 60 o más años de edad) se estima en 650 millones, y se prevé llegue a 2000 millones en 2050 (2).

En el siglo veinte se produjo un incremento de la longevidad humana en los países desarrollados que ha impulsado, estudios causales, para atender las necesidades emergentes de la nueva población. Tal como afirma Gómez (3) la esperanza de vida se ha alargado de forma excepcional, esta situación alegra y a la vez pone en alerta al ser humano debido a que el número de personas envejecidas es muy elevado y en años anteriores no se había dado tal circunstancia demográfica. De tal forma que el envejecimiento de la población es un triunfo, propio de sociedades desarrolladas, porque supone mejoras médicas, ambientales, físicas, sociales, etc. pero también es un desafío porque la sociedad debe adaptarse y contribuir a la mejora de la calidad de vida en el envejecimiento, con la intención de prevenir o paliar el declive de funciones de la persona así como situaciones de dependencia.

Entre los retos que se presentan, está el fomento de la salud y el bienestar en la vejez, también el cuidado que necesitan las personas que envejecen, potencialmente dependientes, los beneficios psicosociales de la actividad física, la calidad de vida, la influencia de los estilos de vida en las imágenes y actitudes frente al envejecimiento, la educación y la formación en esta etapa de la vida $(4,5)$.

El envejecimiento se asocia a fragilidad que, desde un punto de vista fisio-patológico es el resultado de una serie de alteraciones biológicas y fisiológicas que acompañan en una menor o mayor proporción al envejecimiento (2).

En la actualidad, los 60 años de edad se define por gobiernos y organizaciones internacionales como la del "adulto mayor", no obstante las expectativas de vida varían en diferentes escenarios y hay muchos factores que afectan el proceso de envejecimiento de 
una persona. Algunas personas podrían ser "viejas" a los 35 años; otras viven en plena forma y productiva cumplidos ya los 100 años. En muchos lugares las personas no definen su edad en términos de cuantos años han vivido, sino en términos de lo que son capaces de hacer (5).

Para la OMS (1) hay muchos factores que pueden influir en el buen envejecimiento como: hábitos alimentarios, la actividad física, exposición a riesgos para la salud como el fumar de forma habitual, el consumo nocivo de alcohol o el consumo de sustancias tóxicas.

Autores como Villar (6) definen un buen envejecimiento como un proceso crucial. Según señala este autor, es la capacidad para iniciar procesos adaptativos, que maximicen la probabilidad de obtener ganancias, y minimizar la probabilidad de experimentar pérdidas, así como prolongar los estados que las personas que consideran satisfactorios y que permiten regular las pérdidas cuando éstas son inevitables (7-10).

También Villar (6), defiende que el modelo de envejecimiento exitoso ha potenciado la investigación sobre los factores para un envejecimiento satisfactorio: biológicos, comportables y sociales. Pero también este modelo, establece unos criterios universales a los que sólo pueden llegar un número muy reducido de personas y quedan fuera aquellas que presentan algún tipo de discapacidad, de exclusión social, o que presentan un estado muy avanzado de envejecimiento. En este sentido, cabe destacar que para alcanzar una longevidad satisfactoria, debe lograrse un envejecimiento saludable, etapa esta última que comienza mucho antes de los 60 años y que solo puede obtenerse desarrollando desde edades tempranas hábitos y estilos de vida saludables, así como realizando prevención temprana de algunas enfermedades y discapacidades (11).

Desde hace décadas que se estudia la influencia de las relaciones sociales sobre la salud ya que los individuos más aislados socialmente tienen peor salud física y psicológica y mayores probabilidades de morir. Pero en los últimos años se duplican los estudios que revelan la influencia de las relaciones sociales en la morbilidad, mortalidad o discapacidad (12-14). 
El primer modelo conceptual sobre el efecto de las relaciones sociales en la salud fue propuesto con la teoría del apoyo social, como un efecto protector de las relaciones sociales. Los diseños de los estudios relacionados son de diversa metodología estudios ecológicos, observacionales y experimentales. Todos los revisados, estudian distintas medidas de redes, apoyo y cohesión social en distintas etapas de la vida y exploraban su relación con variables de salud diversas: bajo peso al nacer, complicaciones del embarazo, síntomas autor referidos, uso de medicación, recuperación tras cirugía, tensión arterial, cardiopatía isquémica, artritis, tuberculosis, depresión, alcoholismo o muerte $(4,15)$.

El énfasis reciente en los apoyos sociales de las personas mayores se debe a que en la vejez se experimenta un debilitamiento de las redes sociales a través de la pérdida de la pareja, los amigos y compañeros siendo la soledad uno de los factores relacionados con la fragilidad y la dependencia. A su vez la existencia de redes de apoyo social en las edades avanzadas permite la integración social de las personas y evita el aislamiento. $(16,17)$

Existe una preocupación por estudiar las relaciones sociales en los países desarrollados que están justificadas, porque el Estado no puede asegurar los recursos suficientes para responder a las necesidades de las personas mayores con una mayor dependencia relacionada sobre todo con el aumento de la esperanza de vida. De ahí que las investigaciones relacionadas con el apoyo informal y las redes sociales, su evolución con la edad y como contribuyen a disminuir las situaciones de fragilidad y aumentar el bienestar de las personas mayores se hayan incrementado en los últimos tiempos.

Con este objetivo se presenta esta investigación que tiene por objeto conocer las características de la población mayor de Castellón respecto a las posibles relaciones entre fragilidad y relaciones sociales para ello contamos con la encuesta FRALLE que consta de nueve dimensiones estructuradas en escalas validadas que nos ayudara en nuestro cometido. 



\section{MARCO TEÓRICO}

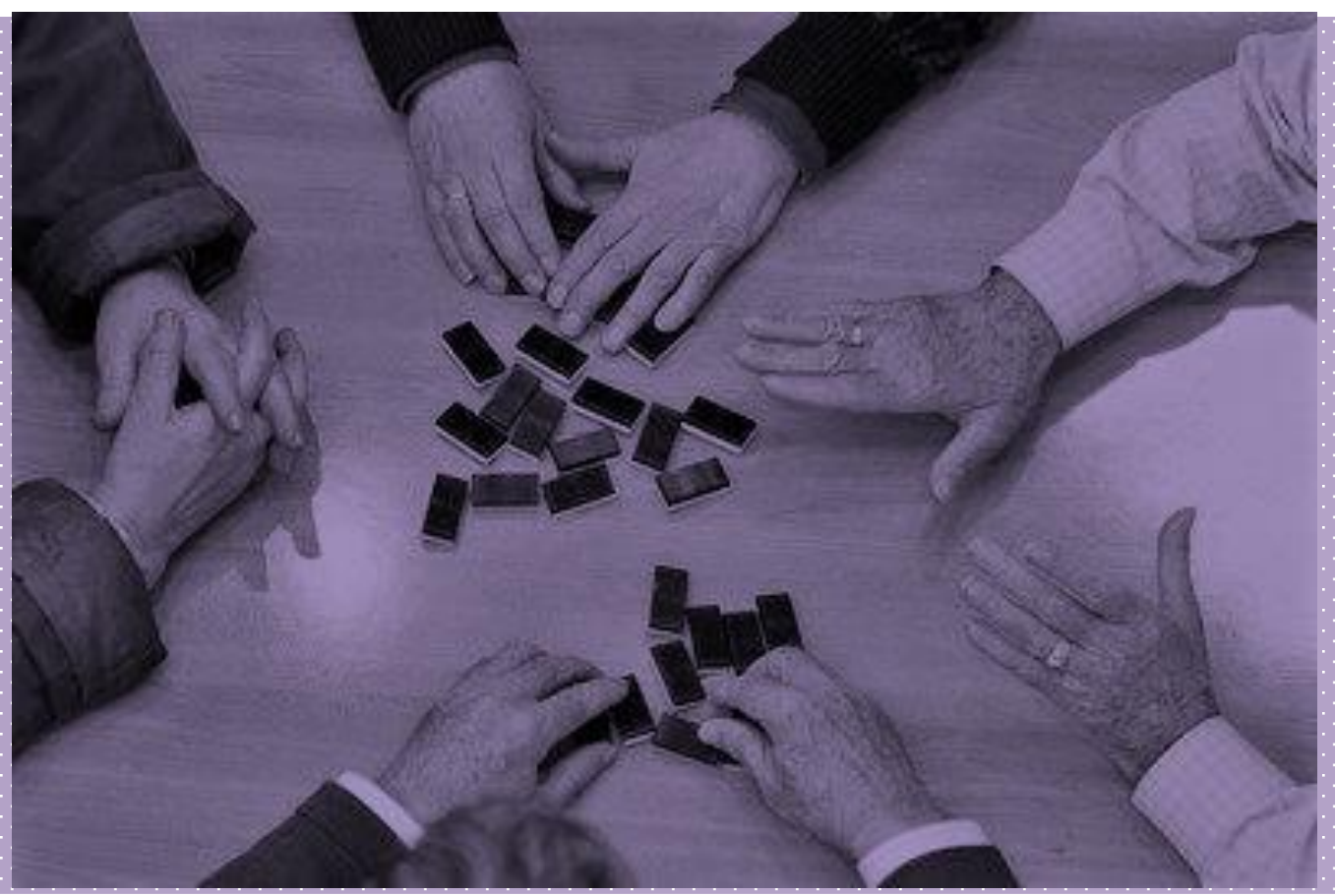





\section{Marco Teórico}

En los siguientes apartados, se expone la justificación de la investigación de acuerdo a la literatura consultada.

\subsection{Definición y características propias de la persona mayor}

Según la OMS, considera a las personas de 60 a 74 años de edad avanzada; de 75 a 90 viejas o ancianas y a las que sobrepasan los 90 se les denomina grandes viejos o grandes longevos. A todo individuo mayor de 60 años se le denomina de tercera edad con independencia del grupo a que pertenecen. Las Naciones Unidas considera anciano a toda persona mayor de 65 años para los países desarrollados y de 60 para los países en desarrollo (18).

La expresión tercera edad es un término que se refiere a la población de las personas mayores o ancianas. En esta etapa de la vida el sinónimo de vejez y ancianidad viene dado por el deterioro del cuerpo. En España y América latina se utiliza más el término persona mayor. Las etapas de la vida de una persona se divide en 7, y la persona mayor está en la séptima etapa (prenatal, infancia, niñez, adolescencia, juventud, adultez y vejez o ancianidad). En la estructura de población este grupo va creciendo en la pirámide de población distribuida por edades como consecuencia del descenso de la natalidad, como ya se ha visto con anterioridad, disminución de las tasas de mortalidad y mejora de la calidad y esperanza de vida (18).

Otras clasificaciones aplicables a la persona mayor (19):

- Sana: Cuyas características físicas, mentales y sociales está de acuerdo con su edad cronológica, aunque ha alcanzado los 65 años no tiene patología diagnosticada ni problemática funcional, psíquica o social.

- Enferma: Tiene 65 años y presenta alguna afección, aguda o crónica, en diferente grado de gravedad, que no le invalida y que no cumple los criterios de paciente geriátrico. 
- Geriátrica: Es el que cumple tres o más criterios.

- $\quad$ Edad superior a los 75 años

- Pluripatología relevante

- $\quad$ Enfermedad principal con carácter incapacitante

- Patología mental acompañante o predominante

- Problemática social en relación con su estado de salud

- Frágil:Es aquella que se encuentra en una situación de alta inestabilidad derivada de sus circunstancias físicas, psíquicas o funcionales. Con gran probabilidad de convertirse en una persona dependiente e incluso necesitar la institucionalización. Se considera AAR a todas las personas mayores de 80 años y a los que entre 65 y 80 años cumplen cualquiera de los criterios.

- Vivir sólo: carencia de apoyo familiar

- Enviudamiento reciente (menos de un año)

- Cambio de domicilio (menos de 1 año)

- Enfermedad crónica que condiciona incapacidad funcional: enfermedad cerebrovascular con secuelas, cardiopatía isquémica o insuficiencia cardíaca reciente (menos de 6 meses), enfermedad de Parkinson, enfermedad pulmonar obstructiva crónica (EPOC), enfermedad osteoarticular, caídas, déficit visual o hipoacusia, enfermedad terminal (pronóstico vital menor de 6 meses), limitación funcional en extremidades inferiores/inmovilismo

- Incapacidad funcional por otras causas o incapacidad para las actividades instrumentales

- Hospitalización reciente (menor de 12 meses)

- Toma de tres fármacos o prescripción de antihipertensivos, antidiabéticos 0 psicofármacos

- Deterioro cognitivo o demencia según criterios del DSM-III

- Depresión

- Situación económica precaria o ingresos insuficientes

- Necesidad de atención médica o de enfermería en el domicilio, al menos una vez al mes

- Ancianos institucionalizados 


\subsection{Proceso de envejecimiento}

Es difícil determinar su inicio, por no ser probablemente un fenómeno genéticamente programado (20).

Encontramos en la literatura especializada numerosas definiciones de envejecimiento. Hay autores que lo definen como la suma de las alteraciones que se producen en el organismo con el paso del tiempo y que producen una pérdida de la independencia, autonomía e incluso la muerte (21).

Otros autores, definen el envejecimiento humano como un fenómeno ecológico en el que influye la genética, el ambiente físico y social y la conducta individual de la persona. Se distinguen varios tipos de envejecimiento $(22,23)$ :

1. Biológico: Es diferencial, por órganos y funciones; es también multiforme pues se produce a varios niveles: molecular, celular, tisular y sistémico, y es a la vez estructural y funcional.

2. Psicológico: Es el resultado de acontecimientos vitales como el duelo o la jubilación, entre otros.

3. Sociológico: Es el que comprende los papeles que se supone han de desempeñarse en la sociedad. Es cierto que ciertas variables sociales evolucionan con la edad, pero sin seguir necesariamente a la edad cronológica.

4. Demográfico: Es el cambio en la composición etérea de la población por la cual gana en importancia relativa la población mayor, o sea, aquélla constituida por personas de edad cronológica igual y superior a cierta edad.

Otras definiciones de envejecimiento son (20):

- $\quad$ Proceso nocivo

- Proceso progresivo

- Proceso intrínseco

- Proceso universal 
Estos procesos se producen mediante una interacción genética y ambiental o como todas las alteraciones que se producen en el cuerpo humano mediante el paso del tiempo y provocan un deterioro funcional, el cual puede desembocar en la muerte (20).

Strehler (24), define el envejecimiento como cuatro postulados:

1. Envejecimiento Universal: Fenómeno que debe darse en menor o mayor medida en todos los individuos de una especie.

2. Envejecimiento Intrínseco:Las causas que lo provocan tienen que ser de origen endógeno, sin que dependan de factores externos o de origen ambiental.

3. Envejecimiento Progresivo: Los cambios ligados al envejecer se dan de manera paulatina a lo largo de la vida.

4. Envejecimiento Deletéreo:Lleva a una progresiva pérdida de función. Se diferencia del proceso de crecimiento y desarrollo en que la finalidad de éste es alcanzar una madurez en la función.

Además, las diferencias entre jóvenes y personas mayores se dan en dos esferas: la cognoscitiva, que afecta la manera de percibir el mundo y las capacidades; y la psicoafectiva más centrada en la personalidad y el afecto (23).

En la actualidad, se estima un máximo para la esperanza de vida de alrededor de 120 años si el envejecimiento se desarrolla de una manera adecuada. El desarrollo de la vida, la longevidad y la capacidad funcional junto a una adecuada salud puede llevar a lo anteriormente comentado. $\mathrm{Si}$, por el contrario no es así pude llevar a una dependencia o discapacidad por lo que la OMS propone una búsqueda del envejecimiento activo y saludable. Para ello tenemos que prepararnos con buenas condiciones físicas, psíquicas, sociales y funcionales (20). 


\subsection{Definición de envejecimiento con éxito, saludable y activo}

El análisis conceptual del envejecimiento activo puede ser sintetizado en los siguientes hechos relevantes (25):

a) Los términos más utilizados suelen ser aquellos que sirven para definir tanto el grupo poblacional de análisis como el proceso.

b) Existe una clara interrelación entre los conceptos, cualquiera que sea la decisión que se tome para su análisis. En este caso, la pre-asignación de referencias bibliográficas de acuerdo con los conceptos de envejecimiento saludable (healthy), exitoso (successful) y productivo (productive) ha generado nubes en las que, primero, aparecen más frecuentemente aquellos conceptos previamente asignados, confirmando la validez de la preasignación, y, segundo, demostrando la interrelación entre todos los conceptos analizados y el de Envejecimiento Activo.

c) La salud se posiciona más frecuentemente como componente del Envejecimiento Activo, sea cual sea el concepto relacionado (saludable, exitoso, productivo), mientras otros términos adoptan una posición más secundaria, pero siempre en relación con la salud.

d) Ello significa que el envejecimiento, cualquiera sea la orientación analítica empleada, es conceptuado ante todo como un proceso de base biológica, asociado con el deterioro de capacidades físicas, psicológicas y emocionales que se acelera con la edad.

e) Sin embargo, envejecer activamente significa también desarrollar las capacidades personales y los recursos sociales para hacer mínimo ese deterioro. Ello se refleja asimismo en la nube de palabras: cuando se analizan el envejecimiento saludable, ahondan en aspectos relacionados con la salud como la enfermedad, los riesgos, la discapacidad, la atención de salud, la superación del deterioro biológico a través de actividades, la participación o la promoción de conductas saludables. En el caso del envejecimiento exitoso, la relación con la salud es evidente también, como condición para ello, pero asimismo con otros 
comportamientos positivos (activo, productivo) que potencian la realización de actividades y la participación social, como componentes esenciales de una satisfacción personal y una mejor calidad de vida. Finalmente, el envejecimiento productivo se relaciona, específicamente, con aspectos económicos que condicionarían la jubilación y con otros vinculados con el empleo del tiempo disponible en actividades generales o de implicación social como las relaciones sociales.

El envejecimiento está definido por diferentes autores, bajo diferentes puntos de vista:

- Baltes y Carstensen (26):“con éxito”. Viene definido por salud física y mental, habilidades funcionales, satisfacción con la vida, apoyo social percibido, y compromiso social.

- Vaillant y Vaillant (27): "saludable". Como el de aquella que mantiene y vela por el mantenimiento de las relaciones familiares y posee unas habilidades adecuadas de enfrentamiento a situaciones de estrés.

- $\quad$ OMS (28): "activo". Como el proceso de optimizar las oportunidades de salud, participación y seguridad en orden a mejorar la calidad de vida y el bienestar en la vejez.

En resumen, condiciones de salud, funcionamiento físico óptimo, alto funcionamiento cognitivo, afecto positivo y participación social son los criterios generalmente aceptados (parcialmente o en su conjunto) para identificar esta forma de envejecer. Es más, todas estas condiciones multidimensionales también aparecen en el concepto «popular» de envejecer bien que las propias personas mayores tienen y ello está extendido entre distintos países y culturas (29).

El modelo de envejecimiento satisfactorio propuesto por Rowe y Kahn se basa en investigaciones longitudinales (30).El modelo parte de la hipótesis de que el envejecimiento con éxito se identifica con tres dimensiones: una baja probabilidad de enfermar y de discapacidad, un alto funcionamiento cognitivo y físico, y un alto compromiso con la vida. 
Estas tres dimensiones están relacionadas jerárquicamente, de manera que cada una de ellas hace posible el mantenimiento de las demás. No obstante, cada una por sí sola es un indicador de bienestar independiente. Desde este modelo, el envejecimiento con éxito es más que la ausencia de enfermedad y que el simple mantenimiento de las capacidades funcionales, siendo su combinación junto con un compromiso activo con la vida lo que define totalmente el concepto de envejecimiento activo o satisfactorio (31). Caprara, Carrasco, Fernández-Ballesteros y Aguerre afirman que las investigaciones recientes realizan un análisis del envejecimiento satisfactorio desde un enfoque multifactorial e integrado (32).

\subsection{Determinantes del envejecimiento con éxito, saludable, activo y competente}

El modelo de envejecimiento activo según la OMS (6) surge para superar los límites del anterior modelo. Parte de la idea de que las personas que envejecen con múltiples condiciones críticas, pueden mantenerse física, cognitiva y socialmente activas. El término de envejecimiento activo "indica el proceso de optimización de las oportunidades de salud, participación y seguridad de las personas mayores, con el fin de mejorar la calidad de vida a medida que las personas envejecen.

Algunas definiciones que se han dado a lo largo de los años sobre el envejecimiento con éxito, saludable y activo y que ponen de relieve aspectos relativos a la salud, la autonomía, la ausencia de enfermedad, el buen funcionamiento físico, psicológico, cognitivo, social, además de la relación con la satisfacción con la propia vida, competencia social, la productividad, la realización de actividades productivas en la sociedad, etc. Se reflejan a continuación en la tabla siguiente (33):

- Reducir los factores de riesgo asociados a enfermedades y aumentar la salud conductual y la forma física (alimentación adecuada, hábitos saludables).

- Promover los factores protectores del funcionamiento cognitivo (programas de formación continua, ejercicios de habilidades verbales y de comunicación). 
- Iniciar el afecto positivo, el control y las habilidades de afrontamiento del estrés y los problemas afrontamiento de conflictos, manejo del estrés, el control, envejecimiento activo: programa en competencias sociales.

- Originar el funcionamiento psicosocial y la participación (autonomía, participación, confianza y valoración en sí mismo, comportamientos pro-sociales, etc.

Si analizamos la vejez como la última etapa de la vida desde el área psicosocial común periodo no sólo de pérdidas, sino también de ganancias, además de destacar las posibles competencias que puede mejorar o desarrollar la persona mayor. En esta línea, los procesos que mejoran la percepción del ocio son fundamentales. Así, y con un planteamiento opuesto al postulado inicialmente por la teoría de la desvinculación, uno de los retos de las personas mayores en la sociedad actual es demostrar que su edad no es sinónimo de enfermedad y que pueden todavía realizar una vida activa e independiente (34).

Una forma que las personas mayores tienen para romper con esta imagen pasiva y patológica del proceso de envejecimiento pasa, sin duda, por optimizar su tiempo libre, vinculándolo a la participación e integración social, así como al disfrute personal de la cultura, favoreciendo así sus relaciones sociales y el bienestar personal forma de envejecer como son el modelo de envejecimiento satisfactorio, de envejecimiento activo y un tercer modelo de Selección, Optimización y Compensación (SOC) (35).

El modelo contempla factores poblacionales que determinan el envejecimiento con éxito, y factores personales y comportamentales que refieren las condiciones individuales de cada persona. Es el modelo SOC propuesto por Baltes y Freund (30) que incluye tres mecanismos: Selección, Optimización y Compensación (SOC). Estos mecanismos se entienden como condiciones de regulación del desarrollo que variarán en su intensidad según sean las circunstancias socio-históricas y personales del individuo, el contexto y los aspectos examinados (36). En este sentido, la Selección es el mecanismo presente en el ciclo vital que permite a la persona adaptarse ante la gran cantidad de estímulos del contexto y la limitación de recursos que posee. La Optimización se refiere a la mejora continua de los conocimientos, habilidades y demás características y virtudes humanas. 
Finalmente, la compensación contrarresta las pérdidas y deterioros propios del envejecimiento, para así mantener un buen funcionamiento De Juanas, Limón y Navarro (37).

Pero Berkman y Glass (38) han elaborado un modelo conceptual más completo sobre la influencia de las relaciones sociales en la salud como un factor predictor de mortalidad. Los efectos sobre la salud vienen producidos por mecanismos psicisociales (psicológicas, fisiológicas o hábitos de vida), los procesos psicobiológicos y macrosociales que tienen un impacto en las relaciones sociales.

\section{- Condiciones socio-estructurales}

Las variaciones en las relaciones sociales son debidas en parte a diferentes oportunidades estructurales para desarrollar y mantener las relaciones sociales. En este modelo se consideran los siguientes condicionantes socioestructurales: la cultura, la economía y la política de una determinada sociedad y los cambios sociales como el envejecimiento, la urbanización o las situaciones catastróficas a las que haya estado expuesta.

\section{- Redes sociales}

El siguiente eslabón en la cadena se refiere al dominio de las redes sociales. Las redes sociales se describen por su estructura y por las características de los vínculos:

- El tamaño se refiere al número de personas relacionadas directamente con la persona objeto de estudio. Este concepto es importante porque determina la disponibilidad de los recursos y del apoyo.

- La diversidad de la red se refiere a qué tipo de personas la constituyen según el tipo de relación o parentesco. Una red social variada en su composición permite a las personas mayor flexibilidad de roles y relaciones. La red está constituida por: La familia y sus componentes, que se consideran como uno de las principales fuentes de apoyo. La familia incluye al conyugue, hijos, nietos, hermanos y sobrinos. Las redes de amigos son establecidos por intereses comunes y actividades compartidas. 
- La participación social se define como la participación en la comunidad, incluyendo el pertenecer a "asociaciones o clubes culturales", organizaciones religiosas u organizaciones no gubernamentales" o si acude a lugares céntricos como la plaza o al mercado.

- La proximidad se refiere a la distancia geográfica entre los miembros de la red.

Relacionado con la estructura social se utilizan los siguientes términos para describir las características de los lazos de la red o vínculos sociales:

- La frecuencia del contacto visual y telefónico se define como el número de veces que cada uno de los individuos se relaciona dentro de un marco temporal dado. Se incluye el contacto físico y no visual (por teléfono). Aunque algunos autores no lo contemplan Avlund et al. (39), han resaltado la importancia de observar los contactos telefónicos puesto que su contenido puede ser complementario, e incluso causar menos tensiones que los personales.

- La frecuencia de participación social se define como cuanto participa una persona en la comunidad.

- La reciprocidad se define como la medida en que los intercambios o transacciones son recíprocas e incluyen el dar y el recibir.

- La intimidad se define como la posibilidad de intercambiar sentimientos y confidencias con alguien especial. Alguien en quien puedan confiar. Generalmente el apoyo emocional lo proporciona el confidente.

Los mecanismos psicosociales a través de los cuales se relacionan las redes sociales con la salud por:

- El apoyo social que valora cuatro categorías de apoyo: instrumental, emocional, informacional y evaluativo.

- La influencia social. Se entienden los valores y normas explícitas o implícitas que regulan los comportamientos en una comunidad.

- La satisfacción con el apoyo recibido. la percepción de los adultos mayores acerca de lo que dan y reciben en las redes y de la importancia que éstas tienen para su calidad de vida. 
- La vinculación social o rol del individuo se refiere al desarrollo de roles sociales u ocupacionales (por ejemplo, el cuidado de los hijos o los ancianos) que proporcionan un sentimiento de valía, de pertenencia a la comunidad y de identidad. Esta vinculación genera además oportunidades para disfrutar de la compañía de otros.

Y por último las relaciones sociales a través de mecanismos psicosociales influyen sobre comportamientos de salud como son el consumo de tabaco y alcohol, la dieta, prácticas sexuales o el ejercicio físico. Por otro lado también influyen sobre estados psicológicos o cognitivos como son la autoestima, la sensación de bienestar, la depresión o la capacidad de adaptación. Las relaciones sociales pueden tener un efecto directo sobre la salud por la influencia que tienen sobre vías fisiológicas relacionadas con la respuesta al estrés como son el sistema neuroendocrino o inmunitario. De hecho esta línea de trabajo es la que se relaciona con la fragilidad y disminución de la respuesta del organismo ante situaciones de estrés (38). 


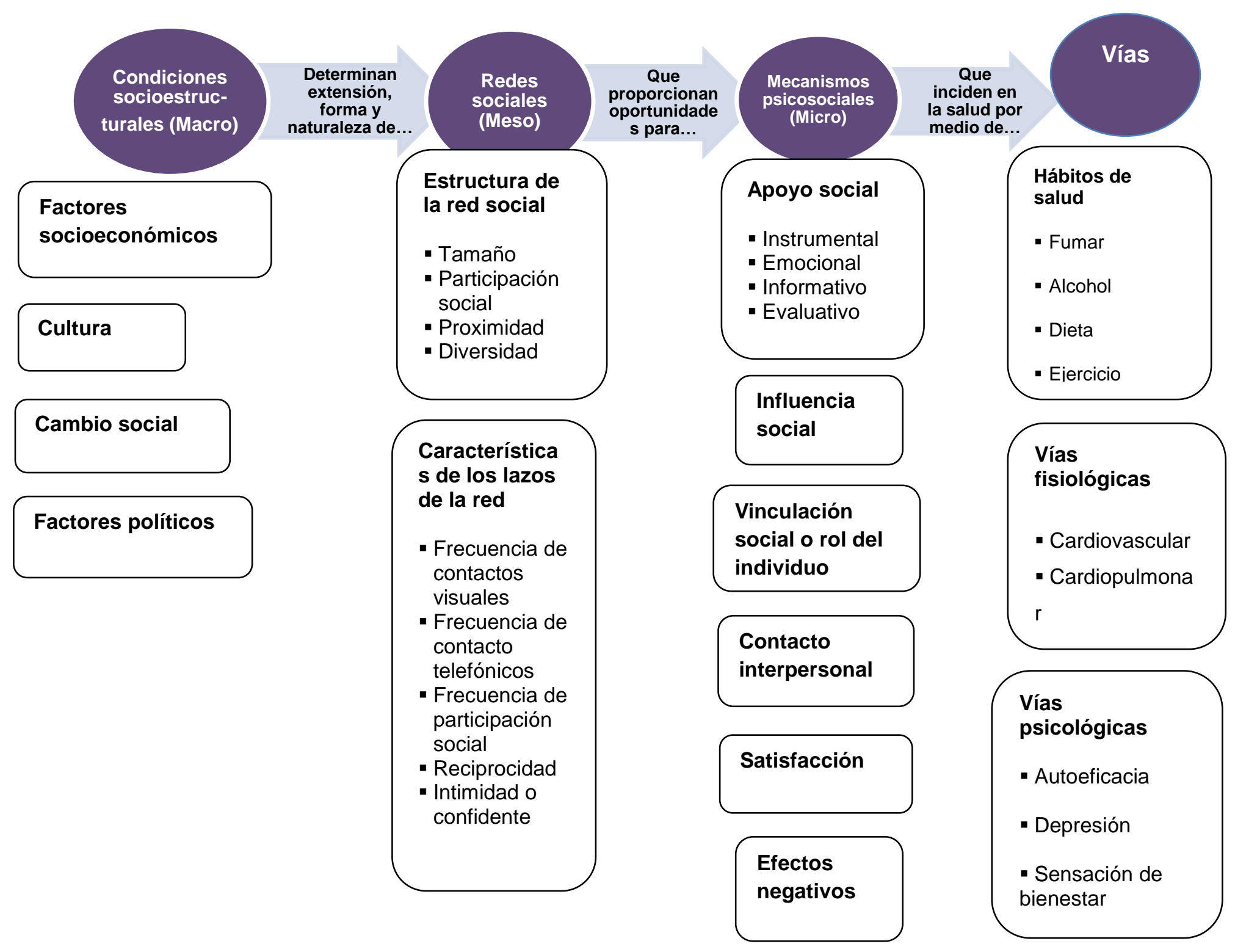

Figura 1: Modelo conceptual de Berckman y Glass en el que se inscribe la tesis (38) 


\subsection{Envejecimiento activo.}

Para la OMS se define el "envejecimiento activo" como "el proceso por el que se optimizan las oportunidades de bienestar físico, social y mental durante toda la vida, con el objetivo de ampliar la esperanza de vida saludable, la productividad y la calidad de vida en la vejez". Esta definición no sólo contempla el envejecimiento desde la atención sanitaria, sino que incorpora todos los factores de las áreas sociales, económicos y culturales que afectan al envejecimiento de las personas (40).

Este nuevo paradigma del envejecimiento se conoce con diferentes denominaciones: saludable (41), buen envejecer (42), competente (43), con éxito (44) o activo (45).

El objetivo del envejecimiento activo es que la persona mantenga la productividad y esperanza de vida en edades avanzadas. Además de mantener su actividad física (46), social y mental participando en actividades recreativas, de voluntariado o remuneradas, culturales, sociales, y educativas hasta el final de la vida. El envejecimiento activo se sitúa en la base del reconocimiento de los derechos humanos de las personas mayores respecto a independencia, participación, dignidad, atención y auto-desarrollo. Así, desde esta perspectiva, los determinantes del envejecimiento activo serían económicos, sociales, físicos, servicios sociales y de salud, biológicos de estilos de vida (47). 


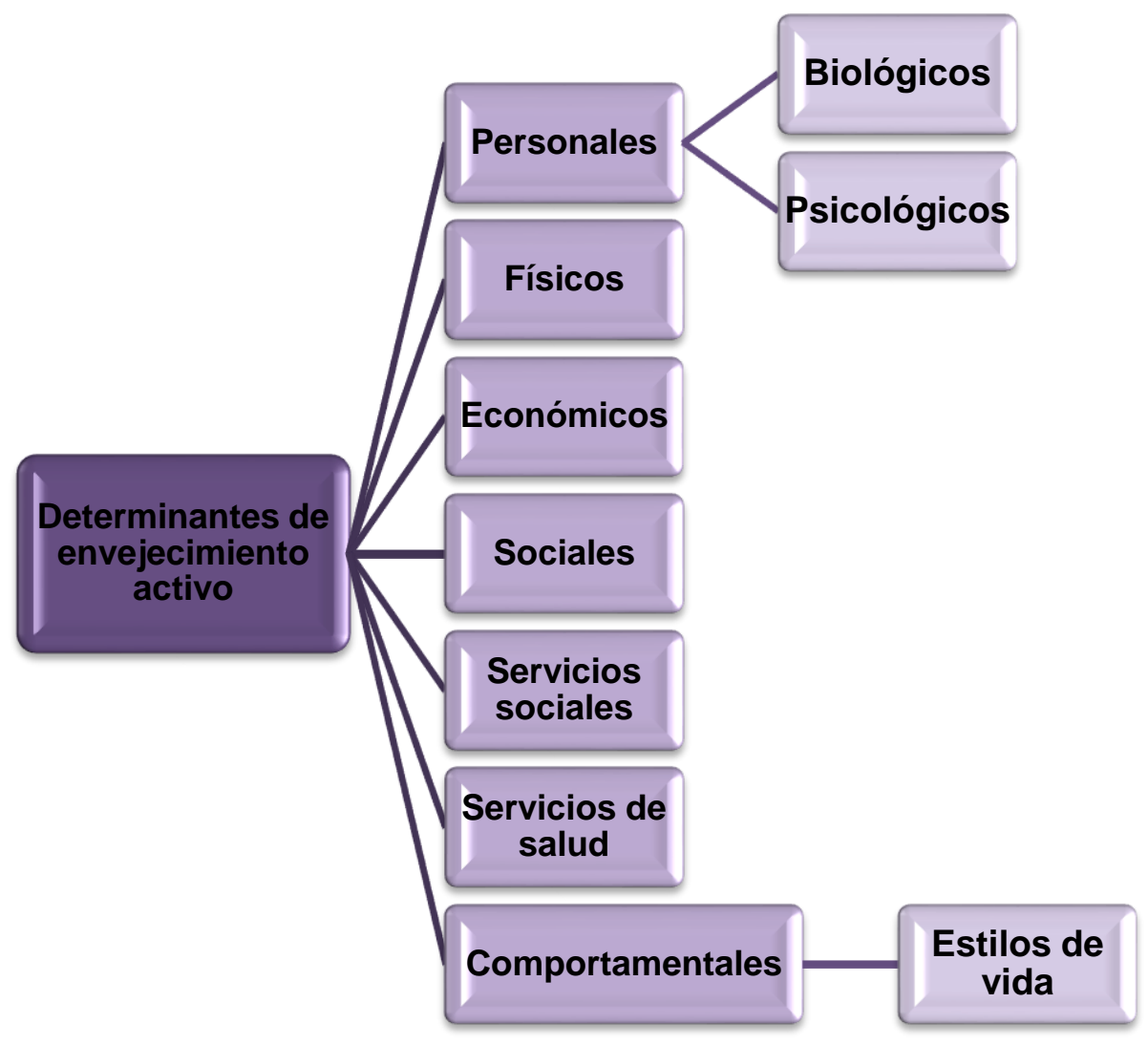

Figura 2. Determinantes de envejecimiento activo. Elaboración propia

En España se empieza a poner de manifiesto una tendencia de los mayores hacia la independencia, sobre todo del núcleo familiar, pero también de los entornos sociales más próximos, para asumir, progresivamente modos de vida en los que la autonomía, entendida como capacidad de decisión sobre su propia vida empieza a tener un valor social e individual importante (47).

Las políticas de acción propuestas por la OMS (48) para potenciar los determinantes psicológicos y conductuales del envejecimiento activo son reducir los factores de riesgo asociados a enfermedades e incrementar la protección de la salud a través de hábitos saludables y ejercicio físico así como promover los factores de protección del funcionamiento cognitivo unido al control de las emociones y un afrontamiento positivo de las mismas, así como promover la participación de las relaciones sociales. 


\subsection{Transición demográfica y envejecimiento}

La población mundial, estaba estimada, en torno a 300 millones de personas en el primer siglo de nuestra era, y en la actualidad se ha alcanzado 7.000 millones con una previsión de alcanzar 9.000 millones en el 2050. El aumento de la población observado en los últimos tiempos se debe entre otras variables, a las mejoras de la condición de vida (49) en algunos países del mundo.

Como ejemplo, se puede observar, el descenso de la mortalidad infantil relacionado con la mejora de los hábitos saludables, nutrición y la vacunación de esta población. Sucede lo mismo con la disminución de la mortalidad en mayores de 65 años asociada, entre otras causas, a la mejora en la atención sanitaria. Sin embargo, lo que más influye en la longevidad son otros determinantes de salud que se desarrollan a partir de la década de los 70 del siglo XX (49).

Entre los modelos más estudiados en relación a los determinantes de salud, se destaca el que, desarrolla Marc Lalonde (50) cuando fue Ministro de salud en Canadá. Definió un marco conceptual para el análisis de la situación de salud y la gestión sanitaria denominado modelo Lalonde, que incluye los cuatro factores condicionantes de la salud en la población. Se ubican en cuatro dimensiones de la realidad llamadas "campos de la salud" que se observan en la figura 3 (51). Estilos de vida y conductas de salud; Biología humana; Medio ambiente; Sistema de asistencia sanitaria. En el modelo Lalonde, se observa el peso de los determinantes de salud, en relación a la esperanza de vida y el impacto económico de los mismos. 


\section{SALUD}

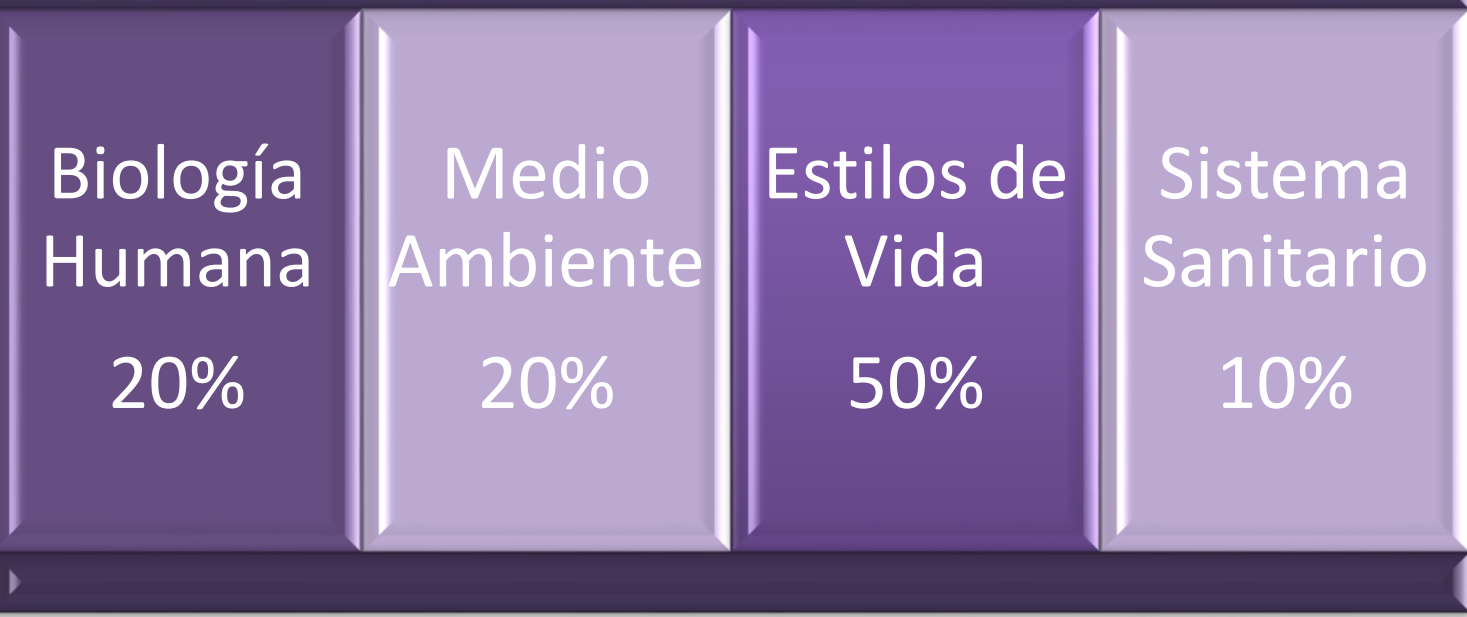

Figura 3. Determinantes de salud según Lalonde (52).

\subsubsection{Transición demográfica en Europa}

Se espera que entre 2000 y 2050,se duplique la población mundial con más de 60 años de edad, pasando del $11 \%$ al $22 \%$ del total aumentando de 60 a 2000 millones, con una previsión para 2050 de cerca de 400 millones de personas con 80 años o más. Por primera vez en la historia, la mayoría de los adultos de mediana edad tienen a sus padres vivos (53).

En Europa, los datos demográficos que se presentan en la figura 4 de manera escalonada y porcentual, nos permiten observar la población de personas mayores de 65 y más años en los distintos estados países del continente. Cabe señalar que la media de población mayor (PM) en la Unión Europea (UE) es del 18,2\% (54) y en España, la media es $18,8 \%$ (cercana a la media europea).

A grandes rasgos los países con los porcentajes más bajos de mayores son: Irlanda $(12,5 \%)$, Eslovaquia (13,3\%), Chipre (13,9\%) y Luxemburgo (14\%). Por otro lado los países con los porcentajes de mayores más elevados son: Italia (21,2\%), Alemania (20,9\%), Grecia $(20,5 \%)$, y Portugal $(19,9 \%)$ todos con porcentajes superiores a la media Europea (18,5\%) . la distribución porcentual se muestra en la figura4 (54). 


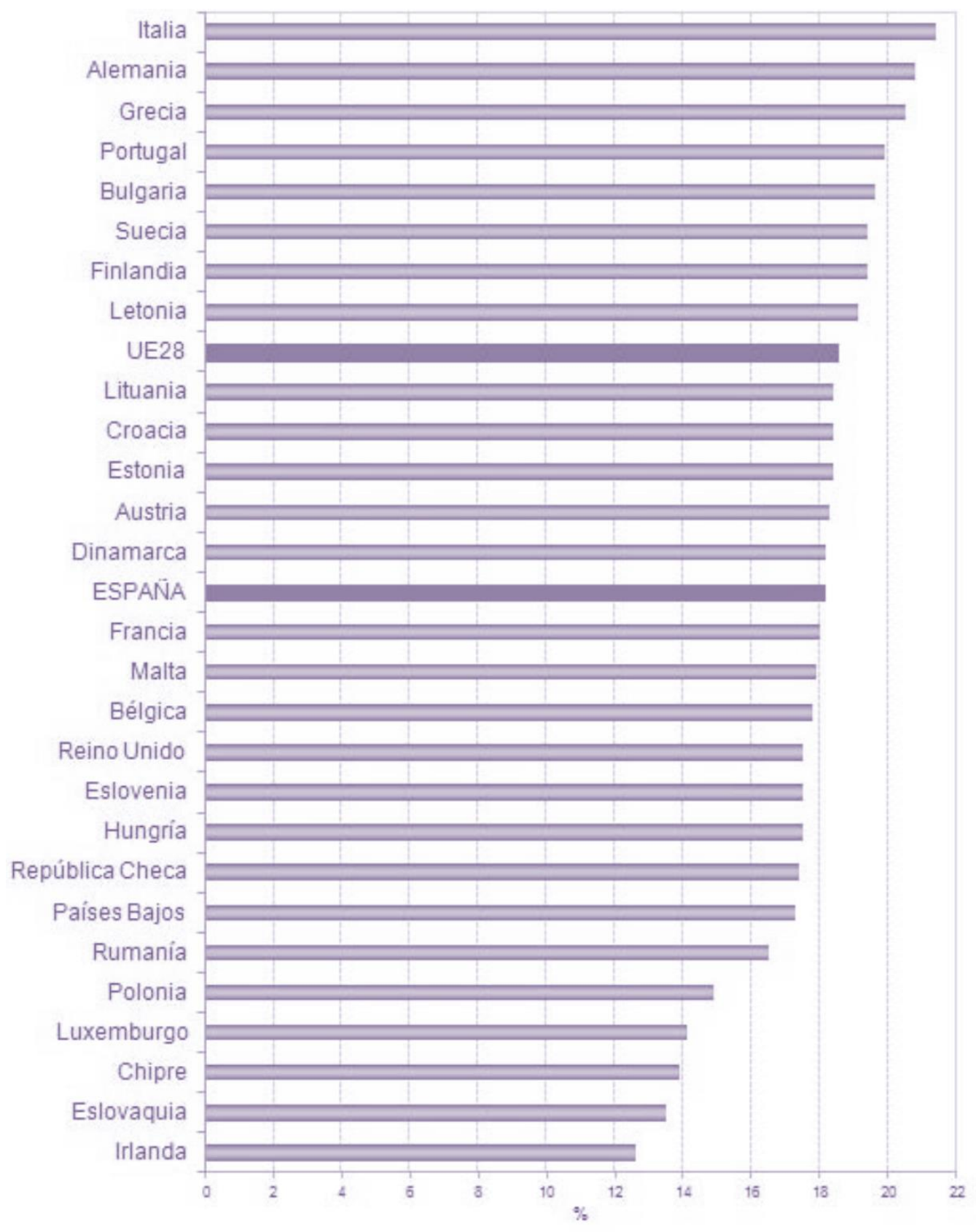

Figura 4. Población de 65 y más años en la Unión Europea (18,4\%), 2014 (54).

El envejecimiento de Europa comenzó hace varias décadas. Con un incremento en los últimos diez años de 2,1 puntos porcentuales. Con el aumento de la población mayor en el Continente, se incrementa la participación relativa de las personas mayores en la sociedad (55) y el incremento de la importancia de las relaciones sociales en esta etapa de la vida. 
En España los datos de la tabla 1, permiten observar el proceso de envejecimiento de la población en consonancia al entorno. En enero de 2014 se registran 8.573 .985 personas mayores (65 y más años), que suponen el 18,4\% sobre el total de la población (46.624.382), según los datos del Padrón Continuo (INE). Sigue creciendo en mayor medida la proporción de octogenarios que actualmente representan el 5,7\% de toda la población (54).

La relación con la evolución porcentual de la población de las personas mayores en vista al futuro y la previsión es, de un aumento considerable hasta llegar en 2061 al 38,7\% (54).

\begin{tabular}{|c|c|c|c|c|c|c|c|}
\hline \multirow[b]{2}{*}{ Años* } & \multirow{2}{*}{$\begin{array}{c}\text { Total España } \\
\text { Absoluto }\end{array}$} & \multicolumn{2}{|c|}{65 años y más } & \multicolumn{2}{|c|}{$65-79$ años } & \multicolumn{2}{|c|}{80 años y más } \\
\hline & & Absoluto & $\begin{array}{c}\% \text { respecto } \\
\text { al total }\end{array}$ & Absoluto & $\begin{array}{c}\% \text { respecto } \\
\text { al total }\end{array}$ & Absoluto & $\begin{array}{c}\% \text { respecto } \\
\text { al total }\end{array}$ \\
\hline 1900 & 18.618 .086 & 967.774 & $5,2 \%$ & 852389 & $4,6 \%$ & 115.385 & $0,6 \%$ \\
\hline 1910 & 19.995 .686 & 1.105 .569 & $5,5 \%$ & 972.954 & $4,9 \%$ & 132.615 & $0,7 \%$ \\
\hline 1920 & 21.389 .842 & 1.216 .693 & $5,7 \%$ & 1.073 .679 & $5,0 \%$ & 143.014 & $0,7 \%$ \\
\hline 1930 & 23.677 .794 & 1.440 .744 & $6,1 \%$ & 1.263 .632 & $5,3 \%$ & 177.112 & $0,7 \%$ \\
\hline 1940 & 26.015 .907 & 1.699 .860 & $6,5 \%$ & 1.475 .702 & $5,7 \%$ & 224.158 & $0,9 \%$ \\
\hline 1950 & 27.976 .755 & 2.022 .523 & $7,2 \%$ & 1.750 .045 & $6,3 \%$ & 272.478 & $1,0 \%$ \\
\hline 1960 & 30.528 .539 & 2.505 .165 & $8,2 \%$ & 2.136 .190 & $7,0 \%$ & 368.975 & $1,2 \%$ \\
\hline 1970 & 34.040 .989 & 3.290 .800 & $9,7 \%$ & 2.767 .061 & $8.1 \%$ & 523.739 & $1,5 \%$ \\
\hline 1981 & 37.683 .362 & 4.236 .740 & $11,2 \%$ & 3.511 .599 & $9,3 \%$ & 725.141 & $1,9 \%$ \\
\hline 1991 & 38.872 .268 & 5.370 .252 & $13,8 \%$ & 4.222 .384 & $10,9 \%$ & 1.147 .868 & $3,0 \%$ \\
\hline 2001 & 40.847 .371 & 6.958 .516 & $17,0 \%$ & 5.378 .194 & $13,2 \%$ & 1.580 .322 & $3,9 \%$ \\
\hline 2011 & 46.815 .916 & 8.116 .347 & $17,3 \%$ & 5.659 .442 & $12,1 \%$ & 2.456 .908 & $5,2 \%$ \\
\hline 2021 & 46.037 .605 & 9.466 .481 & $20,6 \%$ & 6.462 .726 & $14,0 \%$ & 3.003 .755 & $6,5 \%$ \\
\hline 2031 & 45.351 .545 & 11.903 .963 & $26,2 \%$ & 8.044599 & $17,7 \%$ & 3.859 .364 & $8,5 \%$ \\
\hline 2041 & 44.680 .774 & 14.791 .516 & $33,1 \%$ & 9.531 .604 & $21,3 \%$ & 5.259 .912 & $11,8 \%$ \\
\hline 2051 & 43.581 .814 & 16.486 .938 & $37,8 \%$ & 9.327 .682 & $21,4 \%$ & 7.159 .256 & $16,4 \%$ \\
\hline 2061 & 41.603 .330 & 16.095 .184 & $38,7 \%$ & 7.326 .273 & $17,6 \%$ & 8.768 .911 & $21,1 \%$ \\
\hline
\end{tabular}

Tabla 1. Evolución de la población mayor, 1900-2061(54)

El sexo predominante en la vejez es el femenino. Hay un $33 \%$ más de mujeres (4.897.713) que de hombres (3.676.272). Nacen hombres más que mujeres y este exceso se mantiene durante muchos años. Ahora bien, se alcanza el equilibrio entre sexos hacia los 50 años. En las primeras décadas del S.XX, la edad en la que las mujeres excedían en 
número a los hombres era los 14 años, con mayor supervivencia femenina, por una mayor tasa de mortalidad masculina a partir de 60 años como se observa en la figura 5 (54).

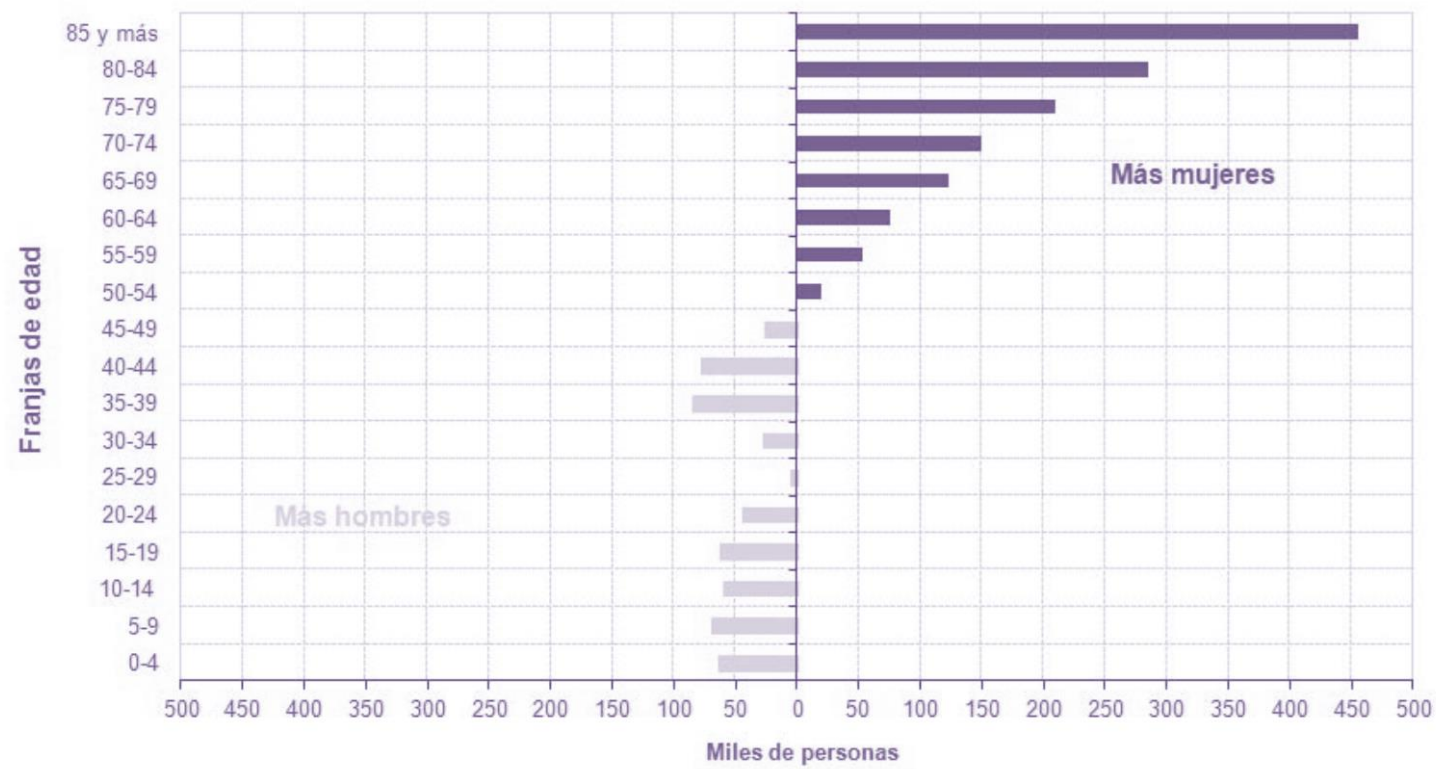

Figura 5. Diferencia entre la población de hombres y mujeres por franja de edad, 2015 (54)

\subsubsection{Transición demográfica en la Comunidad Valenciana}

La población valenciana es una población adulta-envejecida. El proceso de envejecimiento que comenzó a mitad de los 80 del siglo $X X$, se ha enlentecido desde el comienzo del siglo XXI por la llegada de flujos migratorios de personas jóvenes y adultas. De hecho, la estructura de la población nacional española es más envejecida que la estructura de la población total, como efecto rejuvenecedor que ejercen los inmigrantes, como podemos apreciar en la figura 6 (56).

La distribución de la población actual tanto en la Comunidad Valenciana como en la ciudad de Castellón, se observa en las figuras 6 y 7donde podemos ver la similitud demográfica con datos de 2010. Se observa en el ancho de la pirámide y en las bajas tasas de natalidad y de mortalidad, que el crecimiento natural es muy pequeño en el ciclo demográfico actual, lo que corresponde con una población envejecida, con más número de mujeres que de hombres dato, coincidente entre la Comunidad Autónoma y la ciudad de Castellón donde se ha realizado la investigación (Fig.7). 


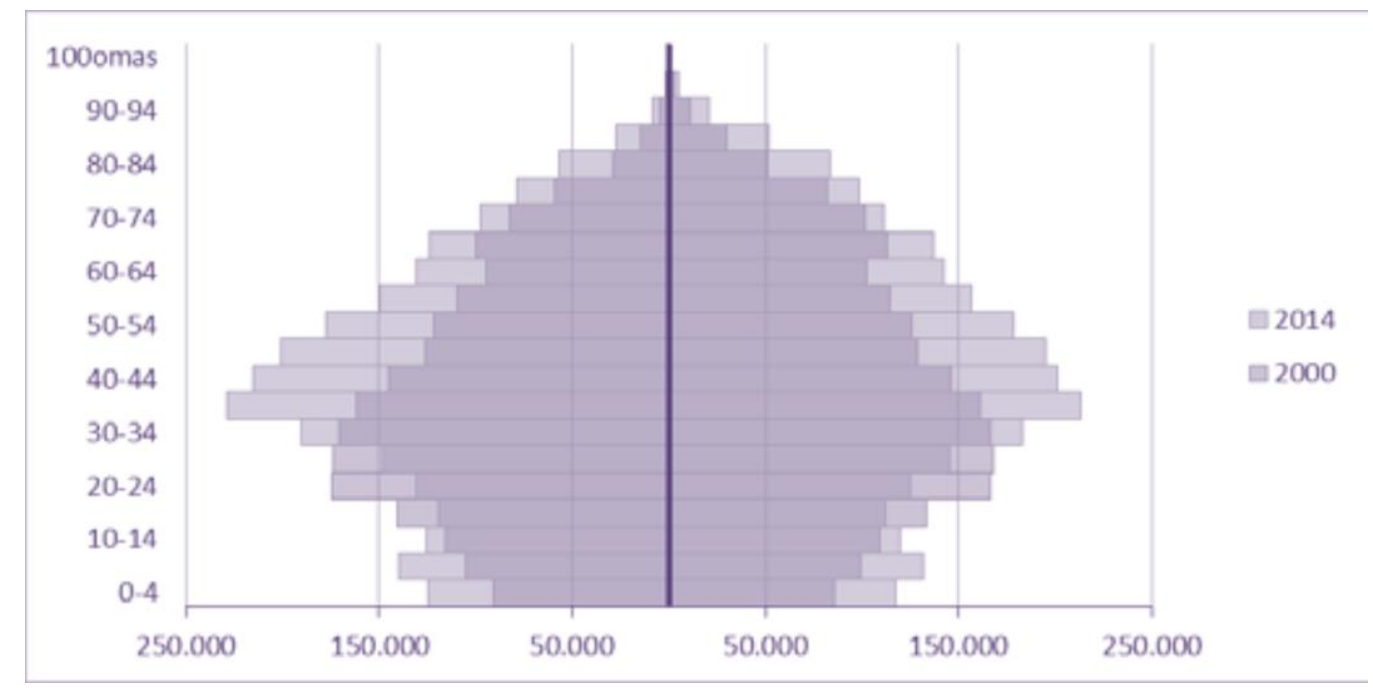

Figura 6: Pirámide de la población total de la Comunidad Valenciana

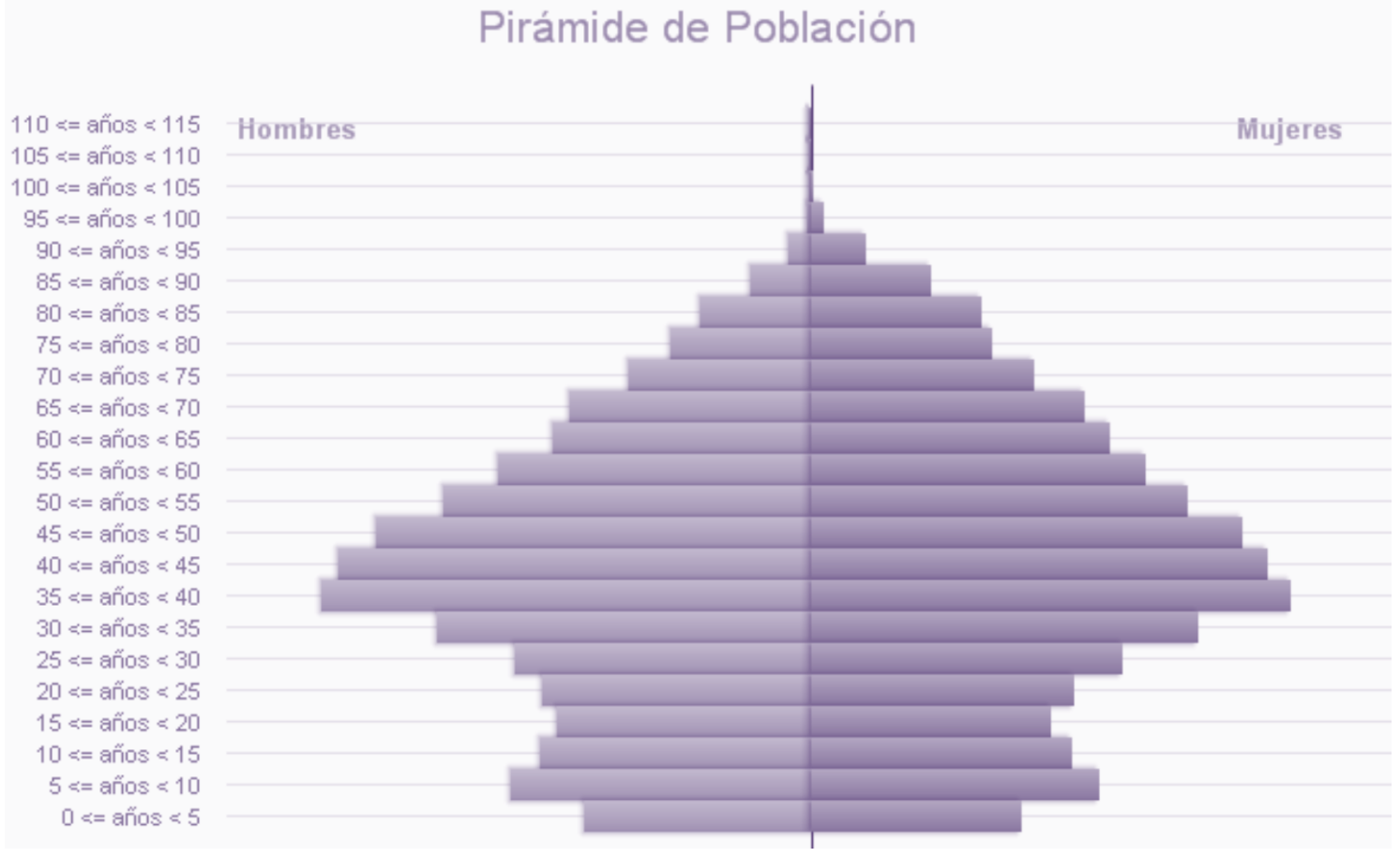

Figura 7: Pirámide de la población de Castellón de la Plana 
Después de mostrar las transiciones demográficas y siguiendo en el ámbito de la población mayor, pasaremos a incluir en este marco teórico aspectos relacionados con las ciencias que estudian el envejecimiento.

\subsection{Conceptos generales de geriatría, gerontología y su aplicación en el ámbito de la enfermería}

En 1903 Michael Elie Metchnikoff propuso definir la gerontología como estudio del envejecimiento. Este será el origen de las ciencias que estudiaran el proceso de envejecimiento. Son dos, los ámbitos científicos más relacionados con el estudio de la vejez, se trata de geriatría, gerontología. La parte de estos ámbitos que aplica la enfermería se entienden como enfermería geriátrica y gerontológica (57).

Mientras que, la Geriatría es la ciencia encargada del mantenimiento, promoción, prevención, asistencia y rehabilitación de los adultos mayores (58), la Gerontología es la ciencia que se encarga del envejecimiento humano en todas sus facetas: social, demográfica, cultural, económica, política y ambiental (59).

Una de sus facetas, la Gerontología social fue definida en 1914 por Eduardo Sthiglitz como "una ciencia que se ocupa del hombre como organismo social, que existe en un ambiente social y aceptado por éste" (57).

Como sucede en todas las ramas de la ciencia, la gerontología social se nutre de las ciencias biológicas (biología, bioquímica, medicina, enfermería, biofísica), psicológicas (psicología del desarrollo, cognitiva, social), sociales (demografía, ecología humana, interacción social y sociología de la salud) (54).

Los objetivos más importantes de la gerontología social son (56): 
1) Promocionar y fomentar un estilo saludable de vida para un envejecimiento activo.

2) Prevenir daños a la salud de los mayores.

3) Estudiar los procesos intergeneracionales y familia.

4) Implementar de estrategias de intervención.

5) Garantizar la calidad y accesibilidad a los servicios de salud gerontológicos.

6) Implementar estrategias de cambio en seguridad social y políticas públicas.

\section{Enfermería geriátrica y Gerontológica.}

Aparece en el Reino Unido, de la mano de su precursora la británica Marjory Warren, en la segunda mitad del siglo XX, que defiende la necesidad de ofrecer unos cuidados diferenciados a las personas mayores para favorecer su recuperación y bienestar, al demostrar que los mayores con enfermedades crónicas, mediante unos planes individualizados de rehabilitación mejoraban las condiciones de vida. Consideró necesaria la implicación de todos los profesionales relacionados con la salud, así como la valoración de aspectos físicos, psicológicos, ambientales en el cuidado de las personas mayores (54).

La producción científica específica del ámbito de la Gerotología, Journal of Gerotologic se publicó en 1946 y en 1947 se fundó la sociedad Española de geriatría y gerontología. 30 años más tarde, en 1977 se celebra la primera asamblea mundial del envejecimiento patrocinada por Naciones Unidas (54).

En enfermería geriátrica y gerontológica, el profesional de enfermería desarrolla tareas relacionadas con el estudio y cuidados del proceso del envejecimiento en la persona mayor a todos los niveles llevando a cabo intervenciones destinadas a mantener la salud, prevenir la enfermedad y cuidar en caso de enfermedad y discapacidad (54).

La sociedad española de enfermería geriátrica y gerontológica (SEEGG) (60) propone que las competencias de la enfermera en el ámbito de la gerontología están relacionadas con "proporcionar atención integral a este grupo de población en el conjunto 
de sus necesidades, en cualquier situación en que se encuentren ya sea en instituciones específicas, en el domicilio o en la atención comunitaria".

En la orden SAS/3225/2009, de 13 de noviembre se recoge la regulación de la especialidad de Enfermería geriátrica, establece las competencias que se adquieren en este nivel de estudios (61):

1. Conocimiento relevante de los aspectos históricos y antropológicos en el cuidado de la persona anciana y capacidad para su aplicación.

2. Conocimiento relevante de la gerontología, capacidad para desarrollarla y para realizar valoraciones gerontológicas utilizando las herramientas y marcos adecuados para la persona anciana.

3. Conocimiento relevante del envejecimiento poblacional y capacidad para analizar las causas y consecuencias del mismo.

4. Conocimiento relevante de los factores que influyen en el envejecimiento saludable y capacidad para su aplicación.

5. Capacidad para responder a las necesidades personales durante las etapas del envejecimiento y proceso de muerte, teniendo presente la historia de vida y desarrollar las bases de la tanatología.

6. Conocimiento exhaustivo de teorías, modelos de enfermería y práctica de enfermería avanzada mediante los diagnósticos, intervenciones y resultados esperados en el cuidado de la persona anciana y capacidad para su aplicación.

7. Capacidad para reconocer los diversos roles, responsabilidades y funciones de una enfermera especialista en el marco de un equipo interdisciplinar, en los distintos niveles asistenciales.

8. Capacidad para planificar, ejecutar y evaluar cuidados relacionados con las actividades básicas e instrumentales de la vida diaria considerando los aspectos emocionales, físicos, sociales y espirituales. 
9. Capacidad para evaluar los programas individualizados más apropiados de atención, junto a la persona anciana, sus cuidadores, familia y otros profesionales.

10. Capacidad para enseñar, educar, facilitar, supervisar y apoyar a los estudiantes de cuidados de salud y otro personal involucrado.

Los cuidados requeridos por este grupo de población superan las limitaciones del paradigma biomédico, de hecho el propósito de los cuidados en salud, en particular para los profesionales de enfermería, es evitar que las limitaciones de la edad, se conviertan en impedimentos para el desarrollo de actividades que el adulto mayor necesite o desee realizar, y la actividad profesional, se orientara hacia la disminución del nivel de dependencia de este grupo de edad y la promoción de oportunidades de mejora vinculadas a esta etapa de la vida (62).

\subsection{Envejecimiento normal y personas mayores frágiles (dependencia)}

En las últimas décadas se han modificado los cambios demográficos, sociales y científicos en profundidad y la perspectiva sobre la vejez. En la actualidad, se considera, como las etapas más largas de la vida, y en la que conviven tanto el deterioro y problemas, como la estabilidad e, incluso, las ganancias y los nuevos aprendizajes. Por lo que sabemos, la mayoría de las personas mayores no sufren problemas graves y tienden a ser individuos autónomos, independientes y motivados hacia el aprendizaje. No obstante, conforme avanza la edad del anciano, pueden aparecer diversos problemas psicológicos, especialmente los asociados al estado del ánimo y al deterioro cognitivo (63).

Conceptos como discapacidad, fragilidad y comorbilidad intervendrán en el llamado envejecimiento satisfactorio (successful aging). Desde la última década son múltiples las descripciones de fragilidad aparecidas, que muestran un fenotipo de fragilidad como un síndrome multifactorial con disminución de la capacidad adaptativa del individuo para compensar de manera efectiva factores estresantes que lo hacen vulnerable, desligándose de conceptos como la comorbilidad y discapacidad, con los que a menudo ha sido unida y utilizada de forma indistinta (63). 
Desde entonces, diversos estudios han intentado encontrar además los modelos biológicos que llevarían a un envejecimiento satisfactorio, entendido como un estado óptimo o una forma de envejecer mejor de la normalidad (15).

El síndrome del anciano frágil sugiere que los criterios de fragilidad pueden ser diferentes según el medio en el que se desarrolle el estudio: comunitario, hospitalario. El concepto no es estático, las personas se encuentran en una escala continua que va desde un extremo donde existe un estado de energía, fuerza y vigor hasta la "fragilidad" en el otro. No todos los sujetos son frágiles en la misma medida. Además, también es posible que cualquier persona no permanezca igual de frágil o de vigoroso por largos períodos de tiempo (64). En la tabla 2 podemos observar la cuestión desde un aspecto más fragmentario $(63,65)$.

Tabla 2: Factores que influyen en la fragilidad. Elaboración propia

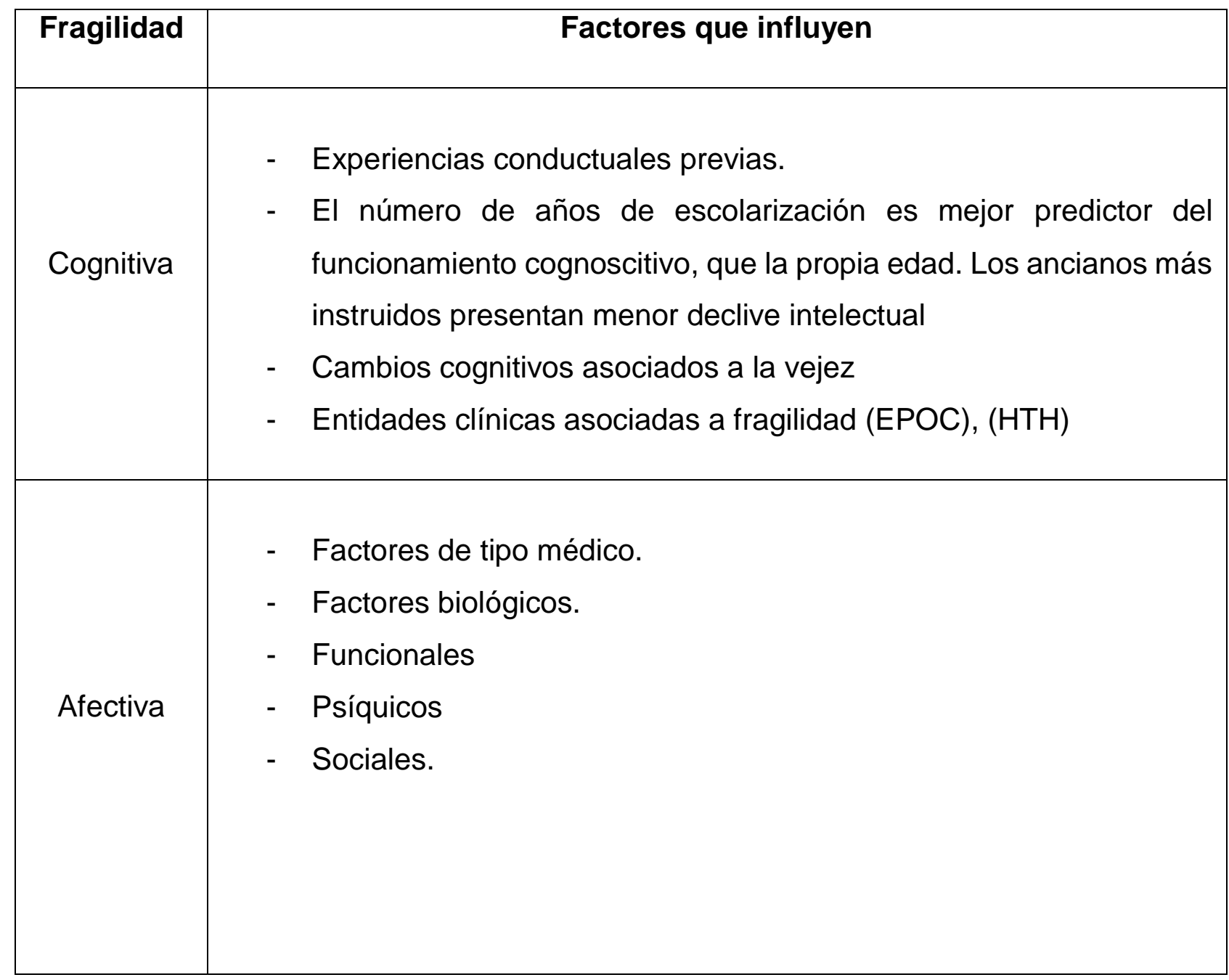




\begin{tabular}{|l|l|}
\hline & - Economía precaria \\
Social & - Viviendas inadaptadas \\
& - Familia con sus conflictos generacionales \\
& - Emigración \\
& - La carga de marginación \\
\hline
\end{tabular}

Las conductas positivas en salud en los ancianos no sólo prolongan la vida; también disminuyen el riesgo de inmovilidad y dependencia. Tener baja actividad física, inactividad, restricción a la movilidad, son factores de riesgo que aumentan la fragilidad en el anciano. Instrumentos de detección del anciano frágil (63).

\subsection{Hábitos de Salud de las Personas Mayores}

En el transcurrir de su vida a los hombres y las mujeres los colocan con una marcada diferencia en la salud cuando llegan a la edad de la vejez, que reflejan los estilos de vida que adoptaron a lo largo de su existencia. Debido a su rol social como proveedor económico de la familia, así como a su actividad más intensa en el mercado laboral, los hombres en general pueden estar sujetos a mayores presiones físicas y mentales que ponen en riesgo su organismo. Por ejemplo, los hombres participan más que las mujeres en actividades que conllevan riesgos a la salud como ingerir alcohol, fumar cigarrillos, experimentar con drogas, trabajar horas extras, conducir a gran velocidad, no acudir al médico y no cuidar su dieta, entre otros riegos. Estas situaciones pueden generar en los hombres condiciones cardiovasculares, accidentes laborales y de tráfico, cáncer, enfisema, problemas del hígado, depresión, ansiedad y angustia $(66,67)$.

Por otro lado, la mujer, por su rol reproductivo, larga carrera de labor doméstica y otro tipo de presiones asociadas con su rol de cuidadora de la unidad familiar, tiene necesariamente un marco epidemiológico muy distinto al del hombre. Así, la carga de la enfermedad en la vejez refleja grandes divergencias por sexo, que van de acuerdo con la acumulación de riesgos asociados a los papeles sociales desempeñados a lo largo de su vida (68). 
Las mujeres españolas tienen una esperanza de vida al nacer de 85,6 años, y los hombres de 80,0 años (2013). Se encuentran entre las más altas de la Unión Europea. A los 65 años, la esperanza de vida de hombres y mujeres es de las más altas de la UE, detrás de Francia. El patrón de mortalidad de la población española en su conjunto está determinado por las causas de muerte de los mayores: las enfermedades degenerativas sustituyen a otras históricamente más importantes. Existe una cierta homogeneización del proceso de muerte, que se produce más tarde y se concentra en edades elevadas y por causas similares (69).

La principal causa de muerte entre los mayores está relacionada con enfermedades del aparato circulatorio, provocó 111.704 fallecimientos. El cáncer es la segunda causa de muerte (83.115 fallecidos). En tercer lugar, a distancia, se encuentran las muertes por enfermedades respiratorias. Destaca el aumento de mortalidad por enfermedades mentales y nerviosas (demencias, Alzheimer) en los últimos lustros. El sexo es un factor diferenciador de la salud subjetiva; el $39,7 \%$ de los hombres de 75 y más años autovalora bien o muy bien su estado de salud, mientras que sólo el 30,6\% de las mujeres de esta edad considera su salud como buena (69).

\subsection{Las relaciones sociales, red social y apoyo social}

\subsubsection{Definiciones}

Se entienden como relaciones sociales el conjunto de personas con las que interacciona el individuo, a las características de los vínculos que se establecen entre ellas, y las interacciones que se producen a través de dichos vínculos (70).

Los términos apoyo social ,redes sociales y redes de apoyo social en gerontología se usan muy a menudo para referirse a lazos que dan apoyos a las personas mayores, no existe consenso que sean los mismos estudios centrales de las relaciones sociales para los de redes sociales y apoyo social, por lo que habrá que diferenciarla estructura de las relaciones sociales $(59,71)$. Cuando se habla de redes sociales está implícita la idea de intercambio de apoyos, que constituye la esencia de la configuración de las redes. No obstante, hay que tener presente que la importancia de las redes de relaciones varía en el 
tiempo y en el espacio; en coyunturas específicas pueden ser muy importantes, pero en otras son menos relevantes (72).

La paulatina prolongación de la esperanza de vida y el acelerado incremento de la población mayor han suscitado preocupación por conocer el grado de bienestar al que tienen acceso, otorgando especial atención a los mecanismos de apoyo social formales e informales. Entre los primeros destacan el papel de los sistemas de seguridad social. En lo que respecta a los segundos, sobresale la función de las redes sociales, estudiada a través de los vínculos con familiares, amigos, vecinos y compañeros de trabajo, entre otros. El énfasis reciente en los apoyos sociales a las personas mayores se debe al hecho de que en la vejez se puede experimentar un deterioro económico y de la salud (física o mental), pero también al reconocimiento de que se trata de una etapa de la vida en la cual existen mayores probabilidades de ser afectado por el debilitamiento de las redes sociales como consecuencia de la pérdida de la pareja, los amigos y compañeros (59).

La preocupación por estudiar los apoyos sociales a las personas mayores tiene que ubicarse en dos contextos fundamentales:

1. Por una parte, en los países desarrollados existe inquietud respecto de la incapacidad estatal para financiar políticas y programas dedicados al mantenimiento físico y material de la población mayor. La organización histórica de asistencia a la población y los recursos económicos para mantenerla en el futuro cercano se ven amenazados por los cambios que ha experimentado la estructura productiva de las sociedades (73). De ahí que sea la familia y las redes sociales de la comunidad un marco perfecto para poder analizar, y así que haya un mayor bienestar de la población mayor (74).

2. Por otro lado, la función de las relaciones sociales, o apoyo social, hace referencia a las interacciones personales dentro de dicha estructura, al contenido relacional de las mismas como son el apoyo instrumental y emocional, vinculación social o desarrollo de roles sociales, la influencia social, la reciprocidad, la satisfacción con la red o los efectos negativos de las relaciones sociales. El flujo de apoyo social opera sobre el bienestar a través de la estructura de la red social (70). 


\subsubsection{Las relaciones sociales y envejecimiento}

El aumento de la longevidad va acompañado de un aumento discapacidad y morbilidad y necesidad de ayuda. En este contexto se hace necesario saber si el apoyo social habitual tendrá continuidad en la etapa de la vejez, en casos de enfermedad o en casos de pocos apoyos económicos, ya que las redes de las personas mayores tienen mayor riesgo en cambiar la composición de sus miembros (75).

Hay experiencias que se asocian con la edad que hacen más difícil la sociabilización pérdida de un cónyuge, de un amigo, la jubilación, la salida de los hijos de la casa, hacen que los científicos se planteen que los adultos mayores son vulnerables a la pérdida de apoyo social, (76) y en cambio declinan en tamaño las redes sociales conforme las personas se van haciendo mayores (77).

Las relaciones interpersonales impulsan la participación social de las personas mayores, y por tanto, son un aspecto clave para el envejecimiento activo. Además, previene riesgos de dependencia y ayudan a mantener la independencia, a la vez que fomentan la autonomía personal. Varios estudios interdisciplinarios coinciden en la identificación de algunos aspectos que pueden incidir sobre la soledad y el aislamiento social (78):

- Limitaciones funcionales, discapacidad o dependencia por enfermedades físicas y/o mentales asociadas a una falta de ayuda y de compañía, o a una falta de productos de apoyo (por ejemplo: andadores, teléfonos u ordenadores adaptados).

- Falta de condiciones adecuadas del entorno ambiental y físico. Por ejemplo: temperaturas extremas, desniveles orográficos pronunciados, etc.; accesibilidad reducida de los espacios falta de escaleras mecánicas, de ascensores, de rampas, escasez de barandillas y bancos en el espacio público, falta de iluminación, etc.

- $\quad$ Cambio en las redes sociales: pérdidas de seres queridos (viudedad, muerte de amigos y personas de su edad); cambios de residencia de la propia persona mayor o de familiares, amigos y vecinos; ruptura de vínculos por separaciones, por peleas o por desencuentros con personas queridas; jubilación, prejubilación o

pérdida del trabajo (lo que implica una pérdida de las relaciones laborales, el cambio de los espacios que frecuenta la persona y los usos que hace del tiempo). 
- Aspectos comportamentales: estilos de vida poco sociables, dificultad de adaptación a los cambios, depresión, añoranza, etc.

- Composición del hogar: vivir solo/a.

- $\quad$ Competencias formativas: la dificultad de relacionarse por desconocimiento de un idioma vinculante o por falta de dominio de algún conocimiento específico: por ejemplo, por desconocer el funcionamiento de herramientas de comunicación tecnológicas como el correo electrónico.

- Nivel de ingresos: los ingresos económicos insuficientes pueden ser un impedimento para participar en actividades.

No hay que olvidar que una parte esencial de las redes son los intercambios entre las personas, sean de tipo material, instrumental, emocionales, etc., todos ellos son intercambios que influirán en el grado de satisfacción de las necesidades de las personas. Aunado a lo anterior, se alcanzan a distinguir dos tipos de redes: la informales (en donde las interacciones existentes, se dan principalmente por la familia, cónyuge, hijos, hermanos, familiares y amistades), y las formales (en el que las interacciones que se brindan se dan principalmente por grupos, organizaciones, centros sociales, centros de salud, etc.), y en el que, todas ellas, en menor o mayor grado, son importantes y necesarias ante cualquier situación, sea esta crítica o no (73).

El apoyo social juega un papel fundamental en la actividad, en la satisfacción con la vida del adulto mayor, al mantener o conformar relaciones sociales tanto familiares como de amistades que le proporcionan bienestar y la prevención de alteraciones de tipo emocional como la depresión y de índole físico como las enfermedades crónicas $(63,79)$.

En los años 70 del pasado siglo , el apoyo social surge como un concepto de interés en las investigaciones de distintas disciplinas; fundamentalmente, en la descripción de los efectos negativos del estrés sobre el estado de la salud de las personas y de las familias, debidos al aislamiento social o la baja integración social; reconociendo una relación positiva entre el apoyo social y la salud de las mismas (80). 
Para este enfoque nos basamos en la definición de la OMS, que declara que la calidad de vida como "la percepción que un individuo tiene de su lugar en la existencia, en el contexto de la cultura y del sistema de valores en los que vive y en relación con sus objetivos, sus expectativas, sus normas, sus inquietudes. Se trata de un concepto muy amplio que está influido de modo complejo por la salud física del sujeto, su estado psicológico, su nivel de independencia, sus relaciones sociales, así como su relación con los elementos esenciales de su entorno" (81).

En un estudio comparativo entre adultos mayores de dos grupos de edades de Gran Bretaña y Taiwán, con el empleo del "Nottingham Health Profile" (NHP), se encontraron diferencias en los puntajes de los grupos pareados por edad, a pesar de que el NHP ha sido validado y adaptado para diferentes culturas en pruebas repetidas. Esto indica que la multidimensionalidad y la subjetividad complican la interpretación de los resultados de las investigaciones sobre la calidad de vida (82).

La validez clínica de algunos instrumentos empleados en ancianos como el CASP-19 (83)que contiene dimensiones para el control, la autonomía, la autorrealización y el placer de vivir se basa en la asociación inversa entre los puntajes totales y la fragilidad del anciano, las enfermedades crónicas que padece, los trastornos depresivos, la circunstancia de vivir solos y de haber sufrido caídas en los últimos 12 meses, lo cual revela el impacto de las alteraciones físicas y psíquicas, especialmente las primeras, en la percepción de la calidad de vida del adulto mayor (84).

Utilizando ese mismo instrumento en una cohorte de personas mayores en Irlanda, se encontró que el incremento en los puntajes relativos a la percepción de una "buena" calidad de vida se asoció con la longevidad, siempre que los ancianos tuviesen niveles razonables de salud mental y física, pero sobre todo por la participación del anciano en actividades sociales y las relaciones sociales frecuentes y de alta calidad. Se encontró además, que aun cuando la salud física empeorara, los puntajes de calidad de vida se mantenían altos en las personas que encontraban valores y disfrute espirituales en otras dimensiones de la vida (85). 
Este efecto del componente psíquico y de la estabilidad de la personalidad en la calidad de vida se ha constatado también en ancianos brasileños. Se ha observado, en particular, que el constructo "sentido de la vida" es una variable mediadora para la percepción de la calidad de vida ante eventos estresantes en las personas mayores por lo que si bien las afectaciones de la salud física son muy importantes, los aspectos relacionados con su salud psíquica han ganado terreno paulatinamente, de manera que los instrumentos empleados actualmente han ido incluyendo dimensiones cada vez más amplias que consideran los componentes afectivos y de estructura de la personalidad así como los del apoyo familiar, social, económico, de satisfacción con la vida, de la concepción de felicidad y del proyecto de vida entre otras (86).

En las investigaciones de Mendes de León (87) y Seeman (88)se ha observado que las personas que viven solas o no tienen pareja han mostrado niveles más elevados de enfermedades crónicas, tuberculosis, accidentes y trastornos psíquicos como la esquizofrenia, todo demuestran que una buena actividad social activa con unas buenas redes sociales y con actividad en la comunidad protegen de la mortalidad y predice el mantenimiento capacidad funcional (15).

El apoyo social ha mostrado tener influencia en diversos aspectos relacionados con los procesos de salud y enfermedad; entre ellos, la forma de afrontar el estrés, la progresión de la enfermedad, el ajuste y la recuperación de la enfermedad, la recuperación posquirúrgica y el inicio y mantenimiento de los cambios conductuales necesarios para prevenir enfermedades o complicaciones. Por ello, se ha llegado a afirmar que el insuficiente apoyo social puede considerarse como un factor de riesgo en cuanto a la morbilidad y la mortalidad al menos comparable a factores tan bien establecidos como el fumar, la hipertensión, la hipercolesterolemia, la obesidad y la escasa actividad física $(89,90)$.

El apoyo social cumple muchas funciones diferentes, las cuales podrían agruparse en tres tipos principales: una función emocional, relacionada con aspectos como el confort, el cuidado y la intimidad; una función informativa, que implica recibir consejo y orientación, y una función instrumental, que implica la disponibilidad de ayuda directa en forma de 
servicios o recursos (79). Aunque cada uno de estos tipos de función puede ser relevante para el bienestar del individuo, se tiende a considerar que el apoyo de tipo emocional es el más importante, en especial en el contexto de las enfermedades graves y, en particular, en el cáncer (15).

Se han desarrollado varios modelos teóricos para comprender la red social en los adultos mayores. Algunos relevantes con lo que verdaderamente acontece con la edad, mientras que otros se centran en las fuentes y tipos de apoyo que recibe el individuo $(91,92)$. Entre los tipos de apoyo asociados a cambios con la edad destaca el que se denomina metafóricamente del convoy, un concepto que hace referencia al análisis de las redes sociales desde una perspectiva evolutiva (91). De acuerdo con Kahn y Antonucci las necesidades y circunstancias de las personas cambian a lo largo del ciclo vital, a medida que se abandonan a determinados roles y asumen otros, existen cambios de trabajo, residencia (93).

\subsubsection{Las relaciones sociales y la salud}

El estudio de las relaciones sociales y la influencia sobre la salud de las que son objeto vienen de hace décadas, pues observaron que los individuos aislados que estaban menos integrados en la sociedad tenían peor salud física y psicológica y mayor probabilidad de morir. Pero es en este siglo y sobre todo en estos últimos años cuando hay estudios que muestran la influencia de las relaciones sociales en la morbilidad, mortalidad o discapacidad (94).

Analizaremos las distintas dimensiones de las relaciones sociales y su impacto sobre la salud así como las orientaciones teóricas y precursoras del modelo conceptual de Berkman y Glass (38). Las redes sociales actúan por medio de un mecanismo psicosocial sobre vías común fisiológicas, psicológicos comporta-mentales que son las que acaban produciendo efectos sobre la salud. 
En este modelo se muestra la diferencia con el componente estructural de las redes sociales y los mecanismos psicológicos por los que actúa que incluye de manera destacada el apoyo social. Existe unos condicionantes socio estructurales en una comunidad que actúan en redes sociales especiales a través de diversos mecanismos son los que actúan en las redes sociales en vías comunes psicológicas, físicas y hábitos de vida $(95,96)$.

En los años70 y 80 del pasado siglo se realizan estudios prospectivos predictivos de mortalidad para casi todas las causa de muerte con el objetivo de analizar el impacto de las relaciones sociales sobre la salud (97) elaboraron una teoría sobre los mecanismos psicosociales y los procesos que relacionan las relaciones sociales con la salud en la que distinguen tres aspectos:

1. Se refiere a la existencia, número y frecuencia de las relaciones sociales.

2. Se refiere a la estructura formal que incluye densidad y reciprocidad en las relaciones.

3. Clásicamente se define el apoyo social como transacciones interpersonales de dos dimensiones (98-101):

a) Apoyo estructural o cuantitativo: También denominado red social. Se refiere a la cantidad de relaciones sociales o número de personas a las que puede recurrir el individuo para ayudarle a resolver los problemas planteados (por ejemplo familia, amigos, situación marital), y la interconexión entre estas redes. Esta red social tendrá unas características en cuanto al tamaño, frecuencia de contactos, composición, densidad, parentesco, homogeneidad y fuerza. En función de estas características una red puede resolver mejor unas necesidades que otras.

b) Apoyo funcional o cualitativo: Tiene un carácter subjetivo y se refiere a las percepciones de disponibilidad de soporte. Cobb3 la concibe como la percepción que lleva el individuo a creer que lo cuidan, que es amado, estimado y valorado, que pertenece a una red de comunicaciones y obligaciones mutuas. Sus componentes más importantes son el apoyo emocional, informativo, instrumental, afectivo e interacción social positiva.

c) Apoyo emocional: relacionado con el cariño y empatía. Parece ser uno de los tipos de apoyo más importantes. 
d) Apoyo informativo: se refiere a la información que se ofrece a otras personas para que estas puedan usarla para hacer frente a las situaciones problemáticas. Se diferencia del apoyo instrumental en que la información no es en sí misma la solución sino que permite a quien la recibe ayudarse a sí mismo.

e) Apoyo instrumental: es ofrecido cuando se utilizan ayudas instrumentales o materiales que directamente ayudan a quien lo necesita.

f) Apoyo afectivo: se refiere a las expresiones de afecto y amor que le son ofrecidas a los individuos por parte de su grupo más cercano.

Además de analizar los diferentes tipos de apoyo social y su relación con la salud, dos modelos teóricos sugieren que las diferentes fuentes de apoyo social aportan funciones de apoyo diferentes:

1. En el modelo de tarea específica de Litwak $(89,91)$ se evidencia como los amigos proveen apoyo emocional (compañía) y la familia apoyo instrumental (limpieza de la casa). En relación a esta teoría Simons (85) encontró que las relaciones de las personas mayores con sus cónyuges e hijos, pero no con otros individuos estaban relacionadas, con sentimientos de seguridad. Felton y Berry (101) encontraron que el apoyo informacional a las personas mayores contribuye a un mayor bienestar si lo proveen los familiares que los no familiares.

2. El equilibrio en el intercambio de entre al menos dos individuos. Al respecto, Kim y otros (102) plantean que cuando se tiene un intercambio recíproco de apoyos, se producen efectos psicológicos positivos en las personas involucrada apoyos es otro de los factores que influye sobre la calidad de los vínculos y fortalece las redes con que cuentan las personas mayores. Las transacciones o intercambios pueden ser diversos y en un intento por analizar con detalle el apoyo social, Shumaker (103) lo describe como un "intercambio de recursos. Los individuos con los que uno establece una relación interpersonal y los vínculos que existen entre ellos se llaman estructura social. La estructura tiene dos dimensiones: las relaciones formales y las relaciones sociales, debido a la posición o el rol que adoptamos en la sociedad por ejemplo los roles profesionales. Los individuos forman una red social, los vínculos que se establecen entre los individuos con quien tienen una estrecha relación de afecto. En 
cuanto a la función de las relaciones sociales se definen como las interacciones personales dentro de la estructura de las relaciones sociales. La función abarca aspectos cualitativos y comportamentales de las relaciones sociales. La dimensión funcional de las relaciones sociales incluye el apoyo social, el anclaje social y los aspectos negativos (16).

La integración social no se produce solamente en las redes sociales informales formadas por amigos y familiares sino por la participación social o el compromiso social e importante para la sociabilización. Es importante la participación social porque provee de una visión más dinámica y da más oportunidades para la sociabilización de acuerdo con el contexto global en el que se asientan las relaciones sociales, conceptualiza la participación social como el resultado de la participación en las actividades de la vida diaria (102). Autores como McDonald (103) plantea la definición de la participación social en tres dimensiones teniendo en cuenta el vecindario, la implicación en actividades organizadas de asociaciones y desde la amistad (104), como son viajar acudir a lugares púbicos o hacer actividades diversas fuera de casa, como, ir a la plaza ir misa a misa, hacer deporte (105).

Al igual que otros roles como ir a misa disfrutar con los amigos, atender compromisos sociales. Así con las oportunidades de participación las redes sociales se refuerzan y adquieren significado incluyendo los roles familiares, ocupacionales y comunitarios, lo que a su vez proporciona un sentido de valor, pertenencia, identidad y apego. Estos roles proporcionan a cada individuo un sentido de identidad que solo es posible en el contexto social, siendo solo posible de esta manera que los roles puedan desarrollarse (106).

El adulto mayor vive en un entorno en el cual coexisten aspectos positivos y negativos que pueden repercutir en la capacidad funcional y que se asocia con un incremento de la susceptibilidad para que éste desarrolle enfermedades, se pueda accidentar, pierda autonomía o muera (107).

Fujisawa (108) encontró diferencias en los índices de calidad de vida (apoyo social, autonomía, salud mental y relaciones familiares) con respecto al género. Céspedes $A$ y Cols. concluyeron, en una investigación sobre calidad de vida y adulto mayor, que existen 
carencias de tipo afectivo por falta de interacción social, falta de contacto social y problemas de inactividad bastante acentuados (109).

Este último elemento es fundamental porque se considera la dimensión negativa del aspecto funcional de las relaciones sociales y se define como los falta de privacidad, competencia, ausencia de reciprocidad o sentimiento de rechazo. Actualmente estamos familiarizados con el sentimiento de cuidar por obligación y todo esto da origen del maltrato o de la perdida de salud del cuidador. Es así como en los últimos tiempos han surgido numerosos estudios sobre aspectos negativos de las relaciones sociales $(110,111)$.

Finalmente se ha elaborado un modelo conceptual (38) más completo sobre la influencia de las relaciones sociales en la salud siendo el único que las analiza como predictor de la mortalidad, y las describe como un proceso en cascada que conecta los procesos macro sociales con los psico-biológicos. En dicho proceso hay condicionantes socio-estructurales que determinan unos patrones de redes sociales específicos que proporcionan oportunidades atreves de diferentes mecanismos psicosociales y finalmente actúan sobre vías comunes psicológicas, fisiológicos o hábitos de vida que son los que acaban produciendo los efectos sobre la salud.

En las relaciones sociales se dan diferentes oportunidades para desarrollarlas y mantenerlas con sus diferentes variaciones. En este modelo se consiguen las siguientes condiciones socio-estructurales: la cultura la economía (25). La política de una sociedad y los cambios sociales como el envejecimiento, la urbanización o cambios que hayan estado expuestos.

Componentes y estructura de la red social (25):

a) El tamaño, se refiere al número de personas relacionadas con el objeto estudio.

b) La diversidad de la red, se refiere a que tipo de personas la constituyen según el tipo de relación o parentesco.

c) La familia y sus componentes, que se consideran uno de las principales fuentes de apoyo.

d) Las redes de amigos, establecidos por intereses comunes y actividades compartidas. 
e) La participación social, que es la participación a la comunidad, incluyendo o perteneciendo a asociaciones o clubs culturales, organizaciones religiosas, u otro tipo de organizaciones no gubernamentales.

f) La proximidad o distancia geográfica entre los miembros de la red.

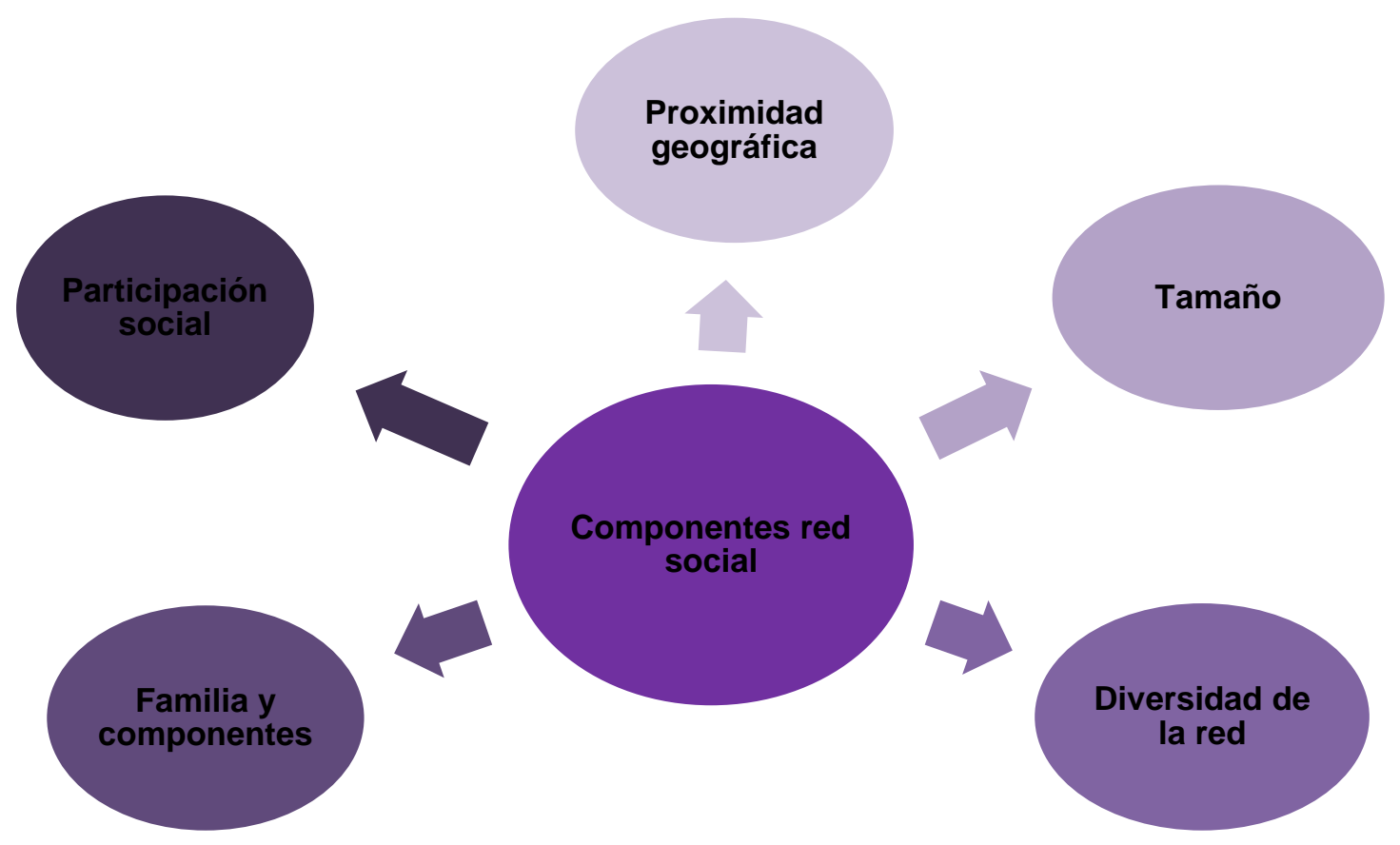

Figura 8: Componentes de la red social. Elaboración propia

Características de los lazos de la red o vínculos sociales(39):

1. La frecuencia del vínculo visual y telefónico, número de veces que uno de los individuos se relaciona dentro del marco temporal. Aunque hay autores que no lo contemplan.

2. La frecuencia de participación social, cuanto participa una persona en la comunidad.

3. La intimidad, la posibilidad de intercambiar sentimientos y confidencias con alguien especial. El apoyo emocional lo proporciona el confidente.

4. La reciprocidad, es la medida en que los intercambios o transacciones son reciprocas, incluyen el dar y el recibir. 


\subsubsection{Factores asociados a las relaciones sociales}

Socio-demográficos y socioeconómicos.

- Edad

Según la teoría socioemocional aunque el registro de vínculos sociales disminuye con el tiempo, la cantidad de apoyo instrumental y emocional aumenta. Aunque la familia ha sido siempre el apoyo más importante informal para la mayoría de los mayores, últimamente han aumentado los apoyos de los externos a la familia como es el apoyo de los amigos, vecinos y cuidadores, aumentan, conforme envejecen los individuos. Esto tiene una explicación por los de la disponibilidad del apoyo familiar y de los cambios de las redes sociales. Las familias se dispersan geográficamente debido al trabajo, se retrasa la edad de la paternidad, y se dispone de una menor disponibilidad de tiempo para cuidar a los mayores. Hay otros estudios que manifiestas que conforme aumenta la edad manifiesta menor contacto con los amigos, pero mantiene estable el contacto con la familia (112-115).

Se ha observado que personas mayores con redes más grandes de apoyo incrementan un mayor apoyo emocional de familiares, amigos y mayor apoyo instrumental porque probablemente habían trabajado para mantener sus redes (116).

\section{-Genero}

Existen más mujeres que hombres que tienen una alta significación y participación social. La estructura de las redes sociales según demuestran en algunos estudios que para los hombres las actividades con las amistades no familiares, disminuyen con la edad, en cambio con las mujeres tienen más diversa red social que los hombres con más personas que consideran, amistoso y confidentes $(117,118)$.

Hay estudios que señalan las diferencias de género en cuanto a la variedad de redes y la satisfacción con las mismas (117). Sin embargo existen diferencias de género según

las fuentes y tipos de relaciones sociales: las mujeres reciben y dan más apoyo a lo largo del ciclo vital y experimentan mayores beneficios de la interacción con la red social, que los 
hombres (119-121) las mujeres reciben el apoyo emocional de sus hijos y parientes, en cambio los hombres lo reciben de sus esposas $(122,123)$.

Los roles y expectativas difieren si es hombre o mujer y como género es el más robusto el uso del apoyo social (124).

Aunque los estudios lo sugieran no hay acuerdo para demostrar que el apoyo funcional puede ser beneficioso para el hombre y el apoyo emocional especial mente beneficioso para la mujer $(11,125)$.

\section{-Nivel Educativo}

Cuando mayor elevado es el nivel de educación de las personas mayores, mayor número de relaciones sociales y más diversas las tiene, menos relaciones con la familia y mayor participación social(126)quizá debido a los mayores recursos cognitivos y habilidades que son necesarios para desarrollar y sostener las relaciones sociales. Los beneficios potenciales de la educación en relación a las características de las redes pueden ser similar tanto para hombres como para mujeres, pero otros estudios confirman que un elevado nivel educativo está asociado con una gran red social para hombres, pero no con el número de personas con los que los encuestados se sienten más confidentes o con otras características de las redes sociales. Entre las mujeres, el elevado nivel educativo, influye o está asociado con una gran red social, por la menor de su proximidad geográfica, pero no influye en la composición (127).

\section{-Estatus Socioeconómico}

Individuos con un elevado estado nivel educativo, elevados ingresos y con puesto de trabajo, lo que llamamos status socioeconómico, tienen relaciones sociales más fuertes y reciben más apoyo (127).Se observa una reacción una reacción positiva entre el estatus socioeconómico y el apoyo social recibido por los amigos y una relación negativa entre el estatus socioeconómico y el apoyo recibido por los parientes (128). Las personas con estatus más elevado tienen mayores oportunidades así como mejores capacidades para desarrollar y utilizar los lazos débiles "weakties" con los amigos. La desigualdad que se observa en el apoyo instrumental, reflejan que los de menor estatus, tienen preferencia por los parientes, y los de mayor estatus tienen preferencia pueden pagar el apoyo instrumental y contara con otros recursos. En cuanto al apoyo emocional que provee de los familiares, 
no hay diferencias entre personas de diferente estatus y todos tienen estrechos vínculos emocionales con sus hilos, hermanos y otros familiares (129).

\section{Hábitos de salud}

El apoyo sociales facilitador del desarrollo de conductas y hábitos saludables al igual que el tamaño de la red influye en los hábitos de salud (130).

Según diferentes estudios han puesto de relieve que los estilos de vida son excelentes predictores de la salud y de la capacidad funcional durante la vejez (131).

Se ha detectado que los contactos sociales tienen influencia en los hábitos de salud, modificándolos o creando otros nuevos. Concretamente, desde los dispositivos sanitarios se ha detectado un incremento en la demanda de cuidados especializados por problemas de dependencia y vulnerabilidad en el subgrupo de personas mayores de 80 años $(132,133)$.

Las patologías asociadas a los trastornos afectivos son una de las alteraciones más comúnmente detectadas en la población mayor, una interpretación puede ser que los parientes ofrezcan consejos sobre hábitos saludables y accesos a los servicios de salud, además de actuar de modelos y estos ancianos que tienen este tipo de relación con estos parientes se ha demostrado que tienden a desarrollar menor riesgo a la discapacidad. Los mayores son más receptivos a los consejos dados por parientes que a lo dados por esposa, hijos, nietos (134).

En un estudio descriptivo de los trastornos conductuales en el DCL en contextos clínicos (135), la tasa de conversión a demencia fue del 10\%. Por otra parte, la demencia se encuentra asociada a un deterioro cognitivo múltiple persistente, relacionado con el menoscabo de la memoria (incapacidad de aprender nueva información o de recordar la previamente aprendida), por estar acompañado por otros trastornos cognitivos (afasia, apraxia, agnosia, alteración de las funciones superiores), y por cambios importantes en las relaciones sociales y/o familiares. Según Lázaro (136) la prevalencia de la demencia varía de acuerdo con la edad, así si bien el $2 \%$ de mayores del grupo de entre 70 y 74 años presentan este trastorno, este dato alcanza el 13\% en ancianos de entre 85y 90 años. Las demencias más frecuentes en términos de práctica clínica son la demencia frontal, la 
vascular y la de tipo Alzheimer. La primera de ellas no está basada en la pérdida de la memoria sino más bien en cambios de carácter y comportamiento (apatía, falta de iniciativa, rigidez, escasa tolerancia a la improvisación). La segunda, a diferencia de la mayoría de las demencias, puede presentar un inicio brusco (debido a infartos cerebrales y a la falta de irrigación de ciertas zonas del cerebro), así como múltiples síntomas, dependiendo de las zonas donde exista alteración con la irrigación (136). Por su parte, el Alzheimer es considerado el tipo de demencia más frecuente (en concreto, supone el de los casos de demencia), y se caracteriza por un deterioro progresivo y total de las funciones cognitivas, acompañado por cambios en la personalidad y en el comportamiento del mayor (133). Concretamente, y de acuerdo con el DSM y VI (137), la demencia tipo Alzheimer es un trastorno neurocognitivo mayor que incluye déficits en la memoria y al menos una de las siguientes manifestaciones clínicas: afasia, apraxia, agnosia y síntomas ejecutivos, perturbando de esta manera la vida social y familiar de la persona de manera significativa. Su pronóstico se encuentra influido por varios factores a tener en cuenta: la edad de comienzo, el retraso en el diagnóstico, la alteración del sueño, la alteración precoz del lenguaje y la asociación a cuadros depresivos. En cuanto a esto último, es posible confundir los inicios de la demencia tipo Alzheimer con trastornos del estado del ánimo y concretamente con la depresión. Se considera que su origen es multicausal en las personas mayores de 65 años, y tiende a estar más presente en la mujer $(133,136)$.

\section{Estados de salud}

Si bien es cierto que, de acuerdo al ENSE 2011,T2012 (138), buena parte de los ancianos y ancianas presentan un estado de salud bueno o muy bueno, el porcentaje disminuye entre los de mayor edad. Así, esta situación viene condicionada, entre otras circunstancias (características personales del individuo, estatus socioeconómico o entorno del mayor), por la presencia de diversas patologías. En este apartado se expondrán los principales trastornos de corte psicológico que suelen encontrarse en las personas mayores. Existen causas de morbi-mortalidad como las enfermedades cardiovasculares o el cáncer que se han registrado menos incidencia en aquellos individuos que reportan mayor apoyo social (139).

\section{Deterioro cognitivo}

También aparece causas de comorbilidad psicológica o deterioro cognitivo según apuntan estudios (140) en personas mayores que apuntan la existencia de varios factores 
que fomentan la aparición de este deterioro, uno de ellos y que tiene mayor impacto es el entorno y que afecta más a las pautas de funcionamiento cognitivo, al número de patologías físicas y mentales como son las enfermedades cardiacas, hipertensión y depresión, que su vez están relacionadas con el deterioro cognitivo, al riesgo social y la soledad experimentada. Estos trastornos en la vejez se encuentran asociados a una reducción significativa de la calidad de vida, por lo que es imprescindible considerar su temprana detección e intervención (140).

Se ha observado que el tamaño de la red social influye en los factores intermedios reduciendo los problemas de salud física la vulnerabilidad psicológica y contribuye al mejor funcionamiento cognitivo (141).

El compromiso social medido por la participación en las diferentes actividades sociales y con una merma del funcionamiento cognitivo y predice un menor riesgo de demencia $(142,143)$.

Diferentes estudios de las redes sociales que analizan aspectos cualitativos como estructurales en relación con la edad cognitiva, refieren que un gran número de contactos con familiares, amigos, participación en actividades la red social es un buen predictor para frente al deterioro cognitivo $(144,145)$.

Generalmente, cuando se reflexiona en torno a las patologías asociada a la vejez o sobre los síndromes geriátricos clásicos, el deterioro cognitivo aparece en uno de los primeros lugares. Sin embargo debe diferenciarse entre el deterioro normativo de la mecánica cognitiva, por un lado, el deterioro cognitivo ligero (DCL) y la demencia, por otro. EL DCL se encuentra asociado al envejecimiento patológico, por lo que está caracterizado por una mayor alteración de las funciones cognitivas (atención, memoria) en comparación con las dificultades asociadas al envejecimiento normativo. existen todavía unos criterios definitivos para detectar el DCL (146).

Las redes sociales extensas y la satisfacción con el apoyo recibido se asocian con baja morbilidad y mejor salud percibida en edades avanzadas (147).

\section{Discapacidad}

Resultados de investigaciones han demostrado que no todos los componentes de las relaciones sociales son igualmente beneficiosos, las asociaciones son complejas, de forma 
que los efectos de la red y el apoyo social sobre la salud son diferentes. Las medidas que enfatizan en los componentes estructurales de las relaciones sociales muestran un efecto protector frente a la discapacidad e incluso un mayor efecto protector frente a la progresión de la discapacidad a largo plazo que aquellos que enfatizan en aspectos funcionales. La red social ha sido identificada como un factor protector frente al declive funcional, al inicio de una discapacidad básica (88).

Por ser la discapacidad un fenómeno complejo, resultante de la relación entre la salud individual, el entorno, las características personales y los factores psicosociales. El modelo de discapacidad propuesto por Verbrugge y Jette, (148). Dicho modelo define el proceso de discapacidad como la dificultad para realizar actividades que se consideran habituales entre individuos de las mismas características en el mismo entorno físico y social, vinculándola en mayor medida a la función social que a la función orgánica, a la que se asocian patología y deficiencia (149). A menudo, este concepto se hace operativo en términos de dificultad o incapacidad para la realización de actividades básicas de la vida diaria (ABVD), y actividades instrumentales de la vida diaria (AIVD) (150).

Las limitaciones funcionales crean dependencia y pueden influir en las relaciones sociales por esa necesidad de ayuda que se produce indirectamente e inversamente puede producirse un efecto contrario a causa de los síntomas depresivos (151).

Hay autores que informan que el tamaño de la red y la frecuencia de los contactos son factores protectores frente a la discapacidad mientras no se producía efecto en los familiares (151). Sin embargo hay otros autores que difieren de estos resultados demostrando que cuando mayormente persiste el efecto protector de las relaciones sociales sobre la discapacidad es cuando la relación es mayor con los familiares, siendo mínima en el caso de los amigos .Este caso es el español y debe interpretarse por la importancia que tiene la vida familiar para los mayores españoles (152).

En cuanto a la relación con los hijos, no se ha encontrado beneficio sobre la aparición de la discapacidad $(151,153)$. Hay otros estudios como el de "Unger" informa que el mayor número de contactos está asociado con menor discapacidad (124).

Por su parte, Saenan, Bruce and McAvay demostraron que las mujeres tenían menos probabilidades de experimentarla aparición de nuevas discapacidades para las AVD con contactos más próximos (154). 
Pertenecer a grandes redes sociales, participar en ellas (con grupos de amigos y familiares ) tener más de un contacto semanal con o por teléfono pertenecer a un club de jubilados, la satisfacción emocional, la satisfacción con las relaciones sociales y dar apoyo instrumental a otras personas, tiene efecto protector frente el desarrollo de incapacidad $(39,155)$. Sin embargo si el individuo está solo, no tiene pareja, está insatisfecho con las relaciones sociales habrá un incremento de la discapacidad funcional $(39,154,156)$.

Según en la encuesta realizada en las ciudades de Madrid y Barcelona en el 2005, se demostró que existe para medir (ABVD) y las (AIVD) al igual que en otros ámbitos geográficos existe una relación estadísticamente significativa entre el indicador de diversidad de red social utilizado y la discapacidad en sus dos niveles de gravedad. Por tanto, la diversidad de la red social parece mostrar un efecto protector frente a la discapacidad entre la población urbana al comienzo de la vejez (157).

También se puede afirmar que, al igual que en otros ámbitos geográficos, la diversidad de la red social tomada en su conjunto resulta predictora de discapacidad entre la población urbana española entre 70 y 74 años, así como del nivel de gravedad de la misma. Hay que añadir que este efecto se debe principalmente a la participación social más que a la red social familiar, lo que es consistente con los hallazgos de otros estudios tanto europeos como españoles y americanos. Cabría esperar, por tradición cultural, que la red social familiar tuviera un mayor efecto en una cultura mediterránea como la española, pero no ha resultado ser así ya que, al igual que en otros estudios españoles, ha sido la participación social la que parece proteger en mayor medida de la aparición de la discapacidad. Así, la participación en actividades sociales es una muestra de persistencia en el entramado social, a la vez que estas actividades tienen un valor simbólico de salud, de posibilidad de mover el propio cuerpo $(4,39,151,158-160)$.

\section{Depresión}

Por otra parte, hay una amplia literatura que aborda los diversos factores de riesgo de la depresión en general y, en concreto, la depresión en personas mayores; entre los factores de riesgo que, últimamente, han provocado más producción científica, destacamos la clase social, explicada por los diferentes componentes del nivel socioeconómico (ingresos, trabajo y educación) $(161,162)$. Además de la dimensión «posición social desfavorable» para explicar los síntomas depresivos, destacamos otros factores que también han sido resaltados en diferentes artículos como factores de riesgo de la depresión en los adultos 
mayores; así, diversas variables relacionadas con la soledad y con el mayor o menor capital social, el estado civil, el apoyo social y la vida en solitario están altamente correlacionadas con la depresión en la vejez (163-165).

Sin embargo, también debemos tener en cuenta las diferencias entre hombres y mujeres a la hora de analizar los factores antes dichos como determinantes de la depresión, ya que en algunos estudios se observan variaciones sustanciales en la influencia de, por ejemplo, el estado civil y las redes sociales en la depresión entre varones y féminas adultos mayores además, normalmente, las mujeres tienen más riesgo que los hombres de padecer síntomas depresivos, aunque se controlen la edad, la forma de convivencia, los parámetros socioeconómicos y los aspectos relacionados con la salud (166-169). Dimensiones como los eventos estresantes que acontece en la vejez, la percepción subjetiva de salud, la funcionalidad física, el deterioro cognitivo y la edad también pueden influir en la depresión, aunque en muchas ocasiones dichas dimensiones están mediatizadas por las variables de clase, apoyo social y género (170).

Así como ya hemos dicho con anterioridad el apoyo social en la prevención de la soledad es un factor muy importante en la prevención de la depresión tal como se observa en los estudios llevados a cabo en España (171). De hecho los factores sociales especialmente el apoyo social, son protectores frente a los estresores al final de la vida que pueden conducir a la depresión $(4,172,173)$.

\section{Desnutrición}

Por otro lado, existen factores socioeconómicos y psicológicos que influyen en la nutrición del anciano. El aislamiento social, los recursos financieros limitados, la escasa educación sobre nutrición, la falta de apoyo familiar, la pérdida de seres queridos o de personas encargadas de su cuidado y la menor movilidad debido a limitaciones físicas o aislamiento social pueden, todos ellos, disminuir la disponibilidad de diversos alimentos $(174,175) \cdot$ La existencia de enfermedades crónicas, como la diabetes, la hipertensión, la neumopatía obstructiva crónica, las cardiopatías o la artritis, junto con el tratamiento farmacológico o dietético asociado, incrementan aún más las posibilidades de nutrición inadecuada en el anciano. 
La importancia de la mala nutrición radica en su valor pronóstico, porque interfiere en la evolución satisfactoria de los pacientes, al producir deterioro inmunológico, prolongación del tiempo de cicatrización de las heridas, anemia, prolongación del tiempo de coagulación, osteoporosis, deterioro de las funciones enzimáticas, y aceleración del proceso de envejecimiento, entre otras (176).

Aislamiento social: una de las primeras áreas que descuidan los ancianos que viven solos o los que tienen un pobre soporte social, es la nutrición. Puede ser por pérdida de la motivación para comer o por desconocimiento para preparar adecuadamente los alimentos. Un buen ejemplo es el llamado "escorbuto del viudo", descrito en Inglaterra en los años cuarenta en aquellos ancianos que habían enviudado recién, y por desconocimiento en la preparación de los alimentos consumían solo alimentos enlatados, por lo que tenían una baja ingesta de vitamina $\mathrm{C}(177)$.

\section{Salud autopercibida}

El indicador autopercepción de salud resulta útil para medir el nivel de salud de una población, ya que se relaciona fuertemente con la presencia de enfermedades crónicas (178). Adicionalmente, la ayuda recibida y la satisfacción con la vida se relacionaron con la autopercepción de salud (179).

En el proyecto Envejecer en Leganés los resultados apuntan que el contacto frecuente o la correspondencia con hijos está asociada a unan buena percepción de estado de salud y una menor presencia de signos depresivos en la población mayor (4). Por lo contrario la persona mayor que más ayuda demanda para las actividades de la vida diaria (AVD) es aquella que peor valora su estado de salud (180).

El envejecimiento activo propone los siguientes datos que revelan la necesidad de proponer actuaciones socioculturales dirigidas a este colectivo como son que el $53 \%$ de personas mayores inician nuevas actividades después de los 65 años y el $43 \%$ de los mayores quieren participar activamente en la sociedad (48).

Y el tener un adecuado apoyo emocional también se asocia con una mejor percepción de la salud (181). 


\section{Caídas}

La OMS (2012) define las caídas como "consecuencia de cualquier acontecimiento que precipite al paciente al suelo en contra de su voluntad". La mayoría de las caídas que se producen en los adultos mayores son de origen multifactorial, y se incrementa con la acumulación de factores, aunque suelen ser por una inadaptación al medio en el que se encuentran viviendo o por causa de una inadecuada accesibilidad, enfermedades o procesos invalidan tés, hipotensión ortostática, debido a los efectos de la medicación, deterioro del equilibrio y la deambulación (182).

Existe una alta incidencia de caídas en estos en ancianos más en hombres que en mujeres (183). Y la satisfacción con el apoyo social fue baja tanto en los hombres como en las mujeres posiblemente debido a una reducción de las actividades sociales asociadas al temor a las caídas (181).

\subsubsection{Instrumentos para analizar las relaciones sociales}

Uno de los principales problemas que enfrentan los investigadores en esta área es la definición del término relaciones sociales, de hecho la falta de consenso respecto a los elementos que se consideran como parte de la red, y los instrumentos de medidas que deben emplearse para evaluar las relaciones sociales generan avances incipientes e inconmensurables. Se proponen el empleo común de algunos elementos conceptuales y

metodológicos indispensables en el estudio de redes de apoyo social para adultos mayores, que permitirá reordenar y esclarecer los conocimientos actuales en el área (184).

Beerkman y Glass recomiendan que el instrumento deben adecuarse para según el tipo de análisis en función de los objetivos, las hipótesis y las fuentes de datos (38).

En los estudios consultados, se analizan el efecto protector de las relaciones sociales $(12,185)$ en la salud de las personas mayores, han utilizado índices de redes sociales o variables relacionadas con aspecto específicos (186). También se ha observado la variabilidad cultural puede explicar diferencia de asociación entre las relaciones sociales y la salud tal como muestra en un estudio de tres estados de USA (187). 
Las investigaciones de las relaciones sociales que viven en países mediterráneos y sus relaciones con la salud es todavía escasa y se vienen desarrollando en el Norte de Europa (estudio CLESA), América del Norte y Sur (utilizan estudio SABE y CASEN), Australia (estudio ALSA) y Asia Oriente. En los diferentes estudios pueden revelar efectos no descritos suficientemente sobre la variabilidad en la naturaleza e intensidad de las relaciones sociales en los diferentes contextos culturales $(16,134,154,186,188-190)$.

El estudio CLESA en Finlandia, Países Bajos y España estudia la discapacidad en cuatro actividades de la vida diaria se determinó al inicio del estudio y durante el seguimiento. La participación social, el número de lazos familiares y la presencia de amigos, que se añadieron para obtener un índice de lazos sociales, se sacaron datos a la prevalencia e incidencia entre discapacidad y los lazos sociales y la influencia que tiene educación, la comorbilidad y la autopercepción de la salud. Y el efecto diferencial y modificador de cada país, edad y sexo (191).

EL estudio SABE estudia con relación a los arreglos residenciales, los resultados muestran que existe una mayor propensión a vivir independientes en los países que se encuentran en etapas más avanzadas de la transición demográfica. Esto sugiere que, independientemente de factores culturales, se podría esperar un incremento importante en la incidencia de adultos mayores. Un hallazgo no esperado es que el hecho de estar casado parece actuar como un "factor protector" contra las dificultades en ejercer las actividades de la vida diaria, además de aumentar significativamente la probabilidad del adulto mayor de recibir o prestar apoyo de naturaleza material. Como era de esperarse, por otra parte, el número de hijos se mostró positivamente asociado con la probabilidad del adulto mayor de recibir apoyo material. El número de hijos, sin embargo, no afecta de manera importante a la probabilidad del adulto mayor de prestar este tipo de apoyo. Las condiciones socioeconómicas de los adultos mayores han probado tener un efecto importante en las transferencias informal de apoyo. Con relación a las ayudas funcionales e instrumentales en actividades de la vida diaria, un nivel socioeconómico más elevado disminuye significativamente la probabilidad del adulto mayor de declarar algún tipo de dificultad. Curiosamente, sin embargo, los niveles más bajos incrementan la probabilidad de recibir este tipo de ayuda. Con respecto al apoyo material, parece estar presente una especie de 
"efecto de sustitución" entre el apoyo formal y el informal, determinado por las condiciones socioeconómicas (192).

En el entorno europeo encontramos estudios de Denmark que valoran sexo, edad, capacidad funcional, autopercepción, relaciones sociales (diversidad de vínculos con las que tienen personal de contacto), participación social y características psicosociales $(193,194)$.

Son pocos los estudios realizados en España que analizan las relaciones sociales y su influencia sobre la salud utilizando diferentes instrumentos de medida y estos son:

- En el estudio multidimensional de la población mayor de Córdoba ANCO1 $(195,196)$ se utilizó el cuestionario OARS-MFAQ adaptado y validado por Grau et al., con 9 preguntas que recogen información sobre aspectos cuantitativos, cualitativos y de apoyo emocional y material. Cuantitativamente analiza el núcleo familiar, su composición, que el sujeto conoce bien a sus miembros como para ir de visita a sus hogares, cuantificar el número de visitas por días y por semanas. En el aspecto emocional explora el sentimiento de soledad y de confidente del anciano y la frecuencia que este ve a sus familiares. En el apoyo material investiga la disponibilidad de ayuda y la duración y fuente de esta.

- En 1992 en la Encuesta de Barcelona (185) entre las variables que reflejan el apoyo social, se utilizó un instrumento ESB92, con las siguientes variables:

- Apoyo emocional y apoyo vecinal: recogen la existencia de personas en el vecindario con la que poder contar con la que pedir pequeños favores y obtener apoyos emocionales.

- $\quad$ Las redes comunitarias: recogen la asistencia a sitios públicos como la iglesia, el mercado o algún lugar céntrico del barrio.

- $\quad$ Red familiar: al número de familiares o amigos disponibles que tenía la persona mayor.

- $\quad$ El estado civil y la situación de convivencia.

- En el instrumento en la encuesta de Salud de Barcelona 2000 fue el Perfil de Duke que mide la red con cuatro variables: la frecuencia de contacto con 
la red social, con el apoyo social, el apoyo emocional y el tipo de convivencia (197).

- El estudio FREDA se ha estudiado la escala socio familiar de Gijón abreviada y modificada para medir el riesgo social que evalúa la situación familiar las relaciones y contactos sociales y apoyos de la red social. Dicha versión ha sido validada para la predicción del retorno al domicilio y del riesgo de institucionalización $(198,199)$.

- Envejecer en Leganés (4): que es un estudio integrado en el modelo de Berkman y Glass (38) adaptado, y cuyo instrumento utilizaremos, que recoge información de la estructura de la red social y de los mecanismos psicosociales. El instrumento fue creado para valorar el papel de las redes sociales, la integración social, el apoyo social, y la vinculación social en el mantenimiento de la salud en función con la edad. Es uno de los pocos instrumentos validados en España de población mayor que vive en la comunidad, que cumple con los requisitos de la definición clara de los dominios de apoyo social investigados, desglose por vínculos y validez interna y externa. Dicho instrumento es el único que basándose en estudios previos incluye preguntas relativas a mecanismos psicosociales, más concretamente al apoyo emocional recibido y al papel que juega la persona en cada uno de los vínculos. Esta última variable representa un concepto relacionado pero distinto al del apoyo prestado por el individuo, que sí se ha asociado a la mortalidad $(200,201)$. La mayor parte de autores en la última década en la necesidad de diferenciar entre la estructura de las relaciones sociales y su función (38).

- Por último en el estudio de Escobar (157), que nos habla de la red social y la discapacidad al principio de la vejez en las ciudades de Madrid y Barcelona, nos remarca que la red social ha sido un factor protector frente al declive funcional al inicio de la discapacidad básica, sin embargo la evidencia no es concluyente con los estudios EPESE, NORA y CLESA, en cambio en el estudio de MacArthur (202), nos muestra efectos protectores de las redes sociales. En este estudio las ABVD y AIVD son estudiados por los test de Katz y Lawton $(203,204)$. La prevalencia de la discapacidad se mide por medio del estudio SHARE (205). 
Análisis de las relaciones sociales y la fragilidad en las personas mayores de 75 años residentes en Castellón de la Plana 



\section{JUSTIFICACIÓN}

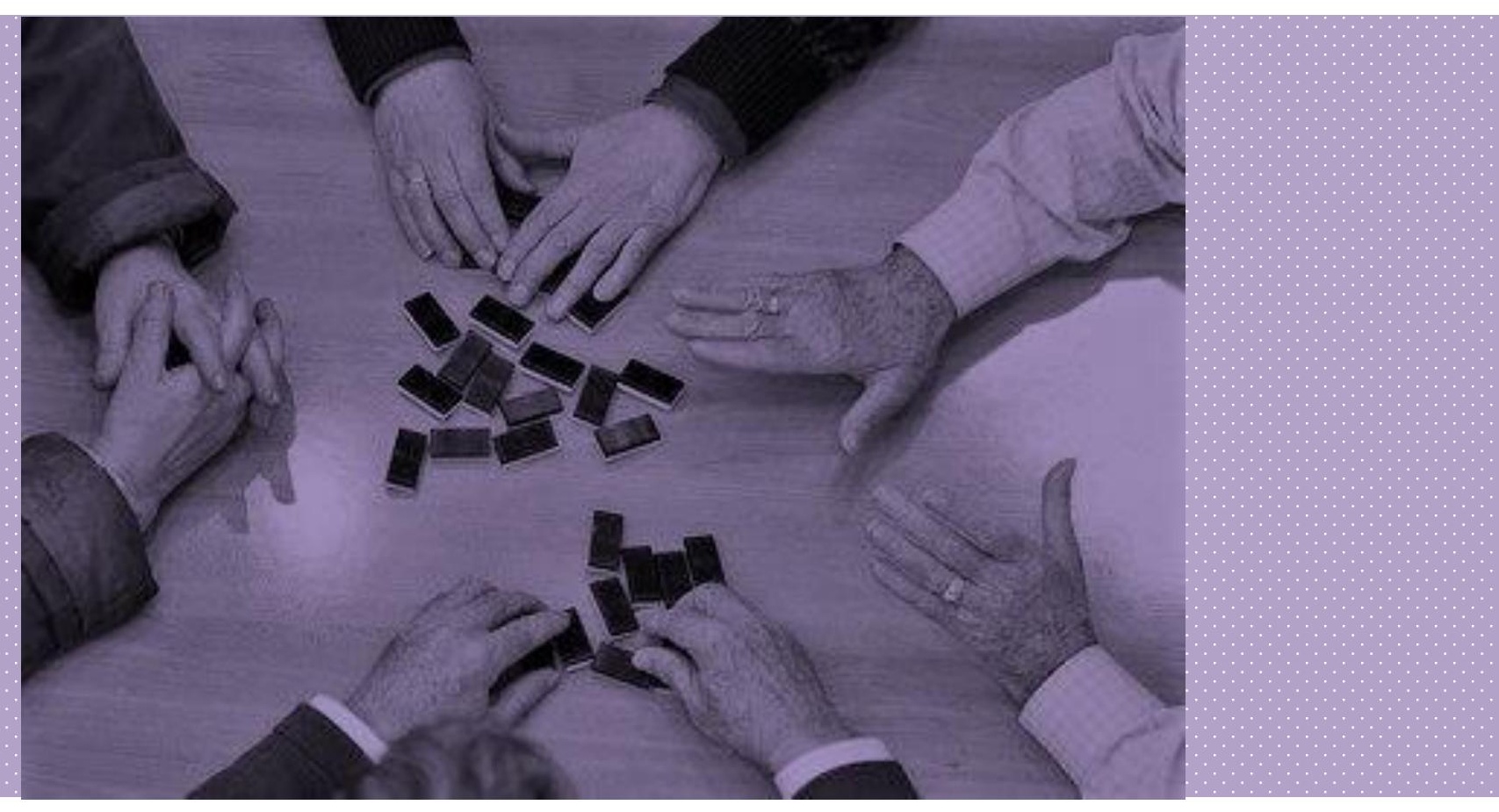





\section{Justificación}

Nuestra investigación está enmarcada en un estudio sobre fragilidad de mayores en distintas poblaciones y está focalizado en la relación entre fragilidad y relaciones sociales (206).

Es difícil hablar e imposible sintetizar en el estudio de todos y cada uno de los escenarios que influyen y sobre los que actúan las personas mayores. Aquí pretendemos enumerar aquellos decisivos en la experiencia social de la vejez (207).

Los apoyos sociales y familiares son importantes para un envejecimiento saludable. El tipo de hogar de las personas mayores en España ha cambiado menos que el resto de sus coetáneos europeos, aunque, cada vez más, prefieren, en la medida que les es posible, vivir independientemente de sus hijos; sin embargo, la corresidencia en nuestro país sigue siendo más elevada que en el resto de Europa. Precisamente, los vínculos familiares son muy fuertes, ya que procuran vivir cerca de sus hijos 0 , incluso, hermanos. Además son frecuentes los contactos comunicativos, aunque sea por teléfono. $Y$, como llegan a la jubilación, en alta proporción, con buenas condiciones de salud, suelen ser una ayuda muy importante para sus hijos, en la crianza de sus nietos pequeños e, incluso, para sus vecinos. Como consecuencia, la tendencia en los últimos años ha sido expulsar de la actividad laboral prematuramente a las personas maduras y mayores, que se encuentran útiles y con mucho tiempo libre disponible para poder realizar una gran variedad de actividades: política, laboral, ámbito educativo, ocio y en movimiento sociales y asociaciones (208).

En todos y cada uno de estos escenarios es necesario analizar el grado de satisfacción personal que produce su implicación en ellos. Incluir datos y referencias de estos dos aspectos de cada uno de ellos es muy importante para poder definir factores de riesgo en la situación social de las personas mayores como la tendencia al aislamiento social y al soledad (207). 
Existen pocos estudios que investiguen sobre las escasas o malas relaciones sociales y la fragilidad, siendo estos de procedencia extranjera. Lo que más se ha estudiado es sobre la soledad y el aislamiento social, pero no se profundiza en todas las dimensiones de las relaciones sociales (80).

Se presenta una investigación que tiene como objeto, describir la realidad de las relaciones sociales en la población mayor de Castellón de la Plana. 
OBJETIVOS

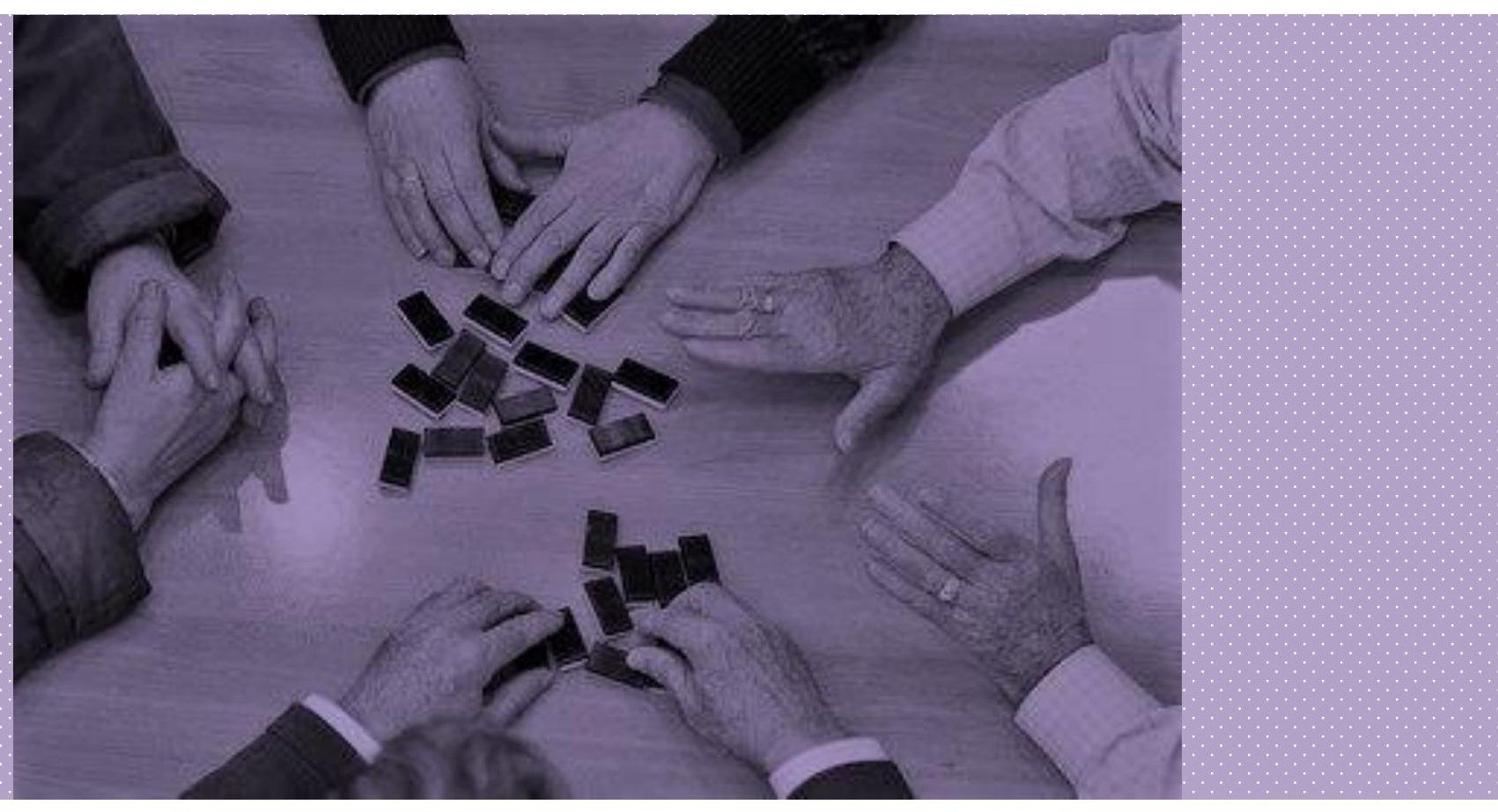





\section{Objetivos}

\section{Objetivo general:}

- Analizar las relaciones entre fragilidad y relaciones sociales en personas mayores de 75 años que viven en el entorno de la ciudad de Castellón de la Plana.

\section{Objetivos específicos:}

- Conocerlas características demográficas, hábitos de salud y estado de salud de las personas mayores de la ciudad de Castellón.

- Determinar la prevalencia de la fragilidad de las personas mayores de Castellón de la Plana.

- Conocer las relaciones sociales de las personas mayores de dicha población. 



\section{METODOLOGÍA}

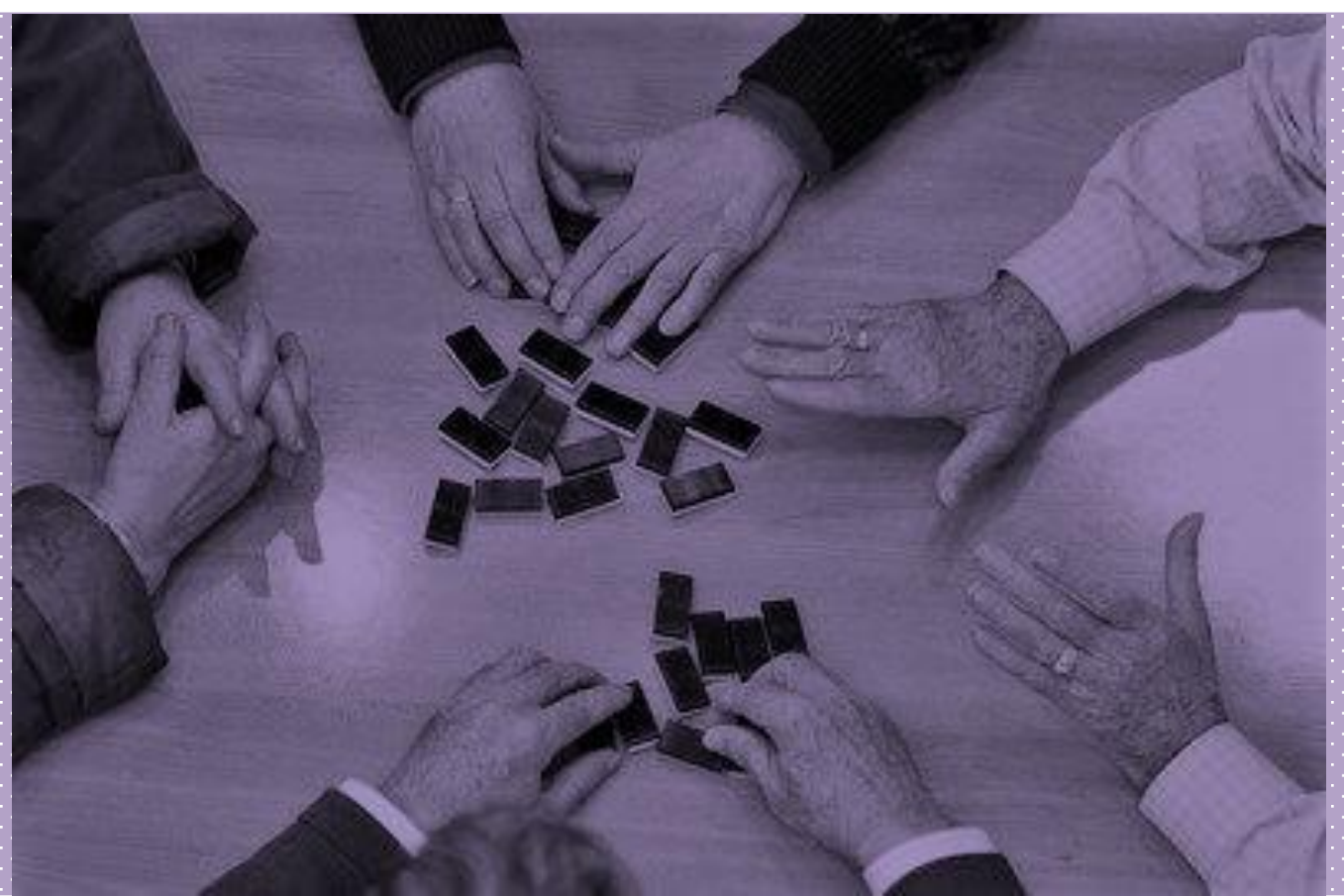





\section{Metodología}

\subsection{Diseño del estudio}

Se trata de un estudio observacional de corte transversal realizado sobre la población mayor de Castellón de la Plana, que incluye un estudio descriptivo y analítico de las variables objeto de estudio y sus correlaciones. La recogida de datos se realizó por la investigadora durante el primer semestre de 2015, mediante entrevistas individualizadas.

El estudio se enmarca en el programa de prevención de la fragilidad en mayores de Castellón de la Plana, y los datos se recogen en un cuestionario adaptado de la Encuesta FRALLE (209) realizada en la ciudad de Lleida con el mismo objetivo y para el estudio de las relaciones sociales llevado a cabo Castellón de la Plana en 2015 (ANEXO 1).

\subsection{Población de estudio}

La población son todos los mayores de Castellón que residen en la comunidad.

\subsubsection{Criterios de inclusión}

Se incluirán en el estudio los individuos de ambos sexos que en el momento de la entrevista tengan 75 o más años de edad, residentes en viviendas familiares de la ciudad de Castellón, con tarjeta sanitaria, que acuden a los servicios de atención primaria de salud durante el periodo de estudio y que expresen su conformidad en participar.

\subsubsection{Criterios de exclusión}

Quedaran excluidos del estudio aquellas personas que en el periodo de estudio se encuentren en fase terminal, así como todos los institucionalizados. No se incluirán aquellos de los que no pudo obtenerse información subrogada de familiares o cuidadores en los casos que así se precisó por presentar deterioro cognitivo evidenciado

por un valor mayor o igual a 3 errores en el test de Pfeiffer. Así mismo, aquellas personas que no desean participar en el estudio. 


\subsection{Diseño muestra}

En la ciudad de Castellón la población adscrita es de 181.439 personas de las cuales 14.139 tienen 75 años o más; de estos 5.487 son hombres y 8.652 son mujeres.

La medida de la muestra se calculó para estimar una proporción, que asumiendo el porcentaje poblacional previsible es del $30 \%$, con un nivel de confianza del $95 \%$ y con una precisión del 5\%. Así, la medida de la muestra resultante es de 326 individuos.

La captación de individuos se realizó en los Centros de Atención primaria de la ciudad de Castellón de acuerdo a un protocolo establecido (ANEXO 2), con la colaboración de las enfermeras del departamento de salud de Castellón que quisieron participar voluntariamente en el estudio.

La captación de individuos se realizó mediante un muestreo intencionado, donde la enfermera de atención primaria pregunta a todas las personas mayores que acuden al centro de salud y cumplen los criterios de inclusión, si desean participar en el estudio. Aquellos que manifestaron el deseo de participar fueron citados para que la investigadora junto con el equipo de investigación realizase las entrevistas a modo individual.

De los nueve centros de salud de la ciudad de Castellón, se incluyen siete centros porque el resto no quisieron participar y aunque no se consigue una representación de todas las zonas de la ciudad, sí que se garantiza la representación de los diferentes niveles socioeconómicos de la población de Castellón.

\subsection{Variables e instrumentos de medida}

Para la recogida de datos a partir de la entrevista se utiliza la Encuesta FRALLE adaptada a las características de la ciudad de Castellón de la Plana, considerando las 
variables objeto del estudio actual y sus correspondientes instrumentos de medida que vienen detalladas a continuación.

Para la recogida de datos a partir de la entrevista se utiliza la Encuesta FRALLE adaptada a las características de la ciudad de Castellón de la Plana, considerando las variables objeto del estudio actual y sus correspondientes instrumentos de medida que vienen detalladas a continuación.

La encuesta tiene nueve dimensiones, estructuradas en escalas validadas. Estas dimensiones son:

- Dimensión estado cognitivo y afectivo: (depresión). Consta de dos variables cualitativas de multirespuesta con valores $0,1,2,3$. Una la mediremos con la escala Hamilton y la otra con el test de Pfeirffer.

- Dimensión estado de salud: Conjunto de 8 variables que incluyen presencia de alteraciones sensoriales, enfermedades pasadas y presentes, nombre de fármacos que toman habitualmente y cormobilidades. Las 6 variables cualitativas de respuesta dicotómica $1 \mathrm{SI}$ 2NO (alteraciones sensoriales): 1 variable cuantitativa (medicamentos día). La comorbilidad se mide a partir del Índice de Charlson. Variable cuantitativa que se obtiene de la puntuación de cada individuo.

- Dimensión Hábitos de salud: Conjunto 5 variables cualitativas de 4 o 5 respuesta tipo Likert que incluyen hábitos tóxicos (alcohol y tabaco), patrón del sueño, y hábitos de lectura.

- Dimensión Capacidad funcional: Evalúa la capacidad para la realización de las actividades básicas e instrumentales de la vida diaria. Esta dimensión consta de 14 variables cualitativas de multirespuesta asignando valores 0 y 1 . Se utilizan los Índices de Katz y Lawton \& Brodry.

- Dimensión dificultad y limitaciones: Consta de 4 variables cualitativas con respuesta, dicotómica $1 \mathrm{SI}$ / 2NO. Observa la dificultad/limitaciones para realizar 
ciertos movimientos o actividades y obstáculos o barreras arquitectónicas en el hogar.

- Dimensión caída: Existencia o no de caídas y posibles causas y consecuencias de las mismas. Consta de 27 variables cualitativas de 4 o 5 con respuesta tipo Likert.

- Dimensión Estado nutricional: Antropometría. Estado de la boca. Tipo de dieta, textura y vía de administración de la misma. Dificultad en la deglución y síntomas gastrointestinales. Las 27 variables cualitativas con distinto número de respuestas. Incluye algunas de respuesta dicotómica 1SI / 2NO.

- Dimensión Relaciones sociales: amigos, hijos, hermanos, sobrinos, nietos esposo/a pareja y confidente. Consta de 27 variables cuantitativas y 60 cualitativas. Del total de las cualitativas algunas respuestas son dicotómicas 1SI / 2NO

- Dimensión Calidad de vida relacionada con la salud. Consta de 11 variables cualitativas con respuesta tipo Likert. El cuestionario además, recoge información relacionada con: Utilización de servicios asistenciales: utilización de servicios sociales y/o sanitarios, ingresos hospitalarios o institucionalización durante el periodo de estudio.

\section{Variables independientes}

\subsubsection{Variables sociodemográficas}

- Edad: Expresada en años en el momento de la entrevista. Variable cuantitativa.

- Sexo: Variable cualitativa dicotómica. Hombre y mujer.

- Estado Civil: Variable cualitativa categorizada en 5 grupos. Soltero/a, Casado/a, con pareja (pero no casado/a), separado/a o divorciado/a (sin pareja actualmente) y viudo/a.

- Nivel de estudios (Nivel máximo de estudios alcanzado por la persona entrevistada en la entrevista): Variable cualitativa de 7 categorías. Analfabeto (no sabe leer ni escribir), sin estudios (no acabó los estudios primarios), estudios primarios, secundarios de primer grado, secundarios de segundo grado y estudios universitarios. 
- Convivencia (con quien convive actualmente): Variable cualitativa de 5 categorías. Solo/a, con el esposo/a, con los hijos/as, con el esposo/a e hijos/as u otros.

- Ingresos mensuales (total de ingresos que entran en el hogar mensualmente): Variable cualitativa de 6 categorías. Menos de $400 €$, de $400 €$ a $600 €$, de $600 €$ a $900 €$, de $900 €$ a $1200 €$, de $1200 €$ a $1800 €$, más de $1800 €$ o prefiere no contestar.

\subsubsection{Hábitos de salud}

- Problemas de sueño: Variable cualitativa, se midieron en 4 ítems, se despierta muy pronto (antes de lo que quería), le cuesta mucho dormirse, duerme mal durante la noche o se despierta muchas veces durante la noche. Cada ítem tiene 4 respuestas, que varían entre nunca con una puntuación de 1; rara vez con 2 puntos; a veces con 3 puntos y a menudo con 4 puntos. Consideramos la variable dicotómica, $>4$ tiene problemas de sueño y $\leq 4$ sin problemas de sueño.

- Polifarmacia: Variable cuantitativa. Se valora el número de fármacos diferentes que toma normalmente la persona encuestada en 24 horas. El consumo >3 medicamentos por día se considera polimedicación.

- Hábito tabáquico: Variable cuantitativa. Clasifica a los sujetos según su consumo de tabaco en cuatro categorías: no fumador (no ha fumado nunca), exfumador (ha fumado pero ahora ya no fuma), fumador ocasional (fumador actual de 10 cigarrillos o puros o menos al día) y fumador habitual (fumador actual de 10 cigarrillos o puros o más al día).

- Consumo de alcohol, según la frecuencia en el consumo de alcohol: Variable cuantitativa. Clasifica a los sujetos según su consumo, si no bebe nunca, o bebe en alguna ocasión, una o dos veces al mes, una o dos veces a la semana, diariamente, solo en las comidas y diariamente o entre las comidas o durante las mismas.

- Caminar (Frecuencia con las que camina a la semana). Variable cuantitativa. Se mide el número de días que caminan a la semana. Hay cinco opciones de respuesta que van desde nunca a 5-7 días por semana. Categoría: se considera que camina si lo hace al menos de 1 a 2 días a la semana. 


\subsubsection{Estado de salud}

- Conjunto de variables que incluyen presencia de alteraciones sensoriales, enfermedades pasadas y presentes, nombre de fármacos que toman habitualmente y cormobilidades. Las variables cualitativas de respuesta dicotómica 1SI/2NO (alteraciones sensoriales): y variable cuantitativa (medicamentos día).

- La comorbilidad: Se mide con el índice de Charlson(210) que cuenta diecinueve factores de comorbilidad. Variable cuantitativa. Se considera ausencia de comorbilidad de 0 a 1 punto; comorbilidad baja, 2 puntos; y alta, 3 o más puntos; con una puntuación máxima de 37, considerando comorbilidad una puntuación $\geq 3$.

- Discapacidad básica: Es la dificultad para realizar las actividades básicas de la vida diaria (ABVD). Se utilizó el índice de Katz (211) el cual evalúa seis ABVD, cuya respuesta puede ser independiente $\mathrm{O}$ dependiente. Es independiente cuando realiza las actividades sin supervisión, dirección o ayuda personal activa. Cuando la actividad se realiza de manera independiente se otorga 1 punto y cuando la actividad se realiza con ayuda o no se realizase le dan 0 puntos. Se considera discapacidad básica a la incapacidad para realizar una o más actividades. Variable cualitativa.

- Discapacidad instrumental: Es la dificultad para realizar las actividades instrumentales de la vida diaria (AIVD), se utiliza el índice de Lawton \&Brody (212) el cual evalúa ocho AIVD. La persona es autónoma si su puntuación es 8; dependencia moderada es 4-7; dependencia severa es $\leq 3$. Se considera discapacidad instrumental a la incapacidad para realizar una o más actividades.

- Síntomas depresivos: Variable cualitativa. Se ha utilizado la escala "The Center for Epidemiologic Studies Depresion Scale" (CES-D) (213) para medir los síntomas depresivos. Este cuestionario contiene 20 ítems estudia los componentes cognitivo y conductual de la sintomatología depresiva. Cuando se ha analizado los síntomas depresivos con la fragilidad se han eliminado dos preguntas que se utilizan para medir el apartado de "agotamiento" de la fragilidad. Para el análisis se ha utilizado la escala completa, considerando la persona con síntomas depresivos cuando obtienen una puntuación $\geq 16$. Su rango es de 0 a 60 . Si la persona entrevistada obtiene un valor de 0 a 15, la persona entrevistada no presenta sintomatología depresiva; por lo contrario su valor es $\geq 16$ presenta síntomas depresivos. 
- Desnutrición o estado nutricional: variable cualitativa. Para la desnutrición utilizamos el "Test Mini Nutricional Assessment Short Form" (MNA-SF) (214), consta de 6 ítems, con 14 puntos como máximo. Normal sería 12-14 puntos; riesgo de desnutrición sería 8-11 puntos; y desnutrición sería 0-7 puntos. Las personas encuestadas con valores $\geq 12$ estarían bien nutridos y con valores $\leq 11$ tienen riesgo de desnutrición. En lugar del IMC se utilizó la medida de la circunferencia de la pantorrilla (medida alternativa que se incluye en el MNE-SF) ya que el IMC forma parte de uno de los criterios de la fragilidad.

- Problemas de audición: variable dicotómica cualitativa. Dicotómica si/no. Consideramos que la persona entrevistada tiene problemas de audición cuando no puede escuchar la televisión a un volumen normal para otras personas (si utiliza prótesis auditivas o audífonos).

- Problemas de visión: se considera que la persona entrevistada tiene problemas de visión cuando a una distancia de 4 metros no reconoce a otra persona (si utiliza gafas o lentes de contacto, considere la pregunta se refiere a aquellas situaciones en que las está utilizando). Variable dicotómica cualitativa Si/no.

- Auto percepción del estado de salud: el estado de salud general percibido se mide como excelente, muy buena, buena, regular o mala.

\section{Variables dependientes}

\subsubsection{Fragilidad}

Para medir la fragilidad se ha utilizado la "escala de Fried y Watson" (215) validada en el Estudio de Salud Cardiovascular (CHS). Aunque se han utilizado los cinco criterios originales, algunas de las medidas para caracterizar la fragilidad fueron ligeramente modificadas siguiendo el criterio aplicado por Ávila-Funes en el estudio "Three-City Study" (este es un estudio que evalúa el riesgo de demencia y deterioro cognitivo atribuible a defectos vasculares) (216) Variable cualitativa. 


\section{Criterios de fragilidad:}

- Pérdida involuntaria de peso. Los participantes que manifestaron pérdida de peso en los últimos 3-6 meses de manera no intencionada o tienen un Índice de Masa Corporal (IMC) inferior a $21 \mathrm{Kg} / \mathrm{m} 2$ fueron considerados frágiles para este ítem. Este criterio, se ha asociado con incremento de mortalidad y resultados adversos en personas mayores que viven en la comunidad $(217,218)$.

- Baja energía o "agotamiento" (Exhaustion) Mediante dos preguntas incluidas en la escala "Center for Epidemiological Studies Depression" (CES-D) (213) que miden el estado depresivo. Se preguntó a los participantes: ¿Alguna de las siguientes frases reflejan como se ha sentido en la última semana?: "Sentía que todo lo que hacía era un esfuerzo" y "No tenía ganas de hacer nada". Estos podían contestar: $0=$ nunca 0 casi nunca (menos de 1 día); $1=$ a veces $(1-2$ días); 2 = con frecuencia (3-4 días); 3 = siempre o casi siempre (5-7 días). Categoría: los que contestaron "2" o " 3 " a cualquiera de estas dos preguntas fueron catalogados en este criterio como frágiles.

- Lentitud en la movilidad: Categoría: la lentitud en la movilidad se valoró teniendo en cuenta como punto de corte la quinta parte del valor más bajo del tiempo en segundos que se tarda en recorrer 4,5 metros.

- Debilidad muscular: La fuerza muscular se valoró mediante una pregunta sencilla: ¿presenta dificultad para sentarse/levantarse de la silla? Categoría: los participantes que contestaron que sí fueron categorizados como frágiles.

- Baja actividad física: Para el bajo nivel de actividad física se utilizó la escala de actividad física para las personas mayores (PASE) (219)Categoría: se consideraron activos aquellos participantes que realizaban trabajos ligeros diarios y/o actividades deportivas por semana e inactivos los que no lo hacían. Estos últimos fueron considerados frágiles.

Categorías de fragilidad de los participantes se consideraron:

- Frágiles si presentaban tres o más componentes de fragilidad.

- Pre-frágiles si cumplían uno o dos criterios de fragilidad.

- No frágiles si no tenían ninguno. 


\subsubsection{Relaciones sociales}

Se mide la red social y los mecanismos psicosociales de las relaciones sociales. Para ello se ha utilizado el cuestionario de Leganés que parte de instrumentos previos adaptados a la situación española (4).

En relación a la estructura de la red social y las características de los lazos de la red se incluyen preguntas relacionadas con:

- La participación social (actividades comunitarias y frecuencia): se considera que acude a la plaza o lugar céntrico, a la iglesia o lugar de culto o al hogar del pensionista si lo hace al menos una vez al mes.

- El tamaño y diversidad de la red: se considera el tener o no pareja y para cada uno de los vínculos (amigos, hijos, hermanos, sobrinos o nietos) si tiene, uno, dos o tres o cuatro o más.

- La frecuencia de contactos visuales y telefónicos con cada uno de los vínculos (amigos, hijos, hermanos, sobrinos y nietos): se ven o hablan por teléfono al mes de cero a tres veces, más de tres veces o nunca.

- La proximidad con el miembro más cercano para cada uno de los vínculos (amigos, hijos, hermanos, sobrinos y nietos): distante del vínculo menos de 15 minutos, entre 15 y 30 minutos y a más de 30 minutos.

Las dimensiones de las variables tamaño y diversidad de la red, frecuencia de contactos visuales y telefónicos y proximidad con el miembro más cercano parten de las utilizadas por Escobar a partir de la encuesta "Procesos de vulnerabilidad en la vejez. Seguimiento longitudinal de los efectos ambientales y sociales" (171).

En relación a los mecanismos psicosociales, los individuos fueron preguntados por:

- El confidente: tener o no confidente y tipo de relación con dicha persona Categoría: en el tipo de relación se han agrupado los ítems hermana, hermano, otro familiar (mujer) y otro familiar (hombre) y la categoría resultante se ha 
denominado familia extendida. Los ítems amiga, amigo, profesional u otro se han agrupado y la categoría resultante se ha denominado amigos u otros. Para los cuatro tipos de vínculos fundamentales, (amigos, hijos, familia extendida, que incluye hermanos-sobrinos-nietos y cónyuge), se formularon las siguientes preguntas:

- Apoyo emocional recibido: frecuencia con que respecto a los de ese vínculo, el individuo: a) se sentía querido y cuidado y b) se sentía escuchado. Los aspectos negativos: frecuencia con que respecto a los de ese vínculo el individuo: a) se sentía reprochado y b) desearía poder confiar más en ellos.

- El rol del individuo (en la vida de los vínculos): frecuencia con que respecto a los de ese vínculo, el individuo: a) les ayudaba; b) sentía que tenía un papel importante para ellos y c) se sentía útil. Categoría: las respuestas posibles eran nunca, a veces, con frecuencia, siempre. La asignación de puntuación a cada respuesta era de 0 a 3 excepto para los aspectos negativos que se asigna de 3 a 0.

A partir de las preguntas sobre relaciones sociales se construyen los siguientes índices globales que miden las redes sociales y los mecanismos psicosociales:

a) Redes sociales (índices globales)

- Índice de vínculos familiares con contacto (familias): Se construyó otorgando un punto por estar casado o con pareja, otro por ver o hablar por teléfono con al menos uno de los hijos por lo menos una vez al mes, y otro por ver o hablar por teléfono al menos una vez al mes con un hermano, sobrino o nieto (familia extendida). El rango de puntuación va por tanto de 0 a 3.

- Índice de actividades comunitarias (social participación): Se construyó sumando las actividades a las que el individuo acudía por lo menos una vez al mes incluyendo la pertenencia a un club o asociación. Su rango de puntuación va de 0 a 4.

- Índice de diversidad de la red (sociales). Sumando los dos índices anteriores con la variable contacto con los amigos, que contiene la información de si se veía o hablaba por teléfono con un amigo por lo menos mensualmente, se obtuvo este índice cuyo rango es de 0 a 7.

b) Mecanismos psicosociales (índices globales) 
- Índice de apoyo emocional recibido (social support): Medida de la puntuación de las escalas de apoyo emocional recibido de los hijos, familia extendida y conyugue que incluye los ítems sentirse querido, escuchado y satisfacción. En el caso de los amigos se construye un índice de apoyo emocional recibido que no incluye el ítem de satisfacción.

- Índice de rol del individuo (en la vida de sus vínculos) (social engagement). Es la media de las cuatro escalas de rol del individuo en la vida de cada uno de los cuatro vínculos (hijos, familia extendida, amigos y cónyuge) que incluye las variables de sentirse útil, prestar ayuda y tener un papel importante.

Una vez seleccionados los ítems que constituyen cada uno de los índices se definió la puntuación en cada una de ellos como la media de las puntuaciones de los ítems siempre que se hubiera contestado al menos dos. En el caso de los índices compuestos por dos ítems (el de los amigos) se admitió que la respuesta a uno solo de ellos fuera suficiente.

\subsection{Recogida de datos}

El instrumento de recogida de la información fue la Encuesta FRALLE (209) elaborada por la Universidad de Lleida y diseñado para el estudio "Evolución del proceso de fragilidad en la población mayor de Lleida" Dicho cuestionario, está diseñado y estructurado en 9 dimensiones que recogen todas las características biológicas, psicológicas y sociales que guardan relación con la fragilidad (incluidas en todas las variables previamente especificadas). El cuestionario se cumplimentó a partir de una entrevista personal de $1 \mathrm{~h}$ y media de duración. Los encuestadores fueron cinco Enfermeros miembros del equipo investigación entrenados para ello. La captura de individuos se realizó por la enfermera de los centros de salud, la cual preguntaba a las personas mayores que cumplían los criterios de inclusión, si querían participar en el estudio. Una vez expresado el consentimiento informado se concertó una cita para proceder a la entrevista. Cada entrevista tuvo lugar en el Centro de Salud, a excepción de aquellos casos en los que el participante no pudo desplazarse, en cuyo caso el investigador se desplazó al domicilio del participante. 
Una vez finalizado el trabajo de campo con los datos, en formato papel, se realizó un volcado de los datos de los cuestionarios a una hoja de cálculo Excel para facilitar su posterior análisis.

\subsection{Consideraciones éticas}

Antes de empezar el estudio, el Comité Ético de Investigación Clínica del departamento de salud de Castellón informó favorablemente la solicitud del proyecto del estudio (ANEXO 3). Del mismo modo, se comunicó al concejal del ayuntamiento de Castellón el estudio y no opuso inconveniente alguno.

Antes de comenzar la entrevista y para asegurar el anonimato, la confidencialidad, el consentimiento y la voluntariedad de las personas encuestadas, se redactó una hoja informativa para la persona donde se detallaban todos los datos del estudio de investigación, junto a un consentimiento informado que debían firmar como muestra de su conformidad (ANEXOS 4 - 5).

Para garantizar el anonimato en el cuestionario se incluyó un código de identificación y sólo en un documento diferente de la encuesta se especificaron los datos personales de la persona entrevistada con el mismo código de identificación y el teléfono. Sólo el investigador principal podía relacionar estos datos con el entrevistado y con su documentación; recibiendo permiso para custodiar los mismos con el fin de informarles cuando se lleven a cabo los programas de intervención secundarios a los resultados de la presente investigación.

\subsection{Análisis estadístico}

Se realiza un análisis descriptivo de la muestra utilizando para los datos cuantitativos medidas de tendencia central y de dispersión, y para los datos cualitativos medidas de distribución de frecuencias. 
La prevalencia se especifica por el total de la muestra y por grupo de género. Todas ellas se presentaran en \% y acompañadas del intervalo de confianza del 95\%.

Para el análisis bivariante de los factores asociados se utiliza la prueba de chicuadrado de Pearson o en su caso, el test exacto de Fisher para los datos cualitativos y la prueba t-Student para los datos cuantitativos.

Posteriormente se realizó un análisis multivariante mediante la regresión logística siguiendo el procedimiento "formadstepwise" de incorporación progresiva paso a paso de aquellas variables explicativas (posible factores asociados) que había presentado en el análisis bivariado un grado de significación inferior a 0,25 en la asociación con la variable dependiente (fragilidad).

Para el análisis de los datos se utilizó la versión 21.0 del programa estadístico SPSS. 
RESULTADOS

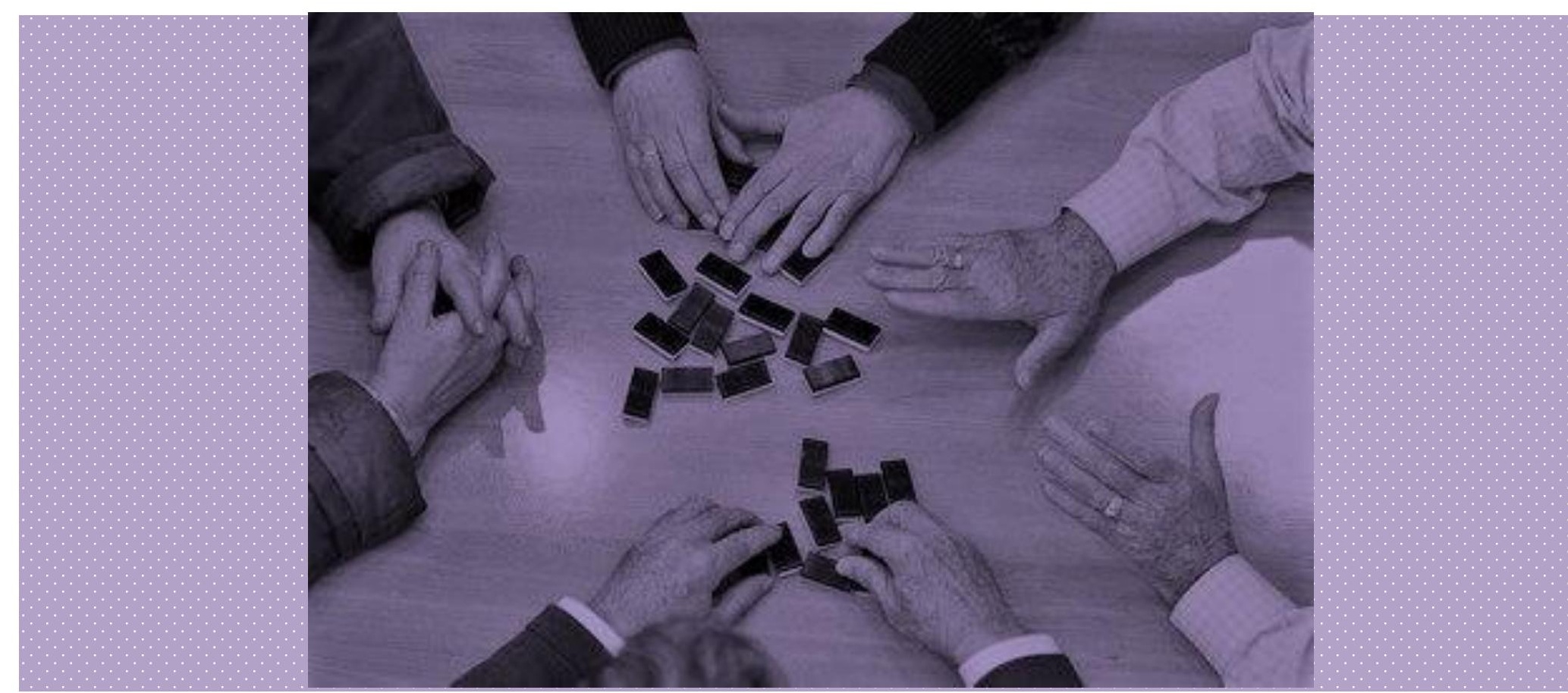





\section{Resultados}

En este apartado, se presentan los resultados obtenidos en la investigación objeto de la tesis.

El total de personas captadas que cumplimentaron la entrevista cumpliendo los criterios de inclusión fue de 326 pertenecientes a 7 Centros de Salud de la ciudad de Castellón de la Plana, con una distribución que se recoge en la Tabla 3.

Tabla 3. Distribución de la muestra estudiada por centro de salud: recuento $(n)$ y frecuencia

\begin{tabular}{lcc}
\hline$\%)$ & N & $\%$ \\
\hline Centro de Atención Primaria & 90 & 27,6 \\
\hline Pintor Sorolla & 47 & 14,4 \\
\hline Gran Vía & 66 & 20,2 \\
\hline Palleter & 13 & 4,0 \\
\hline Illes Columbretes & 74 & 22,7 \\
\hline Grao & 3 & 1 \\
\hline Rafalafena & 33 & 10,1 \\
\hline San Agustín & &
\end{tabular}

\subsection{Características sociodemográficas globales de la población estudiada por sexo}

Respecto a las características sociodemográficas, como puede observarse en la tabla 4, la edad media de las personas mayores estudiadas fue de 81,32 años, de los cuales el $48,2 \%$ fueron hombres y el $51,8 \%$ fueron mujeres.

La mayoría de los sujetos están casados 211, aunque también encontramos un mayor porcentaje de personas mayores viudas, (de un total 103, el $76 \%$ lo son). Sobre su nivel de estudios podemos apreciar que la mayoría no acabó los estudios primarios y son muy pocos los que tienen estudios secundarios, de $2^{\circ}$ grado o universitarios. Hay un alto porcentaje de las personas mayores que viven con su esposo/a pero cabe destacar 
que el $21,2 \%$ viven solos. En cuanto a los ingresos mensuales podemos ver que la mayoría se encuentran entre 600-1200 euros, pero debemos resaltar el 22,1\% de personas mayores que no contestaron la pregunta.

De los resultados, se puede desprender que, en el entorno de Castellón las mujeres presentan una situación más desfavorecida que los hombres, con significación estadística $(p=0,001)$. La mayoría de viudas son mujeres casi triplicando la cifra con respecto a los hombres. En lo que concierne al nivel de estudios las diferencias son similares, es decir, no varían por sexos. También observamos como dato significativo que se triplica el número de mujeres que viven solas a comparación de los hombres $(p=0,001)$. Por último, en lo referente a los ingresos mensuales podemos destacar que en el caso de las mujeres, la mayoría de los sueldos oscilan entre 600-900 euros.

Tabla 4. Características sociodemográficas globales por sexo: recuento (n) y frecuencia (\%)

Sexo

$\mathbf{P}$

\begin{tabular}{|c|c|c|c|c|c|c|c|c|}
\hline \multicolumn{2}{|c|}{ Variables sociodemográficas } & \multicolumn{2}{|c|}{ Total } & \multicolumn{2}{|c|}{ Hombre } & \multicolumn{2}{|c|}{ Mujer } & \\
\hline & & $\mathbf{n}$ & $\%$ & $\mathbf{n}$ & $\%$ & $\mathbf{n}$ & $\%$ & \\
\hline Edad $^{*}$ & & 81,3 & 4,2 & 81,6 & 4,3 & 81,0 & 4,1 & NS \\
\hline \multirow{5}{*}{ Estado civil } & Soltero & 7 & 2,1 & 2 & 1,3 & 5 & 3,0 & \multirow{5}{*}{$<0,001$} \\
\hline & Casado & 211 & 64,8 & 124 & 79,0 & 87 & 51,5 & \\
\hline & En pareja & 1 & 0,3 & 1 & 0,6 & 0 & 0,0 & \\
\hline & Separado & 4 & 1,2 & 3 & 1,9 & 1 & 0,6 & \\
\hline & Viudo & 103 & 31,6 & 27 & 17,2 & 76 & 45,0 & \\
\hline \multirow{4}{*}{ Nivel de estudios } & No sabe leer ni escribir & 48 & 14,7 & 19 & 12,1 & 29 & 17,3 & \multirow{4}{*}{ NS } \\
\hline & No acabó primarios & 125 & 38,3 & 61 & 38,9 & 64 & 38,1 & \\
\hline & Primarios & 90 & 27,6 & 43 & 27,4 & 47 & 27,4 & \\
\hline & $\begin{array}{l}\text { Secundarios } \\
1^{\circ} \text { grado }\end{array}$ & 39 & 12,0 & 17 & 10,8 & 22 & 13,1 & \\
\hline
\end{tabular}




\begin{tabular}{|c|c|c|c|c|c|c|c|c|}
\hline & Secundarios $2^{\circ}$ grado & 12 & 3,7 & 8 & 5,1 & 4 & 2,4 & \\
\hline & Universitarios & 12 & 3,7 & 9 & 5,7 & 3 & 1,8 & \\
\hline \multirow{5}{*}{ Convivencia } & Solo & 69 & 21,2 & 17 & 10,8 & 52 & 30,8 & \multirow{5}{*}{$<0,001$} \\
\hline & Esposo/Esposa & 187 & 57,4 & 114 & 72,6 & 73 & 43,2 & \\
\hline & Hijos/as & 41 & 12,6 & 12 & 7,6 & 29 & 17,2 & \\
\hline & $\begin{array}{l}\text { Esposo/esposa e } \\
\text { hijos/as }\end{array}$ & 14 & 4,3 & 6 & 3,8 & 8 & 4,7 & \\
\hline & Otros & 15 & 4,6 & 8 & 5,1 & 7 & 4,1 & \\
\hline \multirow{7}{*}{$\begin{array}{l}\text { Ingresos } \\
\text { mensuales }\end{array}$} & $<400 €$ & 3 & 0,9 & 0 & 0,0 & 3 & 1,8 & \multirow{7}{*}{$<0,024$} \\
\hline & $400-600 €$ & 26 & 8 & 10 & 6,4 & 16 & 9,5 & \\
\hline & $600-900 €$ & 77 & 23,6 & 28 & 17,9 & 49 & 29,2 & \\
\hline & $900-1200 €$ & 67 & 20,6 & 35 & 22,4 & 32 & 19,0 & \\
\hline & $1200-1800 €$ & 59 & 18,1 & 37 & 23,7 & 22 & 13,1 & \\
\hline & $>1800 €$ & 22 & 6,7 & 13 & 8,3 & 9 & 5,4 & \\
\hline & Prefiere no contestar & 72 & 22,1 & 34 & 21,2 & 38 & 22,0 & \\
\hline
\end{tabular}

* Media y Desviación estándar (DE)

*NS. No tiene significación estadística

\subsection{Resultados de los hábitos de salud por sexo}

Como se observa en la tabla 5 , en cuanto a los hábitos de salud más del $97 \%$ de los encuestados no fuma o es exfumador, y solo es fumador habitual3\%. La mayoría de fumadores y exfumadores suelen ser hombres, y el fumador habitual también. El 74,26\% dice no beber nunca siendo los hombres $64,46 \%$ las mujeres, $p=0,000$. El problema más significativo de problemas de sueño es que le cuesta mucho dormir con un $p=0,000$ $(62,58 \%$ mujeres versus $45,09 \%)$ el resto de problemas del sueño no son significativos. 
Tabla 5. Características de hábitos de salud por sexo: recuento $(\mathrm{n})$ y frecuencia $(\%)$

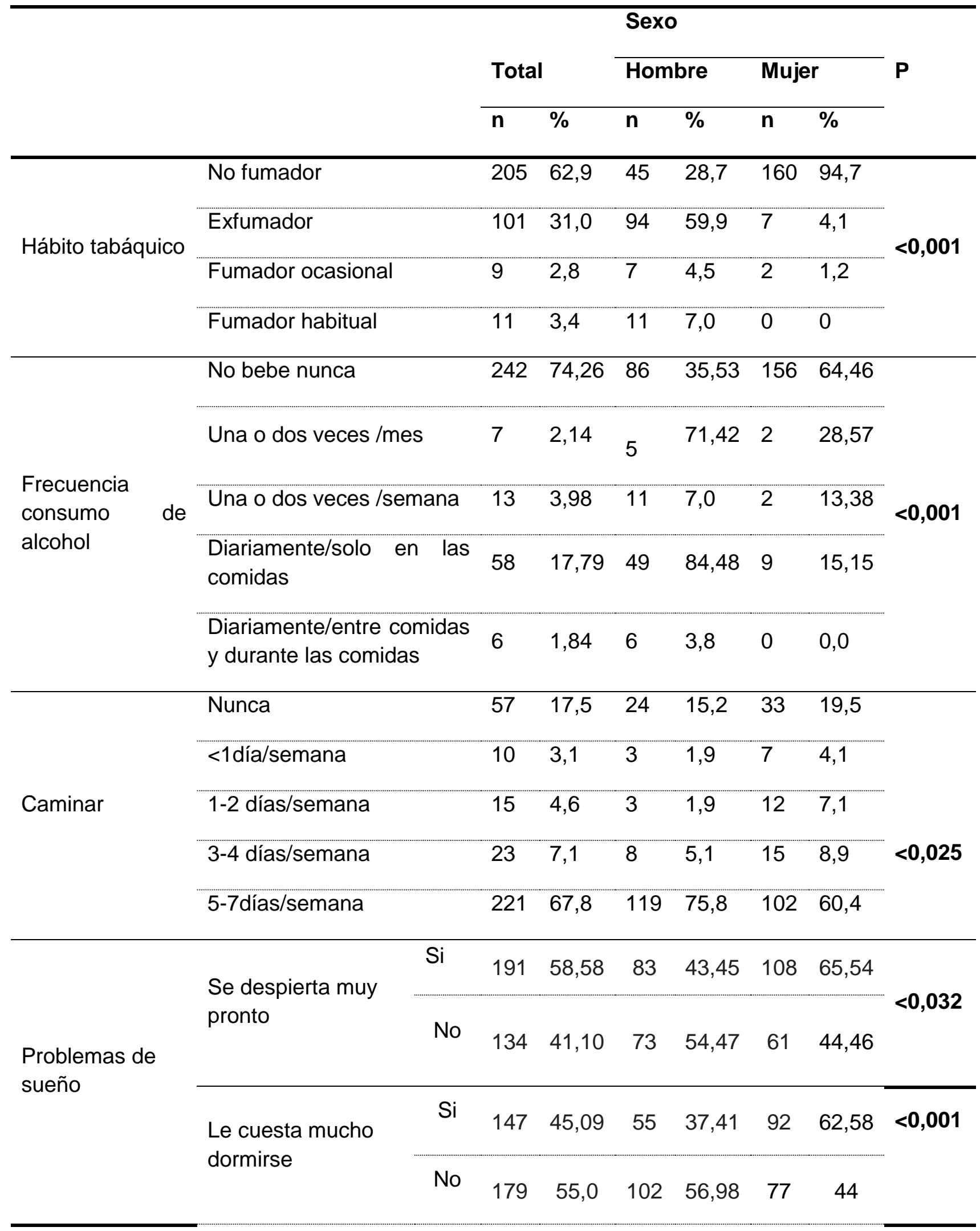


Duerme mal

Si $\quad 122 \quad 37,42 \quad 49 \quad 40,16 \quad 73 \quad 59,83 \quad<0,015$

durante la noche

No $203 \quad 62,26 \quad 108 \quad 53,20 \quad 95 \quad 46,80$

Se despierta muchas veces Si $\quad 271 \quad 83,13 \quad 130 \quad 47,98 \quad 141 \quad 52,02$

durante la noche

No $\begin{array}{llllll}54 & 16,56 & 27 & 8,28 & 27 & 50\end{array}$

\subsection{Características del estado de salud de la población separada por sexo}

En la tabla 6, se recogen los resultados del análisis descriptivo, en relación con las características del estado de salud de la población objeto de estudio. Podemos observar que la ausencia de deterioro cognitivo y discapacidad básica tienen rango que oscila entre el $87,5 \%$ y $93,6 \%$, respectivamente y no hay diferencias significativas entre hombres y mujeres. El deterioro cognitivo leve 8,9\% y moderado 4,25 es mayor en las mujeres y en cambio el severo es mayor en los hombres1, 3\%. Con respecto a la comorbilidad baja es $73 \%$, pero tampoco hay diferencias significativas por sexo. El 50\% de la muestra refirió problemas de audición y $76,1 \%$ problemas de visión. Más del $94 \%$ refieren tener problemas de sueño. Con respecto al estado nutricional, el $98,4 \%$ es normal.

En el estudio encontramos como significativos, la discapacidad instrumental moderada podemos observar que es superior en los hombres $23,4 \%$ que en las mujeres $11,5 \%$; los síntomas depresivos podemos apreciar que hay $45,3 \%$ de mujeres y un 27,5 $\%$ en hombres. En cuanto la percepción del estado de salud, el 42,3\% de encuestados refieren tener un estado de salud bueno, de estos un $51 \%$ son hombres y un $40 \%$ son mujeres. En lo que se refiere al consumo de $>3$ medicamentos cabe destacar el $80,9 \%$ son hombres. Hay que tener en cuenta que en el estudio que el $52,7 \%$ son personas prefrágiles y hay un $62,4 \%$ mujeres pre-frágiles frente a un $42 \%$ de hombres. 
Tabla 6. Características del estado de salud por sexo: recuento (n) y frecuencia (\%)

\section{Sexo}

Estado de salud

Total Hombre Mujer

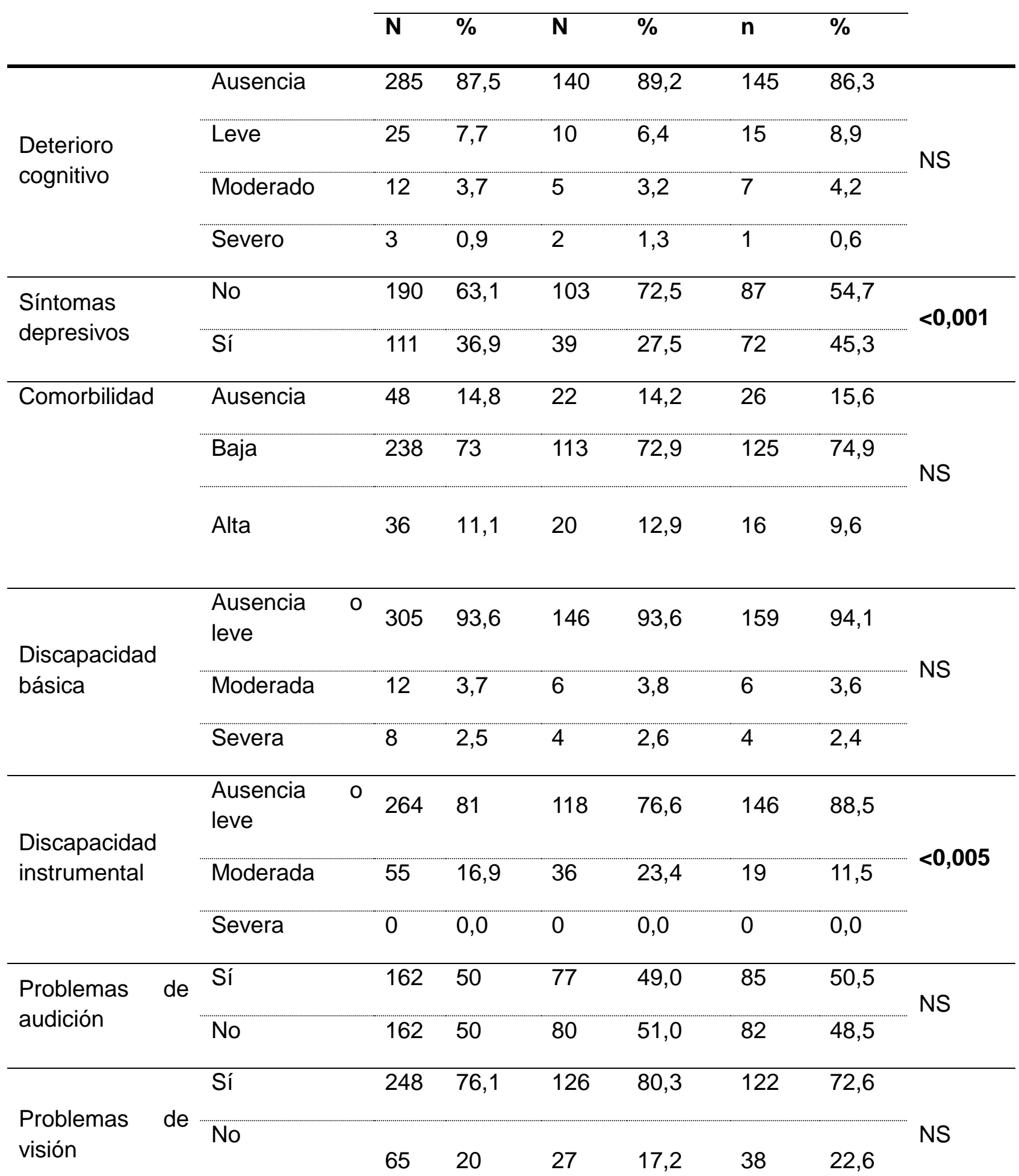




\begin{tabular}{|c|c|c|c|c|c|c|c|c|}
\hline \multirow{2}{*}{$\begin{array}{l}\text { Problemas } \\
\text { sueño }\end{array}$} & Sí & 307 & 94,2 & 144 & 91,7 & 163 & 96,4 & \multirow{2}{*}{ NS } \\
\hline & No & 19 & 5,9 & 13 & 8,3 & 6 & 3,6 & \\
\hline \multirow{5}{*}{$\begin{array}{l}\text { Autopercepción } \\
\text { de salud }\end{array}$} & Excelente & 19 & 5,8 & 14 & 9,7 & 5 & 3,1 & \multirow{5}{*}{$<0,004$} \\
\hline & Muy buena & 31 & 9,5 & 12 & 8,3 & 19 & 11,9 & \\
\hline & Buena & 138 & 42,3 & 74 & 51,0 & 64 & 40,0 & \\
\hline & Regular & 91 & 27,9 & 39 & 26,9 & 52 & 32,5 & \\
\hline & Mala & 26 & 7,9 & 6 & 4,1 & 20 & 12,5 & \\
\hline \multirow{2}{*}{$\begin{array}{l}\text { Consumo >3 } \\
\text { medicamentos }\end{array}$} & Sí & 224 & 68,7 & 127 & 80,9 & 97 & 57,4 & \multirow{2}{*}{$<0,001$} \\
\hline & No & 97 & 29,7 & 27 & 17,2 & 70 & 41,4 & \\
\hline \multirow{3}{*}{$\begin{array}{l}\text { Estado } \\
\text { nutricional }\end{array}$} & Normal & 321 & 98,5 & 153 & 97,5 & 168 & 99,4 & \multirow{3}{*}{ NS } \\
\hline & $\begin{array}{l}\text { Riesgo de } \\
\text { desnutrición }\end{array}$ & 5 & 1,5 & 4 & 2,5 & 1 & 0,6 & \\
\hline & Desnutrición & 0 & 0,0 & 0 & 0,0 & 0 & 0,0 & \\
\hline \multirow{3}{*}{ Fragilidad } & No frágiles & 101 & 33,7 & 69 & 48,3 & 32 & 20,4 & \multirow{3}{*}{$<0,001$} \\
\hline & Pre-frágiles & 158 & 52,7 & 60 & 42,0 & 98 & 62,4 & \\
\hline & Frágiles & 41 & 13,7 & 14 & 9,80 & 27 & 17,2 & \\
\hline
\end{tabular}

\subsection{Resultados del análisis descriptivo de las relaciones sociales y los mecanismos psicosociales separado por sexo.}

El análisis de las relaciones sociales incluye la descripción de la estructura de la red social, la presencia de confidente y el tipo de relación y por último los índices globales que conforman las redes sociales (índice de vínculos familiares con contacto, índice de actividades comunitarios e índice de diversidad de la red) y los mecanismos psicosociales (apoyo emocional recibido, rol del individuo en la vida de los vínculos)dentro de la Dimensión Relaciones sociales. 


\subsubsection{Estructura de la red social de los encuestados en cuanto la cantidad de personas con las que mantiene relación}

En la tabla 7 se describe la estructura de la red social de los encuestados y se analiza la diversidad de los vínculos y con respecto a los mismos la distancia a la que viven y el tipo y frecuencia de los contactos. Se analiza los vínculos que forman parte de la familia extensa (hermanos, sobrinos, nietos) aproximadamente tres cuartas partes declara tener un hermano o más hermanos (88,3\%) el $88,5 \%$ tiene uno o más sobrinos y el $90 \%$ tiene uno o más nietos. En relación a los amigos es la más significativa con un $p<0,000$.

Tabla 7. Estructura de la red social sexo: recuento (n) y frecuencia (\%)

\section{Sexo}

Red Social

\begin{tabular}{llllll}
\hline Total & \multicolumn{4}{l}{ Hombre } & \multicolumn{2}{c}{ Mujer } & \\
& & & & & \\
\hline $\mathbf{n}$ & $\%$ & $\mathbf{n}$ & $\%$ & $\mathbf{n}$ & $\%$
\end{tabular}

\begin{tabular}{|c|c|c|c|c|c|c|c|c|c|}
\hline \multirow{5}{*}{$\begin{array}{l}\text { ¿Cuántos hijos } \\
\text { tienen? }\end{array}$} & $\begin{array}{l}\text { Cuatro } \\
\text { más }\end{array}$ & 0 & 56 & 17,2 & 26 & 16,6 & 30 & 17,8 & \multirow{5}{*}{ NS } \\
\hline & Dos o tres & & 199 & 61,0 & 93 & 59,2 & 106 & 62,7 & \\
\hline & Ninguno & & 31 & 9,5 & 18 & 11,5 & 13 & 7,7 & \\
\hline & Uno & & 40 & 12,3 & 20 & 12,7 & 20 & 11,8 & \\
\hline & Total & & 326 & 100 & 157 & 100 & 169 & 100 & \\
\hline \multirow{6}{*}{$\begin{array}{l}\text { ¿Cuántos nietos } \\
\text { tienen? }\end{array}$} & $\begin{array}{l}\text { Cuatro } \\
\text { más }\end{array}$ & 0 & 160 & 49,1 & 73 & 46,5 & 88 & 51,5 & \multirow{5}{*}{ NS } \\
\hline & Dos o tres & & 113 & 34,7 & 56 & 35,7 & 58 & 33,7 & \\
\hline & Ninguno & & 32 & 9,8 & 17 & 10,8 & 10 & 6,9 & \\
\hline & Uno & & 21 & 6,4 & 11 & 7,0 & 11 & 7,9 & \\
\hline & Total & & 326 & 100 & 157 & 100 & 169 & 100 & \\
\hline & $\begin{array}{l}\text { Cuatro } \\
\text { más }\end{array}$ & 0 & 55 & 16,9 & 27 & 17,2 & 28 & 16,6 & NS \\
\hline
\end{tabular}




\begin{tabular}{|c|c|c|c|c|c|c|c|c|c|}
\hline \multirow{4}{*}{$\begin{array}{l}\text { ¿Cuántos } \\
\text { hermanos } \\
\text { tienen? }\end{array}$} & Dos o tres & & 98 & 30,1 & 53 & 33,8 & 45 & 26,6 & \\
\hline & Ninguno & & 87 & 26,7 & 37 & 23,6 & 50 & 29,6 & \\
\hline & Uno & & 86 & 26,4 & 40 & 25,5 & 46 & 27,2 & \\
\hline & Tota & & 326 & 100 & 157 & 100 & 169 & 100 & \\
\hline \multirow{5}{*}{$\begin{array}{l}\text { ¿Cuántos } \\
\text { sobrinos } \\
\text { tienen? }\end{array}$} & $\begin{array}{l}\text { Cuatro } \\
\text { más }\end{array}$ & 0 & 201 & 61,7 & 100 & 63,7 & 101 & 59,8 & \multirow{5}{*}{ NS } \\
\hline & Dos o tres & & 71 & 21,8 & 29 & 18,5 & 42 & 24,9 & \\
\hline & Ninguno & & 38 & 11,7 & 23 & 14,6 & 15 & 8,9 & \\
\hline & Uno & & 16 & 4,9 & 5 & 3,2 & 11 & 6,5 & \\
\hline & Total & & 326 & 100 & 157 & 100 & 169 & 100 & \\
\hline \multirow[t]{5}{*}{$\begin{array}{l}\text { ¿Cuántos } \\
\text { amigos tienen? }\end{array}$} & $\begin{array}{l}\text { Cuatro } \\
\text { más }\end{array}$ & 0 & 126 & 38,7 & 78 & 49,7 & 48 & 28,4 & \multirow{5}{*}{$<0,001$} \\
\hline & Dos o tres & & 41 & 12,6 & 11 & 7,0 & 30 & 17,8 & \\
\hline & Ninguno & & 132 & 40,5 & 60 & 38,2 & 72 & 42,6 & \\
\hline & Uno & & 27 & 8,3 & 8 & 5,1 & 19 & 11,2 & \\
\hline & Total & & 326 & 100 & 157 & 100 & 169 & 100 & \\
\hline
\end{tabular}

\subsubsection{Estructura de la red social de los encuestados en cuanto la frecuencia de relación en términos de contacto a modo de vistas con otras personas}

En la tabla 8 describe la estructura de la red social de los encuestados los vínculos de contacto visual con hijos, hermanos, sobrinos, nietos y amigos, se observa que tienen más valor significativo con los amigos que ven una vez al mes ya que con los hijos, hermanos, sobrinos y nietos no tiene valor significativo. 
Tabla 8. Estructura de la red social respecto al contacto visual por sexo: recuento (n) y frecuencia $(\%)$

\section{Sexo}

Contacto visual

\begin{tabular}{llllll}
\hline Total & \multicolumn{3}{l}{ Hombre } & \multicolumn{2}{l}{ Mujer } \\
& & & & & \\
\end{tabular}

\begin{tabular}{|c|c|c|c|c|c|c|c|c|}
\hline \multirow{4}{*}{$\begin{array}{l}\text { Cuantos hijos } \\
\text { ve al menos } \\
\text { una v/mes }\end{array}$} & Más de tres & 40 & 12,3 & 18 & 11,5 & 22 & 13,0 & \multirow{4}{*}{ NS } \\
\hline & Uno a tres & 244 & 74,8 & 115 & 73,2 & 129 & 76,3 & \\
\hline & Ninguno & 42 & 12,9 & 24 & 15,3 & 18 & 10,7 & \\
\hline & Total & 326 & 100 & 157 & 100 & 169 & 100 & \\
\hline \multirow{4}{*}{$\begin{array}{l}\text { Cuantos nietos } \\
\text { ve al menos } \\
\text { una } v / \text { mes }\end{array}$} & Más de tres & 129 & 39,6 & 60 & 38,2 & 69 & 40,8 & \multirow{4}{*}{ NS } \\
\hline & Uno a tres & 148 & 45,4 & 73 & 46,5 & 75 & 44,4 & \\
\hline & Ninguno & 49 & 15,0 & 24 & 15,3 & 25 & 14,8 & \\
\hline & Total & 326 & 100 & 157 & 100 & 169 & 100 & \\
\hline \multirow{4}{*}{$\begin{array}{l}\text { Cuantos } \\
\text { hermanos ve al } \\
\text { menos una } \\
\text { v/mes }\end{array}$} & Más de tres & 13 & 4,0 & 8 & 5,1 & 5 & 3,0 & \multirow{4}{*}{ NS } \\
\hline & Uno a tres & 108 & 33,1 & 52 & 33,1 & 56 & 33,1 & \\
\hline & Ninguno & 205 & 62,9 & 97 & 61,8 & 108 & 63,9 & \\
\hline & Total & 326 & 100 & 157 & 100 & 169 & 100 & \\
\hline \multirow{4}{*}{$\begin{array}{l}\text { Cuantos } \\
\text { sobrinos ve al } \\
\text { menos una } \\
\text { v/mes }\end{array}$} & Más de tres & 42 & 12,9 & 21 & 13,4 & 21 & 12,4 & \multirow{4}{*}{ NS } \\
\hline & Uno a tres & 63 & 19,3 & 29 & 18,5 & 34 & 21,1 & \\
\hline & Ninguno & 221 & 67,8 & 107 & 68,2 & 114 & 67,5 & \\
\hline & Total & 326 & 100 & 157 & 98,1 & 169 & 100 & \\
\hline \multirow{4}{*}{$\begin{array}{l}\text { Cuantos amigos } \\
\text { ve al menos } \\
\text { una } v / \text { mes }\end{array}$} & Más de tres & 107 & 32,8 & 67 & 42,7 & 40 & 23,7 & \multirow{4}{*}{$<0,001$} \\
\hline & Uno a tres & 80 & 24,5 & 28 & 17,8 & 52 & 30,8 & \\
\hline & Ninguno & 139 & 42,6 & 62 & 39,5 & 77 & 45,6 & \\
\hline & Total & 326 & 99,9 & 157 & 100 & 169 & 100 & \\
\hline
\end{tabular}




\subsubsection{Estructura de la red social de los encuestados en cuanto la frecuencia de relación en términos de contacto a modo de vistas con otras personas}

En la tabla 9 se describe la estructura de la red social en cuanto la frecuencia de comunicación telefónica donde se observa que no hay significación estadística. Se puede destacar que el 68,1\% hablan de una vez al mes con uno o tres hijos, el 39\% con los nietos, $52,1 \%$ con los hermanos y siempre hablan más las mujeres que los hombres. En lo que respecta a los sobrinos y hermanos el $61,3 \%$ y el $59,2 \%$ respectivamente no hablan con ellos.

Tabla 9. Estructura de la red social y frecuencia de los contactos por sexo: recuento (n) y frecuencia (\%)

\begin{tabular}{|c|c|c|c|c|c|c|c|c|}
\hline \multirow{3}{*}{ Frecuencia } & & \multicolumn{5}{|c|}{ Sexo } & & \multirow[t]{3}{*}{$\overline{\mathbf{P}}$} \\
\hline & & \multicolumn{2}{|c|}{ Total } & \multicolumn{2}{|c|}{ Hombre } & \multicolumn{2}{|c|}{ Mujer } & \\
\hline & & $\mathbf{N}$ & $\%$ & $\mathbf{N}$ & $\%$ & $\mathbf{N}$ & $\%$ & \\
\hline \multirow{4}{*}{$\begin{array}{l}\text { Cuantos hijos } \\
\text { habla por teléfono } \\
1 \mathrm{v} / \mathrm{mes}\end{array}$} & Más de tres & 45 & 13,8 & 23 & 14,6 & 22 & 13,0 & \multirow{4}{*}{ NS } \\
\hline & Uno a tres & 222 & 68,1 & 98 & 62,5 & 124 & 73,4 & \\
\hline & Ninguno & 59 & 18,1 & 36 & 22,9 & 23 & 13,6 & \\
\hline & Total & 326 & 100 & 157 & 100 & 169 & 100 & \\
\hline \multirow{4}{*}{$\begin{array}{l}\text { Cuantos nietos } \\
\text { habla por teléfono } \\
1 \mathrm{v} / \mathrm{mes}\end{array}$} & Más de tres & 112 & 34,4 & 49 & 31,2 & 63 & 37,3 & \multirow{4}{*}{ NS } \\
\hline & Uno a tres & 127 & 39,0 & 59 & 37,6 & 68 & 40,2 & \\
\hline & Ninguno & 87 & 26,7 & 49 & 31,2 & 38 & 22,5 & \\
\hline & Total & 326 & 100 & 157 & 100 & 169 & 100 & \\
\hline \multirow{4}{*}{$\begin{array}{l}\text { Cuantos hermanos } \\
\text { habla por teléfono } \\
1 \mathrm{v} / \mathrm{mes}\end{array}$} & Más de tres & 30 & 9,2 & 17 & 10,8 & 13 & 7,7 & \multirow{4}{*}{ NS } \\
\hline & Uno a tres & 170 & 52,1 & 80 & 51,0 & 90 & 53,3 & \\
\hline & Ninguno & 126 & 38,7 & 60 & 38,2 & 66 & 39,1 & \\
\hline & Total & 326 & 100 & 157 & 100 & 169 & 100 & \\
\hline
\end{tabular}




\begin{tabular}{|c|c|c|c|c|c|c|c|c|}
\hline \multirow{4}{*}{$\begin{array}{l}\text { Cuantos sobrinos } \\
\text { habla por teléfono } \\
1 \mathrm{v} / \mathrm{mes}\end{array}$} & Más de tres & 57 & 17,5 & 22 & 14,0 & 35 & 20,8 & \multirow{4}{*}{$<0,015$} \\
\hline & Uno a tres & 69 & 21,9 & 26 & 16,6 & 43 & 25,4 & \\
\hline & Ninguno & 200 & 61,6 & 109 & 69,4 & 91 & 53,8 & \\
\hline & Total & 326 & 100 & 157 & 100 & 169 & 100 & \\
\hline \multirow{4}{*}{$\begin{array}{l}\text { Cuantos amigos } \\
\text { habla por teléfono } \\
1 \mathrm{v} / \text { mes }\end{array}$} & Más de tres & 71 & 21,8 & 41 & 26,1 & 30 & 17,8 & \multirow{4}{*}{$<0,011$} \\
\hline & Uno a tres & 62 & 19,0 & 20 & 12,7 & 42 & 24,9 & \\
\hline & Ninguno & 193 & 59,2 & 96 & 61,2 & 97 & 57,3 & \\
\hline & Total & 326 & 100 & 157 & 100 & 169 & 100 & \\
\hline
\end{tabular}

\subsubsection{Estructura de la red social de los encuestados en cuanto a la distancia de la persona más cercana conocida o familiar.}

En la tabla 10 se recoge la estructura de la red social y distancia a la que viven los contactos observamos que no hay diferencias significativas entre la distancia y los contactos. Cabe destacar que la mayoría de los contactos (73,6\% hijos, 54,9\% hermanos, $42,8 \%$ sobrinos, $66 \%$ nietos y $98,3 \%$ amigos) viven a menos de 15 minutos.

Tabla 10. Estructura de la red social distancia a la que viven los contactos por sexo: recuento (n) y frecuencia (\%)

\begin{tabular}{|c|c|c|c|c|c|c|c|c|}
\hline \multirow{3}{*}{ Distancia } & & \multicolumn{6}{|c|}{ Sexo } & \multirow{3}{*}{$\mathbf{P}$} \\
\hline & & \multicolumn{2}{|c|}{ Total } & \multicolumn{2}{|c|}{ Hombre } & \multicolumn{2}{|c|}{ Mujer } & \\
\hline & & $\mathbf{n}$ & $\%$ & $\mathbf{N}$ & $\%$ & $\mathbf{N}$ & $\%$ & \\
\hline \multirow{4}{*}{$\begin{array}{l}\text { Distancia al hijo/a } \\
\text { más cercano/a }\end{array}$} & $\begin{array}{l}\text { Menos de } \\
15 \text { min }\end{array}$ & 240 & 73,6 & 116 & 73,9 & 124 & 73,4 & \multirow{4}{*}{ NS } \\
\hline & $15-30 \mathrm{~min}$ & 55 & 16,9 & 29 & 18,5 & 26 & 15,4 & \\
\hline & $\begin{array}{l}\text { Más de } 30 \\
\min \end{array}$ & 31 & 9,5 & 12 & 7,6 & 19 & 11,2 & \\
\hline & Total & 326 & 100 & 157 & 100 & 169 & 100 & \\
\hline
\end{tabular}




\begin{tabular}{|c|c|c|c|c|c|c|c|c|}
\hline \multirow{4}{*}{$\begin{array}{l}\text { Distancia al nieto } \\
\text { más cercano }\end{array}$} & $\begin{array}{l}\text { Menos de } \\
15 \mathrm{~min}\end{array}$ & 215 & 66,0 & 105 & 66,9 & 110 & 65,1 & \multirow{4}{*}{ NS } \\
\hline & $15-30 \mathrm{~min}$ & 68 & 20,9 & 32 & 20,4 & 36 & 21,3 & \\
\hline & $\begin{array}{l}\text { Más de } 30 \\
\text { min }\end{array}$ & 43 & 13,1 & 20 & 12,7 & 23 & 13,6 & \\
\hline & Total & 326 & 100 & 157 & 100 & 169 & 100 & \\
\hline \multirow{4}{*}{$\begin{array}{l}\text { Distancia } \\
\text { hermano } \\
\text { cercano }\end{array}$} & $\begin{array}{l}\text { Menos de } \\
15 \mathrm{~min}\end{array}$ & 179 & 54,9 & 90 & 57,3 & 89 & 52,7 & \multirow{4}{*}{ NS } \\
\hline & $15-30 \mathrm{~min}$ & 37 & 11,3 & 17 & 10,9 & 20 & 11,8 & \\
\hline & $\begin{array}{l}\text { Más de } 30 \\
\text { min }\end{array}$ & 110 & 33,8 & 50 & 31,8 & 60 & 35,5 & \\
\hline & Total & 326 & 100 & 157 & 100 & 169 & 100 & \\
\hline \multirow{4}{*}{$\begin{array}{l}\text { Distancia } \\
\text { sobrino } \\
\text { cercano }\end{array}$} & $\begin{array}{l}\text { Menos de } \\
15 \mathrm{~min}\end{array}$ & 157 & 48,2 & 89 & 56,7 & 68 & 40,2 & \multirow{4}{*}{$<0,011$} \\
\hline & $15-30 \mathrm{~min}$ & 49 & 15,0 & 21 & 13,4 & 28 & 16,6 & \\
\hline & $\begin{array}{l}\text { Más de } 30 \\
\text { min }\end{array}$ & 120 & 36,8 & 47 & 29,9 & 73 & 43,2 & \\
\hline & Total & 326 & 100 & 157 & 100 & 169 & 100 & \\
\hline \multirow[t]{4}{*}{$\begin{array}{l}\text { Distancia al amigo } \\
\text { más cercano }\end{array}$} & $\begin{array}{l}\text { Menos de } \\
15 \mathrm{~min}\end{array}$ & 291 & 89,3 & 143 & 91,1 & 148 & 87,6 & \multirow[t]{4}{*}{ NS } \\
\hline & $15-30 \mathrm{~min}$ & 22 & 6,7 & 10 & 6,4 & 12 & 7,1 & \\
\hline & $\begin{array}{l}\text { Más de } 30 \\
\min \end{array}$ & 13 & 4,0 & 4 & 2,5 & 9 & 5,3 & \\
\hline & Total & 326 & 100 & 157 & 100 & 169 & 100 & \\
\hline
\end{tabular}

\subsubsection{Presencia de confidente y tipo de relación de los encuestados.}

Tal como se observa en la tabla 11 , el $82,5 \%$ de los encuestados tenía un confidente, destacando la relación esposo/a es el más importante y después el hijo con un $\mathrm{p}=0,001$ y versus $p=0,006$. Destacando que solo un $3,1 \%$ de la muestra refiere tener otro confidente. 
Tabla 11. Características de la presencia de confidente y tipo de relación de los encuestados por sexo: recuento $(\mathrm{n})$ y frecuencia $(\%)$

\begin{tabular}{|c|c|c|c|c|c|c|c|c|}
\hline \multirow{3}{*}{ Tipo de confidente } & & & & \multicolumn{4}{|c|}{ Sexo } & \multirow{3}{*}{$\mathbf{P}$} \\
\hline & & \multicolumn{2}{|c|}{ Total } & \multicolumn{2}{|c|}{ Hombre } & \multicolumn{2}{|c|}{ Mujer } & \\
\hline & & $\bar{n}$ & $\%$ & $\mathbf{n}$ & $\%$ & $\mathbf{n}$ & $\%$ & \\
\hline \multirow{3}{*}{ ¿Tiene confidente? } & $\mathrm{Si}$ & 269 & 82,5 & 128 & 81,5 & 141 & 83,4 & \multirow{3}{*}{ NS } \\
\hline & No & 34 & 10,4 & 16 & 10,2 & 18 & 10,7 & \\
\hline & Total & 303 & 92,9 & 144 & 91,7 & 159 & 94,1 & \\
\hline \multirow{3}{*}{ Esposo/a } & $\mathrm{Si}$ & 140 & 42,9 & 94 & 59,9 & 46 & 27,2 & \multirow{3}{*}{$<0,001$} \\
\hline & No & 186 & 57,1 & 63 & 40,1 & 123 & 72,8 & \\
\hline & Total & 326 & 100 & 157 & 100 & 169 & 100 & \\
\hline \multirow{3}{*}{ Hijo/a } & $\mathrm{Si}$ & 144 & 44,2 & 57 & 36,3 & 87 & 51,5 & \multirow{3}{*}{$<0,006$} \\
\hline & No & 182 & 55,8 & 100 & 63,7 & 82 & 48,5 & \\
\hline & Total & 326 & 100 & 157 & 100 & 169 & 100 & \\
\hline \multirow{3}{*}{ Familia Extensa } & $\mathrm{Si}$ & 25 & 7,7 & 9 & 5,7 & 16 & 9,5 & \multirow{3}{*}{ NS } \\
\hline & No & 301 & 92,3 & 148 & 94,3 & 153 & 90,5 & \\
\hline & Total & 326 & 100 & 157 & 100 & 169 & 100 & \\
\hline \multirow{3}{*}{ Otro Confidente } & $\mathrm{Si}$ & 10 & 3,1 & 4 & 2,5 & 6 & 3,6 & \multirow{3}{*}{ NS } \\
\hline & No & 316 & 96,9 & 153 & 97,5 & 163 & 96,4 & \\
\hline & Total & 326 & 100 & 159 & 100 & 169 & 100 & \\
\hline
\end{tabular}

\subsubsection{Participación en actividades comunitarias de los encuestados.}

La descripción de la participación de las personas mayores en actividades comunitarias está resumida en la tabla 12 destacando como la más estadísticamente significativa la de muestra acudía a la iglesia al menos una vez al mes con un $p=0,001$ y acuden más las mujeres que los hombres. En resto de variables no tienen significación 
estadística, pero podemos observar que hay más hombres que mujeres que acuden a la plaza, alguna asociación y al hogar del pensionista.

Tabla 12.Características de la participación en actividades comunitarias de los encuestados por sexo: recuento $(n)$ y frecuencia $(\%)$

\begin{tabular}{|c|c|c|c|c|c|c|c|c|}
\hline \multirow{3}{*}{$\begin{array}{l}\text { Participación } \\
\text { comunitarias }\end{array}$} & \multirow{3}{*}{ actividades } & & & \multicolumn{4}{|c|}{ Sexo } & \multirow{3}{*}{$\mathbf{P}$} \\
\hline & & \multicolumn{2}{|c|}{ Total } & \multicolumn{2}{|c|}{ Hombre } & \multicolumn{2}{|c|}{ Mujer } & \\
\hline & & $\mathbf{n}$ & $\%$ & $\mathbf{n}$ & $\%$ & $n$ & $\%$ & \\
\hline \multirow{3}{*}{$\begin{array}{l}\text { Acude a la Plaza o } \\
\text { lugar céntrico al } \\
\text { menos } 1 \mathrm{v} / \mathrm{mes}\end{array}$} & $\mathrm{Si}$ & 195 & 59,8 & 98 & 62,4 & 97 & 57,4 & \multirow{3}{*}{ NS } \\
\hline & No & 131 & 40,2 & 59 & 37,6 & 72 & 42,6 & \\
\hline & Total & 326 & 100 & 157 & 100 & 169 & 100 & \\
\hline \multirow{3}{*}{$\begin{array}{l}\text { Forma parte de } \\
\text { alguna asociación } 0 \\
\text { club cultural }\end{array}$} & $\mathrm{Si}$ & 106 & 32,5 & 61 & 38,9 & 45 & 26,6 & \multirow{3}{*}{ NS } \\
\hline & No & 218 & 66,9 & 95 & 60,5 & 123 & 72,8 & \\
\hline & Total & 324 & 99,4 & 156 & 99,6 & 168 & 99,4 & \\
\hline \multirow{3}{*}{$\begin{array}{l}\text { Acude a la Iglesia al } \\
\text { menos } 1 \mathrm{v} / \mathrm{mes}\end{array}$} & $\mathrm{Si}$ & 118 & 36,2 & 42 & 26,8 & 76 & 45,0 & \multirow{3}{*}{$<0,001$} \\
\hline & No & 208 & 63,8 & 115 & 73,2 & 93 & 55,0 & \\
\hline & Total & 326 & 100 & 157 & 100 & 169 & 100 & \\
\hline \multirow{3}{*}{$\begin{array}{l}\text { Acude al hogar del } \\
\text { pensionista al menos } \\
1 \mathrm{v} / \mathrm{mes}\end{array}$} & $\mathrm{Si}$ & 83 & 25,5 & 47 & 29,9 & 36 & 21,3 & \multirow{3}{*}{ NS } \\
\hline & No & 243 & 74,5 & 110 & 70,1 & 133 & 78,7 & \\
\hline & Total & 326 & 100 & 157 & 100 & 169 & 100 & \\
\hline
\end{tabular}

\subsubsection{Relaciones sociales en forma de redes sociales. Mecanismos psicosociales de los encuestados. Resultados separados por sexo}

Al distribuir las relaciones sociales por sexo tal como se muestra en la tabla 13 destaca como significativo el índice de vínculos familiares con contacto, con una media de 2,64 hombres frente con una media de 2,40 mujeres. El índice de diversidad de la red y el índice de actividades comunitarias no tienen significación, pero juntos describen los resultados de los índices globales de las redes sociales. 
Tabla 13.Redes sociales de los encuestados por sexo: Media y Deviación estándar(DE)

\begin{tabular}{|c|c|c|c|c|c|}
\hline \multirow{3}{*}{ Redes sociales } & \multicolumn{4}{|c|}{ Sexo } & \multirow{3}{*}{$\mathbf{P}$} \\
\hline & \multicolumn{2}{|c|}{ Hombre } & \multicolumn{2}{|c|}{ Mujer } & \\
\hline & Media & DE & Media & DE & \\
\hline Índice de vínculos familiares (0-3) & 2,64 & 0,620 & 2,40 & 0,621 & $<0,001$ \\
\hline $\begin{array}{l}\text { Indice de actividades comunitarias } \\
(0-4)\end{array}$ & 1,58 & 1,100 & 1,51 & 1,115 & NS \\
\hline Índice de diversidad de la red $(0-8)$ & 4.86 & 1,481 & 4,49 & 1,447 & $<0,023$ \\
\hline
\end{tabular}

De acuerdo a los resultados relacionados con el comportamiento de los mecanismos psicosociales según podemos observar en la tabla 14, no existen diferencias significativas entre apoyo recibido y rol del individuo. Podemos destacar que en las mujeres la media es un 1, 95 y en los hombres es de 1,91.

Tabla14 .Mecanismos psicosociales de los encuestados por sexo: Media y Deviación estándar(DE)

Sexo

\begin{tabular}{lccccc}
\cline { 2 - 5 } Mecanismos psicosociales & \multicolumn{2}{c}{ Hombre } & \multicolumn{2}{c}{ Mujer } & P \\
\cline { 2 - 5 } & Media & DE & Media & DE & \\
\hline Apoyo emocional recibido(0-3) & 1,91 & 0,27 & 1,95 & 0,21 & NS \\
\hline Rol del individuo(0-3) & 1,91 & 0,27 & 1,95 & 0,21 & NS \\
\hline
\end{tabular}




\subsection{8. Índices globales de las redes sociales de los encuestados según las características sociodemográficas}

En la tabla 15 se recogen los resultados de los índices globales de las redes sociales en cuanto de acuerdo a las características sociodemográficas de la muestra estudiada. El índice de diversidad de la red influye el tener o no tener pareja. Todas las variables sociodemográficas arrojan resultados significativos para el índice de vínculos familiares con contacto. El resto no tiene significación estadística.

Tabla 15:Las redes sociales (índices globales) según las características sociodemográficas: media y desviación estándar (DE)

\begin{tabular}{|c|c|c|c|c|c|c|c|c|c|c|}
\hline \multirow{2}{*}{\multicolumn{2}{|c|}{$\begin{array}{l}\text { Características } \\
\text { sociodemográficas }\end{array}$}} & \multirow{3}{*}{$\begin{array}{l}\text { Índice } \\
\text { famili } \\
\text { Med } \\
\text { ia } \\
1,83\end{array}$} & \multicolumn{2}{|c|}{$\begin{array}{l}\text { de vínculos } \\
\text { ares }(0-3)\end{array}$} & \multicolumn{3}{|c|}{$\begin{array}{l}\text { Índice } \\
\text { actividades } \\
\text { comunitarias }(0-4)\end{array}$} & \multicolumn{3}{|c|}{$\begin{array}{l}\text { Índice de diversidad } \\
\text { de la red }(0-8)\end{array}$} \\
\hline & & & DE & $\mathbf{P}$ & Media & DE & $\mathbf{P}$ & Media & DE & $\mathbf{P}$ \\
\hline \multirow{2}{*}{ Estado Civil } & No casado & & 0,41 & \multirow{2}{*}{$<0,001$} & 1,61 & 1,10 & \multirow{2}{*}{ NS } & 4,03 & 1,40 & \multirow{2}{*}{$<0,001$} \\
\hline & Casado & 2,89 & 0,35 & & 1,51 & 1,11 & & 5,01 & 1,39 & \\
\hline \multirow{2}{*}{ Convivencia } & Solo & 1,85 & 0,49 & \multirow{2}{*}{$<0,001$} & 1.73 & 1,12 & \multirow{2}{*}{ NS } & 4.28 & 1,38 & \multirow{2}{*}{$<0,015$} \\
\hline & Acompañado & 2,70 & 0,53 & & 1,49 & 1,10 & & 4,77 & 1,48 & \\
\hline \multirow{2}{*}{ Ingresos } & $>900$ & 2,33 & 0,64 & \multirow{2}{*}{$<0,001$} & 1,58 & 1,09 & \multirow{2}{*}{ NS } & 4,52 & 1,39 & \multirow{2}{*}{$<0,027$} \\
\hline & $<900$ & 2,68 & 0,57 & & 1,63 & 1,15 & & 4,93 & 1,48 & \\
\hline
\end{tabular}

\subsubsection{Resultados de los índices globales de la dimensión Mecanismos psicosociales y su relación con las características sociodemográficas}

En los mecanismos psicosociales según las características sociodemográficas, en la tabla 16 observamos con valor significativo tanto en el apoyo emocional recibido como en el rol del individuo solo el estado civil y la convivencia. Los ingresos mensuales no tienen significación. 
Tabla 16:Los mecanismos psicosociales (índices globales) según las características socioeconómicas: media y desviación estándar (DE)

\begin{tabular}{|c|c|c|c|c|c|c|c|}
\hline \multirow{2}{*}{\multicolumn{2}{|c|}{$\begin{array}{l}\text { Características } \\
\text { sociodemográficas }\end{array}$}} & \multicolumn{3}{|c|}{$\begin{array}{l}\text { Apoyo emocional } \\
\text { recibido }(0-3)\end{array}$} & \multicolumn{3}{|c|}{$\begin{array}{l}\text { Rol del individuo } \\
(0-3)\end{array}$} \\
\hline & & Medi & DE & $\mathbf{P}$ & Media & DE & $\mathbf{P}$ \\
\hline \multirow[t]{2}{*}{ Estado Civil } & No casado & 0,87 & 0,38 & \multirow{2}{*}{$<0,001$} & 0,83 & 0,30 & \multirow{2}{*}{$<0,001$} \\
\hline & Casado & 1,18 & 0,36 & & 1,16 & 0,38 & \\
\hline \multirow[t]{2}{*}{ Convivencia } & Solo & 0,94 & 0,33 & \multirow{2}{*}{$<0,002$} & 0,91 & 0,34 & \multirow{2}{*}{$<0,002$} \\
\hline & Acompañado & 1,11 & 0,41 & & 1,08 & 0,41 & \\
\hline \multirow[t]{2}{*}{ Ingresos } & $>900$ & 1,04 & 0,35 & \multirow{2}{*}{ NS } & 1,01 & 0,34 & \multirow{2}{*}{$<0,045$} \\
\hline & $<900$ & 1,14 & 0,39 & & 1,11 & 0,40 & \\
\hline
\end{tabular}

\subsubsection{Resultados del análisis de las redes sociales (índices globales) relacionados con hábitos de la salud}

Tal como se observa en la tabla 17 en el análisis de todas las variables que describen hábitos de salud no se obtuvieron resultados significativos. Solamente en la variable camina al menos una vez a la semana en dos índices como son en de actividades comunitarias y el de diversidad de la red aparece significación estadística $(p=0,001)$. Y en la variable consumo de alcohol en el índice de diversidad de red con $p=0,028$. 
Tabla 17:Las redes sociales (índices globales) según los hábitos de salud: media y desviación estándar (DE)

\begin{tabular}{|c|c|c|c|c|c|c|c|c|c|c|}
\hline \multirow{2}{*}{\multicolumn{2}{|c|}{ Hábitos de Salud }} & \multicolumn{3}{|c|}{$\begin{array}{l}\text { Índice de vínculos } \\
\text { familiares }(0-3)\end{array}$} & \multicolumn{3}{|c|}{$\begin{array}{l}\text { Índice de actividades } \\
\text { comunitarias (0-4) }\end{array}$} & \multicolumn{3}{|c|}{$\begin{array}{l}\text { Índice de diversidad } \\
\text { de la red }(0-8)\end{array}$} \\
\hline & & Media & $\mathrm{DE}$ & $\mathbf{P}$ & Media & $\mathrm{DE}$ & $\mathbf{P}$ & Media & DE & $\mathbf{P}$ \\
\hline \multirow[t]{2}{*}{$\begin{array}{l}\text { Hábito } \\
\text { Tabáquico }\end{array}$} & No & 2,52 & 0,62 & \multirow[t]{2}{*}{ NS } & 1,52 & 1,10 & \multirow[t]{2}{*}{ NS } & 4,64 & 1,46 & \multirow[t]{2}{*}{ NS } \\
\hline & $\mathrm{Si}$ & 2,50 & 0,76 & & 1,95 & 1,09 & & 5,05 & 1,60 & \\
\hline Consumo & No & 2,50 & 0,61 & \multirow{2}{*}{ NS } & 1,50 & 1,10 & \multirow{2}{*}{ NS } & 4,56 & 1,43 & \multirow{2}{*}{$<0,028$} \\
\hline Alcohol & $\mathrm{Si}$ & 2,58 & 0,66 & & 1,69 & 1,09 & & 4,97 & 1,55 & \\
\hline Problemas de & No & 2,42 & 0,83 & $N C$ & 1,52 & 1,21 & \multirow{2}{*}{ NS } & 4,31 & 1,63 & \multirow{2}{*}{ NS } \\
\hline sueño & $\mathrm{Si}$ & 2,52 & 0,61 & 列 & 1,53 & 1,08 & & 4,67 & 1,44 & \\
\hline \multirow{2}{*}{$\begin{array}{l}\text { Camina al } \\
\text { menos una vez } \\
\text { por semana }\end{array}$} & No & 2,57 & 0,56 & \multirow{2}{*}{ NS } & 0,91 & 0,87 & \multirow{2}{*}{$<0,001$} & 3,98 & 1,31 & \multirow{2}{*}{$<0,001$} \\
\hline & $\mathrm{Si}$ & 2,51 & 0,63 & & 1,68 & 1,10 & & 4,81 & 1,46 & \\
\hline
\end{tabular}

\subsubsection{Redes sociales (índices globales) y su relación con enfermedades o problemas de salud más severos}

En la tabla 18 podemos observar las relaciones sociales en función del estado de salud de la población estudiada. Con significación estadística podemos observar la fragilidad en cuanto a los índices de vínculos familiares y diversidad de la red. El resto de variables no tienen significación estadística, es decir no se correlacionan las relaciones sociales con enfermedades ni consumo de medicamentos. 
Tabla 18:Redes sociales (índices globales) según el estado de salud: media y desviación estándar (DE)

\begin{tabular}{|c|c|c|c|c|c|c|c|c|c|c|}
\hline \multirow[t]{2}{*}{ Estado de Salud } & & \multicolumn{3}{|c|}{$\begin{array}{l}\text { Índice de vínculos } \\
\text { familiares (0-3) }\end{array}$} & \multicolumn{3}{|c|}{$\begin{array}{l}\text { Indice de actividades } \\
\text { comunitarias }(0-4)\end{array}$} & \multicolumn{3}{|c|}{$\begin{array}{l}\text { Índice de diversidad } \\
\text { de la red }(0-8)\end{array}$} \\
\hline & & Media & $\mathrm{DE}$ & $\mathbf{P}$ & Media & DE & $\mathbf{P}$ & Media & DE & $\mathbf{P}$ \\
\hline \multirow{2}{*}{$\begin{array}{l}\text { Síntomas de } \\
\text { depresión }\end{array}$} & No & 2,55 & 0,60 & \multirow{2}{*}{ NS } & 1,58 & 1,12 & \multirow{2}{*}{ NS } & 4,75 & 1,47 & \multirow{2}{*}{ NS } \\
\hline & $\mathrm{Si}$ & 2,49 & 0,65 & & 1,51 & 1,08 & & 4,60 & 1,46 & \\
\hline \multirow{2}{*}{$\begin{array}{l}\text { Discapacidad } \\
\text { instrumental }\end{array}$} & No & 2,45 & 0,65 & \multirow{2}{*}{ NS } & 1,69 & 1,19 & \multirow{2}{*}{$<0,020$} & 4,85 & 1,45 & \multirow{2}{*}{$<0,032$} \\
\hline & $\mathrm{Si}$ & 2,58 & 0,60 & & 1,40 & 0,99 & & 4,50 & 1,47 & \\
\hline \multirow{2}{*}{$\begin{array}{l}\text { Consumo }>3 \\
\text { medicamentos }\end{array}$} & No & 2,53 & 0,64 & \multirow{2}{*}{ NS } & 1,51 & 1,09 & \multirow{2}{*}{ NS } & 4,63 & 1,42 & \multirow{2}{*}{ NS } \\
\hline & $\mathrm{Si}$ & 2,48 & 0,61 & & 1,59 & 1,11 & & 4,72 & 1,54 & \\
\hline \multirow{2}{*}{$\begin{array}{l}\text { Autopercepción } \\
\text { de la salud }\end{array}$} & Buena & 2,52 & 0,65 & \multirow{2}{*}{ NS } & 1,63 & 1,13 & \multirow{2}{*}{ NS } & 4,76 & 1,52 & \multirow{2}{*}{ NS } \\
\hline & Mala & 2,50 & 0,57 & & 1,38 & 1,03 & & 4,48 & 1,34 & \\
\hline
\end{tabular}

\subsubsection{Mecanismos psicosociales (índices globales) y su relación con hábitos de salud}

Tal como se observa en la tabla 19 en el análisis de todas las variables que describen los hábitos de salud los resultados no fueron significativos para los dos índices excepto en lo que se refiere a los problemas del sueño que si tienen correlación con significación estadística tanto en el apoyo emocional recibido como en el rol del individuo. 
Tabla19: Los mecanismos psicosociales (índices globales) según los hábitos de salud: media y desviación estándar (DE)

\begin{tabular}{|c|c|c|c|c|c|c|c|}
\hline \multirow[t]{2}{*}{ Hábitos de Salud } & & \multicolumn{2}{|c|}{$\begin{array}{l}\text { Apoyo emocional } \\
\text { recibido }(0-3)\end{array}$} & \multicolumn{4}{|c|}{ Rol del individuo (0-3) } \\
\hline & & Media & DE & $\mathbf{P}$ & Media & $\mathbf{D E}$ & $\mathbf{P}$ \\
\hline \multirow[t]{2}{*}{ Hábito Tabáquico } & No & 1,08 & 0,39 & \multirow{2}{*}{ NS } & 1,05 & 0,40 & \multirow{2}{*}{ NS } \\
\hline & $\mathrm{Si}$ & 0,98 & 0,47 & & 0,93 & 0,47 & \\
\hline \multirow[t]{2}{*}{ Consumo Alcohol } & No & 1,06 & 0,39 & \multirow{2}{*}{ NS } & 1,03 & 0,39 & \multirow{2}{*}{ NS } \\
\hline & $\mathrm{Si}$ & 1,12 & 0,43 & & 1,08 & 0,44 & \\
\hline \multirow[t]{2}{*}{ Problemas de sueño } & No & 0,74 & 0,59 & \multirow{2}{*}{$<0,001$} & 0,72 & 0,57 & \multirow{2}{*}{$<0,001$} \\
\hline & $\mathrm{Si}$ & 1,10 & 0,37 & & 1,06 & 0,38 & \\
\hline \multirow{2}{*}{$\begin{array}{l}\text { Camina al menos una } \\
\text { vez por semana }\end{array}$} & No & 1,04 & 0,43 & \multirow{2}{*}{ NS } & 1,04 & 0,43 & \multirow{2}{*}{ NS } \\
\hline & $\mathrm{Si}$ & 1,08 & 0,39 & & 1,05 & 0,39 & \\
\hline
\end{tabular}

\subsubsection{Mecanismos psicosociales (índices globales) relacionados con estado de salud}

Tal como se observa en la tabla 20 la fortaleza de los mecanismos psicosociales se relacionan con el estado de salud. Los síntomas depresivos obtuvieron una puntuación muy similar en el índice de apoyo emocional $p=0,001$ y en el rol del individuo $p=0,001$. La discapacidad instrumental $p=0,001$ en cuanto al apoyo emocional y $p=0,002$ en cuanto al rol del individuo. En cuanto a la fragilidad para ambos índices es significativa. Respecto a la variables autopercepción de la salud y el consumo de medicamentos no tiene significación estadística para los índices apoyo emocional y rol del individuo. 
Tabla 20:Mecanismos psicosociales (índices globales) según el estado de salud: media y desviación estándar (DE)

\begin{tabular}{|c|c|c|c|c|c|c|c|}
\hline \multirow[t]{2}{*}{ Estado de Salud } & & \multicolumn{3}{|c|}{ recibido $(0-3)$} & \multicolumn{3}{|c|}{ Rol del individuo (0-3) } \\
\hline & & Media & $\mathrm{DE}$ & $\mathbf{P}$ & Media & $\overline{D E}$ & $\mathbf{P}$ \\
\hline \multirow{2}{*}{$\begin{array}{l}\text { Síntomas de } \\
\text { depresión }\end{array}$} & No & 1,16 & 0,30 & \multirow{2}{*}{$<0,001$} & 1,12 & 0,32 & \multirow{2}{*}{$<0,001$} \\
\hline & Si & 0,99 & 0,46 & & 0,97 & 0,45 & \\
\hline \multirow{2}{*}{$\begin{array}{l}\text { Discapacidad } \\
\text { instrumental }\end{array}$} & No & 1,15 & 0,32 & \multirow{2}{*}{$<0,001$} & 1,11 & 0,33 & \multirow{2}{*}{$<0,002$} \\
\hline & $\mathrm{Si}$ & 1,00 & 0,45 & & 0,97 & 0,45 & \\
\hline \multirow{2}{*}{$\begin{array}{l}\text { Consumo }>3 \\
\text { medicamentos }\end{array}$} & No & 1,05 & 0,42 & \multirow{2}{*}{ NS } & 1,02 & 0,42 & \multirow{2}{*}{ NS } \\
\hline & Si & 1,12 & 0,35 & & 1,09 & 0,35 & \\
\hline \multirow{2}{*}{$\begin{array}{l}\text { Autopercepción de la } \\
\text { salud }\end{array}$} & Buena & 1,04 & 0,44 & \multirow{2}{*}{$<0,021$} & 1,01 & 0,44 & \multirow{2}{*}{$<0,035$} \\
\hline & Mala & 1,15 & 0,28 & & 1,11 & 0,30 & \\
\hline
\end{tabular}

6.5. Resultados del análisis de asociación entre las relaciones sociales de la población estudiada y su grado de fragilidad, separado por características sociodemográficas y su relación con hábitos y estado de salud.

Con la intención de hacer una primera aproximación a la descripción de la fragilidad de la muestra estudiada, se realizaron análisis comparativos cuyo objetivo fue ver la distribución de fragilidad según la presencia o no de las variables control. Para el análisis se ha considerado la fragilidad como variable dicotómica, de manera que los pre-frágiles pertenecen a la categoría de los no frágiles. 


\subsubsection{Características del grado de fragilidad en función de las relaciones sociales}

Podemos observar en la tabla 21 que en cuanto a la fragilidad en de la red social con respecto al número de familiares, la significación estadística la encontramos en el número de amigos.

Tabla 21. Grado de fragilidad en de la red social con respecto al número de familiares: recuento (n) y frecuencia (\%)

\section{Fragilidad}

\begin{tabular}{|c|c|c|c|c|c|c|c|c|c|}
\hline \multicolumn{3}{|c|}{ Número de familia } & \multicolumn{2}{|c|}{ Total } & \multicolumn{2}{|c|}{ Frágil } & \multicolumn{2}{|c|}{ No Frágil } & \multirow[t]{2}{*}{$\mathbf{P}$} \\
\hline & & & $\mathbf{n}$ & $\%$ & $\mathbf{n}$ & $\%$ & $\mathbf{n}$ & $\%$ & \\
\hline \multirow{5}{*}{$\begin{array}{l}\text { ¿Cuántos hijos } \\
\text { tienen? }\end{array}$} & $\begin{array}{l}\text { Cuatro } \\
\text { más }\end{array}$ & 0 & 56 & 17,2 & 34 & 8,8 & 22 & 15,2 & \multirow{5}{*}{ NS } \\
\hline & Dos o tres & & 199 & 61,0 & 106 & 58,6 & 93 & 64,1 & \\
\hline & Ninguno & & 31 & 9,5 & 20 & 11 & 11 & 7,6 & \\
\hline & Uno & & 40 & 12,3 & 21 & 11,6 & 19 & 13,1 & \\
\hline & Total & & 326 & 100 & 181 & 100 & 145 & 100 & \\
\hline \multirow{5}{*}{$\begin{array}{l}\text { ¿Cuántos } \\
\text { Nietos tienen? }\end{array}$} & $\begin{array}{l}\text { Cuatro } \\
\text { más }\end{array}$ & 0 & 160 & 49,1 & 87 & 48,1 & 73 & 50,3 & \multirow{5}{*}{ NS } \\
\hline & Dos o tres & & 113 & 34,7 & 65 & 35,9 & 48 & 33,1 & \\
\hline & Ninguno & & 32 & 9,8 & 20 & 11 & 12 & 8,3 & \\
\hline & Uno & & 21 & 6,4 & 9 & 5 & 12 & 8,3 & \\
\hline & Total & & 326 & 100 & 181 & 100 & 145 & 100 & \\
\hline \multirow{5}{*}{$\begin{array}{l}\text { ¿Cuántos } \\
\text { hermanos } \\
\text { tienen? }\end{array}$} & $\begin{array}{l}\text { Cuatro } \\
\text { más }\end{array}$ & 0 & 55 & 16,9 & 26 & 14,4 & 29 & 20 & \multirow{5}{*}{ NS } \\
\hline & Dos o tres & & 98 & 30,1 & 48 & 26,5 & 50 & 34,5 & \\
\hline & Ninguno & & 87 & 26,7 & 57 & 31,5 & 30 & 20,7 & \\
\hline & Uno & & 86 & 26,4 & 50 & 27,6 & 36 & 24,8 & \\
\hline & Total & & 326 & 100 & 181 & 100 & 145 & 100 & \\
\hline
\end{tabular}




\begin{tabular}{|c|c|c|c|c|c|c|c|c|c|}
\hline \multirow{5}{*}{$\begin{array}{l}\text { ¿Cuántos } \\
\text { sobrinos } \\
\text { tienen? }\end{array}$} & $\begin{array}{l}\text { Cuatro } \\
\text { más }\end{array}$ & 0 & 201 & 61,7 & 109 & 60,2 & 92 & 63,4 & \multirow{5}{*}{ NS } \\
\hline & Dos o tres & & 71 & 21,8 & 39 & 21,5 & 32 & 22,1 & \\
\hline & Ninguno & & 38 & 17,7 & 23 & 12,7 & 15 & 10,3 & \\
\hline & Uno & & 10 & 4,9 & 10 & 5,6 & 6 & 4,2 & \\
\hline & Total & & 326 & 100 & 181 & 100 & 145 & 100 & \\
\hline \multirow[t]{5}{*}{$\begin{array}{l}\text { ¿Cuántos } \\
\text { amigos tienen? }\end{array}$} & $\begin{array}{l}\text { Cuatro } \\
\text { más }\end{array}$ & 0 & 126 & 38,7 & 54 & 29,8 & 72 & 49,7 & \multirow{5}{*}{$<0,001$} \\
\hline & Dos o tres & & 41 & 12,6 & 23 & 12,7 & 18 & 12,4 & \\
\hline & Ninguno & & 132 & 40,5 & 89 & 49,4 & 43 & 29,7 & \\
\hline & Uno & & 27 & 8,3 & 15 & 8,3 & 12 & 8,3 & \\
\hline & Total & & 326 & 100 & 324 & 100 & 2 & 100 & \\
\hline
\end{tabular}

Podemos observar en la tabla 22 que en cuanto a la fragilidad en la estructura de la red social con respecto al contacto visual, la significación estadística la encontramos en el número de amigos que ve habitualmente.

Tabla 22: Grado de fragilidad en la estructura de la red social respecto al contacto visual: recuento $(n)$ y frecuencia $(\%)$

\section{Fragilidad}

\section{Contacto visual}

\begin{tabular}{|c|c|c|c|}
\hline Total & Frágil & No Frágil & \\
\hline
\end{tabular}

\begin{tabular}{|c|c|c|c|c|c|c|c|}
\hline \multirow{4}{*}{$\begin{array}{l}\text { Cuantos hijos ve al } \\
\text { menos una v/mes }\end{array}$} & $\begin{array}{l}\text { Más de } \\
\text { tres }\end{array}$ & 40 & 12,3 & 23 & 12,7 & 17 & 11,7 \\
\hline & Uno a tres & 244 & 74,8 & 132 & 72,9 & 112 & 77,2 \\
\hline & Ninguno & 42 & 12,9 & 26 & 14,4 & 16 & 11,1 \\
\hline & Total & 326 & 100 & 181 & 100 & 145 & 100 \\
\hline
\end{tabular}




\begin{tabular}{|c|c|c|c|c|c|c|c|c|}
\hline \multirow{4}{*}{$\begin{array}{l}\text { Cuantos nietos ve } \\
\text { al menos una } \\
\mathrm{v} / \text { mes }\end{array}$} & $\begin{array}{l}\text { Más de } \\
\text { tres }\end{array}$ & 148 & 45,4 & 82 & 45,3 & 66 & 45,5 & \multirow{4}{*}{ NS } \\
\hline & Uno a tres & 129 & 39,6 & 68 & 37,6 & 61 & 42,1 & \\
\hline & Ninguno & 49 & 15 & 31 & 17,1 & 18 & 12,4 & \\
\hline & Total & 326 & 100 & 181 & 100 & 145 & 100 & \\
\hline \multirow{4}{*}{$\begin{array}{l}\text { Cuantos hermanos } \\
\text { ve al menos una } \\
\text { v/mes }\end{array}$} & $\begin{array}{l}\text { Más de } \\
\text { tres }\end{array}$ & 108 & 33,1 & 49 & 27 & 159 & 40,7 & \multirow{4}{*}{ NS } \\
\hline & Uno a tres & 13 & 4,0 & 6 & 3,3 & 7 & 4,8 & \\
\hline & Ninguno & 205 & 62,9 & 126 & 69,6 & 79 & 54,5 & \\
\hline & Total & 326 & 100 & 181 & 100 & 145 & 100 & \\
\hline \multirow{4}{*}{$\begin{array}{l}\text { Cuantos sobrinos } \\
\text { ve al menos una } \\
\text { v/mes }\end{array}$} & $\begin{array}{l}\text { Más de } \\
\text { tres }\end{array}$ & 63 & 19,3 & 32 & 17,7 & 31 & 21,4 & \multirow{4}{*}{ NS } \\
\hline & Uno a tres & 42 & 12,9 & 20 & 11 & 22 & 15,2 & \\
\hline & Ninguno & 221 & 67,8 & 129 & 71,3 & 92 & 63,4 & \\
\hline & Total & 326 & 100 & 181 & 100 & 145 & 100 & \\
\hline \multirow{4}{*}{$\begin{array}{l}\text { Cuantos amigos } \\
\text { ve al menos una } \\
\text { v/mes }\end{array}$} & $\begin{array}{l}\text { Más de } \\
\text { tres }\end{array}$ & 80 & 24,5 & 44 & 24,3 & 36 & 24,8 & \multirow{4}{*}{$<0,001$} \\
\hline & Uno a tres & 107 & 32,8 & 45 & 24,9 & 62 & 42,8 & \\
\hline & Ninguno & 139 & 42,6 & 92 & 50,8 & 47 & 32,4 & \\
\hline & Total & 326 & 100 & 181 & 100 & 145 & 100 & \\
\hline
\end{tabular}

Observamos en la tabla 23 no hay diferencias significativas entre la fragilidad en la estructura de la red social respecto a frecuencia de los contactos. 
Tabla 23. Grado de fragilidad en la estructura de la red social respecto a frecuencia de los contactos: recuento $(n)$ y frecuencia $(\%)$

\section{Fragilidad}

Contactos Telefónico

Total Frágil No Frágil

\begin{tabular}{llllll}
\hline $\mathbf{N}$ & $\%$ & $\mathbf{N}$ & $\%$ & $\mathbf{n}$ & $\%$
\end{tabular}

\begin{tabular}{|c|c|c|c|c|c|c|c|c|}
\hline \multirow{4}{*}{$\begin{array}{l}\text { Cuantos hijos } \\
\text { habla por teléfono } \\
1 \mathrm{v} / \mathrm{mes}\end{array}$} & Más de tres & 45 & 13,8 & 26 & 14,4 & 19 & 13,1 & \multirow{4}{*}{ NS } \\
\hline & Uno a tres & 222 & 68,1 & 117 & 64,6 & 105 & 72,4 & \\
\hline & Ninguno & 59 & 18,1 & 38 & 21 & 21 & 14,5 & \\
\hline & Total & 326 & 100 & 181 & 100 & 145 & 100 & \\
\hline \multirow{4}{*}{$\begin{array}{l}\text { Cuantos nietos } \\
\text { habla por teléfono } \\
1 \mathrm{v} / \text { mes }\end{array}$} & Más de tres & 127 & 39 & 71 & 39,2 & 56 & 38,6 & \multirow{4}{*}{ NS } \\
\hline & Uno a tres & 112 & 34,4 & 59 & 32,6 & 53 & 36,6 & \\
\hline & Ninguno & 87 & 26,7 & 51 & 28,2 & 36 & 24,8 & \\
\hline & Total & 326 & 100 & 181 & 100 & 145 & 100 & \\
\hline \multirow{4}{*}{$\begin{array}{l}\text { Cuantos hermanos } \\
\text { habla por teléfono } \\
1 \mathrm{v} / \mathrm{mes}\end{array}$} & Más de tres & 170 & 52,1 & 97 & 53,6 & 73 & 50,3 & \multirow{4}{*}{ NS } \\
\hline & Uno a tres & 30 & 9,2 & 11 & 6,1 & 19 & 13,1 & \\
\hline & Ninguno & 126 & 38,7 & 73 & 40,3 & 53 & 36,6 & \\
\hline & Total & 326 & 100 & 181 & 100 & 145 & 100 & \\
\hline \multirow{4}{*}{$\begin{array}{l}\text { Cuantos sobrinos } \\
\text { habla por teléfono } \\
1 \mathrm{v} / \mathrm{mes}\end{array}$} & Más de tres & 69 & 21,2 & 41 & 22,7 & 28 & 19,3 & \multirow{4}{*}{ NS } \\
\hline & Uno a tres & 57 & 17,5 & 29 & 16 & 28 & 19,3 & \\
\hline & Ninguno & 200 & 61,3 & 111 & 61,3 & 89 & 61,4 & \\
\hline & Total & 326 & 100 & 181 & 100 & 145 & 100 & \\
\hline \multirow{4}{*}{$\begin{array}{l}\text { Cuantos amigos } \\
\text { habla por teléfono } \\
1 \mathrm{v} / \text { mes }\end{array}$} & Más de tres & 62 & 22 & 32 & 17,7 & 30 & 20,7 & \multirow{4}{*}{$<0,062$} \\
\hline & Uno a tres & 71 & 25,8 & 32 & 17,7 & 39 & 26,9 & \\
\hline & Ninguno & 193 & 52,2 & 117 & 64,6 & 76 & 52,4 & \\
\hline & Total & 326 & 100 & 181 & 100 & 145 & 100 & \\
\hline
\end{tabular}


Observamos en la tabla 24 no hay diferencias significativas entre la fragilidad en la estructura de la red social respecto a la distancia a la que viven los contactos.

Tabla 24. Grado de fragilidad en la estructura de la red social respecto a la distancia a la que viven los contactos: recuento (n) y frecuencia (\%)

\section{Distancia Contactos}

\section{Fragilidad}

\begin{tabular}{|c|c|c|c|c|c|c|c|c|}
\hline & & \multicolumn{2}{|c|}{ Total } & \multicolumn{2}{|c|}{ Frágil } & \multicolumn{2}{|c|}{ No Frágil } & \\
\hline & & $\mathbf{n}$ & $\%$ & $\mathrm{n}$ & $\%$ & $\mathrm{n}$ & $\%$ & \\
\hline \multirow{4}{*}{$\begin{array}{l}\text { Distancia al hijo/a } \\
\text { más cercano/a }\end{array}$} & $\begin{array}{l}\text { Menos de } \\
15 \mathrm{~min}\end{array}$ & 55 & 16,9 & 31 & 17,1 & 24 & 16,6 & \multirow{4}{*}{ NS } \\
\hline & $15-30 \mathrm{~min}$ & 31 & 9,5 & 17 & 9,4 & 14 & 9,7 & \\
\hline & $\begin{array}{l}\text { Más de } 30 \\
\text { min }\end{array}$ & 240 & 73,6 & 133 & 73,5 & 107 & 73,8 & \\
\hline & Total & 326 & 100 & 181 & 100 & 145 & 100,1 & \\
\hline \multirow{4}{*}{$\begin{array}{l}\text { Distancia al nieto } \\
\text { más cercano }\end{array}$} & $\begin{array}{l}\text { Menos de } \\
15 \mathrm{~min}\end{array}$ & 68 & 20,9 & 37 & 20,4 & 31 & 21,4 & \multirow{4}{*}{ NS } \\
\hline & $15-30 \mathrm{~min}$ & 43 & 13,2 & 26 & 14,4 & 17 & 11,7 & \\
\hline & $\begin{array}{l}\text { Más de } 30 \\
\text { min }\end{array}$ & 215 & 66 & 118 & 65,2 & 97 & 66,9 & \\
\hline & Total & 326 & 100 & 181 & 100 & 145 & 100 & \\
\hline \multirow{4}{*}{$\begin{array}{l}\text { Distancia al } \\
\text { hermano más } \\
\text { cercano }\end{array}$} & $\begin{array}{l}\text { Menos de } \\
15 \mathrm{~min}\end{array}$ & 37 & 11,3 & 18 & 10 & 19 & 13 & \multirow{4}{*}{ NS } \\
\hline & $15-30 \mathrm{~min}$ & 110 & 33,7 & 65 & 35,9 & 45 & 31 & \\
\hline & $\begin{array}{l}\text { Más de } 30 \\
\min \end{array}$ & 179 & 54,9 & 98 & 54,1 & 81 & 56 & \\
\hline & Total & 326 & 100 & 181 & 100 & 145 & 100 & \\
\hline
\end{tabular}




\begin{tabular}{|c|c|c|c|c|c|c|c|c|}
\hline \multirow{4}{*}{$\begin{array}{l}\text { Distancia al } \\
\text { sobrino más } \\
\text { cercano }\end{array}$} & $\begin{array}{l}\text { Menos de } \\
15 \mathrm{~min}\end{array}$ & 49 & 15 & 24 & 13,3 & 25 & 17,2 & \multirow{4}{*}{ NS } \\
\hline & $15-30 \mathrm{~min}$ & 120 & 36,8 & 70 & 38,7 & 50 & 34,5 & \\
\hline & $\begin{array}{l}\text { Más de } 30 \\
\text { min }\end{array}$ & 157 & 48,2 & 87 & 48,1 & 70 & 48,3 & \\
\hline & Total & 326 & 100 & 181 & 100 & 145 & 100 & \\
\hline \multirow{4}{*}{$\begin{array}{l}\text { Distancia al amigo } \\
\text { más cercano }\end{array}$} & $\begin{array}{l}\text { Menos de } \\
15 \mathrm{~min}\end{array}$ & 22 & 6,7 & 14 & 7,7 & 8 & 5,5 & \multirow{4}{*}{ NS } \\
\hline & $15-30 \mathrm{~min}$ & 13 & 4 & 6 & 33 & 7 & 4,8 & \\
\hline & $\begin{array}{l}\text { Más de } 30 \\
\text { min }\end{array}$ & 291 & 89,3 & 161 & 89,1 & 130 & 89,7 & \\
\hline & Total & 326 & 100 & 181 & 100 & 145 & 100 & \\
\hline
\end{tabular}

En la tabla 25, observamos que el grado de fragilidad en la estructura de la red social respecto a las características de la presencia de confidente es significativo y en cuanto al tipo de confidente es el grado de esposo/a.

Tabla 25. Grado de fragilidad en la estructura de la red social respecto a las características de la presencia de confidente y tipo de relación de los encuestados: recuento $(n)$ y frecuencia (\%)

\begin{tabular}{|c|c|c|c|c|c|c|c|c|}
\hline \multirow{3}{*}{ Tipo de confidente } & & & & \multicolumn{4}{|c|}{ Fragilidad } & \multirow{3}{*}{$\mathbf{P}$} \\
\hline & & \multicolumn{2}{|c|}{ Total } & \multicolumn{2}{|c|}{ Frágil } & \multicolumn{2}{|c|}{ No Frágil } & \\
\hline & & $\mathbf{n}$ & $\%$ & $\mathbf{n}$ & $\%$ & $\mathbf{n}$ & $\%$ & \\
\hline \multirow{3}{*}{ ¿Tiene confidente? } & $\mathrm{Si}$ & 269 & 82,5 & 142 & 78,5 & 127 & 87,6 & \multirow{3}{*}{$<0,001$} \\
\hline & No & 34 & 10,5 & 39 & 21,5 & 18 & 12,4 & \\
\hline & Total & 326 & 100 & 181 & 100 & 145 & 100 & \\
\hline \multirow{3}{*}{ Esposo/a } & No & 186 & 57,1 & 121 & 66,9 & 65 & 44,8 & \multirow{3}{*}{$<0,001$} \\
\hline & $\mathrm{Si}$ & 140 & 42,9 & 60 & 33,1 & 80 & 55,2 & \\
\hline & Total & 326 & 100 & 181 & 100 & 145 & 100 & \\
\hline
\end{tabular}




\begin{tabular}{lccccccccc}
\hline & No & 182 & 55,8 & 96 & 53 & 86 & 59,3 & \\
\cline { 2 - 4 } & $\mathrm{Si}$ & 144 & 44,2 & 85 & 47 & 59 & 40,7 & $\mathrm{NS}$ \\
& Total & 326 & 100 & 181 & 100 & 145 & 100 & \\
\hline \multirow{3}{*}{ Familia Extensa } & No & 308 & 94,8 & 174 & 96,7 & 134 & 92,4 & \\
& No & 17 & 5,2 & 6 & 3,3 & 11 & 7,6 & NS \\
& Total & 325 & 100 & 180 & 100 & 145 & 100 & \\
\hline \multirow{3}{*}{ Otro Confidente } & No & 316 & 96,8 & 174 & 95,6 & 143 & 98,6 & \\
& Si & 10 & 3,2 & 7 & 3,9 & 2 & 1,4 & NS \\
& Total & 326 & 100 & 181 & 100, & 145 & 100 & \\
\hline
\end{tabular}

El grado de fragilidad en la estructura de la red social respecto a las características de la participación en actividades comunitarias de los encuestados, como podemos observar en la tabla 26, tiene significación estadística al no poder acudir a las asociaciones o clubs culturales.

Tabla 26. Grado de fragilidad en la estructura de la red social respecto a las características de la participación en actividades comunitarias de los encuestados: recuento (n) y frecuencia (\%)

\begin{tabular}{|c|c|c|c|c|c|c|c|c|}
\hline \multirow{2}{*}{\multicolumn{2}{|c|}{$\begin{array}{l}\text { Participación actividades } \\
\text { comunitarias }\end{array}$}} & \multirow{2}{*}{\multicolumn{2}{|c|}{ Total }} & \multicolumn{4}{|c|}{ Fragilidad } & \multirow{3}{*}{$\mathbf{P}$} \\
\hline & & & & \multicolumn{2}{|c|}{ Frágil } & \multicolumn{2}{|c|}{ No Frágil } & \\
\hline & & $\mathbf{n}$ & $\%$ & $\mathbf{n}$ & $\%$ & $\mathbf{n}$ & $\%$ & \\
\hline \multirow{3}{*}{$\begin{array}{l}\text { Acude a la Plaza o } \\
\text { lugar céntrico al } \\
\text { menos } 1 \mathrm{v} / \mathrm{mes}\end{array}$} & No & 131 & 40,2 & 67 & 37,0 & 64 & 44,1 & \multirow{3}{*}{ NS } \\
\hline & $\mathrm{Si}$ & 195 & 59,8 & 114 & 63,0 & 81 & 55,9 & \\
\hline & Total & 326 & 100 & 181 & 100 & 145 & 100 & \\
\hline \multirow{3}{*}{$\begin{array}{l}\text { Forma parte de } \\
\text { alguna asociación o } \\
\text { club cultural }\end{array}$} & No & 218 & 67,3 & 133 & 74,3 & 85 & 58,6 & \multirow{3}{*}{$<0,003$} \\
\hline & $\mathrm{Si}$ & 106 & 32,7 & 46 & 25,7 & 60 & 41,4 & \\
\hline & Total & 324 & 100 & 179 & 100 & 145 & 100 & \\
\hline
\end{tabular}


Análisis de las relaciones sociales y la fragilidad en las personas mayores de 75 años residentes en Castellón de la Plana

\begin{tabular}{|c|c|c|c|c|c|c|c|c|}
\hline \multirow{3}{*}{$\begin{array}{l}\text { Acude a la Iglesia al } \\
\text { menos } 1 \mathrm{v} / \text { mes }\end{array}$} & No & 208 & 63,8 & 118 & 65,2 & 90 & 62,1 & \multirow{3}{*}{ NS } \\
\hline & $\mathrm{Si}$ & 118 & 36,2 & 63 & 34,8 & 55 & 37,9 & \\
\hline & Total & 326 & 100 & 181 & 100 & 145 & 100 & \\
\hline \multirow{3}{*}{$\begin{array}{l}\text { Acude al hogar del } \\
\text { pensionista al menos } \\
1 \mathrm{v} / \mathrm{mes}\end{array}$} & No & 243 & 74,5 & 143 & 79,0 & 100 & 69,0 & \multirow{3}{*}{ NS } \\
\hline & $\mathrm{Si}$ & 83 & 25,5 & 38 & 21,0 & 45 & 31,0 & \\
\hline & Total & 326 & 100 & 181 & 100 & 145 & 100 & \\
\hline
\end{tabular}

En la tabla 27, observamos que los índices globales de las relaciones sociales son significativos en cuanto a la fragilidad.

Tabla 27:Las redes sociales (índices globales) según la fragilidad: media y desviación estándar (DE)

\begin{tabular}{|c|c|c|c|c|c|c|c|c|}
\hline \multirow[t]{2}{*}{ Fragilidad } & \multicolumn{3}{|c|}{$\begin{array}{l}\text { Índice de vínculos } \\
\text { familiares (0-3) }\end{array}$} & \multicolumn{3}{|c|}{$\begin{array}{l}\text { Índice de actividades } \\
\text { comunitarias }(0-4)\end{array}$} & \multicolumn{2}{|c|}{$\begin{array}{l}\text { İndice de diversidad } \\
\text { de la red }(0-8)\end{array}$} \\
\hline & Media & $\overline{D E}$ & $\mathbf{P}$ & Media & DE & $\mathbf{P}$ & Media $\mathrm{DE}$ & $\mathbf{P}$ \\
\hline No frágil & 3,00 & 0,54 & \multirow{3}{*}{$<0,004$} & 3,50 & 0,70 & \multirow{3}{*}{$<0,015$} & 7,50 & \multirow{3}{*}{$<0,001$} \\
\hline Pre-frágil & 2,64 & 0,67 & & 1,63 & 1,03 & & 4,97 & \\
\hline Frágil & 2,41 & 0,63 & & 1,45 & 1,14 & & 4,39 & \\
\hline
\end{tabular}

En la tabla 28, observamos que los índices globales de los mecanismos psicosociales son significativos en cuanto a la fragilidad.

Tabla 28:Mecanismos psicosociales (índices globales) según la fragilidad: media y desviación estándar (DE)

\begin{tabular}{|c|c|c|c|c|c|c|}
\hline \multirow[t]{2}{*}{ Fragilidad } & \multicolumn{2}{|c|}{$\begin{array}{l}\text { Apoyo emocional } \\
\text { recibido }(0-3)\end{array}$} & \multicolumn{4}{|c|}{ Rol del individuo (0-3) } \\
\hline & Media & $\mathrm{DE}$ & $\mathbf{P}$ & Media & DE & $\mathbf{P}$ \\
\hline No frágil & 1,13 & 0,17 & \multirow{3}{*}{$<0,001$} & 1,13 & 0,17 & \multirow{3}{*}{$<0,001$} \\
\hline Pre-frágil & 1,22 & 0,27 & & 1,19 & 0,29 & \\
\hline Frágil & 0,95 & 0,45 & & 0,93 & 0,44 & \\
\hline
\end{tabular}




\subsection{Asociación entre las relaciones sociales y la fragilidad en presencia de características sociodemográficas, estado y hábitos de salud}

Para analizar el efecto de las relaciones sociales sobre la situación de fragilidad, se realizaron análisis de regresión logística. El modelo utilizado se construyó controlando el efecto que sobre la relación fragilidad/relaciones sociales podían tener variables sociodemográficas, estado de salud y hábitos de salud que se han descrito como variables control. Para la selección de las variables se realizaron los análisis bivariados expuestos durante la descripción de la situación de fragilidad de la población objeto de estudio. Aquellas variables seleccionadas como posibles confusoras y que obtuvieron en estos análisis descriptivos un grado de significación estadística inferior a 0,25 fueron incluidas en el modelo. Las variables seleccionadas fueron: sexo, estar casado, deterioro cognitivo, estado nutricional, depresión y consumo de alcohol.

Se realizó una regresión logística múltiple con la variable de Fragilidad como variable dependiente en forma dicotómica y los índices globales de las relaciones sociales como variables independientes. Se construyeron los modelos sucesivos introduciendo las variables de control por bloques de la siguiente forma: el modelo 1 estaba constituido por las variables independientes que constituyen los índices globales de las relaciones sociales; en el modelo 2 se introdujeron las variables sociodemográficas (sexo y estar casado) y en el modelo 3 se añadieron las variables de estado y hábito de salud (deterioro cognitivo, depresión, estado nutricional y hábito alcohólico). Esto permitió analizar el efecto que tienen las relaciones sociales a través de los índices globales sobre la fragilidad y si este efecto actuaba a través de otras variables o directamente.

Los índices globales más destacados y que obtuvieron significación en el primer modelo, fueron los índices de apoyo emocional recibido (OR=0,073; IC95\% 0,006 - 0,841). En el segundo y tercer modelo después de ajustar por sexo y estado y hábitos de salud. Persiste la significación los índices de apoyo emocional recibido pudiendo indicar que actúa sobre la fragilidad, (OR=0,074; IC95\% 0,006 - 0,904) a través de las variables sociodemográficas y el estado de salud. En este modelo final las variables más 
influyentes en la fragilidad además del apoyo emocional recibido, resultaron ser el sexo y el estado nutricional.

La posibilidad de ser frágil para las mujeres se multiplicaba por $(\mathrm{OR}=2,128$; IC95\% 1,179 - 3,840) y para el estado nutricional la posibilidad de ser frágil se multiplicaba por $(\mathrm{OR}=0,510 ; \mathrm{IC} 95 \%$ 0,279 - 0,931).

Tabla 29: Odds Ratio (OR) e intervalos de confianza al 95\% (IC95\%) del modelo de regresión logística binaria que analiza la posibilidad de presentar fragilidad

\section{Fragilidad}

Variable

OR IC 95\% P

\section{Modelo 1}

\begin{tabular}{lccc}
$\begin{array}{l}\text { Índice de Vínculos } \\
\text { Familiares contacto(0-3) }\end{array}$ & 1,152 & $0,607-2,186$ & $\mathrm{NS}$ \\
\hline $\begin{array}{l}\text { Índice actividades } \\
\text { Comunitarias (0-4) }\end{array}$ & 1,073 & $0,559-2,057$ & $\mathrm{NS}$ \\
\hline $\begin{array}{l}\text { Índice de diversidad de la } \\
\text { red }\end{array}$ & 0,856 & $0,480-1,527$ & $\mathrm{NS}$ \\
\hline $\begin{array}{l}\text { Índice de apoyo emocional } \\
\text { recibido }\end{array}$ & 0,073 & $0,006-0,841$ & $<0,036$ \\
$\begin{array}{l}\text { Índice de rol del individuo } \\
\text { (0-3) }\end{array}$ & & $0,195-21,611$ & $\mathrm{NS}$
\end{tabular}




\section{Modelo 2}

Índice de Vínculos

Familiares contacto(0-3)

1,424

$0,580-3,497$

NS

\begin{tabular}{lccc}
$\begin{array}{l}\text { Índice actividades } \\
\text { comunitarias(0-4) }\end{array}$ & 1,023 & $0,526-1,990$ & NS \\
\hline $\begin{array}{l}\text { Índice diversidad de la } \\
\text { red }\end{array}$ & 0,907 & $0,502-1,637$ & NS \\
\hline $\begin{array}{l}\text { Índice d apoyo emocional } \\
\text { recibido }\end{array}$ & 0,074 & $0,006-0,904$ & $<0,041$ \\
$\begin{array}{l}\text { Índice de rol del individuo } \\
(0-3)\end{array}$ & 1,628 & $0,148-17,934$ & NS \\
\hline $\begin{array}{l}\text { Sexo (Mujer) } \\
\text { Casado }\end{array}$ & 2,583 & $1,563-4,268$ & $<0,001$ \\
\hline
\end{tabular}

\section{Modelo 3}

\begin{tabular}{llll}
$\begin{array}{l}\text { Indice de apoyo emocional } \\
\text { recibido }\end{array}$ & 0,143 & $0,011-1,811$ & $\mathrm{NS}$ \\
\hline $\begin{array}{l}\text { Índice de rol del } \\
\text { individuo (0-3) }\end{array}$ & 1,320 & $0,123-14,206$ & $\mathrm{NS}$ \\
\hline $\begin{array}{l}\text { Indice de Vínculos } \\
\text { Familiares contacto(0-3) }\end{array}$ & 1,352 & $0,538-3,396$ & $\mathrm{NS}$ \\
\hline $\begin{array}{l}\text { Índice actividades } \\
\text { comunitarias (0-4) }\end{array}$ & 1,217 & $0,605-2,452$ & $\mathrm{NS}$ \\
\hline $\begin{array}{l}\text { Indice diversidad de la } \\
\text { red }\end{array}$ & 0,780 & $0,418-1,456$ & $\mathrm{NS}$ \\
\hline Sexo (Mujer) & 2,128 & $1,179-3,840$ & $<\mathbf{0 , 0 1 2}$ \\
\hline Casado & 0,974 & $0,374-2,532$ & $\mathrm{NS}$ \\
\hline Deterioro cognitivo & 2,313 & $0,784-6,827$ & $\mathrm{NS}$ \\
\hline Estado nutricional & 0,510 & $0,279-0,931$ & $<\mathbf{0 , 0 2 8}$ \\
\hline Depresión & 1,361 & $0,797-2,322$ & $\mathrm{NS}$ \\
\hline Consumo de Alcohol & 0,910 & $0,486-1,703$ & $\mathrm{NS}$ \\
\hline
\end{tabular}


Análisis de las relaciones sociales y la fragilidad en las personas mayores de 75 años residentes en Castellón de la Plana 
DISCUSIÓN

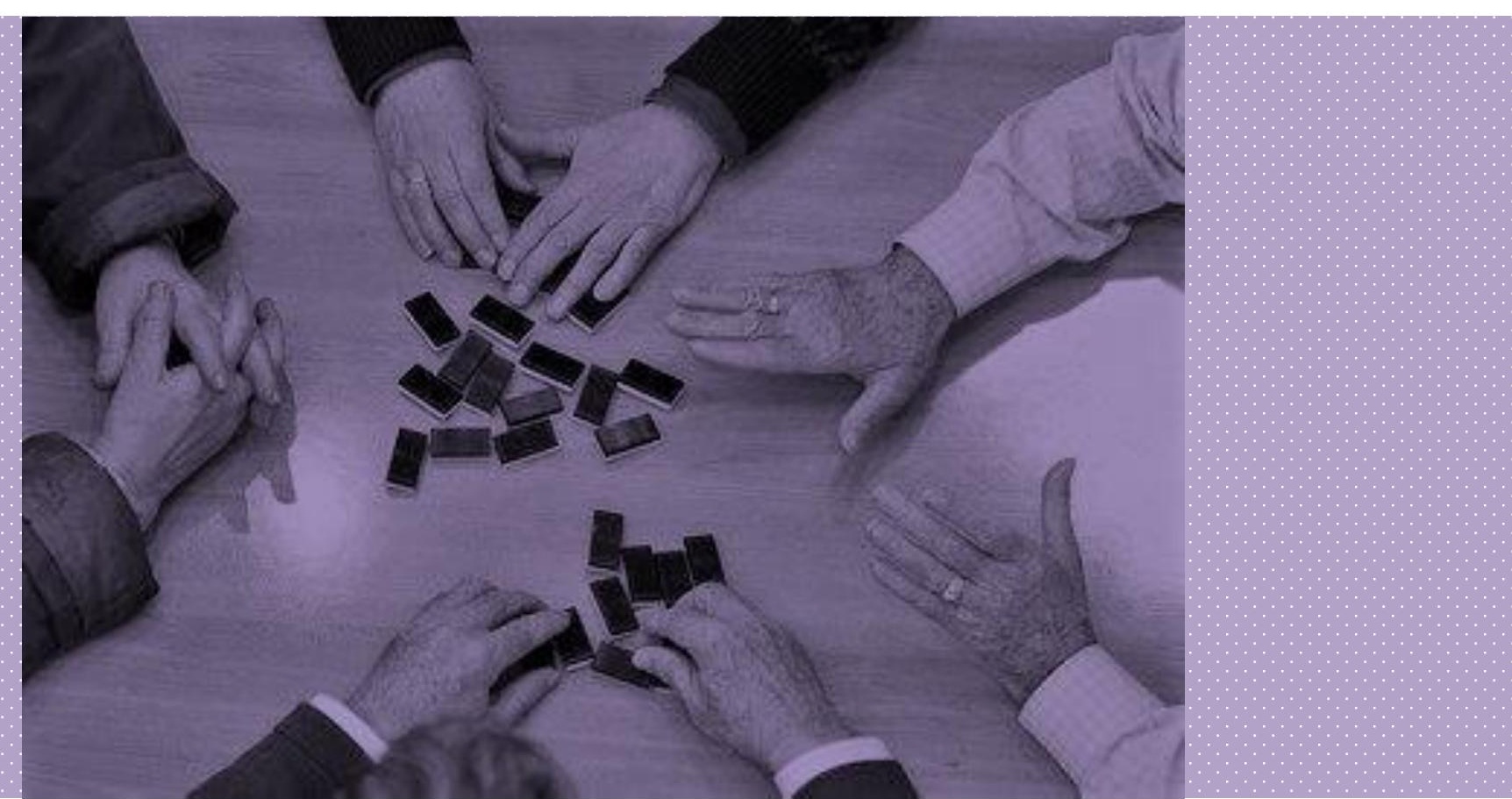





\section{Discusión}

\subsection{Características sociodemográficas globales de la población estudiada por sexo}

Los resultados de este estudio muestran una distribución de la población por sexos con una media de edad de 81,32 años que viven en la comunidad, similar a estudios de población entre 65 y 85 años que viven en entornos similares al nuestro. La mayoría son mujeres por una mayor esperanza de vida donde se nota la influencia del factor hormonal protector y la mayor tendencia cultural de autocuidarse (214).

Los datos sociodemográficos que presenta la comunidad de Castellón de la Plana son comparables a otros estudios españoles y europeos como el de Nilsson et al. (117). Se observa que, la cifra de viudedad es mayor en el sexo femenino y que el índice de analfabetismo también es mayor en este género. Hay un número más elevado de mujeres que viven solas, dato que se asocia a los elevados resultados de viudedad, y que justificaría los bajos ingresos, a diferencia de lo que ocurre con los hombres, la mayoría están casados y el número de viudos es menor. En el estudio Octabaix (209) se han obtenido datos similares a nuestra investigación, con el $71,4 \%$ de hombres casados y $23 \%$ de viudos frente al $21,8 \%$ de mujeres casadas y el $71,8 \%$ de viudas (209).

En nuestro estudio se puede observar que hay un $23,6 \%$, de mayores, cuyos ingresos mensuales están entre 600-900 euros y la mayoría de estos ingresos corresponde a las mujeres. Otros estudios españoles y europeos realizados en Córdoba, Lérida, Madrid y Dinamarca (220-223)muestran población con ingresos inferiores a 900 euros. Sin embargo en una investigación similar realizada en la ciudad de Caracas (224)en el año 2007 las características económicas son parecidas las de Castellón. 
En relación al estado civil, la mayoría de la muestra de Castellón está casada (64,8\%) a diferencia de estudios españoles realizados en Lleida y Barcelona donde la población casada es del 50\% y 40,9\% (209,220). Este aspecto se puede asociar a características culturales de la zona objeto de estudio. Hay un desequilibrio por sexo y edad que aumenta según la característica sociodemográfica del estado civil en la ciudad de Córdoba (223).

\subsection{Características de los hábitos de salud por sexo}

Los hábitos de salud de los encuestados son similares a los mostrados por Escobar y evidencian como las mujeres consumen menos tabaco y alcohol que los hombres $(171,225)$. En todo caso existen diferencias entre las cifras obtenidas en el presente estudio y las de la Encuesta Nacional de Salud del 2006 (ENS). En el primer caso en el hábito tabáquico el resultado en la franja de edad es muy similar, pero en el alcohol en nuestro estudio el bebedor habitual es algo inferior al del ENS (4,1\% a 1,84\%) tanto en hombres como en mujeres. En cuanto a la práctica el hábito del caminar se está integrando en una rutina diaria en casi todos los en los países del mediterráneo. Este hábito además de ser beneficioso para la salud promueve la interacción social (225).

\subsection{Características del estado de salud de la población separado por sexos}

Respecto a los trastornos del sueño en nuestro estudio, la cifra es superior a la mostrada en otros estudios como el de Pachana(226)aunque la edad puede influir, sobresale el problema dentro de este trastorno, que a los mayores les cuesta más dormirse, posiblemente relacionado con la falta de actividad. Este aspecto es igual de significativo como en el estudio de Nuin (220).

En el deterioro cognitivo los resultados muestran cifras inferiores a las de Otero y Gutiérrez-Misis $(4,227)$,esta diferencia se puede atribuir a la utilización de instrumentos 
de valoración diferentes y a que se excluyeron del estudio las personas que presentaron deterioro cognitivo ( $\geq 3$ errores en el test de Pfeiffer) sin un acompañante disponible. La función cognitiva empeora a medida que se envejece aunque existen factores ambientales que pueden modular su evolución.

La edad, el género y el nivel educativo, elevan el riesgo de los síntomas depresivos según Van de Velde y Stek et al. $(228,229)$. En este sentido la prevalencia de los síntomas depresivos en nuestro estudio concuerda con la mostrada en estudios de Otero, GutierrezMisis y Stek et al. $(4,227,228)$.

El estar casado o con pareja se asocian en muchas investigaciones el bajo riesgo de depresión en hombres y mujeres, así como un buen apoyo emocional según afirma en su estudio Van de Velde (229). Por lo que en nuestro estudio la prevalencia de depresión en las persona con apoyo de la familia y que están casadas es menor que las que viven solas $(20,1 \%$ versus $35,6 \%)$ al igual que ocurre en el estudio de Ross (230) que las diferencias de género que indican que aparece más depresión en el género femenino que en el masculino (72\% versus $39 \%)$.

En relación a la comorbilidad solo un $11,1 \%$ en nuestro estudio de las personas encuestadas presenta una o más enfermedades crónicas, cifra poco significativa en nuestro estudio, cifra similar al estudio de Pachana et al. (226).

Cuando se habla de la discapacidad, la prevalencia de discapacidad instrumental fue superior en la investigación realizada que en la encontrada en los estudios Otero et al., Escobar y Castell et al. $(4,171,231)$ pero similar a la referida en los estudios Nuin, Celidoni y Rebba, Avlundet al. $(220,232,233)$. En cambio la prevalencia de la discapacidad básica, no fue significativa en nuestro estudio. Las diferencias podría deberse a que en estos estudios trabajan con población de 65 años o más, mientras que 
la muestra tiene 75 años o más. Otra de las causas que explicarían las diferencias sería la diferente forma de medir las variables. Hay mediciones que solo toman dificultades graves, mientras otras, como la utilizada en este estudio, utilizan cualquier tipo de dificultad sin tener en cuenta el uso de ayudas técnicas que facilitan el ir al lavabo o la higiene, en relación al nivel de estudios, es la población considerada sin estudios la que presenta en mayor proporción discapacidad tal como se observa en el estudio de Jürschik et al. (234), como encuesta de salud 2010 de la Generalitat Valenciana (235).

La tasa de prevalencia de déficit auditivo y visual es similar en ambos sexos y es similar a la de otros estudios de Suemoto et al y Mussoll et al. $(236,237)$.

La población objeto de estudio considera que su salud es muy buena o buena, en un porcentaje superior a la presentada en otros estudios como el de Imsero 2014 (238), Gutiérrez-Misiset al. (227) pero similar a otro estudio Azpiazu et al. (221). Las investigaciones demuestran que la edad apenas influye en la percepción de la salud a edades muy avanzadas. Podría ser que las personas muy mayores a pesar de tener peor salud y vivir en soledad tengan asumidos esos cambios como algo natural y que por ello no consideren que empeora su estado de salud según concluye Azpiazu et al. (221).En todo caso para explicar las diferencias observadas se debería analizar la posible influencia de factores como la morbilidad, la discapacidad o el apoyo social asociados a la percepción de la salud.

En esta investigación la prevalencia del consumo $>3$ medicamentos es elevado, más en el sexo masculino $80,9 \%$ que en el femenino $57,4 \%$, pero si lo comparamos con $\mathrm{La}$ Encuesta de Salud 2010 de la Generalitat Valenciana (235) que los resultados son más elevados que los obtenidos en Castellón, y al revés que en nuestro entorno consumen más medicamentos las mujeres que los hombres. Por el contrario en el estudio realizado en la ciudad de Córdoba en el que no existen diferencias en ambos 
Sexos (223). Y en el estudio realizado en Taiwán (239) consumían más de tres medicamentos.

\subsection{Estructura de la red social de los encuestados en cuanto la cantidad de personas con las que mantiene relación separado por sexo.}

La diversidad de la red es elevada y fuerte ya que la casi totalidad tiene contactos con los hijos y la familia extendida, característica propia de los países mediterráneos como en el estudio de Otero (4). Solo un 31\% de las personas encuestadas en Castellón de la Plana no tiene ningún hijo vivo, cifra algo inferior a la del conjunto de los once países europeos que integran la bases de datos SHARE (240), en la que el 13,8\% de la población de más de 65 años no tienen ningún hijo, y a la de España de Jürschik et al. (234) (13,5\%), todo ello a pesar de que la población es mayor de 75 años. La amplia red de hijos puede deberse a que el descenso acusado de la natalidad que se produjo España en las décadas de los 80 y 90 no afecta a la generación aquí estudiada (4).

En nuestro estudio la relación con los amigos, únicamente el 40,5\% refirió no tener ningún amigo, ni contacto visual $42,6 \%$. Similar al nuestro encontramos los estudios de Otero et al. (4) y Escobar et al. (157).

\subsubsection{Estructura de la red social de los encuestados en cuanto la frecuencia de relación en termino de contacto de modo de visitas con otras personas por sexo.}

En el estudio Envejecer en Leganés (4) se confirma que el $82 \%$ de aquellas personas con una buena red social continuaban vivas, mientras que entre las personas socialmente aisladas esta proporción bajaba al 68\%. A pesar de que el índice de actividades comunitarias, que mide la participación social, es el único componente del índice de diversidad de red que muestra en nuestros análisis una asociación 
estadísticamente significativa con la mortalidad, sería un error considerar que el efecto sea debido sólo a él (los otros componentes del índice se refieren a la familia y a los amigos). Como en nuestro estudio que tanto los hijos como los nietos y hermanos son los que más hablan con sus familiares, esta socialización de que disfruta un individuo es lo que resulta beneficioso aumentar y aunar la estructura de la red social.

\subsubsection{Estructura de la red social de los encuestados en cuanto a la frecuencia de relación visual y oral con otra personas separado por sexo.}

En los resultados obtenidos, se observa que la estructura de la red social y la distancia a la que viven los contactos no es significativa, como sucede en el estudio de Lérida de Nuin (220) del que se diferencia en el número de amigos que habla por teléfono, 57,2\% habla con más de tres amigos y en nuestro estudio el 59,2\%no hablan con ningún amigo, similar al nuestro en cuanto a los amigos con los que se habla por teléfono encontramos el trabajo de Escobar (171).

\subsubsection{Estructura de la red social de los encuestados en cuanto a la distancia de la persona más cercana por sexo.}

Estos elevados niveles de competencia relacional pueden influir favorablemente en la habilidad para mantener y transformar las relaciones con los amigos y adaptarse a los cambios relacionados con la edad, como son la viudedad y la jubilación, Stevens et al. (241). El 82,5\% de las personas encuestadas dice tener una persona especial en quien confiar, similares a los estudios de Escobar y Rodríguez $(171,242)$. 


\subsubsection{Participación en actividades comunitarias de los encuestados por sexo.}

Si analizamos la participación en actividades comunitarias se aprecia como las personas acuden más a la plaza o a un lugar céntrico $(52,8 \%)$ y con menor frecuencia, al hogar del pensionista $(25,5 \%)$ y a la iglesia $(36,2 \%)$, sobre todo las mujeres. Este hecho puede deberse a que en el primer caso la actividad puede considerarse activa, requiriendo capacidad física para desplazarse, y el resto pueden catalogarse como pasivas no requiriendo demasiado esfuerzo. Hay que recordar que el estilo de vida llevado a cabo durante el ciclo vital marca las pautas fundamentales, actuando como un factor condicionante del número y tipología de actividades que la persona mayor puede realizar en esta etapa según el estudio de Brazo (243). Este hecho explicaría porque las personas que desde siempre han acudido a la iglesia o comenzaron a asistir al hogar de jubilado, tras la jubilación continúan haciéndolo ahora que tienen 75 años o más de edad. En todo caso resultará interesante observar si se puede confirmar posteriormente con otros estudios que la participación en actividades comunitarias previene de efectos adversos sobre la salud como la aparición de la discapacidad.

A diferencia de los resultados de Castellón, en el estudio de Nuin (220) con la participación en las actividades comunitarias, las únicas significativas son acudir a una asociación o centro y la mayoría hombres y en el estudio de Nuin era acudir a la iglesia, este último se da más en el sexo femenino.

\subsubsection{Relaciones sociales en forma de redes sociales. Mecanismos psicosociales de los encuestados. Resultados separados por sexo.}

En el Índice global de los vínculos familiares con contacto obtenido es una puntuación media de 2,64 (sobre 3) lo que evidencia la fortaleza de la red social familiar, aunque son las mujeres con una media de 2,40 las que obtienen una puntuación menor. Recordemos que el índice incorpora el estar casado o con pareja. Similar al muestro encontramos el estudio de Leganés y Lleida $(4,220)$ en cuanto a la media de los hombres 2,6 pero es un poco menor en el sexo femenino 2,2. En cambio en el estudio de Envejecer en Leganés 
la media en el sexo masculino es superior 3 y en el femenino es inferior siendo de 2 (4).Cifras inferiores a las nuestras encontramos en el estudio de Escobar (157).

Se obtienen en el Índice de actividades comunitarias una puntuación media de 1,5 en ambos sexos, resultado es similar al estudio de Nuin (220) con 1,5 en hombres y 1,6 en mujeres también en el estudio Giles et al. (87) los resultados son 1,8 en hombres y 1,7 en mujeres. Aunque en España la participación social de los mayores ha ido aumentando, se sigue considerando baja IMSERSO (244) y las diferencias con otros países se explican por las diferencias existentes entre generaciones. Las generaciones de la república y la guerra civil se caracterizan por un claro carácter rural, las siguientes (postguerra, desarrollo y baby-boom) estuvieron marcadas por un carácter más urbano, centradas en el trabajo doméstico y la familia y la más cercana, la de la transición apoyada en una conciencia de derechos adquiridos y socializada en una cultura más participativa, de acuerdo con Amorós et al. (245). De ahí que en un futuro sea necesario observar cómo evoluciona la participación social de los mayores, eje fundamental del envejecimiento activo.

En cuanto a lo referente al Índice de la diversidad de la red en nuestro estudio es mayor en el sexo masculino con una media de 4,86 a diferencia del sexo femenino 4,49 de media. En el estudio de Lleida parecido al entorno de Castellón se obtuvo una media de 5 en los hombres y 4,6 en mujeres (220), similar al de Giles et al. (134) una media de 5,1 en hombres y 4,4 en mujeres.

Según el índice de apoyo emocional recibido y la importancia del rol del individuo (en la vida de los vínculos) con una media de 1,9 en ambos sexos y en ambas escalas. Diferente al nuestro encontramos el estudio de Nuin (220) y Otero et al. (4). Aunque ambos estudios no son significativos.

\subsection{Características de las relaciones sociales y los mecanismos psicosociales.}




\subsubsection{Resultados del análisis de las redes sociales (índices globales) relacionados con las características sociodemográficas}

Las redes sociales y los mecanismos psicosociales con la edad pierden fortaleza a excepción del apoyo emocional recibido que aumenta con la edad. Estos resultados coinciden con los presentados por Ajrouch et al. (127) y con la teoría de la selectividad socioemocional (112) que explica cómo a pesar de que las redes sociales disminuyen con la edad, el soporte emocional se mantiene o aumenta en épocas de crisis, como ocurre cuando la persona es dependiente $(113,246)$ variable asociada con la edad.

En España gracias a los flujos de solidaridad intergeneracional se observa que a partir de los 81,32 años aumenta la convivencia de padres e hijos tras situaciones de soledad, enfermedad o discapacidad (238) incidiendo seguramente en el aumento del apoyo emocional recibido.

A mayor nivel de ingresos mayor fortaleza de los vínculos familiares con contacto y de la diversidad de la red (que incluye el contacto con los amigos) como se puede apreciar en otros estudios $(127,128,247)$. También las personas que viven acompañadas tienen un mayor contacto con la familia poro sin embargo son estas que viven solas las que participan más en actividades comunitarias. Esta mayor participación puede ser debido a que las personas que viven solas tienen mejor salud y suplen el tener menos vínculos familiares con la participación social. Según el último Informe sobre las personas mayores, realizado en 2014 (238), todas estas circunstancias pueden explicar cómo las personas que viven solas tienen una red de vínculos familiares más débil que compensan con la relación que establecen con los amigos $u$ otros al no mostrar diferencias en el índice de diversidad de la red ni en la presencia de confidente como se comprueba en otros estudios $(87,241)$ o con la participación en actividades comunitaria.

En Europa los mayores viven de forma independiente y son los contactos fuera del hogar los que sustentan las relaciones sociales junto con una alta participación social 
según Share, Rodríguez-Laso, Stevens $(87,241,248)$. En España, por ejemplo, a partir de los 85 años se observa un aumento de la convivencia de padres e hijos. Esto se debe, principalmente, a situaciones de soledad debido a la defunción de la pareja, enfermedad y/o discapacidad de los mayores que pasan a residir con algún miembro de la familia, normalmente con los hijos según estudios del Imserso 2014 (238).

A mayor nivel de ingresos mayor fortaleza de los vínculos familiares con contacto y de la diversidad de la red (que incluye el contacto con los amigos) como se puede apreciar en otros estudios de Ajrouch, Broesevan, Groenov-Weyers et al. $(127,128,247)$. También las personas que viven acompañadas tienen un mayor contacto con la familia poro sin embargo son estas que viven solas las que participan más en actividades comunitarias. Esta mayor participación puede ser debido a que las personas que viven solas tienen mejor salud y suplen el tener menos vínculos familiares con la participación social. Según el último Informe sobre las personas mayores, realizado en 2014 (238), todas estas circunstancias pueden explicar cómo las personas que viven solas tienen una red de vínculos familiares más débil que compensan con la relación que establecen con los amigos $u$ otros al no mostrar diferencias en el índice de diversidad de la red ni en la presencia de confidente como se comprueba en los estudios Rodriguez y Stevens $(87,241)$ o con la participación en actividades comunitaria.

En el caso de la población que se estudia tenía 75 años o más en el momento de la entrevista y residía en la ciudad de Castellón de la Plana mientras que en la mayor parte de los estudios la población tiene 65 años o más y vive en zonas rurales y urbanas.

\subsubsection{Resultados de los índices globales de la dimensión mecanismos psicosociales y su relación con las características sociodemográficas}

El consumo de alcohol y tabaco se relaciona con una red social débil al igual que ocurre con las actividades comunitarias y el índice de la diversidad de la red, se explica 
por el bajo consumo de sustancias tóxicas debido a restricciones por razón de enfermedad (enfermedades cardiovasculares o cáncer) y consejo médico (238). Las personas con problemas de sueño tienen redes sociales más débiles tal como ocurre en el estudio de Viana da Costa y Yao et al. $(249,250)$.

El aumento de la práctica de andar por lo menos una vez a la semana se relaciona con fuerte con las actividades comunitarias y la diversidad de la red como en el estudio de Escobar (171)

\subsubsection{Resultados del análisis de las redes sociales (índices globales) relacionados con los hábitos de salud.}

Al igual que en la literatura consultada se muestra que un bajo apoyo social es uno de los factores que se asocia a sintomatología depresiva en las personas mayores $(4,171)$, en la investigación realizada la depresión no la padecen el 87\% por lo que nuestros mayores tienen unas buenas relaciones sociales con los amigos.

La escasa importancia de los amigos (índice de diversidad de la red) sobre los síntomas depresivos se ha confirmado en el estudio de Leganés (4) pero no en el realizado en Barcelona (204). En este último el malestar psicológico está asociado con las escasas relaciones con los amigos (índice de diversidad de la red) mientras que no está asociado con la frecuencia de contacto con familiares (índice de vínculos familiares). Esta diferencia de resultados puede reflejar la transición que se está produciendo entre lo que ocurre en las zonas rurales o poblaciones urbanas de tamaño medio y grandes zonas urbanas, donde hay menor contacto intergeneracional y menor dependencia intrafamiliar. Igualmente se observa una relación inversa entre la depresión y la disponibilidad de apoyo emocional recibido y el rol del individuo en de acuerdo con otros estudios $(4,204)$, aunque no se demuestra esta asociación con el hecho de participar en actividades comunitarias $(4,178)$. 
Con la edad pierden fortaleza las redes sociales y los mecanismos psicosociales a excepción del apoyo emocional recibido que es mayor con la edad. El consumo de alcohol y tabaco se relaciona con una red social débil al igual que ocurre con las actividades comunitarias y el índice de la diversidad de la red, se explica por el bajo consumo de sustancias tóxicas debido a restricciones por razón de enfermedad (enfermedades cardiovasculares o cáncer) y consejo médico (238). Las personas con problemas de sueño tienen redes sociales más débiles tal como ocurre en el estudio de Costa et al. (249).

El aumento de la práctica de andar por lo menos una vez a la semana se relaciona con fuerte con las actividades comunitarias y la diversidad de la red como en el estudio de Escobar (171) más muy significativo con una media de 0,99. Existen estudios como el de Seeman et al. (270) con la teoría de la selectividad socioemocional (116) que explica que a pesar, de que las redes sociales disminuyen con la edad, el soporte emocional se mantiene o aumenta en épocas de crisis, como ocurre cuando la persona es dependiente según Gurung y Krause $(117,266)$, variable asociada con la edad. En España gracias a los flujos de solidaridad inter-generacional se observa que a partir de los 85 años aumenta la convivencia de padres e hijos después de haber tenido alguna enfermedad 0 discapacidad o de enviudar (246) incidiendo seguramente en el aumento del apoyo emocional recibido.

Los resultados de la investigación en cuanto a las relaciones sociales tienen significación similar al estudio de Lérida (220) ,en ambos existe relación .

Las personas que tiene una mala autopercepción de la salud presentan una menor diversidad de la red, es decir tienen un menor contacto con los amigos, caso que no es el caso de Castellón donde la población mayor tienen una buena autopercepción de la salud, por eso se relacionan bien con los amigos, y tienen unas buenas relaciones sociales, lo que no significa que cuando pierden la salud, la familia se ocupa de ellos, puesto que en nuestra cultura predominan los valores relacionados con la 
responsabilidad y la obligación intrafamiliar, y les que proporciona estos cuidados, y en estos casos, se relacionan con redes sociales débiles y peor salud percibida Arthur $(147,149)$

\subsubsection{Mecanismos psicosociales (índices globales) y su relación con hábitos de salud}

En el estudio todas las áreas relacionadas con las relaciones sociales a excepción del apoyo emocional recibido y el rol del individuo asociado a las personas con problemas de sueño tienen redes sociales más débiles tal como ocurre en el estudio Bandeen-Roche y Yao et al. $(250,251)$.

\subsubsection{Redes sociales (índices globales) y su relación con el estado de salud}

En nuestro estudio lo único que nos ha salido significativo en relación a los índices globales de las redes sociales y el estado de salud es la discapacidad instrumental que se asocia al tipo de educación recibido. Los estudios realizados sugieren que independiente de que la vida social de la persona mayor incluya contactos con familiares y amigos, esté basada en la participación en actividades comunitarias con una buena diversidad de la red y eso conlleva una vida activa con sensación de protagonismo que protege ante la discapacidad. El estudio EPESE (Established Populations for Epidemiolog y Sdudies of the Elderly) realizado en EEUU mostró que las redes sociales protegían de la discapacidad y ayudaban a recuperar la función (252). Estudios realizados en el norte de Europa describen que la diversidad de contactos y la elevada participación social predecían el mantenimiento de las ABVD en los mayores, según estudio de Avlund et al. (39). En España se observó que la diversidad de la red social y, especialmente, el índice de participación social, se asocia a un menor número de casos de discapacidad en las ABVD según estudio de Otero Puime et al. (4) al mismo tiempo que la diversidad de la red social resulta predictora de discapacidad según estudios de Otero y Escobar $(4,157)$. 


\subsubsection{Mecanismos psicosociales (índices globales ) relacionados con estados de salud}

Al igual que en la literatura consultada se muestra que un bajo apoyo social es uno de los factores que se asocia a sintomatología depresiva en las personas mayores $(4,171)$, en la investigación realizada la depresión no la padecen el $87 \%$ por lo que nuestros mayores tienen unas buenas relaciones sociales con los amigos. La escasa importancia de los amigos (índice de diversidad de la red) sobre los síntomas depresivos se ha confirmado en el estudio de Leganés (4) pero no en el realizado en Barcelona por Escobar (171). En este último estudio el malestar psicológico está asociado con las escasas relaciones con los amigos (índice de diversidad de la red) mientras que no está asociado con la frecuencia de contacto con familiares (índice de vínculos familiares). Igualmente se observa una relación inversa entre la depresión y la disponibilidad de apoyo emocional recibido y el rol del individuo en de acuerdo con otros estudios Otero y Diaz et al. $(4,204)$, aunque no se demuestra esta asociación con el hecho de participar en actividades comunitarias $(4,171)$.

Con la edad pierden fortaleza las redes sociales y los mecanismos psicosociales a excepción del apoyo emocional recibido que es mayor con la edad, además muy significativos con una media de 0,99. En estudio de Seeman et al. (154) con la teoría de la selectividad socioemocional que explica que a pesar, de que las redes sociales disminuyen con la edad, el soporte emocional se mantiene o aumenta en épocas de crisis, como ocurre cuando la persona es dependiente según Gurung y Krause $(113,246)$, variable asociada con la edad.

Las personas que tiene una mala autopercepción de la salud presentan una menor diversidad de la red, es decir tienen un menor contacto con los amigos, caso que no es 
el de Castellón donde la población mayor tienen una buena autopercepción de la salud, por eso se relacionan bien con los amigos y tienen unas buenas relaciones sociales, lo que no significa que, cuando pierden la salud, la familia se ocupa de ellos, puesto que en nuestra cultura predominan los valores relacionados con la responsabilidad y la obligación intrafamiliar, y les que proporciona estos cuidados, y en estos casos, se relacionan con redes sociales débiles y peor salud percibida Arthur $(147,149)$.

\subsection{Características del grado de fragilidad en función de las relaciones sociales}

Los resultados evidencian que las personas frágiles a pesar de tener una importante red familiar y de amigos (obtienen puntuaciones por encima de la media), la más significativa es el número de amigos con un $\mathrm{p}=0,001$ únicamente el $40 \%$ refirió no tener ningún amigo; cifras similares al estudio Envejecer en Leganés (4) y al de Lleida (220) aunque en otros estudios realizados las cifras son menores (41), destacando la pobre participación social en algunas actividades comunitarias así como la pobre vinculación social, mostrando dificultad para desarrollar roles sociales y ocupacionales que les proporcionen sentimientos de valía, de pertenencia a la comunidad y de identidad

El 87,6\% dice tener una persona especial en quien confiar (confidente), cifras algo más elevadas al estudio de Stevens (241) en nuestro estudio es la esposa/o la personas que más confían, seguida de las hijas y amigos.

Al analizar con mayor detalle la participación en actividades comunitarias se aprecia como las personas frágiles acuden menos a la plaza o a un lugar céntrico no es el caso de nuestro estudio que la mitad de la muestra acuden la plaza y donde menos acuden es a las asociaciones o clubs, teniendo un índice de fragilidad de un $74 \%$ y al hogar del pensionista, y las mujeres siguen acudiendo más a la iglesia, similar al estudio de Leganés y al estudio de Nuin (4) (220). En relación a la presencia o no de fragilidad según el rol del individuo en nuestro estudio es significativo, tenemos una media de frágiles de 0,9 . Se observa una relación inversa para todos los vínculos, aunque resulta más significativa para el rol del individuo en la vida de los amigos personas más frágiles 
tienen una mayor dificultad para establecer relaciones y participar en actividades comunitarias, lo que puede hacer que los datos muestren que a menor fortaleza de las relaciones sociales corresponda mayores índices de fragilidad según Sánchez (253), según los estudios de Nuin (220).

El hecho de que el sujeto juegue un papel activo le proporciona sentido y significado y le ayuda a permanecer activo mental y físicamente previniendo situaciones de fragilidad. Si observamos los diferentes componentes del índice de diversidad de la red como es el estar casado o con pareja la variable que se relaciona con la fragilidad, variable que ya se consideró anteriormente al analizar las características sociodemográficas de la fragilidad (apartado 6.6.1) y que se corresponde con los resultados señalados en otros estudio $(231,254)$.

El 87,6\% dice tener una persona especial en quien confiar (confidente), cifras algo más elevadas al estudio de Nuin y Stevens $(220,241)$ en nuestro estudio es la esposa/o la personas que más confían, seguida de las hijas y amigos.

Al analizar con mayor detalle la participación en actividades comunitarias se aprecia como las personas frágiles acuden menos a la plaza o a un lugar céntrico no es el caso de nuestro estudio que la mitad de la muestra acuden la plaza y donde menos acuden es a las asociaciones o clubs, teniendo un índice de fragilidad de un $74 \%$ y al hogar del pensionista, y las mujeres siguen acudiendo más a la iglesia, similar al estudio de Leganés y al estudio de Nuin $(4,220)$. En relación a la presencia o no de fragilidad según el rol del individuo en nuestro estudio es significativo, tenemos una media de frágiles de 0,9. Se observa una relación inversa para todos los vínculos, aunque resulta más significativa para el rol del individuo en la vida de los amigos personas más frágiles tienen una mayor dificultad para establecer relaciones y participar en actividades comunitarias, lo que puede hacer que los datos muestren que a menor fortaleza de las relaciones sociales corresponda mayores índices de fragilidad según Sánchez (253), según los estudios de Nuin (220). 
Al analizar con mayor detalle la participación en actividades comunitarias se aprecia como las personas frágiles acuden más a la plaza o a un lugar céntrico, pero lo hacen con menor frecuencia, al hogar del pensionista, a la iglesia y menor proporción forman parte de una asociación o club cultural.

Respecto a las redes sociales y los índices globales según la fragilidad en la población mayor de Castellón se puede apreciar que hay una prevalencia de fragilidad de un 13,7\%, más elevada que las obtenidas por Fried de un 6,9\% (215) y Ávila-Funes de un 7\% (216).

La prevalencia de fragilidad en el estudio de Santos-Eggimann (255) realizado en diez países europeos fue del $17 \%$ y en uno español, en la ciudad de Albacete la prevalencia fue superior 16,9\% (198). En España todavía son pocos los estudios que han aplicado los criterios de fragilidad, destacando en Madrid (231), Lérida (220) y Toledo (256) en los que la prevalencia resultó ser del 10,3\%, 9,6\% y 8,4\% respectivamente, comparable a estos está el estudio Europeo de Syddall et al. (257) cuya prevalencia es de 6,5\%.

Estudios realizados América del Sur, Alvarado y Varela $(254,258)$ la prevalencia de fragilidad es $11,0 \%$ y $14,9 \%$ respectivamente y en el estudio de Taiwan (239) con una prevalencia $11 \%$.Otro de los aspectos a considerar es el porcentaje de pacientes prefrágiles que en nuestro estudio es $52,7 \%$ y frágiles $6,3 \%$ y el sexo predominante es el femenino, similar al del estudio de Ávila-Funes (216). Esta cifra es importante ya que probablemente dichos participantes en poco tiempo serán frágiles. 
Análisis de las relaciones sociales y la fragilidad en las personas mayores de 75 años residentes en Castellón de la Plana

\subsection{Asociación entre las relaciones sociales y la fragilidad en presencia de características sociodemográficas, estado y hábitos de salud.}

Índice de apoyo emocional recibido es el único componente de las relaciones sociales que se relaciona con la fragilidad y después de ajustar por el sexo y estado y hábitos de salud (sexo y el estado nutricional) permanecen significativamente asociados. Si bien es cierto, que en un corte transversal puede llevar a una confusión de los datos y requería de llevar a cabo otros estudios para poder confirmar dichos resultados como podría ser haciendo un estudio longitudinal $(123,259)$.

\subsection{Limitaciones del estudio}

La captura de la muestra se realizó a partir de los datos incluidos en la red del sistema de salud, por lo cual no incluía a todas las personas que existen y que no están incluidas en este sistema.

Es previsible que estas pérdidas sean mínimas, dado el origen demográfico la muestra. El presente estudio tiene como centro de referencia para acercarse a la población de estudio, los Centros de Atención Primaria al que pertenece el sujeto, y así obtener un mayor grado de aceptación de los individuos incluidos en ella.

También suele ser frecuente que aparezcan sujetos, en este grupo, con problemas cognitivos y que pueden dificultar la respuesta al cuestionario planteado. Pero en estos casos, para facilitar esta cumplimentación del cuestionario de estudio, está prevista la presencia del cuidador familiar, de todas forma sigue siendo una limitación poblacional. Al igual que al excluir a la población institucionalizada.

Existe otra limitación y es el tipo de estudio que al ser transversal impide establecer la relación entre las variables. Otra limitación es el tipo de análisis al no haberse incluido otro tipo de análisis que permita establecer relaciones sociales y la fragilidad están asociados de forma independiente con los factores sociodemográficos, estado y hábitos de salud. 


\subsection{Futuras líneas de investigación}

El proyecto de la investigación presentada, está enmarcada en un proyecto de colaboración entre la Universitat de Lleida y la Universitat Jaume I. Se ha utilizado el mismo instrumento de recogida de datos (la encuesta FRALLE) y el objetivo inicial del equipo de investigación es conocer las características de la población de Castellón y analizar las dimensiones que afectan a los mayores y están relacionadas con la fragilidad.

En el futuro se prevé diseñar líneas de investigación y diseñar intervenciones para cada una de las dimensiones estudiadas y actuar sobre la población mayor y tratar de paliar en la medida de lo posible la fragilidad y prevenir la aparición de la misma con intervenciones en la pre-fragilidad. 



\section{CONCLUSIONES}

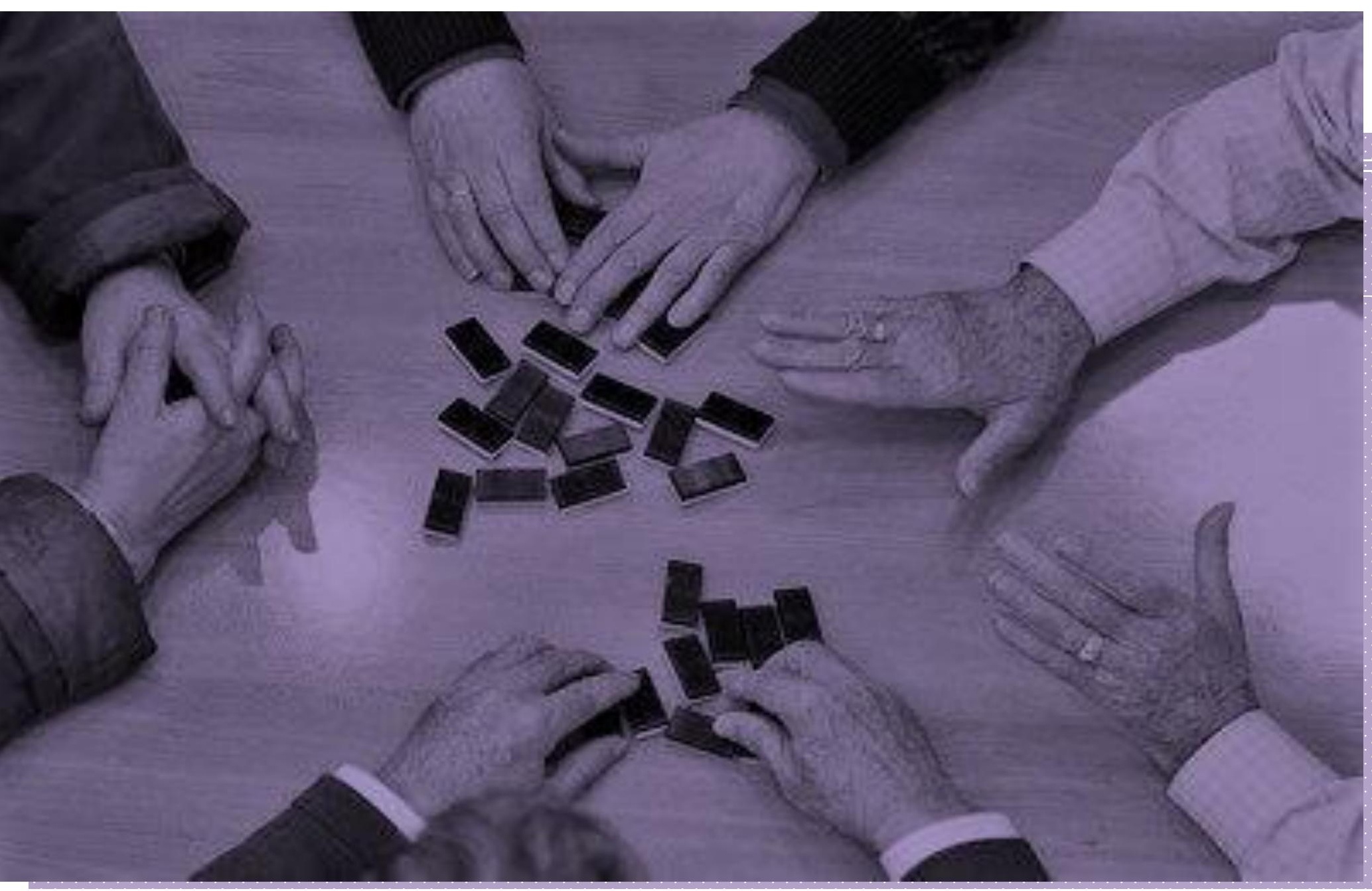





\section{Conclusiones.}

En cuanto a la salud de las personas mayores podemos apreciar que, entre las características de la población estudiada, los factores de mayor significación estadística son: el sexo predominante, el estado civil, convivencia e ingresos mensuales, la frecuencia de caminar, síntomas depresivos, capacidad instrumental, autopercepción de la salud, consumo de medicamentos, fragilidad y deterioro cognitivo. En el sexo femenino, estos factores tienen una mayor influencia.

Los factores más fuertemente relacionados con las relaciones sociales y la fragilidad, como son la estructura y los vínculos de la red social, tienen una mayor diversidad de red y el apoyo emocional dentro de esta. La de mayor significación estadística es la de los amigos, y que pueden confiar con un confidente, que generalmente suele ser esposo/a o hija, dato muy importante para las relaciones sociales y para prevenir la fragilidad.

En cuanto a la participación en actividades comunitarias a las personas mayores de Castellón, donde más suelen ir a ambos sexos es a la plaza, aún siendo personas con un índice de pre-fragilidad y lo de más significación estadística es que la mayoría no forman parte de ningún club y esta muestra, sí que es frágil.

En el modelo final del análisis multivariante, además de la pobre significación del apoyo emocional recibido, las variables independientes asociadas a la fragilidad resultaron ser el sexo y el estado nutricional. 


\section{BIBLIOGRAFÍA}

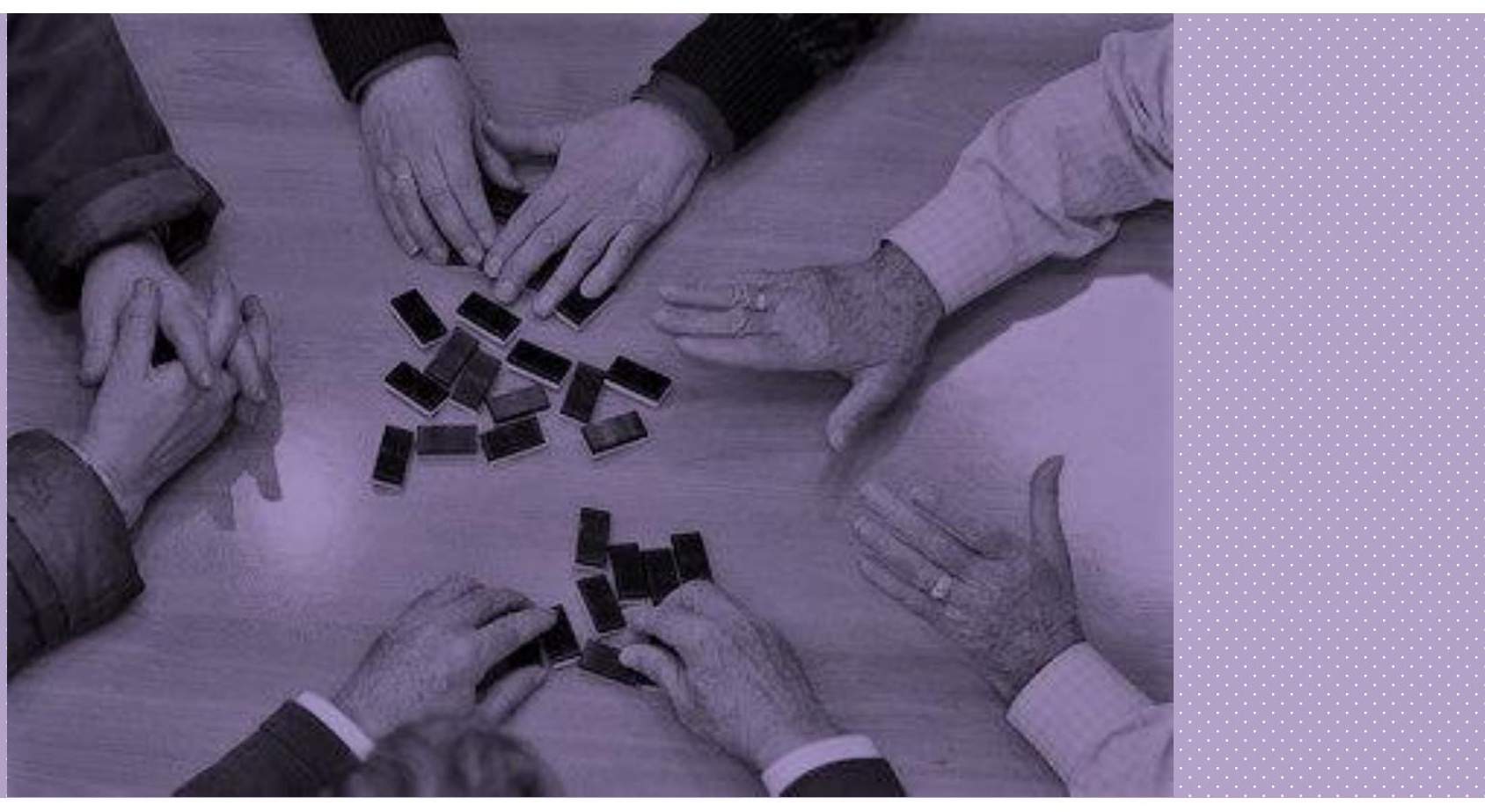





\section{Bibliografía}

1. OMS $\mid 10$ datos sobre el envejecimiento y la salud. WHO. World Health Organization; 2015.

2. OMS | Informe mundial sobre la discapacidad. WHO. 2011;

3. García González J. Contributions of cardiovascular mortality to Spanish life expectancy from 1980 to 2009. Rev española Cardiol. 2013;66(11):848-53.

4. Otero Puime A, Zunzunegui Pastor M, Béland F, Rodríguez Laso A, García de Yébenes J, Prous M. Relaciones sociales y envejecimiento saludable. Vol. 9, Fundación BBVA. 2006. p. 1-111.

5. Marín Larraín P. Envejecimiento Saludable. Universidad Pontificia Católica de Chile. 2015.

6. Villar F, López O, Celdrán M. La generatividad en la vejez y su relación con el bienestar: ¿Quién más contribuye es quien más se beneficia? An Psicol. 2013;29(3):897-906.

7. Antonucci TC. Hierarchical mapping technique. Generations. 1986;10(4):10-3.

8. Bass S, Caro F. Productive aging: A conceptual framework. Eur J Investig Heal. $2001 ; 37-80$.

9. Rodríguez García M, Bori Savigne D, Obre Rodríguez O, Rodríguez Arias O. Algunos aspectos clinicos epidemiológicos de la depresión en la ancianidad. Mesisan [Internet]. 2009;13(5). Available from: http://bvs.sld.cu/revistas/san/vol13_5_09/san01509.pdf

10. Arias Orduña A V, Iglesias-Parro S. La generatividad como una forma de envejecimiento exitoso. Estudio del efecto mediacional de los vínculos sociales. Eur J Investig Heal Psychol Educ. 2015;5(1):109-20.

11. Torres Igdany R, Castillo Herrera J. El envejecimiento humano activo y saludable, un reto para el anciano, la familia, la sociedad. Revista Cubana de Investigaciones Biomédicas. 2011;30(3):454-9.

12. House J, Robbins $\mathrm{C}$, Metzner $\mathrm{H}$. The association of social relation ships and 
activities with mortality: prospective evidence from the tecumseh community health study. Am J Epidemiol. 1982;116 (1):123-40.

13. Blazer D. Social support and mortality in an elderly community population. Am J Epidemiol. 1982;115(5):684-94.

14. Berkman L, Syme S. Social networks, host resistance, and mortality: a nine-year follow-up study of Alameda County residents. Am J Epidemiol. 1979;109(2):186204.

15. Lemos Giralde S, Fernandez Hermida JR. Redes de soporte social y salud. Psicothema. 1990;2(2):113-35.

16. Due P, Holstein B, Lund R, Modvig J, Avlund K. Social relations: network, support and relational strain. Soc Sci Med. 1999;48(5):661-73.

17. Bortz W. A conceptual framework of frailty: a review. journals Gerontol. 2002;57(5):M283-8.

18. Sáenz de Miera F. El adulto mayor. Universidad de las Américas Puebla. 2013.

19. Martín Méndez L, Melgar borrego A, Vanrell Herrero P, García Olmos L. Atención al anciano. Área de atención a la comunidad. Medico. 2003;874:37-48.

20. Llanes Betancourt C. Evaluación funcional y anciano frágil. Rev Cubana Enferm. 2008;24(2):0-0.

21. Gregorio Gil P, Gonzalez Garcia P, Gutierrez Rodriguez J, Verdejo Bravo C. Tratado de geriátria para residentes. Sociedad E. Madrid; 2006. 782 p.

22. Rivadeneira L, Villa M. El proceso de envejecimiento de la población de América Latina y el Caribe: una expresión de la transición demográfica. Eúphoros. 2003;6:87-122.

23. Rinessi J, Gomez S, Lecuna N. Eventos celulares en el envejecimiento. Rev posgrado la Catedra Vila Med. 2000;100:21-3.

24. Strehler B. Ageing: concepts and theories. Lect Gerontol. 1982;1-7.

25. Fernadez-Mayoralas G, Rojo-Perez F, Pietro-Flores M, Forjaz M, RodriguezRodriguez V, Montes de Oca V, et al. Revisión conceptual del envejecimiento activo en el contexto de otras formas de vejez. XIV Congreso Nacional de Ploblación, AGE. 2014;14. 
Análisis de las relaciones sociales y la fragilidad en las personas mayores de 75 años residentes en Castellón de la Plana

26. Baltes Margret M, Carstensen L. The Process of Successful Ageing. Ageing Soc. 1996;16(4):397-422.

27. Vaillant G, Vaillant C. Natural History of Male Psychological Health, XII: A 45-Year Study of Predictors of Successful Aging at Age 65. Am J Psychiatry. $1990 ; 147(1): 31-7$.

28. Abdullah B, Wolbring G. Analysis of Newspaper Coverage of Active Aging through the Lens of the 2002 World Health Organization Active Ageing Report: A Policy Framework and the 2010 Toronto Charter for Physical Activity: A Global Call for Action. Int J Environ Res Public Health. 2013;10(12):6799-819.

29. Fernández-Ballesteros García R, Zamarrón Casinello MD, López Bravo MD, Molina Martínez MÁ, Díez Nicolás J, Montero López P. Envejecimiento con éxito: criterios y predictores. Psicothema. 2010;22(Número 4):641-7.

30. García AJ, García MÁ. New ways for active aging: Quality of Life and Physical Activity from a Psychosocial perspective Nuevas formas de envejecer activamente: Calidad de Vida y Actividad Física desde una perspectiva Psicosocial Editorial. $6(2): 1-5$.

31. Fernández-Ballesteros R. Envejecimiento saludable. In: Universidad Autónoma de Madrid, editor. Congreso sobre EnvejecimientoLa Investigacion en España. Madrid; 2011. p. 1-6.

32. García AJ, García MÁ. Nuevas formas de envejecer activamente: Calidad de Vida y Actividad Física desde una perspectiva Psicosocial. Escritos Psicol - Psychol Writings. 2013;6(2):1-5.

33. García Escribano R. El Envejecimiento Activo: Programa en competencia social con personas mayores. Valladolid; 2014.

34. Villar F. Desarrollo Adulto y Envejecimiento desde el punto de vista Sociocontextual. In: Psicología Evolutiva y Psicología de la Educación. 2003. p. 1110.

35. Limón MR, Ortega MC. Envejecimiento activo y mejora de la calidad de vida en adultos mayores. Rev Psicol y Educ. 2011;1(6):225-38.

36. Villar F. Hacerse bien haciendo el bien: la contribución de la generatividad al estudio del buen envejecer. Inf Psicol. 2013;0(104):39-56. 
Análisis de las relaciones sociales y la fragilidad en las personas mayores de 75 años residentes en Castellón de la Plana

37. De Juanas Oliva A, Limón Mendizábal M, Navarro Asencio E. Análisis del bienestar psicológico, estado de salud percibido y calidad de vida en personas adultas mayores. Rev Interuniv. 2013;22:153-68.

38. Berkman L, Glass T. Social integration, social networks, social support and health. Soc Epidemiol New Yor. 2000;7:137-73.

39. Avlund K, Lund R, Holstein B, Due, PSakari-Rantala R, Heikkinen R. The impact of structural and functional characteristics of social relations as determinants of functional decline. journals Gerontol. 2004;59(1):S44-51.

40. García Vicente S. Envejecimiento Activo y Saludable. Netdoctor. 2015. p. 3.

41. OMS. Healthy aging. In Copenhagen. Who [Internet]. 1990; Available from: http://www.euro.who.int/en/health-topics/Life-stages/healthy-ageing

42. Fries J. Aging Well. Addison-Wesley. New York; 1989.

43. Fernandez Ballesteros R. Psicología del envejecimiento: crecimiento y declive. Universidad autonoma de Madrid; 1996.

44. Rowe J, Kahn R. Successful aging. Gerontologist. 1997;37(4):433-40.

45. Salud O mundial de la. El Abrazo Mundial. OMS. 2001. p. 66.

46. Mazzeo R, Cavanagh P, Evans W, Fiatarone M, Hagberg J, McAuley E, et al. Medicine and science in sports and exercise. Med Sci Sport Exerc. 1998;30(6):992-1008.

47. Zamarrón M, Cassinello M. Envejecimiento activo. Infocop. 2007;34:7-9.

48. Salud O mundial de la. Active Aging. Geneva. WHO. 2002;

49. Abizanda Soler P, Rodriguez Mañas L. Tratado de medicina Geriátrica. Elsevier; 2014. 752 p.

50. Rozo Mogollón S. Problemas de salud y sus determinantes. Rev Cienc Salud. 2005;3(1):62-77.

51. Ramos Domínguez B. Enfoque conceptual y de procedimiento para el diagnóstico o análisis de la situación de salud. Rev Cuba Salud Pública. 2006;32(2):164-70.

52. Lalonde M. A more positive approach to health promotion. Can Nurse. 1974;70(1):19-20. 
Análisis de las relaciones sociales y la fragilidad en las personas mayores de 75 años residentes en Castellón de la Plana

53. Ministerio de Sanidad SS e I. Documento de consenso sobre prevención de fragilidad y caídas en la persona mayor Estrategia de Promoción de la Salud y Prevención en el SNS. 2014;

54. Garcia Abellan A, Pujol Rodriguez R. Un perfil de personas mayores en España, 2016. Indicadores estadísticos básicos. Madrid: Informes Envejecimiento en red; 2016. p. 22.

55. Eurostat E. Population structure and ageing [Internet]. Office of the European Union. 2015. p. 180. Available from: http://ec.europa.eu/eurostat/statisticsexplained/index.php/Population_structure_and_ageing

56. IV Plan de Salud de la Comunidad Valenciana 2016-2020. Conselleria de Sanitat $\mathrm{i}$ Salut Publica. 2016. p. 238.

57. Prieto Ramos O. Gerontología y Geriatría. Breve resumen histórico. Resumed. $1999 ; 12(2): 51-4$.

58. Anzola Pérez E. Enfermería gerontológica: Conceptos para la práctica. Organ Panam la Salud. 1993;

59. Varela Pinedo L, Saavedra Ortiz P, Chavez Jimeno H. Características de los trabajos científicos en geriatría y gerontología. Rev Med Hered. 2003;14(1):18-25.

60. Garcia Hernande M. SEEGG - Sociedad Española de Enfermería Geriátrica y Gerontológica. Enfermería Global. 2004. p. 4.

61. Boletin Oficial del Estado. Programa formativo de la especialidad de Enfermería Geriátrica. Orden SAS/3225/2009 de 13 de noviembre. 2009. p. 101976-92.

62. Sanhueza Parra M, Castro Salas M, Merino Escobar JM. Adultos mayores funcionales: un nuevo concepto en salud. Cienc y enfermería. 2005;11(2):17-21.

63. Alonso Galbán P, Sansó Soberats F, Navarro Díaz-Canel A, Carrasco García M, Carrasco Oliva T. Envejecimiento poblacional y fragilidad en el adulto mayor. Rev Cuba Salud Pública. 2007;33(1).

64. Salado Morales L. La Fragilidad en el anciano. Universidad de Cantabria; 2014.

65. Maestro Casteblanque E, Albert Cuñat V. ¿Quiénes son ancianos frágiles-ancianos de riesgo? Estudio en personas mayores de 65 años del Área Sanitaria de Guadalajara (II). Med Gen. 2002;45:443-59. 
Análisis de las relaciones sociales y la fragilidad en las personas mayores de 75 años residentes en Castellón de la Plana

66. Palacios A. El modelo social de discapacidad: orígenes, caracterización y plasmación en la Convencion Inernacional sobre los Derechos de las personas con Discapacidad. Cermi. CINCA, editor. Madrid; 2008. 524 p.

67. Raggi A, Corso B, Minicuci N, Quintas R, Sattin D, De Torres L, et al. Determinants of Quality of Life in Ageing Populations: Results from a Cross-Sectional Study in Finland, Poland and Spain. PLoS One. 2016;11(7).

68. Salgado-de Snyder VN, Wong R. Género y pobreza: determinantes de la salud en la vejez. Salud Publica Mex. 2007;49(4):s515-21.

69. Abellán García A, Pujol Rodríguez R. Un perfil de las personas mayores en España, 2015. Indicadores estadíscos básicos. Informes Envejecimiento en red; 2015. p. 27.

70. Pellegrino A. La migración internacional en América latina y el Caribe. Tendencias y perfiles migrantes. Santiago de Chile: United Nations Publications; 2003. 39 p.

71. Litwin H. Social network type and morale ind old age. Gerontologist. 2001;41(4):516--524.

72. O’Reilly P. Methodological isuues in social support and social networt research. Soc Sci Med. 1988;26(8):863-73.

73. Pando M. Conceptualización del apoyo social y las redes de apoyo social. Rev Investig en Psicol. 2014;16(1):233-45.

74. Guzmán J, Huenchuán S, Montes de Oca Zavala V. Marco teórico conceptual sobre redes de apoyo social de las personas mayores. Notas Poblacion. 2003;20.

75. Antonucci TC, Akiyama H. An examination of sex differences in social support among older men and women. Sex Roles. 1987;17(11-12):737-49.

76. Bosse R, Aldwin C, Levenson M, Spiro A, Mroczek D. Change in Social Support After Retirement: Longitudinal Findings From the Normative Aging Study. J Gerontol. 1993 Jul;48(4):210-7.

77. Miller S, Cavanaugh J. The Meaning of Grandparenthood and Its Relationship to Demographic, Relationship, and Social Participation Variables. J Gerontol. 1990;45(6):244-6. 
78. Del Valle GómezG, Coll i Planas L. Relaciones sociales y envejecimiento saludable. $1^{\text {a }}$ edición. Instituto Lenvellimentde la Universitat Autónoma de Barcelona, editor. Barcelona; 2011. 62 p.

79. Martín Ortiz JD, Sánchez Pérez MJ, Sierra JC. Estilos de afrontamiento y apoyo social: su relación con el estado emocional en pacientes de cáncer de pulmón. Ter psicol. 2003;21(1):29-37.

80. Bazo M, Domínguez-Alcón C. Los cuidados familiares de salud en las personas ancianas y las políticas sociales. Reis. 1996;73:43-56.

81. Dahlberg L, McKee KJ. Correlates of social and emotional loneliness in older people: evidence from an English community study. Aging Ment Health. 2014 May;18(4):504-14.

82. Zueras Castillo P. Salud, espacios y modos de vida en la vejez. Universitat Autònoma de Barcelona,; 2014.

83. Walker A. Programa britanico de investigación para el incremento de la calidad de vida en la vejez. Rev Esp Geriatr Gerontol. 2006;41(2):49-56.

84. Tai-Yin W, Wei-Chu C, Kuan-Liang W. Quality of life QOL among community dwelling older people in Taiwan measured by the CASP-19, an index to capture QOL in old age. Arch Gerontol Geriatr. 2013;57(2):143-50.

85. Layte R, Sexton E, Savva G. Quality of Life in Older Age: Evidence from an Irish Cohort Study. J Am Geriatr Soc. 2013 May;61(s2):S299-305.

86. Lustosa R, Melo D, Do Maria P, Carmo E, Valdiney Veloso G, HermessonMedeiros Silva D. O Efeito do Estresse na Qualidade de Vida de Idosos: O Papel Moderador do Sentido de Vida. Psicol Reflexão e Crítica. 2012;26(2):222-30.

87. Rodriguez-Laso A, Zunzunegui M, Otero A, Blazer D, Seeman T, Berkman L, et al. The effect of social relationships on survival in elderly residents of a Southern European community: a cohort study. BMC Geriatr. 2007;7(1):19.

88. Seeman TE. Health promoting effects of friends and family on health outcomes in older adults. Am J Health Promot. 2000;14(6):362-70.

89. Kiecolt-Glaser JK, Mcguire L, Robles TF, Glaser R. Psychoneuroimmunology and Psychosomatic Medicine: Back to the Future. Psychosom Med. 2002;64:15-24. 
Análisis de las relaciones sociales y la fragilidad en las personas mayores de 75 años residentes en Castellón de la Plana

90. TarboxSI., Pogue-Geile MF. A multivariate perspective on schizotypy and familial association with schizophrenia: A review. Clin Psychol Rev. 2011;31(7):1169-82.

91. Kenneth Teck Kiat L, Rongjun Y. Aging and wisdom: age-related changes in economic and social decision making. Front Aging Neurosci. 2015;7(120):1-11.

92. Litwak E. Helping the elderly : the complementary roles of informal networks and formal systems. New York: Guilford Press; 1985. 306 p.

93. Antonucci T, Ajrouch K, Birditt K. The convoy model: explaining social relations from a multidisciplinary perspective. Gerontologist. 2014;54(1):82-92.

94. Puga D, Rosero-Bixby L, Glaser K, Castro T. Red social y salud del adulto mayor en perspectiva comparada: Costa Rica, España e Inglaterra. Población y Salud en Mesoamérica. 2007;5:1-21.

95. Wray L, Blaum C. Explaining the Role of Sex on Disability: A Population-Based Study. Gerontologist. 2001;41(4):499-510.

96. Torres Pereira J. Aspectos psicológicos en cuidadores formales de ancianos carga y afrontamiento del estrés : (un estudio en población sociosanitaria) : memoria para optar al grado de doctor. 2010.

97. Cassel J. The contribution of the social environment to host resistance. The Fourth Wade Hampton Frost Lecture. 1976. Am J Epidemiol. 1995;141(9):798-814.

98. Dolbier C, Steinhardt M. The Development and Validation of the Sense of Support Scale. Behav Med. 2000 Jan;25(4):169-79.

99. Chou C, Hirschmann K, Fortin A, Lichstein P. The Impact of a Faculty Learning Community on Professional and Personal Development. Acad Med Assoc Am Med Coll. 2014;89(7):1051-6.

100. Cohen S, Wills TA. Stress, Social Support, and the Buffering Hypothesis. Psychol Bull Cassel. 1985;98(31):310-57.

101. Alonso Fachado A. Influencia del apoyo social en el control metabólico de la diabetes mellitus. Facultad de Medicina y Odontologia Santiago Compostela; 2008.

102. García-González J, Rodríguez-Rodríguez P. «Rompiendo Distancias»: un programa integral para prevenir y atender la dependencia de las personas mayores en el medio rural. Rev Esp Geriatr Gerontol. 2005;40(1):22-33. 
Análisis de las relaciones sociales y la fragilidad en las personas mayores de 75 años residentes en Castellón de la Plana

103. McDonald J. Community Participation in an Australian Retirement Village. Aust J Ageing. 1996;15(4):167-71.

104. Montes de Oca Zavala V. Redes comunitarias, género y envejecimiento:

participación, organización y significado de las redes de apoyo comunitario entre hombres y mujeres adultos mayores: la experiencia de la Colonia Aragón en la Delegación Gustavo A. Madero, Ciudad de México. Madero de Mexic: UNAM; 2005. $161 \mathrm{p}$.

105. Connidis I, McMullin J. Getting out of the House: The Effect of Childlessness on Social Participation and Companionship in Later Life. Can J Aging. 1992;11(4):370-86.

106. Botero de Mejía B, Pico Merchán M. Calidad de vida relacionada con la salud (CVRS) en adultos mayores de 60 años: una aproximación teórica. Hacia la Promoción la Salud. 2007;12:11-24.

107. Abad Gómez H. Envejecer nos "toca" a todos. Unniversidad de Antioquia. Medellín; 2002.

108. Matsubayashi K, Wada T, Okumiya K, Fujisawa M, Taoka H, Kimura S, et al. Comparative study of quality of life in the elderly between in Kahoku and in Yaku. Japanese J Geriatr. 1994;31(10):790-9.

109. Céspedes A. Influencia de los factores socioeconómicos en la pérdida de autonomía de los adultos mayores costarricenses entre los 65 y 80 años. Costa Rica; 1987.

110. Tobiasz-Adamczyk B, Brzyska M, Woźniak B, Kopacz M. The current state and challenges for the future of health promotion in Polish older people. Int $\mathrm{J}$ Public Health. 2009;54(5):341-8.

111. Rook K. Social Networks in Later Life: Weighing Positive and Negative Effects on Health and Well-Being. Curr Dir Psychol Sci. 2015;24(1):45-51.

112. Carstensen LL. Selectivity theory: Social activity in life-span context. Annu Rev Gerontol Geriatr. 1991;11:195-217.

113. Gurung R, Taylor S, Seeman T. Accounting for Changes in Social Support Among Married Older Adults: Insights From the MacArthur Studies of Successful Aging. Psychol Aging. 2003;18(3):487-96. 
114. Nocon A, Pearson M. The roles of friends and neighbours in providing support for older people. Ageing Soc. 2000;20(3):341-67.

115. Walker R HJ. Places and health: A qualitative study to explore how older women living alone perceive the social and physical dimensions of their neighbourhood. Soc Sci Med. 2007;65(6):1154-65.

116. Krause B, Bennett J. Tracking changes in social relations throughout late life. journals Gerontol. 2007;62(2):S90-9.

117. Nilsson C, Avlund K, Lund R. Social inequality in onset of mobility disability among older Danes: the mediation effect of social relations. J Aging Health. 2010;22(4):522-41.

118. Field D. Continuity and change in friendships in advanced old age: findings from the Berkeley older generation study. Int J Aging Hum Dev. 1999;48(4):325-46.

119. Berkman L, Vaccarino V, Seeman T. Gender differences in cardiovascular morbidity and mortality: The contribution of social networks and suppor. Ann Behav Med. 1993;15(2-3):112-8.

120. Shumaker B, Hill D. Gender differences in social support and physical health. Heal Psychol. 1991;10:102-11.

121. Antonucci T, Akiyama $\mathrm{H}$. Social networks in adult life and a preliminary examination of the convoy model. J Gerontol. 1987;42(5):519-27.

122. Gurung RA, Taylor SE, Seeman TE. Accounting for changes in social support among married older adults: insights from the MacArthur Studies of Successful Aging. Psychol Aging. 2003 Sep;18(3):487-96.

123. Vivaldi F, Barra E. Bienestar Psicológico, Apoyo Social Percibido y Percepción de Salud en Adultos Mayores. Ter psicológica. 2012;30(2):23-9.

124. Unger JB, McAvay G, Bruce ML, Berkman L, Seeman T. Variation in the impact of social network characteristics on physical functioning in elderly persons: MacArthur Studies of Successful Aging. journals Gerontol. 1999;54(5):S245-51.

125. Shye D, Mullooly J, Freeborn D, Pope C. Gender differences in the relationship between social network support and mortality: a longitudinal study of an elderly cohort. Soc Sci Med. 1995;41(7):935-47. 
126. Krause N, Borawski-Clark E. Social Class Differences in Social Support Among Older Adults. Gerontol. 1995;35(4):495-508.

127. Ajrouch K, Blandon A, Antonucci T. Social networks among men and women: the effects of age and socioeconomic statu. J Gerontol B Psychol Sci Soc Sci. 2005;60(6):S311-7.

128. Broese van Groenou M, Van Tilburg T. Network size and support in old age: Differentials by socio-economic status in childhood and adulthood. Ageing Soc. 2003;23:625-45.

129. Merrill D, Elderly Parents C. Juggling Work, Family and Caregiving in Middle Class and Working Families. Auburn Hou. wesport. Connecticut; 1997. 248 p.

130. York Cornwell E, Waite L. Social disconnectedness, perceived isolation, and health among older adults. J Health Soc Behav. 2009;50(1):31-48.

131. Borja Tapia PE. Autopercepción y percepción familiar de la calidad de vida del adulto mayor. ER12, La Victoria, 2015-2016. Ambato-Ecuador; 2016.

132. Abades Porcel M, Rayón Valpuesta E. El envejecimiento en España:¿ un reto o problema social? Gerokomos. 2012;23(4):151-5.

133. Esteban Arbués A, Herves Carrasco L. Arteterapia para personas mayores [Internet]. Asanart. 2016. Available from: 571b2f3f08ae6eb94d0d1f6d.pdf

134. Giles L, Metcalf P, Glonek G, Luszcz M, Andrews G. The effects of social networks on disability in older Australians. J Aging Health. 2004;16(4):517-38.

135. Baquero M. Descriptive study of behavioural didorders in mild cognitive impairment. Rev Neurl. 2004;38(4):323-6.

136. Lázaro-Del Nogal M, Ribera-Casado J. Síndrome confusional (delirium) en el anciano. Psicogeriatria. 2009;1(4):209-21.

137. Miguelena Torrado N. Programa de salud para cuidadores de personas con Enfermedad de Alzheimer y trastornos de conducta. Universidad Pública de Navarra. Navarra; 2015.

138. Ministerio de Sanidad SS e I. Encuesta Nacional de Salud 2011-2012 [Internet]. Encuesta Nacional de Salud. 2013. Available from: http://www.ine.es/dyngs/INEbase/es/operacion.htm?c=Estadistica_C\&cid=1254736 $176783 \&$ menu $=$ resultados\&idp $=1254735573175$ 
139. Eng PM, Rimm E, Fitzmaurice G, Kawachi I. Social Ties and Change in Social Ties in Relation to Subsequent Total and Cause-specific Mortality and Coronary Heart Disease Incidence in Men. Am J Epidemiol. 2002;155(8):700-9.

140. Losada A, Alvarez Strauch M. Síntomas depresivos en adultos mayores de 65 años. Influencia del vivir solo o acompañado. Vol. 1, Neurama. 2014. p. 14.

141. López A, Calero MD. Predictors of cognitive decline in the elderly. Rev española Geriatr y Gerontol. 2009;44(4):220-4.

142. Chi-Hua Y, Chih-Jung Y, Cheng-Ching W, Wen-Chun L, Al. E. Determinants of cognitive impairment over time among the elderly in Taiwan: results of the national longitudinal study. Arch Gerontol Geriatr. 2010;50(1):S53-7.

143. Fauth E, Schwartz S, Tschanz J, Østbye T, Corcoran C, Norton M. Baseline disability in activities of daily living predicts dementia risk even after controlling for baseline global cognitive ability and depressive symptoms. Int J Geriatr Psychiatry. 2013;28(6):597-606.

144. Fratiglioni L, Wang HX, Ericsson K, Maytan M, Winblad B. Influence of social network on occurrence of dementia: a community-based longitudinal study. Lancet. 2000;355(212):1315-9.

145. Zunzunegui M, Alvarado B, Del Ser T, Otero A. Social networks, social integration, and social engagement determine cognitive decline in community-dwelling Spanish older adults. journals Gerontol. 2003;58(2):S93-100.

146. Gutierrez Robledo LM. El proceso de envejecimiento. Politicas de atención integral a la tercera edad en America Latina. 1995;45-54.

147. Healter A. Depression, isolation, social support and cardiovascular disease in older adulto. J Cardiovasc Nursin. 2006;21(5):S2-7.

148. González Puga M, Abellán García A. El proceso de discapacidad. Un análisis de la Encuesta sobre discapacidades, deficiencias y estado de salud. Pfizer F, editor. Consejo Superior de Investigaciones Científica. Alcobendas (Madrid); 2004. 210 p.

149. Puga D. La dependencia de las personas con discapacidad:entre lo sanitario y lo social, entre lo privado y lo público. Rev Esp Salud Pública. 2005;79:327-30. 
Análisis de las relaciones sociales y la fragilidad en las personas mayores de 75 años residentes en Castellón de la Plana

150. Beydoun M, Popkin B. The impact of socio-economic factors on functional status decline among community-dwelling older adults in China. Soc Sci Med. 2005;60(9):2045-57.

151. Mendes de Leon CF, Gold D, Glass TA, Kaplan L, George LK. Disability as a function of social networks and support in elderly African Americans and Whites: the Duke Epese 1986--1992. journals Gerontol. 2001;56(3):S179-90.

152. Avlund K, Lund R, Holstein B, Due P. Social relations as determinant of onset of disability in aging. Arch Gerontol Geriatr. 2004;38(1):85-99.

153. Guzmán J, Huenchuan S, MontesdeOca V. Redes de apoyo social de personas mayores:marco téorico conceptual. In: Congreso Internacional de Americanistas. Santiago de Chile; 2003. p. 20.

154. Seeman TE, Bruce ML, McAvay GJ. Social network characteristics and onset of ADL disability: MacArthur studies of successful aging. journals Gerontol. 1996;51(4):S191-200.

155. Escobar-Bravo M, Puga-González D, Martín-Baranera M. Protective effects of social networks on disability among older adults in Madrid and Barcelona, Spain, in 2005. Arch Gerontol Geriatr. 2012;54(1):109.

156. Avlund K, Damsgaard MT, Osler M. Social position and functional decline among non-disabled old men and women. Eur J Public Health [Internet]. 2004 Jun [cited 2016 Aug 17];14(2):212-6. Available from: http://www.ncbi.nlm.nih.gov/pubmed/15230514

157. Escobar Bravo MA, Puga D, Martín M. Asociaciones entre la red social y la discapacidad al comienzo de la vejez en las ciudades de Madrid y Barcelona en 2005. Rev Esp Salud Pública. 2008;82(6):637-51.

158. Michael Y, Berkman L, Colditz G. Living arrangements, social integration, and change in functional health status. Am J Epidemiol. 2001;15(153(2)):123-31.

159. Bennett K. Social engagement as a longitudinal predictor of objective and subjective health. Eur J Ageing. 2005;2:48-55.

160. Waidmann T, Liu K. Disability Trends Among Elderly Persons and Implications for the Future. Journals Gerontol. 2000;55(5):S298-307. 
Análisis de las relaciones sociales y la fragilidad en las personas mayores de 75 años residentes en Castellón de la Plana

161. Butterworth $P$, Rodgers $B$, Windsor T. Financial hardship, socio-economic position and depression: results from the PATH Through Life Survey. Soc Sci Med. 2009;69(2):229-37.

162. Djernes J K. Prevalence and predictors of depression in populations of elderly: a review. Acta Psychiatr Scand. 2006;113(5):372-87.

163. Webber M, Huxley P, Harris T. Social capital and the course of depression: sixmonth prospective cohort study. J Affect Disord. 2011;129(1-3):149-57.

164. Yan X, Huang S, Huang C, Wu W, Qin Y. Marital status and risk for late life depression: a meta-analysis of the published literature. J Int Med Res. $2011 ; 39(4): 1142-54$.

165. Zhang B, Li J. Gender and marital status differences in depressive symptoms among elderly adults: the roles of family support and friend support. Aging Ment Health. 2011;15(7):844-54.

166. Zunzunegui MV, Minicuci N, Blumstein T, Noale M, Deeg D, Jylhä M, et al. Gender differences in depressive symptoms among older adults: a cross-national comparison: the CLESA project. Soc Psychiatry Psychiatr Epidemiol. 2007;42(3):198-207.

167. Back J, Lee Y. Gender differences in the association between socioeconomic status (SES) and depressive symptoms in older adults. Arch Gerontol Geriatr. $2011 ; 52(3): e 140-4$.

168. ChenLin P, HungWang $\mathrm{H}$. Factors associated with depressive symptoms among older adults living alone: an analysis of sex difference. Aging Ment Health. $2011 ; 15(8): 1038-44$.

169. Navarro Rivera J, Benito León J, Pazzi Olazarán K. La depresión en la vejez: un importante problema de salud en México. Depression in the aging: an important health problem in Mexico. Am Lat Hoy. 2015;71:103-18.

170. Shoshana Berenzon D, Lara M, Robles R, Medina-Mora M. Depression: state of the art and the need for public policy and action plans in Mexico. Salud Publica Mex. 2013;55(1). 
171. Escobar Bravo M. Redes sociales como factor predictivo de situaciones de discapacidad al comienzo de la vejez. Doctorado en Salud Publica y Metodología. Barcelona; 2009.

172. Korte J, Bohlmeijer E, Cappeliez P, Smit F, Westerhof G. Life review therapy for older adults with moderate depressive symptomatology: a pragmatic randomized controlled trial. Psychol Med. 2012;42(6):1163-73.

173. Vanderhorst S, McLaren R. Social relationships as predictors of depression and suicidal ideation in older adults. Aging Ment Health. 2005;9(6):517-25.

174. Steen B, Rothenberg E. Aspects on nutrition of the elderly at home a review. J Nutr Health Aging. 1998;2(1):28-33.

175. Cuervo M, García A, Ansorena D, Sánchez-Villegas A, Martínez-González M, Astiasarán I, et al. Nutritional assessment interpretation on 22,007 Spanish community-dwelling elders through the Mini Nutritional Assessment test. Public Health Nutr. 2009;12(1):82-90.

176. Serra Rexach J. Factores de riesgo de malnutrición en el anciano. Galénita N. Revista Española de Geriatría. 2000. 186 p.

177. Barrera Sotolongo J, Osorio León S. Envejecimiento y nutrición. Rev Cuba Investig Biomédicas. 2007;26(1):0-10.

178. Cherry K, Brown JS, Sangkyu K, Jazwinski SM. Social Factors and Healthy Aging: Findings from the Louisiana Healthy Aging Study (LHAS). Kinesiol Rev. 2016;5(1):50-6.

179. Acosta L, Carrizo E, Pelaez E. Factores asociados a la autopercepción de salud en adultos mayores. Rev Cuba I a Salud. 2015;41(4):1-10.

180. Zunzunegui M V, Béland F, Otero A. Support from children, living arrangements, self-rated health and depressive symptoms of older people in Spain. Int $\mathrm{J}$ Epidemiol. 2001;30(5):1090-9.

181. Sinha S, White A, Ed D, Philogene G, Fine L. Social Support and SelfReported Health Status of Older Adults in the United States. Am J Public Heal. 2009;99(10):1872-8. 
182. Calero J, López-Cala G, Ortega A, Cruz-Lendínez A. Prevención de caídas en el adulto mayor: revisión de nuevos conceptos basada en la evidencia. Univ Jaen,. 2016;2(2254-9625):71-82.

183. Breijo Mato LR, Pérez Mijares E, Breijo Madera G, Padrón Rodríguez R. Estudio socio-epidemiológico de ancianos accidentados. Rev Ciencias Médicas Pinar del Río. 2014;18(6):1017-26.

184. Del Refugio Acuña Gurrola M, Hernandez-Pozo MR G, Refugio D, Acuña G, Del Rocío Hernández-Pozo M. Reflections about current research on social support Networks of orfor eldeirs. J Behav Heal Soc Issues. 2009;1(1):69-79.

185. Nebot M, Lafuente J, Tomás Z, Borrell C, Ferrando J. Preventive effect of social support on mortality among elderly population: a longitudinal study. Rev española salud pública. 2002;76(6):673-82.

186. Shufang Wu Y. Social networks and health among rural-urban migrants in China: a channel or a constraint. Health Promot Int. 2010;25(3):371-80.

187. Seeman TE, Berkman LF, Kohout F, Lacroix A, Glynn R, Blazer D. Intercommunity variations in the association between social ties and mortality in the elderly. A comparative analysis of three communities. Ann Epidemiol. 1993;3(4):325-35.

188. Mendes de Leon C, Glass T, Berkman L. Social engagement and disability in a community population of older adults: the New Haven EPESE. Am J Epidemiol. 2003;157(7):633-42.

189. Hill T, Uchino BN, Eckhardt J, Angel J. Perceived Social Support Trajectories and the All-Cause Mortality Risk of Older Mexican American Women and Men. Res Aging. 2016;38(3):374-98.

190. Shor E, Roelfs D. Social contact frequency and all-cause mortality: a meta-analysis and meta-regression. Soc Sci Med. 2015;128:76-86.

191. Zunzunegui M, Rodriguez-Laso A, Otero A, Pluijm S, Al. E. Disability and social ties: comparative findings of the Clesa study. Orig Investig. 2005;2:40-47.

192. Comisión Económica para América Latina y el Caribe Centro Latinoamericano y Caribeño de Demografía (CELADE) - División de Población. Notas de Población. Santiago se Chile: Naciones Unidas; 2003. p. 1-47. 
193. Nilsson C, Avlund K, Lund R. Onset of mobility limitations in old age: the combined effect of socioeconomic position and social relations. Age Ageing. 2011;40(5):60714.

194. Vass M, Avlund K, Hendriksen C, Andersen CK, Keiding N. Preventive home visits to older people in Denmark: methodology of a randomized controlled study. Aging Clin Exp Res. 2002;14(6):509-15.

195. Espejo Espejo J, Martínez de la Iglesia J, Rubio Cuadrado V, Dueñas Herrero, RM Fernández Fernández, A Casalilla Y. Recursos sociales en mayores de 60 años: su relación con factores sociodemográficos y de salud (proyecto ANCO). Atención Primaria. 1998;21(2):88-96.

196. Luquez Hugo R, Madorery L, De Loredo L, Hebe de Roitter S, Capra R, Zelaya H. Prevalencia de hipertension arterial y factores de riesgo asociados. Rev Fed Arg Cardiol. 1999;93-104.

197. La-huerta C, Borrell C, Perez C, Rodríguez-Sanz M, Nebot M. La influencia de la red social en la salud mental de la población anciana. Gac Sanit. 2004;18(2):8391.

198. Abizanda Soler P, López-Torres Hidalgo J, Romero Rizos L, López Jiménez M, Sánchez Jurado P, Atienzar Núñez P, et al. Fragilidad y dependencia en Albacete (estudio FRADEA): razonamiento, diseño y metodología. Rev Esp Geriatr Gerontol. 2011;46(2):81-8.

199. Alarcón Alarcón T, González Montalvo J. La Escala Socio-Familiar de Gijón, instrumento útil en el hospital general. Rev Esp Geriatr Gerontol. 1998;33(3):1759.

200. Brown Stephanie L, Nesse Randolph M, Vinokur Amiram D, Smith Dylan M. Providing social support may be more beneficial than receiving it: results from a prospective study of mortality. Psychol Sci. 2003;14(4):320-7.

201. Kaplan GA, Wilson TW, Cohen RD, Kauhanen J, Wu M, Salonen JT. Social functioning and overall mortality: prospective evidence from the Kuopio Ischemic Heart Disease Risk Factor Study. Epidemiology. 1994;5(5):495-500. 
202. Seeman TE, Berkman LF, Charpentier PA, Blazer DG, Albert MS, Tinetti ME. Behavioral and psychosocial predictors of physical performance: MacArthur studies of successful aging. journals Gerontol. 1995;50(4):M177-83.

203. Katz S, Akpom CA. A measure of primary sociobiological functions. Vol. 6 , International Journal of Health Services. 1976. 493-508 p.

204. Díaz V, Díaz T I, Rojas G, Novogrodsky D. Evaluación geriátrica en la atención primaria Geriatric assessment of elderly subjects consulting in a public primary care outpatient clinic. Rev Med Chil. 2003;131(8):895-901.

205. Ortuño R. El Instrumento de Fragilidad para Atención Primaria de la Encuesta de Salud, Envejecimiento y Jubilación en Europa (SHARE-FI): resultados de la muestra española. Rev Esp Geriatr Gerontol. 2011;46(5):243-9.

206. Ávila-Funes J, Aguilar-Navarro S, Melano-Carranza E. La fragilidad, concepto enigmático y controvertido de la geriatría. La visión biológica. Gac Méd Méx. 2008;144(3).

207. Barreto Martín P, Fernandez Ballesteros P, Andres Navia V, Bas Ramallo F. Gerontologia Social. Madrid; 2000.611 p.

208. Novella Minguez M. El voluntariado social de las personas mayores como elemento de envejecimiento activo. Valencia; 2016.

209. Ferrer Feliu A, Badía T, Formiga Pérez F, Almeda Ortega J, Fernández C, Pujol Farriols R. Diferencias de género en el perfil de salud de una cohorte de 85 años. Estudio Octabaix. Publicación Of la Soc Española Fam y Comunitaria. $2011 ; 43(11): 577-84$.

210. Charlson ME, Pompei P, Ales KL MC. A new method of classifying prognostic comorbidity in longitudinal studies: development and validation. JChronic Dis. $1987 ; 40(5): 373-83$.

211. Katz S, Ford A, Moskowitz RW, Jackson B, Jaffe M. Studies of illness in the aged: the index of ADL: a standardized measure of biological and psychosocial function. J Am Med Assoc. 1963;185:914-9. 
Análisis de las relaciones sociales y la fragilidad en las personas mayores de 75 años residentes en Castellón de la Plana

212. KATZ S. Assessing Self-maintenance: Activities of Daily Living, Mobility, and Instrumental Activities of Daily Living. J Am Geriatr Soc [Internet]. 1983 Dec [cited 2016 Aug 30];31(12):721-7. Available from: http://doi.wiley.com/10.1111/j.15325415.1983.tb03391.x

213. Radloff LS. The CES-D Scale: A Self-Report Depression Scale for Research in the General Population. Appl Psychol Meas [Internet]. 1977 Jun 1 [cited 2016 Aug 30];1(3):385-401. Available from: http://apm.sagepub.com/cgi/doi/10.1177/014662167700100306

214. Vellas B, Guigoz Y, Garry P, Nourhashem F, Bennahum D, Lauque S, et al. The mini nutritional assessment (MNA) and its use in grading the nutritional state of elderly patients. Nutrition. 1999;15(2):116-22.

215. Fried LP, Tangen CM, Walston J, Newman AB, Hirsch C, Gottdiener J, et al. Frailty in older adults: evidence for a phenotype. Journals Gerontol. 2001;56(3):146-56.

216. Avila-Funes J, Helmer C, Amieva H, Barberger-Gateau P, Le Goff M, Ritchie K, et al. Frailty among community-dwelling elderly people in France: the three-city study. Journals Gerontol. 2008;63(10):1089-96.

217. Larrieu S, Pérès K, Letenneur L, Berr C, Dartigues JF, Ritchie K, et al. Relationship between body mass index and different domains of disability in older persons: the 3C study. Int J Obes [Internet]. 2004 Dec 17 [cited 2017 Mar 15];28(12):1555-60. Available from: http://www.nature.com/doifinder/10.1038/sj.ijo.0802755

218. Nourhashémi F, Deschamps V, Larrieu S, Letenneur L, Dartigues J-F, BarbergerGateau P, et al. Body mass index and incidence of dementia: the PAQUID study. Neurology. 2003 Jan 14;60(1):117-9.

219. Washburn RA, Smith KV, Jette A M JC. The Physical Activity Scale for the Elderly (PASE): development and evaluation. J Clin Epidemiol. 1993;46(2):153-62.

220. Nuin Orrio C. Asociación entre las las relaciones sociales y la fragilidad en personas mayores que viven en la comunidad. Tesis Doctoral. Lérida; 2011.

221. Azpiazu Garrido M, Cruz Jentoft A, Villagrasa Ferrer J, Abanades Herranz J, García Marín N, Álvarez de Mon Rego C. Calidad de vida en mayores de 65 años no institucionalizados de dos áreas sanitarias de Madrid. Atención Primaria. 2003;31(5):285-92. 
222. Avlund K, Damsgaard MT, Holstein BE. Social relations and mortality. An eleven year follow-up study of 70-year-old men and women in Denmark. Soc Sci Med. 1998;47(5):635-43.

223. Navarro Rodriguez V. Eficacia de un programa de intervención multifactorial para la prevención de caídas en los ancianos de la comunidad. Servicio de Publicaciones de la Universidad de Córdoba. Cordoba; 2011.

224. Espejo Espejo J, Martínez de la Iglesia J, Aranda Lara J, Rubio Cuadrado V, Enciso Bergé I, Zunzunegui Pastor M, et al. Capacidad funcional en mayores de 60 años y factores sociosanitarios asociados (proyecto ANCO). Atención Primaria. 1997;20(1):3-11.

225. Ministerio de Sanidad y Consumo. Encuesta Nacional de Salud 2006. 2006;39.

226. Pachana N, Smith N, Watson M, McLaughlin D, Dobson A. Responsiveness of the Duke Social Support sub-scales in older women. Age Ageing. 2008;37(6):666-72.

227. Gutiérrez-Misis A, Sánchez-Santos M, Otero Á. Utilización de un proxy al índice de Charlson para estudiar la asociación entre comorbilidad y mortalidad a corto y largo plazo en mayores. Atención Primaria. 2012;44(3):153-61.

228. Stek ML, Vinkers D, Gussekloo J, van der Mast R, Beekman A, Westendorp RJ. Natural history of depression in the oldest old: population-based prospective study. Br J Psychiatry. 2006;188:65-9.

229. Van de Velde S, Bracke P, Levecque K. Gender differences in depression in 23 European countries. Cross-national variation in the gender gap in depression. Soc Sci Med. 2010;71(2):305-13.

230. Ross C, Mirowsky J. Sex differences in the effect of education on depression: resource multiplication or resource substitution? Soc Sci Med. 2006;63(5):140013.

231. Castell Alcalá M, Otero Puime Á, Sánchez Santos M, Garrido Barral A, González Montalvo J, Zunzunegui M. Prevalencia de fragilidad en una población urbana de mayores de 65 años y su relación con comorbilidad y discapacidad. Atención Primaria. 2010;42(10):520-7.

232. Celidoni M, Rebba V. Healthier lifestyles after retirement in Europe? Evidence from SHARE. Eur J Heal Econ. 2015;1-26. 
233. Avlund $\mathrm{K}$, Vass $\mathrm{M}$, Hendriksen $\mathrm{C}$. Onset of mobility disability among communitydwelling old men and women. The role of tiredness in daily activities. Age Ageing. 2003;32(6):579-84.

234. Jürschik $P$, Escobar $M$, Nuin $C$, Botigué T. Atención Primaria Criterios de fragilidad del adulto mayor. Estudio piloto. Atención Primaria. 2009;43(4):190-6.

235. Viedma P, Toner M, Irles M, López R. Encuesta de Salud de la comunidad Valenciana. Conselleria de Sanidad Generalitat Valenciana. 2010. p. 254.

236. Suemoto C, Ueda P, Beltrán-Sánchez H, Lebrão M, Duarte $Y$, Wong R, et al. Development and Validation of a 10-Year Mortality Prediction Model: Meta-Analysis of Individual Participant Data From Five Cohorts of Older Adults in Developed and Developing Countries. journals Gerontol A, Biol Sci Med Sci. 2017;72(3):410-6.

237. Mussoll J, Espinosa M, Quera D, Serra M, Pous E, Villarroya I, et al. Resultados de la aplicación en atención primaria de un protocolo de valoración geriátrica integral en ancianos de riesgo. Rev Esp Geriatr Gerontol. 2002;37(5):249-53.

238. Instituto de Mayores y Servicios Sociales (IMSERSO). Las Personas Mayores en España. Ministerio de Sanidad y Politica social. Madrid; 2014.

239. Ching-I C, Ding-Cheng C, Kuo K, Agnes Hsiung C, Ching-Yu C. Prevalence and Correlates of Geriatric Frailty in a Northern Taiwan Community. J Formos Med Assoc. 2011;110(4):247-57.

240. Avendano M, Hendrik Mackenbach J, Johann P. Educational level and changes in health across Europe: Iongitudinal results from SHARE. J Eur Soc Policy. 2009;19(4):301-16.

241. Stevens N, Van Tilburg T. Cohort differences in having and retaining friends in personal networks in later life. J Soc Pers Relat. 2011;28(1):24-43.

242. Rodríguez Laso Á. El efecto de las relaciones sociales sobre la mortalidad en las personas mayores el estudio envejecer en Leganés". Madrid; 2004.

243. Brazo M. La sociedad anciana :CISS y Siglo XXI. 1990. 223 p.

244. Imserso. La participación social de las personas mayores. Minist Sanid y Política Soc. 2008;

245. Amorós P, Bartolomé M, Sabariego M, De Santos J. Construyendo un Futuro. Las personas mayores: una fuerza social emergente. Alianza Editor. 2007;70:192-3. 
246. Krause N. Longitudinal study of social support and meaning in life. Psychol Aging. 2007;22(3):456-69.

247. Weyers S, Dragano N, Möbus S, Beck E, Stang A, Möhlenkamp S, et al. Low socio-economic position is associated with poor social networks and social support: results from the Heinz Nixdorf Recall Study. Int J Equity Health. 2008;7(1):13.

248. SHARE. Health, ageing and retirement in Europe. 2005. 355 p.

249. Viana da Costa S, Ceolim MF, Liberalesso Neri A. Sleep problems and social support: Frailty in a Brazilian Elderly Multicenter study. Rev Latino-Americana Enferm. 2011;19(4):920-7.

250. Yao K, Yu S, Cheng S, Cheng I. Relationships between personal, depression and social network factors and sleep quality in community-dwelling older adults. J Nurs Res. 2008;16(2):131-9.

251. Bandeen-Roche K, Xue Q-L, Ferrucci L, Walston J, Guralnik JM, Chaves P, et al. Phenotype of Frailty: Characterization in the Women's Health and Aging Studies. Journals Gerontol Ser A Biol Sci Med Sci. 2006;61(3):262-6.

252. de Leon CFM, Glass TA, Beckett LA, Seeman TE, Evans DA, Berkman LF. Social Networks and Disability Transitions Across Eight Intervals of Yearly Data in the New Haven EPESE. Journals Gerontol Ser B Psychol Sci Soc Sci. 1999;54B(3):S162-72.

253. Sánchez Jurado PM. Prevalencia y atributos de la fragilidad en una cohorte española mayor de 70 años. Ruidera UCLM. Universidad de Castilla-La Mancha; 2013.

254. Alvarado B, Zunzunegui M, Béland F, Bamvita J. Life Course Social and Health Conditions Linked to Frailty in Latin American Older Men and Women. J Gerontol A Biol Sci Med Sci. 2008;63(12):1399-406.

255. Santos-Eggimann B, Cuénoud P, Spagnoli J, Junod J. Prevalence of frailty in middle-aged and older community-dwelling Europeans living in 10 countries. Journals Gerontol. 2009;64(6):675-81.

256. García-García F, Larrión Zugasti J, Rodríguez Manas L. Fragilidad:un fenotipo en revisión. Gac Sanit. 2011;25(S):51-8. 
257. Syddall H, Roberts H, Evandrou M, Cooper C, Bergman H, Sayer AA. Prevalence and correlates of frailty among community-dwelling older men and women: findings from the Hertfordshire Cohort Study. Age Ageing. 2010;39(2):197-203.

258. Varela-Pinedo L, Ortiz-Saavedra P. Síndrome de fragilidad en adultos mayores de la comunidad de Lima Metropolitana. Rev Soc Peru Med. 2008;21(1):11-5.

259. Weyers S, Dragano N, Richter M, Bosma H. How does socio economic position link to health behaviour? Sociological pathways and perspectives for health promotion. Glob Health Promot. 2010;17(2):25-33. 
ANEXOS

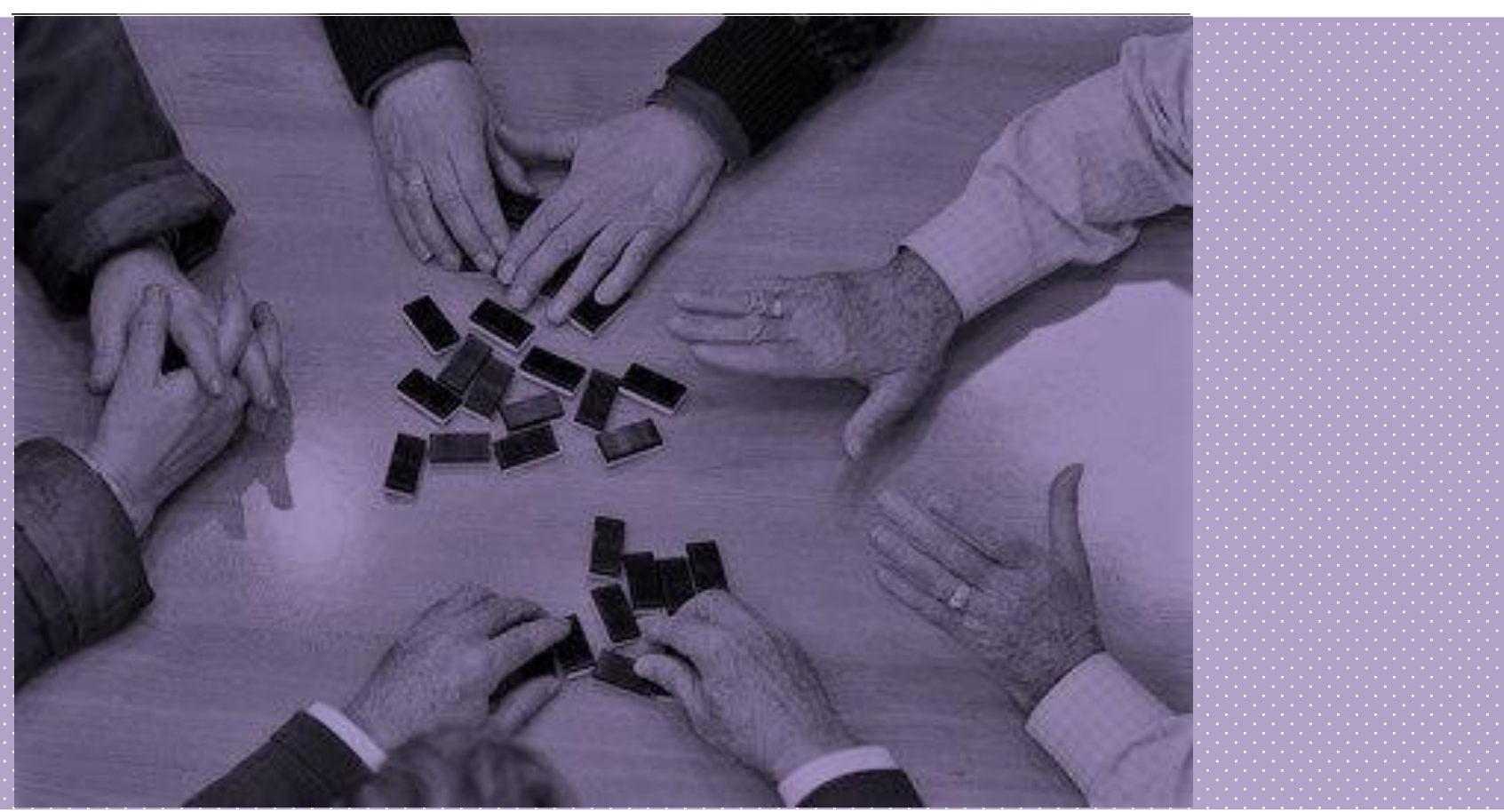





\section{Anexos}

ANEXO 1.

COD. IDENT.

Datos del investigador

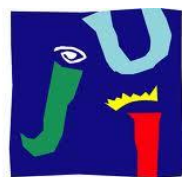

UNIVERSITAT

JAUME • I

Cuaderno de recogida de datos del estudio

\section{Estudio de salud de la población mayor de Castellón que permita organizar programas de mejora para prevenir y tratar la fragilidad}

\section{Colaboran:}

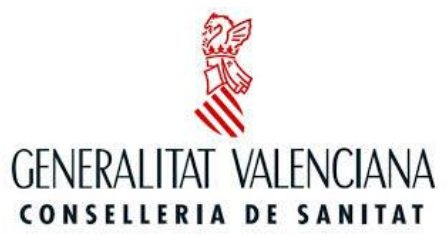

Buenos días, desde la Universidad Jaume I estamos llevando a cabo un estudio sobre la prevención y tratamiento de fragilidad en personas mayores. Se trata de analizar si, la población mayor de Castellón tiene indicios de fragilidad y en ese caso, realizar intervenciones para su prevención y tratamiento.

Nos gustaría contar con usted y si acepta le realizaremos una entrevista que durará aproximadamente unos $\mathbf{5 0}$ minutos. Posteriormente, si usted desea entrar en el programa de prevención, contactaríamos directamente para notificarle las actividades relacionadas. 
CAP de referencia:

Partida: $\square$ 1. Sí $\square$ 2. No

Vive solo/a con familia en una

institución otros Ocupacióncuandoestaba en activo/a

Estado civi

No de hijos

1. Estado físico

Exploración física

1.- En primer lugar, deberá caminar desde la marca de inicio hasta el final. Ha de hacerlo andando pero lo más rápidamente posible, sin correr. Es para saber el tiempo que tarda seg.

A continuación realizaremos una serie de medidas antropométricas que nos servirán para saber su estado nutricional.

2.- Peso habitual: kg.

3.- Peso actual: kg.

4.- Talla: cm.

5.- Altura talón-rodilla: cm.

6.- Circunferencia pantorrilla: cm.

7.- Circunferencia braquial: cm.

8.- Longitud del cubito: cm.

9.- Extensión del brazo: cm.

\section{2.- FACTORES PSICOLÓGICOS}

10.- Iniciaremos el cuestionario haciéndole unas preguntas con el fin de evaluar su memoria. Si alguna no la sabe o no la recuerda, pasaremos a la siguiente. 


\begin{tabular}{|l|l|l|}
\hline & Correcto & Incorrecto \\
\hline 10.A.- ¿Cuál es la fecha de hoy? & & \\
\hline 10.B.- ¿qué día de la semana es hoy? & & \\
\hline 10.C.- ¿En qué ciudad estamos? & & \\
\hline 10.D.- ¿Cuál es su número de & & \\
teléfono? Si no tiene, ¿cuál es su & & \\
dirección? & & \\
\hline 10.E.- ¿Qué edad tiene usted? & & \\
& & \\
\end{tabular}

\begin{tabular}{|l|l|l|}
\hline & Correcto & Incorrecto \\
\hline $\begin{array}{l}\text { 10.F.- ¿Cuál es la fecha de su } \\
\text { nacimiento? }\end{array}$ & & \\
\hline $\begin{array}{l}\text { 10.G.- ¿Cómo se llama el } \\
\text { presidente del gobierno? }\end{array}$ & & \\
\hline $\begin{array}{l}\text { 10.H.- Quién fue el anterior } \\
\text { presidente del gobierno }\end{array}$ & & \\
\hline $\begin{array}{l}\text { 10.I.- ¿Cuáles son los dos } \\
\text { apellidos de su madre? }\end{array}$ & & \\
\hline $\begin{array}{l}\text { 10.J.- Reste de } 3 \text { en } 3 \text { desde el } \\
\text { número } 20 \text { hasta llegar a } 0\end{array}$ & & \\
\hline
\end{tabular}

\section{ERRORES TOTALES}

\section{1.- ¿Alguna de las siguientes frases reflejan} como se ha sentido durante la última semana?

\begin{tabular}{|c|c|c|c|c|}
\hline & $\begin{array}{c}\text { Nunca o } \\
\text { casi nunca } \\
\text { (menos de } \\
1 \text { día) }\end{array}$ & $\begin{array}{c}\text { A veces } \\
\text { (1-2 } \\
\text { días) }\end{array}$ & $\begin{array}{c}\text { Con } \\
\text { frecuencia } \\
\text { (3-4 días) }\end{array}$ & $\begin{array}{c}\text { Siempre o casi } \\
\text { siempre (5-7 } \\
\text { días) }\end{array}$ \\
\hline $\begin{array}{l}\text { - Me molestaron cosas que usualmente no me } \\
\text { molestan }\end{array}$ & $\square 0$ & $\square 1$ & $\square 2$ & $\square 3$ \\
\hline $\begin{array}{l}\text { - No me sentía con ganas de comer; tenía mal } \\
\text { apetito }\end{array}$ & $\square 0$ & $\square 1$ & $\square 2$ & $\square 3$ \\
\hline $\begin{array}{l}\text { - Me sentía que no podía quitarme de encima la } \\
\text { tristeza aún con la ayuda de su familia o amigos }\end{array}$ & $\square 0$ & $\square 1$ & $\square 2$ & $\square 3$ \\
\hline $\begin{array}{l}\text { - Sentía que yo era tan bueno como cualquier } \\
\text { otra persona }\end{array}$ & $\square 0$ & $\square 1$ & $\square 2$ & $\square 3$ \\
\hline $\begin{array}{l}\text { - Tenía dificultad en mantener mi mente en lo } \\
\text { que estaba haciendo }\end{array}$ & $\square 0$ & $\square 1$ & $\square 2$ & $\square 3$ \\
\hline - Me sentía deprimido & $\square 0$ & $\square 1$ & $\square 2$ & $\square 3$ \\
\hline - Sentía que todo lo que hacía era un esfuerzo & $\square 0$ & $\square 1$ & $\square 2$ & $\square 3$ \\
\hline - Me sentía optimista sobre el futuro & $\square 0$ & $\square 1$ & $\square 2$ & $\square 3$ \\
\hline - Pensé que mi vida había sido un fracaso & $\square 0$ & $\square 1$ & $\square 2$ & $\square 3$ \\
\hline - Me sentía con miedo & $\square 0$ & $\square 1$ & $\square 2$ & $\square 3$ \\
\hline - Mi sueño era inquieto & $\square 0$ & $\square 1$ & $\square 2$ & $\square 3$ \\
\hline - Estaba contento & $\square 0$ & $\square 1$ & $\square 2$ & $\square 3$ \\
\hline
\end{tabular}




\begin{tabular}{|l|c|c|c|c|}
\hline - Hablé menos de lo usual & $\square 0$ & $\square 1$ & $\square 2$ & $\square 3$ \\
\hline - Me sentí solo & $\square 0$ & $\square 1$ & $\square 2$ & $\square 3$ \\
\hline - La gente no era amistosa & $\square 0$ & $\square 1$ & $\square 2$ & $\square 3$ \\
\hline - Disfruté de la vida & $\square 0$ & $\square 1$ & $\square 2$ & $\square 3$ \\
\hline - Pasé ratos Ilorando & $\square 0$ & $\square 1$ & $\square 2$ & $\square 3$ \\
\hline - Me sintí triste & $\square 0$ & $\square 1$ & $\square 2$ & $\square 3$ \\
\hline - Sentía que no le caía bien a la gente & $\square 0$ & $\square 1$ & $\square 2$ & $\square 3$ \\
\hline - No tenía ganas de hacer nada & $\square 0$ & $\square 1$ & $\square 2$ & $\square 3$ \\
\hline - Sufrí de los nervios & $\square 0$ & $\square 1$ & $\square 2$ & $\square 3$ \\
\hline - Me sentí nervioso, preocupado o alterado & $\square 0$ & $\square 1$ & $\square 2$ & $\square 3$ \\
\hline
\end{tabular}

\section{3.- ASPECTOS SOCIODEMOGRAFICOS}

\section{2.- ¿Cuál es su estado civil?}

\author{
$\square$ 1. Soltero/a \\ $\square$ 2. Casado/a \\ ๑ 3. En pareja \\ $\square$ 4. Separado/a, divorciado/a $\square$ 5. Viudo/a
}

\section{$\square 2$. Ventas o servicios}

$\square$ 3. Trabajador/a cualificado o personal administrativo

๑ 4. Trabajador/a semicualificado/a o no cualificado/a

๑5. Granja o campo
13.- ¿Qué nivel de estudios es el más alto que terminó?
$\square$ 1. No sabe leer ni escribir
$\square$ 2. No acabó los estudios primarios
๑3. Primarios
$\square$ 4. Secundarios de Primer Grado
$\square$ 5. Secundarios de Segundo
$\square$ 6. Universitarios

\section{4.- ¿Qué profesión tenía?}

$\square$ 1. Profesional o alto cargo administrativo
๑ 6. Militar

$\square$ 7. Ama de casa

$\square$ 8. Trabajo sin sueldo

9. Otros:

\section{5.- ¿Con quién vive habitualmente?}

$\square$ 1. Solo/a

๑2. Esposo/a

$\square$ 3. Hijos/as

$\square$ 4. Esposo/a e Hijos/as 
5. Otros:

16.- ¿Cuál es el total de ingresos que, para todos los conceptos, entran en su hogar mensualmente?

$\square 1$. Menos de $400 €$

口2. Entre $400 €$ y $600 €$
口 3. Entre $600 €$ y $900 €$

口 4. Entre $900 €$ y $1200 €$

口 5. Entre $1200 €$ y $1800 €$

๑ 6. Más de $1800 €$

$\square$ 7. Prefiere no contestar

\section{4.- ESTADO DE SALUD}

17.- ¿Puede usted escuchar un programa de televisión a un volumen que otros consideran normal?

๑1. Sí

$\square$ 2. No

18.- ¿Puede escucharlo al aumentar el volumen?
口1. Sí
$\square$ 2. No

20.- ¿Y la puede reconocer a una distancia de un metro?
$\square 1 . \mathrm{S}$
$\square$ 2. No

21.- ¿Cree que le ha disminuido el gusto?

口1. Sí

$\square$ 2. No

22.- ¿Cree que le ha disminuido el olfato?
口 1. Sí
$\square$ 2. No

23.- ¿Cuántos medicamentos diferentes toma usted cada día?

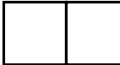

24.- ¿Ha sufrido o sufre algunas de las siguientes enfermedades? 


\section{5.- HÁBITOS DE SALUD}

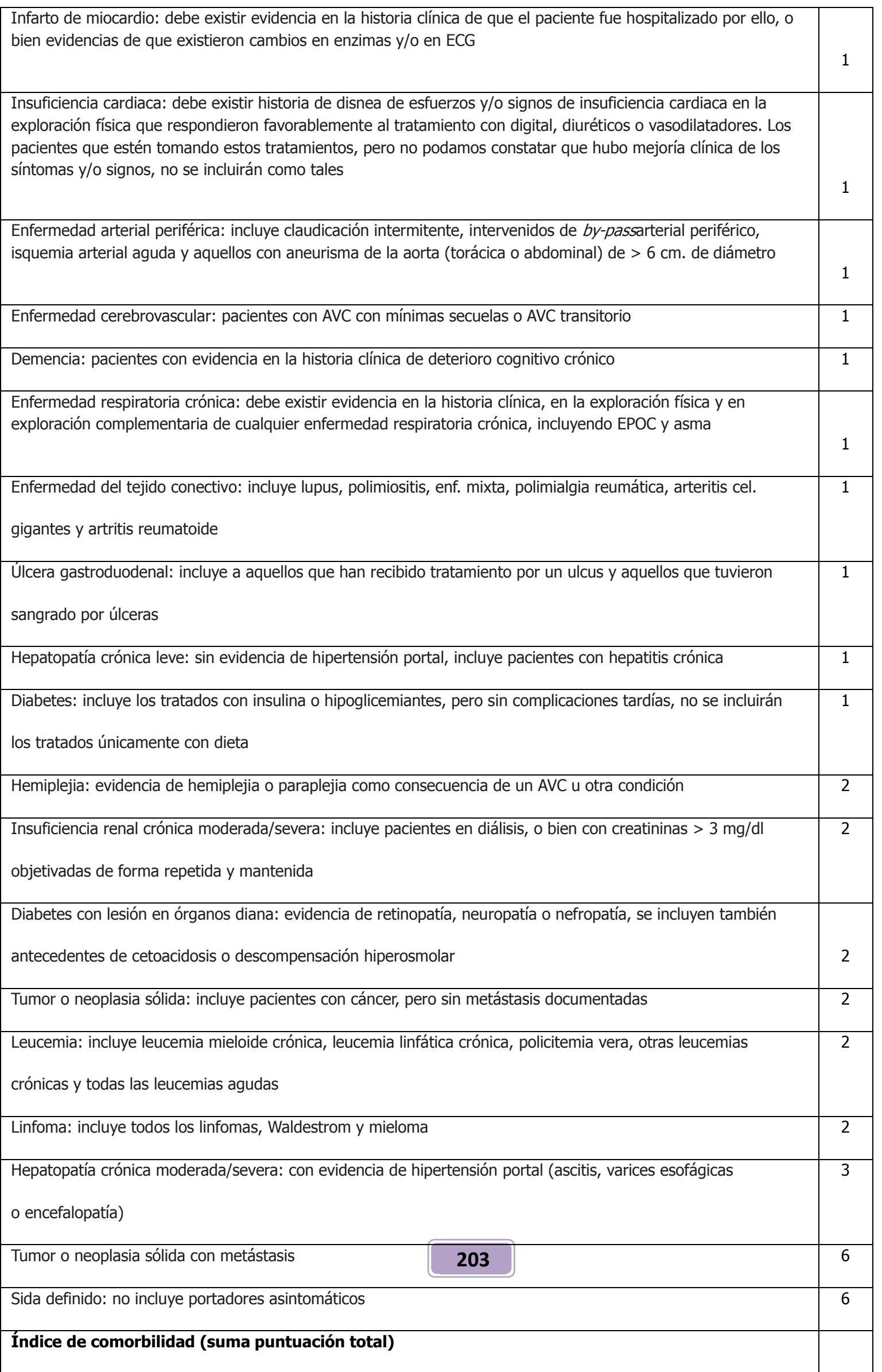




\section{5.- ¿Podría usted decirme si fuma?}

$\square$ 1. No he fumado nunca

$\square$ 2. Ex fumador

$\square$ 3. Fumador ocasional

4. Fumador habitual

\section{6.- ¿Con qué frecuencia bebe alcohol?}

$\square$ 1. No bebe nunca

$\square$ 2. Una o dos veces al mes

$\square$ 3. Una o dos veces a la semana

๑ 4. Diariamente, sólo en las comidas

$\square$ 5. Diariamente, entre comidas i durante las comidas
27.- ¿Lee el diario, libros o revistas?
$\square$ 1. A diario
$\square$ 2. Con frecuencia
$\square$ 3. Pocas veces
$\square$ 4. Nunca o casi nunca

$\square$ 5. No sabe leer

28.- ¿Toma alguna medicación para dormir?
$\square$ 1. Diariamente
$\square$ 2. Ocasionalmente
$\square$ 3. Nunca

29.- Y respecto al sueño, ¿tiene alguno de los siguientes problemas?

\begin{tabular}{|l|c|c|c|c|}
\cline { 2 - 5 } \multicolumn{1}{c|}{} & Nunca & Rara vez & A veces & A menudo \\
\hline Se despierta muy pronto (antes de lo que querría) & $\square 1$ & $\square 2$ & $\square 3$ & $\square 4$ \\
\hline Le cuesta mucho dormirse & & $\square 2$ & $\square 3$ & $\square 4$ \\
\hline Duerme mal durante la noche & $\square 1$ & $\square 2$ & $\square 3$ & $\square 4$ \\
\hline Se despierta muchas veces durante la noche & $\square 1$ & $\square 2$ & $\square 3$ & $\square 4$ \\
\hline
\end{tabular}

\section{6.- CAPACIDAD FUNCIONAL}




\section{0.- Le nombraré una serie de actividades habituales de la vida diaria de cualquier persona. Me gustaría saber si tiene dificultades para realizar alguna de ellas.}

\section{BAÑARSE: (en la bañera o ducha)}

No necesita ayuda (entra y sale de la bañera por sí mismo, recibe ayuda sólo para una parte del cuerpo, ej.: espalda, piernas).

VESTIRSE:(incluye sacar la ropa de armarios y cajones, y manejo de botones y medias)

\begin{tabular}{|l|c|}
\hline Saca la ropa y se viste sin ayuda, excepto atarse los zapatos. & $\square 1$ \\
\hline Necesita ayuda para sacar la ropa o vestirse, o queda parcialmente vestido. & $\square 0$ \\
\hline
\end{tabular}

USO DEL WC:(incluye ir al WC, arreglarse la ropa y la limpieza de los órganos excretores)

\begin{tabular}{|l|c|}
\hline $\begin{array}{l}\text { Va al WC, se limpia y se arregla la ropa sin ayuda (puede utilizar un objeto de ayuda, como un bastón o una silla de } \\
\text { ruedas, o utilizar la cuña o silla de baño, si las vacía sin ayuda. }\end{array}$ & $\square 1$ \\
\hline Necesita ayuda para ir al WC, limpiarse, arreglarse la ropa o para utilizar la cuña o silla de baño. No va al WC. & $\square 0$
\end{tabular}

\section{DESPLAZARSE:}

Entra y sale de la cama, se levanta y se acuesta de la cama y se levanta y se sienta de una silla, sin ayuda (puede utilizar un objeto de ayuda como un bastón).

\section{CONTINENCIA:}

Control completo de la micción y la defecación.

Incontinencia total o parcial. Necesita supervisión, sonda vesical, enemas o es incontinente.

ALIMENTARSE:(incluye llevar el alimento hasta la boca des del plato o equivalente)

\begin{tabular}{|l|c|}
\hline Se alimenta sin ayuda excepto para cortar la carne o mojar el pan & $\square 1$ \\
\hline Necesita ayuda para alimentarse o se alimenta parcial o completamente mediante sondas o líquidos intravenosos. & $\square 0$ \\
\hline
\end{tabular}

UTILIZAR EL TELÉFONO: (Incluye buscar y marcar los números)

\begin{tabular}{|l|c|}
\hline 1. Utiliza el teléfono por iniciativa propia y sin ayuda & $\square 1$ \\
\hline 2. Marca bien números conocidos & $\square 1$ \\
\hline
\end{tabular}




\begin{tabular}{|l|c|}
\hline 3. Contesta al teléfono, pero no marca & $\square 1$ \\
\hline 4. No utiliza nunca el teléfono & $\square 0$ \\
\hline
\end{tabular}

\section{HACER COMPRAS:}

\begin{tabular}{|l|c|}
\hline 1. Realiza todas las compras necesarias sin ayuda & $\square 1$ \\
\hline 2. Realiza independientemente pequeñas compras & $\square 0$ \\
\hline 3. Necesita ir acompañado para hacer cualquier compra & $\square 0$ \\
\hline 4. No puede ir a comprar & $\square 0$ \\
\hline
\end{tabular}

\section{PREPARAR LA COMIDA:}

\begin{tabular}{|l|c|}
\hline 1. Organiza, prepara y sirve la comida sin ayuda & $\square 1$ \\
\hline 2. Prepara adecuadamente las comidas si se le proporcionan los ingredientes & $\square 0$ \\
\hline 3. Prepara, calienta y sirve las comidas, pero no sigue una dieta adecuada. & $\square 0$ \\
\hline 4. Necesita que le preparen y sirvan las comidas & $\square 0$ \\
\hline
\end{tabular}

\section{TAREAS DOMÉSTICAS:}

\begin{tabular}{|l|c|}
\hline 1. Mantiene la casa sólo o con ayuda ocasional (para tareas pesadas) & $\square 1$ \\
\hline 2. Realiza tareas ligeras, como lavar los platos o hacer las camas & $\square 1$ \\
\hline 3. Realiza tareas ligeras, pero no puede mantener un adecuado nivel de limpieza & $\square 1$ \\
\hline 4. Necesita ayuda en todas las tareas de la casa & $\square 1$ \\
\hline 5. No participa en ninguna tarea doméstica & $\square 0$ \\
\hline
\end{tabular}

\section{LAVAR LA ROPA:}

1. Lava por sí mismo toda la ropa

2. Lava por sí mismo pequeñas piezas

3. Todo el lavado de la ropa ha de ser realizado por otro 


\begin{tabular}{|l|l|}
\hline 1. Viaja sólo en transporte público o conduce su propio vehículo & $\square 1$ \\
\hline 2. Es capaz de coger un taxi, pero no otro medio de transporte & $\square 1$ \\
\hline 3. Viaja en transporte público cuando va acompañado de otra persona & $\square 1$ \\
\hline 4. Sólo utiliza el taxi o el coche con ayuda de otros & $\square 0$ \\
\hline 5. No viaja & $\square 0$ \\
\hline
\end{tabular}

RESPONSABILIDAD RESPECTO A LA MEDICACIÓN: (aunque no tome medicación, en el caso de que tuviera)

\begin{tabular}{|l|l|}
\hline 1. Es capaz de tomar la medicación a la hora y con la dosis correcta & $\square 1$ \\
\hline 2. Toma medicación si la dosis la preparan previamente (se acuerda de tomárselo, pero necesita que se la preparen) \\
\hline 3. No es capaz de responsabilizarse de su medicación \\
\hline$\square 0$ \\
\hline
\end{tabular}

\section{MANEJO DE ASUNTOS ECONÓMICOS:}

\begin{tabular}{|l|l|}
\hline 1. Se encarga de los asuntos económicos por sí mismo & $\square 1$ \\
\hline 2. Realiza las compras cada día, pero necesita ayuda en las grandes compras, bancos, ... \\
\hline 3. Incapaz de manejar dineros \\
\hline$\square 0$ \\
\hline
\end{tabular}

\section{7.- LIMITACIONES Y DIFICULTADES}

31.- ¿Algunos de los siguientes elementos representan un obstáculo o una barrera para su vida diaria?
1. Escaleras:
๑1.1. Sí $\square$ 1.2. No

2. El pavimento u otros elementos:

$\square$ 2.1. Sí $\square$ 2.2. No

3. Características del transporte público:

๑ 3.1. Sí $\square$ 3.2. No

4. Otras barreras exteriores a su vivienda:

๑4.1. Sí $\square$ 4.2. No ¿Cuáles?

5. La bañera u otros elementos del baño:

$\square$ 5.1. Sí $\square$ 5.2. No 

6. Otras barreras dentro de la vivienda:
๑6.1. Sí
口 6.2. No ¿Cuáles?

32.-¿Alguno de los siguientes aspectos de su vivienda supone para usted un problema?
1. Tamaño:
$\square$ 1.1. Sí $\square$ 1.2. No
2. Estado de conservación de la vivienda:
๑2.1. Sí $\square 2.2$ No
3. Estado de conservación del edificio:
๑3.1. Sí $\square 3.2$ No

33.- ¿Considera que su casa está adaptada a sus necesidades?

๑1. Sí

$\square$ 2. No, necesita reparaciones y se harán

$\square$ 3. No, necesita reparaciones pero no pueden hacerse.

\section{4.- ¿Tiene ascensor?}
๑1. Sí
$\square$ 2. No

\section{8.- CAÍDAS}

\section{5.-¿¿Tiene usted miedo a caer?}

37.-¿̈Ha dejado por eso de realizar alguna actividad?
口 1. Sí
2. No
2. No

口 1. Sí

38.-¿¿Desde cuándo?

\section{6.-¿¿Desde cuándo?}

$\square$ 1. Hace menos de 1 año
๑ 1. Hace menos de 1 año

๑2. Entre 1 y 2 años

口2. Entre 1 y 2 años

口 3. Más de 2 años

๑ 3. Más de 2 años

39.- ¿Presenta usted dificultad para...?

$\square$ 1. Sostenerse de pie 
$\square$ 2. Sentarse o levantarse de la silla

$\square$ 3. Mantenerse sentado

$\square$ 4. Recoger un objeto del suelo

5. Levantarse

$\square$ 6. Correr

$\square$ 7. Utilizar ambos brazos

8. Utilizar ambas piernas

40.- ¿Como es su deambulación?

$\square$ 1. Normal

$\square$ 2. Segura con ayuda

$\square$ 3. Insegura con o sin ayuda

$\square$ 4. Imposible

41.- ¿Padece alguna enfermedad en los pies?

$\square$ 1. Sí

$\square$ 2. No

\section{2.- ¿Ha caído en el último año?}

$\square$ 1. Sí

$\square$ 2. No

$\square$ 3. No lo sabe

๑4. Si se ha caído; ¿cuántas veces?

La caída: se refiere a la última caída

43.- ¿Era la primera caída? $\square$ 1. Sí

$\square$ 2. No

$\square$ 3. No lo sabe

44.- Precisar día y mes:

\section{5.- Momento del día:}

๑ 1. Mañana

$\square$ 2. Tarde

$\square$ 3. Noche:

46.- Motivo de la caída:

$\square$ 1. Mareo

$\square$ 2. Accidentalmente

$\square$ 3. Producida por terceros

$\square$ 4. No lo recuerda

$\square$ 5. Otros:

\section{7.- ¿Cayó cuan largo es?}

๑ 1. Sí

$\square$ 2. No

$\square$ 3. De la cama

48.- ¿Cuánto tiempo ha permanecido en el suelo?

$\square$ 1. Se levantó inmediatamente

$\square$ 2. Unos minutos

$\square$ 3. Menos de 1 hora

$\square$ 4. Más de 1 hora

$\square$ 5. Más de 12 horas

$\square$ 6. No lo recuerda 
49.- ¿Pudo levantarse?
$\square$ 1. Sí, solo
๑2. Sí, con ayuda
$\square$ 3. No

Información sobre las características de la caída

50.- Lugar de la caída:

$\square$ 1. Domicilio

$\square$ 2. En un lugar público

$\square$ 3. En la calle

$\square$ 4. No lo recuerda

51.- ¿En el domicilio, donde se ha caído?

$\square$ 1. Cocina

๑2. Baño

$\square$ 3. Terraza

$\square$ 4. Escaleras

$\square$ 5. Dormitorio

6. Otros:

\section{3.- Iluminación del lugar de la caída:}
$\square$ 1. Bien iluminado
$\square$ 2. Mal iluminado
$\square$ 3. No lo recuerda

\section{4.- Condiciones meteorológicas:}
$\square$ 1. Lluvia
$\square$ 2. Nieve
$\square$ 3. Viento

$\square$ 4. Hielo

$\square$ 5. Muy soleado

๑6. Ninguno de los anteriores:

55.- ¿Había algún objeto capaz de favorecer la caída?

๑1. Sí

$\square$ 2. No

$\square$ 3. No lo recuerda

56.- ¿Había sido instalado recientemente?

๑ 1. Sí

$\square$ 2. No

$\square$ 3. No lo sabe

\section{7.- Condiciones del suelo:}

52.- Percepción del lugar:

$\square$ 1. Liso

$\square$ 1. Conocido

๑2. Resbaladizo

$\square$ 2. No conocido

$\square$ 3. Irregular

$\square$ 3. No lo recuerda

$\square$ 4. Pendiente

$\square$ 5. Escaleras 
$\square$ 6. Ninguno de los anteriores:

58.- Tipo de calzado:

$\square$ 1. Descalzo

$\square$ 2. Zapatillas

$\square$ 3. Zapatos

$\square$ 4. Otro:

$\square$ 5. No recuerda $\square$ 4. Heridas profundas

5. Traumatismo craneal

$\square$ 6. Ingreso hospitalario

๑ 7. Hospitalización

60.- ¿Ha cambiado su modo de vida como consecuencia de la caída?
$\square$ 1. Sí
$\square$ 2. No

\section{9.- Consecuencias inmediatas de la caída:}

$\square$ 1. Contusiones, hematomas

$\square$ 2. Fracturas. ¿Cuáles?

\section{1.-¿Tiene usted miedo de volver a caer?}

$\square$ 1. Sí

$\square$ 3. Heridas superficiales

$\square$ 2. No

$\square$ 3. No lo sabe

\begin{tabular}{|c|c|c|c|c|}
\hline & $\begin{array}{l}\text { En absoluto } \\
\text { (nada) } \\
\text { preocupado }\end{array}$ & $\begin{array}{c}\text { Algo } \\
\text { preocupado }\end{array}$ & $\begin{array}{c}\text { Bastante } \\
\text { preocupado }\end{array}$ & $\begin{array}{c}\text { Muy } \\
\text { preocupado }\end{array}$ \\
\hline 1. Limpiar la casa (ej., barrer, pasar la aspiradora o limpiar el polvo) & $\square 1$ & $\square 2$ & $\square 3$ & $\square 4$ \\
\hline 2. Vestirse o desvertirse & $\square 1$ & $\square 2$ & $\square 3$ & $\square 4$ \\
\hline 3. Preparar comidas cada día & $\square 1$ & $\square 2$ & $\square 3$ & $\square 4$ \\
\hline 4. Bañarse o ducharse & $\square 1$ & $\square 2$ & $\square 3$ & $\square 4$ \\
\hline 5. Ir a la compra & $\square 1$ & $\square 2$ & $\square 3$ & $\square 4$ \\
\hline 6. Sentarse o levantarse de una silla & $\square 1$ & $\square 2$ & $\square 3$ & $\square 4$ \\
\hline 7. Subir o bajar escaleras & $\square 1$ & $\square 2$ & $\square 3$ & $\square 4$ \\
\hline 8. aminar por el barrio (o vecindad, fuera de casa) & $\square 1$ & $\square 2$ & $\square 3$ & $\square 4$ \\
\hline 9. Coger algo alto (por encima de su cabeza) o en el suelo & $\square 1$ & $\square 2$ & $\square 3$ & $\square 4$ \\
\hline 10. Ir a contestar el teléfono antes de que deje de sonar & $\square 1$ & $\square 2$ & $\square 3$ & $\square 4$ \\
\hline 11. Caminar sobre una superficie resbaladiza (ej., mojada o con hielo) & $\square 1$ & $\square 2$ & $\square 3$ & $\square 4$ \\
\hline 12. Visitar a un amigo o familiar & $\square 1$ & $\square 2$ & $\square 3$ & $\square 4$ \\
\hline
\end{tabular}




\begin{tabular}{|l|c|c|c|}
\hline 13. Caminar en un lugar con mucha gente & $\square 1$ & $\square 2$ & $\square 4$ \\
\hline $\begin{array}{l}\text { 14. Caminar en una superficie irregular (ej., pavimento en mal estado, sin } \\
\text { asfaltar) }\end{array}$ & $\square 1$ & $\square 2$ & $\square 3$ \\
\hline $\begin{array}{l}\text { 15. Subir y bajar una rampa } \\
\text { 16. Salir a un evento social (por ejemplo, religioso, reunión familiar o } \\
\text { reunión social) }\end{array}$ & $\square 1$ & $\square 2$ & $\square 3$ \\
\hline
\end{tabular}

62.-Para cada actividad indique la preocupación ante la posibilidad de caerse.

\section{9.- VALORACIÓN NUTRICIONAL}

63.- ¿̈Ha comido menos por falta de apetito, problemas digestivos, dificultades de masticación o deglución en los últimos 3 meses?

$0=$ ha comido mucho menos

$1=$ ha comido menos

$2=$ ha comido igual

\section{4.- Pérdida reciente de peso ( $<3$ meses)}

$0=$ pérdida de peso $>3 \mathrm{~kg}$

$1=$ no lo sabe

2 = pérdida de peso entre 1 y $3 \mathrm{~kg}$

$3=$ no ha habido pérdida de peso

\section{5.- Movilidad}

0 = de la cama al sillón

1 = autonomía en el interior

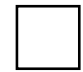

66.- ¿Ha tenido una enfermedad aguda o situación de estrés psicológico en los últimos 3 meses?

0 = sí

$2=$ no

\section{7.- Problemas neuropsicológicos}

$0=$ demencia 0 depresión grave

1 = demencia moderada

$2=$ sin problemas psicológicos

68.- Índice de masa corporal (IMC $=$ peso / (talla) $)^{2}$ en $\mathbf{k g} / \mathrm{m}^{2}$ )

$0=$ IMC $<19$

$1=19 \leq \mathrm{IMC}<21$

$2=21 \leq \mathrm{IMC}<23$

$3=\mathrm{IMC} \geq 23$

$2=$ sale del domicilio 
69.- Estado de los dientes:

$\square$ 1. Mantiene la dentadura

$\square$ 2. Portador de prótesis dental parcial

$\square$ 3. Portador de prótesis dental total

$\square$ 4. Falta de piezas dentarias

\section{0.- Estado de la boca:}

$\square$ 1. Correcta

$\square$ 2. Sucia

๑ 3. Xerostomía

$\square$ 4. Candidiasis bucal

$\square$ 5. Abscesos, erupciones y/o úlceras

$\square$ 6. Otros (especificar): $\square$ 2. Blanda

๑3. Triturada

๑ 4. Líquida

74.- Vía de administración:

$\square$ 1. Oral

$\square$ 2. SNG

๑ 3. GEP

๑ 4. Parenteral

$\square$ 5. Otros (especificar):

\title{
75.- Tipo de dieta:
}

\section{1.- Estado de las encías:}

$\square$ 1. Normal

$\square$ 1. Correctas

$\square$ 2. Diabética

๑3. Sin sal

$\square$ 2. Inflamadas

๑ 3. Hemorrágicas

๑ 4. Otros (especificar):
๑ 4. Hipocalórica
$\square$ 5. Otros (especificar):

\section{6.- Síntomas gastrointestinales}

\section{2.- Presenta dificultades en la deglución:}

\author{
$\square$ 1. Ninguno
}

$\square$ 2. Nauseas

2. Disfagia a líquidos

๑ 3. Disfagia a sólidos

๑ 3. Vómitos

๑4. Diarrea

๑ 4. Disfagia a líquidos y sólidos

$\square$ 5. Estreñimiento

\section{3.- Textura de la dieta habitual:}

$\square$ 6. Anorexia

$\square$ 1. Normal 
AMIGOS:

77.- En general, ¿Cuántos amigos tiene?

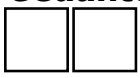

78.-¿̇A cuántos amigos ve al menos una vez al mes?

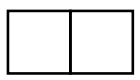

79.- ¿Con cuántos de ellos habla usted por teléfono al menos una vez al mes?

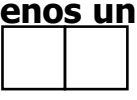

80.- ¿Cuánto tarda en llegar a casa del más cercano?

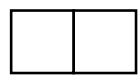

81.- ¿Con qué frecuencia sus amigos le hacen sentirse querido/a y cuidado/a?

$\square$ 1. Nunca

$\square 2$. A veces

$\square$ 3. Con frecuencia

$\square$ 4. Siempre

82.- ¿Con qué frecuencia sus amigos le escuchan cuando usted necesita hablar de sus preocupaciones o problemas?

$\square$ 1. Nunca

$\square$ 2. A veces

$\square$ 3. Con frecuencia

๑ 4. Siempre
83.- ¿Con qué frecuencia siente que sus amigos le reprochan lo que hace?

$\square$ 1. Nunca

$\square 2$. A veces

$\square$ 3. Con frecuencia

๑ 4. Siempre

84.- ¿Con qué frecuencia desearía poder confiar más en sus amigos?

$\square$ 1. Nunca

$\square 2$. A veces

$\square$ 3. Con frecuencia

口4. Siempre

85.- ¿Con qué frecuencia ayuda usted a sus amigos?

$\square$ 1. Nunca

$\square 2$. A veces

๑3. Con frecuencia

๑4. Siempre

86.- ¿Con qué frecuencia siente usted que tiene un papel importante entre sus amigos?

$\square$ 1. Nunca

$\square 2$. A veces

๑ 3. Con frecuencia

๑4. Siempre 
87.- ¿Con qué frecuencia se siente usted útil para sus amigos?
$\square$ 1. Nunca
$\square 2$. A veces
$\square$ 3. Con frecuencia
๑ 4. Siempre

88.- ¿En general, tiene usted la sensación de que durante el año pasado hizo más por sus amigos de lo que ellos hicieron por usted?

$\square$ 1. Los otros hicieron más
口2. Yo hice más

๑ 3. Un poco más

$\square$ 4. Aproximadamente lo mismo

89.- Teniendo en cuenta todas las cosas, ¿cómo está de satisfecho de su relación con sus amigos?
$\square$ 1. Nada satisfecho
$\square$ 2. Poco satisfecho
$\square$ 3. Algo satisfecho
口 4. Satisfecho
$\square$ 5. Muy satisfecho

\section{HIJOS:}

90.- ¿Cuántos hijos tiene?

95.- ¿Con qué frecuencia sus hijos le hacen sentirse querido/a y cuidado/a?

91.- ¿A cuántos de ellos ve al menos una vez al mes?

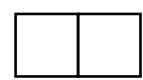

$\square$ 1. Nunca

$\square 2$. A veces

$\square$ 3. Con frecuencia

92.- ¿Con cuántos de ellos habla usted por teléfono al menos una vez al mes?

\section{4. Siempre}

96.- ¿Con qué frecuencia sus hijos le escuchan cuando usted necesita hablar de sus preocupaciones o problemas?

93.- ¿Cuánto tarda en llegar a casa del más cercano?

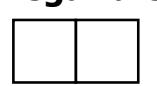
$\square$ 1. Nunca

$\square$ 2. A veces

94.- ¿Con cuántos de sus hijos cree usted que tiene una relación muy buena?

$\square$ 3. Con frecuencia

๑ 4. Siempre 
97.- ¿Con qué frecuencia siente que sus hijos le reprochan lo que hace?

$\square$ 1. Nunca

$\square 2$. A veces

3. Con frecuencia

$\square$ 4. Siempre

98.- ¿Con qué frecuencia desearía poder confiar más en sus hijos?

$\square$ 1. Nunca

$\square 2$. A veces

$\square$ 3. Con frecuencia

口4. Siempre

99.- ¿Con qué frecuencia ayuda usted a sus hijos?
$\square$ 1. Nunca
$\square 2$. A veces
$\square$ 3. Con frecuencia
$\square$ 4. Siempre

100.- ¿Con qué frecuencia siente usted que tiene un papel importante entre sus hijos?

$\square$ 1. Nunca

$\square 2$. A veces

口 3. Con frecuencia

口 4. Siempre
101.- ¿Con qué frecuencia se siente usted útil para sus hijos?

$\square$ 1. Nunca

$\square$ 2. A veces

$\square$ 3. Con frecuencia

$\square$ 4. Siempre

102.- ¿En general, tiene usted la sensación de que durante el año pasado hizo más por sus hijos de lo que ellos hicieron por usted?

$\square$ 1. Los otros hicieron más

๑2. Yo hice más

๑3. Un poco más

$\square$ 4. Aproximadamente lo mismo

103.- Teniendo en cuenta todas las cosas, ¿cómo está de satisfecho de su relación con sus hijos?
$\square$ 1. Nada satisfecho
$\square$ 2. Poco satisfecho
๑3. Algo satisfecho
4. Satisfecho
$\square$ 5. Muy satisfecho

\section{HERMANOS:}


104.- ¿Cuántos hermanos tiene?

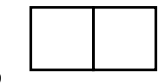

105.- ¿A cuántos de ellos ve al menos una vez al mes?

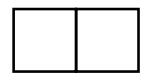

106.- ¿Con cuántos de ellos habla usted por teléfono al menos una vez al mes?

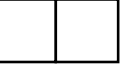

107.- ¿Cuánto tarda en llegar a casa del más cercano?

108.- ¿Con qué frecuencia sus hermanos le hacen sentirse querido/a y cuidado/a?

$\square$ 1. Nunca

$\square 2$. A veces

3. Con frecuencia

口4. Siempre

109.- ¿Con qué frecuencia sus hermanos le escuchan cuando usted necesita hablar de sus preocupaciones o problemas?

$\square$ 1. Nunca

$\square 2$. A veces

3. Con frecuencia

口4. Siempre

110.- ¿Con qué frecuencia siente que sus hermanos le reprochan lo que hace?

$\square$ 1. Nunca

$\square$ 2. A veces

3. Con frecuencia
๑ 4. Siempre

111.- ¿Con qué frecuencia desearía poder confiar más en sus hermanos?

$\square$ 1. Nunca

$\square 2$. A veces

․ Con frecuencia

$\square$ 4. Siempre

112.- ¿Con qué frecuencia ayuda usted a sus hermanos?

$\square$ 1. Nunca

$\square 2$. A veces

$\square$ 3. Con frecuencia

๑ 4. Siempre

113.- ¿Con qué frecuencia siente usted que tiene un papel importante entre sus hermanos?
$\square$ 1. Nunca
$\square 2$. A veces
$\square$ 3. Con frecuencia
$\square$ 4. Siempre

114.- ¿Con qué frecuencia se siente usted útil para sus hermanos?

$\square$ 1. Nunca

$\square 2$. A veces 

$\square$ 3. Con frecuencia
$\square$ 4. Siempre

115.- ¿En general, tiene usted la sensación de que durante el año pasado hizo más por sus hermanos de lo que ellos hicieron por usted?

$\square$ 1. Los otros hicieron más

$\square$ 2. Yo hice más

3. Un poco más $\square$ 4. Aproximadamente lo mismo

116.- Teniendo en cuenta todas las cosas, ¿cómo está de satisfecho de su relación con sus hermanos?
$\square$ 1. Nada satisfecho
2. Poco satisfecho
3. Algo satisfecho
4. Satisfecho
5. Muy satisfecho

SOBRINOS:

117.- ¿Cuántos sobrinos tiene?

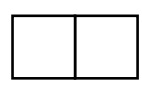

$\square$ 4. Siempre

122.- ¿Con qué frecuencia sus sobrinos le escuchan cuando usted necesita hablar de sus preocupaciones o problemas?

$\square$ 1. Nunca

$\square$ 2. A veces

$\square$ 3. Con frecuencia

$\square$ 4. Siempre

123.-. ¿Con qué frecuencia siente que sus sobrinos le reprochan lo que hace?
$\square$ 1. Nunca

$\square$ 2. A veces

$\square$ 3. Con frecuencia

$\square$ 4. Siempre 
124.- ¿Con qué frecuencia desearía poder confiar más en sus sobrinos?
$\square$ 1. Nunca
$\square 2$. A veces
3. Con frecuencia
๑ 4. Siempre

125.- ¿Con qué frecuencia ayuda usted a sus sobrinos?

$\square$ 1. Nunca

$\square 2$. A veces

$\square$ 3. Con frecuencia

๑ 4. Siempre

126.- ¿Con qué frecuencia siente usted que tiene un papel importante entre sus sobrinos?

$\square$ 1. Nunca

$\square 2$. A veces

$\square$ 3. Con frecuencia

口4. Siempre

127.- ¿Con qué frecuencia se siente usted útil para sus sobrinos?

$\square$ 1. Nunca $\square 2$. A veces

๑ 3. Con frecuencia

๑ 4. Siempre

128.- ¿En general, tiene usted la sensación de que durante el año pasado hizo más por sus sobrinos de lo que ellos hicieron por usted?

๑ 1. Los otros hicieron más

๑2. Yo hice más

๑3. Un poco más

$\square$ 4. Aproximadamente lo mismo

129.- Teniendo en cuenta todas las cosas, ¿cómo está de satisfecho de su relación con sus sobrinos?

๑ 1. Nada satisfecho

$\square$ 2. Poco satisfecho

$\square$ 3. Algo satisfecho

口 4. Satisfecho

5. Muy satisfecho

\section{NIETOS:}

130.- ¿Cuántos nietos tiene?

131.- ¿A cuántos de ellos ve al menos una vez al mes?

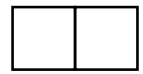


132.- ¿Con cuántos de ellos habla usted por teléfono al menos una vez al mes?

133.- ¿Cuánto tarda en llegar a casa del más cercano?

134.- ¿Con qué frecuencia sus nietos le hacen sentirse querido/a y cuidado/a?

$\square$ 1. Nunca

$\square 2$. A veces

$\square$ 3. Con frecuencia

4. Siempre

135.- ¿Con qué frecuencia sus nietos le escuchan cuando usted necesita hablar de sus preocupaciones o problemas?

$\square$ 1. Nunca

$\square$ 2. A veces

$\square$ 3. Con frecuencia

$\square$ 4. Siempre

136.-¿Con qué frecuencia siente que sus nietos le reprochan lo que hace?

$\square$ 1. Nunca

$\square 2$. A veces

$\square$ 3. Con frecuencia

๑ 4. Siempre

137.- ¿Con qué frecuencia desearía poder confiar más en sus nietos?

$\square$ 1. Nunca $\square 2$. A veces

๑3. Con frecuencia

๑ 4. Siempre

138.- ¿Con qué frecuencia ayuda usted a sus nietos?

$\square$ 1. Nunca

$\square 2$. A veces

$\square$ 3. Con frecuencia

$\square$ 4. Siempre

139.- ¿Con qué frecuencia siente usted que tiene un papel importante entre sus nietos?

$\square$ 1. Nunca

$\square 2$. A veces

๑3. Con frecuencia

⒋ Siempre

140.- ¿Con qué frecuencia se siente usted útil para sus nietos?

$\square$ 1. Nunca

$\square 2$. A veces

๑ 3. Con frecuencia

⒋ Siempre

141.- ¿En general, tiene usted la sensación de que durante el año pasado hizo más por sus nietos de lo que ellos hicieron por usted?

$\square$ 1. Los otros hicieron más

๑2. Yo hice más

๑3. Un poco más 

$\square$ 4. Aproximadamente lo mismo
$\square$ 4. Satisfecho
$\square$ 5. Muy satisfecho

142.- Teniendo en cuenta todas las cosas, ¿cómo está de satisfecho de su relación con sus nietos?
$\square$ 1. Nada satisfecho
$\square$ 2. Poco satisfecho
3. Algo satisfecho

\section{ESPOSO/A - PAREJA:}

143.- ¿Con qué frecuencia su esposo/apareja le hace sentirse querido/a y cuidado/a?
$\square$ 1. Nunca
$\square 2$. A veces
$\square$ 3. Con frecuencia
$\square$ 4. Siempre

144.- ¿Con qué frecuencia su esposo/apareja le escucha cuando usted necesita hablar de sus preocupaciones o problemas?
$\square$ 1. Nunca
$\square 2$. A veces
$\square$ 3. Con frecuencia
$\square$ 4. Siempre

145.- ¿Con qué frecuencia siente que su esposo/a-pareja le reprocha lo que hace? $\square$ 2. A veces

$\square$ 3. Con frecuencia

$\square$ 4. Siempre

146.- ¿Con qué frecuencia desearía poder confiar más en su esposo/a-pareja?

$\square$ 1. Nunca

$\square 2$. A veces

$\square$ 3. Con frecuencia

$\square$ 4. Siempre

147.- ¿Con qué frecuencia ayuda usted a su esposo/a-pareja?

$\square$ 1. Nunca

$\square 2$. A veces

$\square$ 3. Con frecuencia

$\square$ 4. Siempre

$\square$ 1. Nunca 
148.- ¿Con qué frecuencia siente usted que tiene un papel importante para su esposo/a-pareja?

$\square$ 1. Nunca

$\square 2$. A veces

๑ 3. Con frecuencia

4. Siempre

149.- ¿Con qué frecuencia se siente usted útil para su esposo/a-pareja?

$\square$ 1. Nunca

$\square 2$. A veces

3. Con frecuencia

๑4. Siempre

150.- ¿En general, tiene usted la sensación de que durante el año pasado hizo más por

su esposo/a- pareja de lo que él/ella hizo por usted?

๑ 1. Él/ella hizo más

$\square$ 2. Yo hice más

๑3. Un poco más

$\square$ 4. Aproximadamente lo mismo

151.- Teniendo en cuenta todas las cosas, ¿cómo está de satisfecho de su relación con su esposo/a-pareja?

$\square$ 1. Nada satisfecho

$\square$ 2. Poco satisfecho

$\square$ 3. Algo satisfecho

๑ 4. Satisfecho

$\square$ 5. Muy satisfecho

\section{CONFIDENTE:}

152.- ¿Hay algunas personas especiales con quien pueda usted compartir confidencias y sentimientos, alguien en quien usted sienta que puede confiar?
口 1. Sí
$\square$ 2. No

153.- ¿Qué relación tiene usted con esas personas?

口 1. Esposo/a

๑2. Hija

๑ 3. Hijo 

4. Hermana
5. Hermano
$\square$ 6. Otro familiar (mujer)
7. Otro familiar (hombre)
$\square$ 8. Amiga
口 9. Amigo
$\square$ 10. Profesional:
$\square$ 11. Otro:

154.- ¿Cuántas veces, durante el último año, ha utilizado estos servicios?
$\square$ 1. Consulta especialista

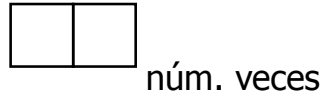

$\square 2$. Ingreso hospitalario

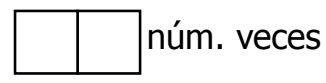

๑3. Rehabilitación

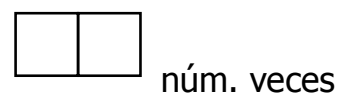

155.- Y durante el último mes, ¿cuántas veces ha utilizado los siguientes?

$\square$ 1. Médico de cabecera

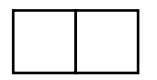

núm. veces

157.- ¿Forma parte de alguna asociación o club cultural?

156.- Si no ha ido usted al médico de cabecera/enfermera, ¿ha ido alguien por usted?
๑1. Sí
$\square$ 2. No

๑ 1. Sí

$\square$ 2. No

2. Enfermera de familia

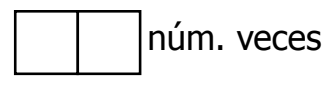

158.- ¿Cuántas veces al mes acude usted a:

$\square$ 1. Plaza o lugar céntrico del barrio?: vec/mes

$\square$ 2. Hogar del pensionista o centro de tercera edad?: vec/mes

$\square$ 3. Parroquia, iglesia o culto?: vec/mes 
159.- Le leeré una serie de servicios sociales existentes para personas mayores. Me gustaría que me dijera cuáles utiliza

$\square$ 1. Hogares y clubes de personas mayores

$\square$ 2. Comedores sociales

$\square$ 3. Vacaciones o viajes

口 4. Balnearios

5. Teleasistencia

口 6. Ayuda a domicilio

7. Centros de día

8. Estancias temporales

9. Comidas a domicilio

\section{1.- CALIDAD DE VIDA RELACIONADA CON EL ESTADO DE SALUD}

Las preguntas siguientes se refieren a lo que usted piensa de su salud. Sus respuestas nos permitirán saber como se encuentra usted y hasta que punto es capaz de hacer las actividades habituales.

\begin{tabular}{|c|c|c|c|c|}
\hline $\begin{array}{l}\text { 160.- En general, usted diría que su salud es: } \\
\square \text { 1. Excelente } \\
\square 2 \text {. Muy buena } \\
\square 3 \text {. Buena } \\
\square 4 \text {. Regular } \\
\square 5 \text {. Mala }\end{array}$ & \multicolumn{4}{|c|}{$\begin{array}{l}\text { 161.- ¿Cómo diría que es su salud actual, comparada con } \\
\text { la de hace un año? } \\
\square \text { 1. Mucho mejor ahora que hace un año } \\
\square \text { 2. Algo mejor ahora que hace un año } \\
\square \text { 3. Más o menos igual que hace un año } \\
\square \text { 4. Algo peor ahora que hace un año } \\
\square \text { 5. Mucho peor ahora que hace un año }\end{array}$} \\
\hline \multicolumn{5}{|c|}{$\begin{array}{l}\text { 162.- Las preguntas siguientes se refieren a actividades o cosas que usted podría hacer en un día normal. Su salud } \\
\text { actual, ¿Le limita para hacer estas actividades o cosas? Si es así, ¿Cuánto? }\end{array}$} \\
\hline \multicolumn{2}{|l|}{ dades } & $\begin{array}{l}\text { Sí, me limita } \\
\text { mucho }\end{array}$ & $\begin{array}{l}\text { Sí, me limita } \\
\text { un poco }\end{array}$ & $\begin{array}{l}\text { No me } \\
\text { limita }\end{array}$ \\
\hline \multicolumn{2}{|c|}{$\begin{array}{l}\text { a. Esfuerzos intensos (correr, levantar objetos pesados o participar en deportes } \\
\text { agotadores) }\end{array}$} & $\square 1$ & $\square 2$ & $\square 3$ \\
\hline \multicolumn{2}{|c|}{$\begin{array}{l}\text { b. Esfuerzos moderados (mover una mesa, pasar la aspiradora, jugar a los } \\
\text { bolos, caminar más de una hora) }\end{array}$} & $\square 1$ & $\square 2$ & $\square 3$ \\
\hline \multicolumn{2}{|l|}{ c. Coger o llevar la bolsa de la compra } & $\square 1$ & $\square 2$ & $\square 3$ \\
\hline \multicolumn{2}{|l|}{ d. Subir varios pisos por las escaleras } & $\square 1$ & $\square 2$ & $\square 3$ \\
\hline \multicolumn{2}{|l|}{ e. Subir un sólo piso por la escalera } & $\square 1$ & $\square 2$ & $\square 3$ \\
\hline \multicolumn{2}{|l|}{ f. Agacharse 0 arrodillarse } & $\square 1$ & $\square 2$ & $\square 3$ \\
\hline \multicolumn{2}{|l|}{ g. Caminar $1 \mathrm{~km}$ o más } & $\square 1$ & $\square 2$ & $\square 3$ \\
\hline \multicolumn{2}{|l|}{ h. Caminar varios centenares de metros } & $\square 1$ & $\square 2$ & $\square 3$ \\
\hline \multicolumn{2}{|l|}{ i. Caminar unos 100 metros } & $\square 1$ & $\square 2$ & $\square 3$ \\
\hline \multicolumn{2}{|l|}{ j. Bañarse o vestirse por sí mismo } & $\square 1$ & $\square 2$ & $\square 3$ \\
\hline
\end{tabular}




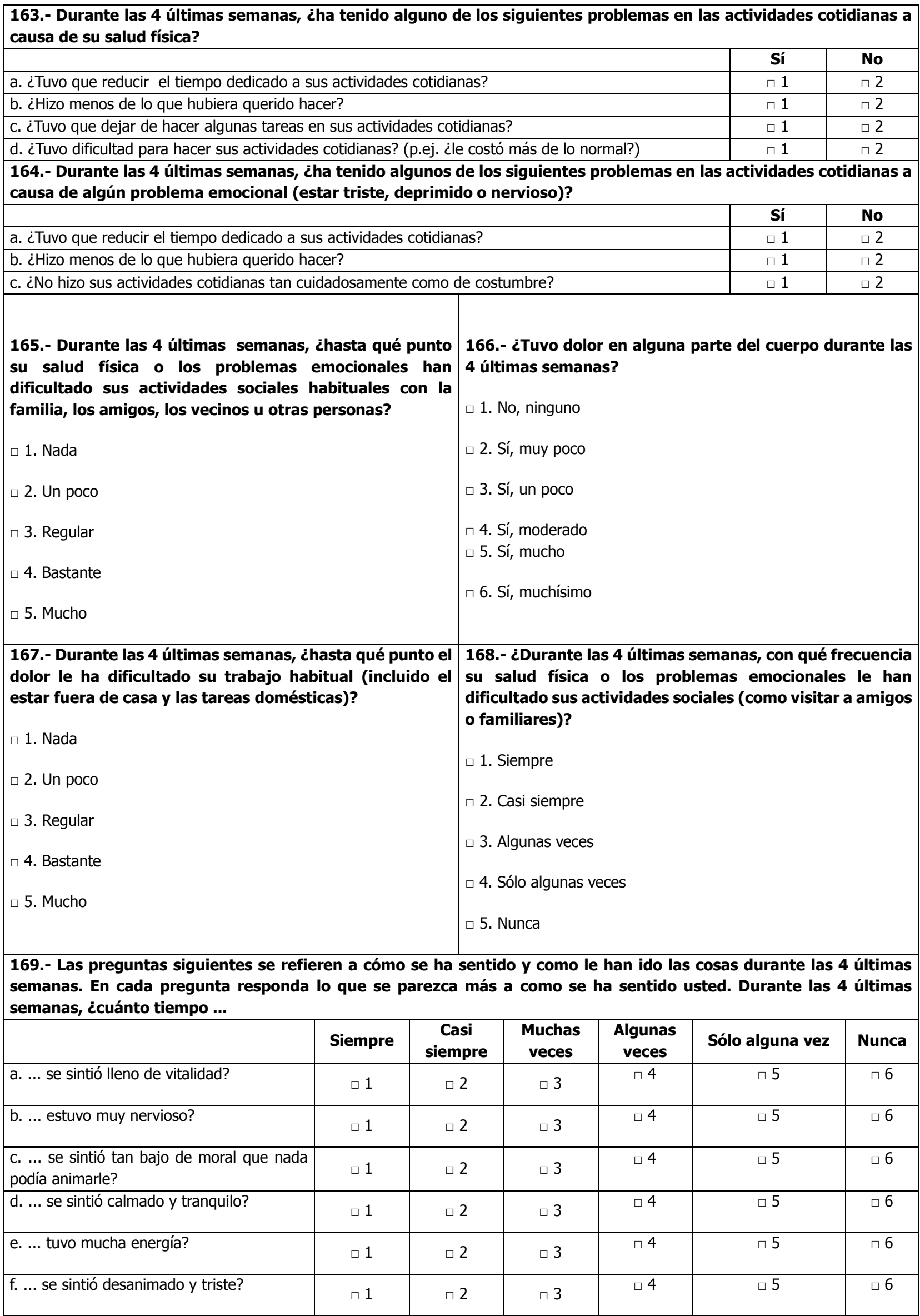


Análisis de las relaciones sociales y la fragilidad en las personas mayores de 75 años residentes en Castellón de la Plana

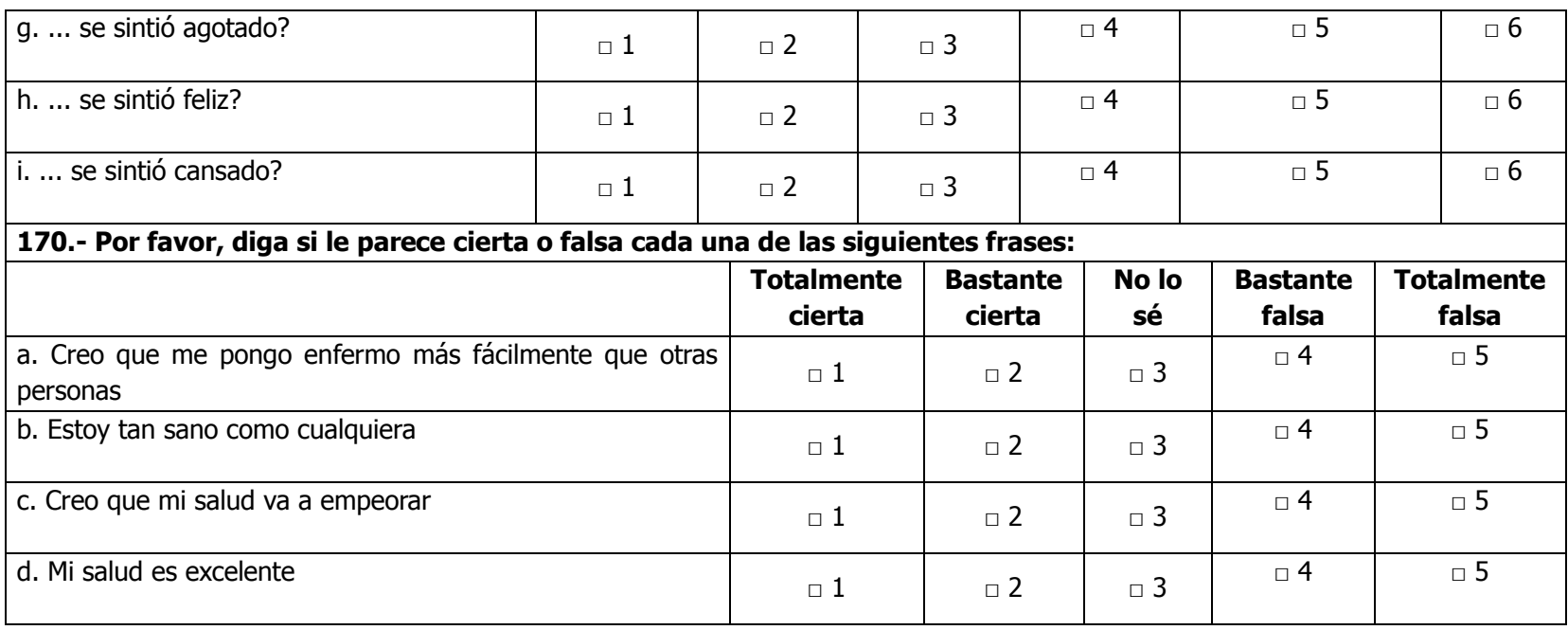

\section{5.- HÁBITOS DE SALUD 2a Parte}

171.- Diga con qué frecuencia realiza las siguientes actividades:

\begin{tabular}{|c|c|c|c|c|c|c|c|c|}
\hline & Nunca & $\begin{array}{l}<1 \\
\text { por } \\
\text { sem }\end{array}$ & $\begin{array}{l}1-2 \\
\text { por } \\
\text { sem }\end{array}$ & $\begin{array}{l}\text { 3-4 } \\
\text { por } \\
\text { sem }\end{array}$ & $\begin{array}{l}\text { 5-7 } \\
\text { por } \\
\text { sem }\end{array}$ & $\begin{array}{c}<30 \\
\text { min. } \\
\text { cada vez }\end{array}$ & $\begin{array}{c}\text { 30-60 } \\
\text { min. } \\
\text { cada vez }\end{array}$ & $\begin{array}{l}>60 \mathrm{~min} . \\
\text { cada vez }\end{array}$ \\
\hline 1. Caminar & $\square 0$ & $\square 1$ & $\square 2$ & $\square 3$ & $\square 4$ & $\square 1$ & $\square 2$ & $\square 3$ \\
\hline $\begin{array}{l}\text { 2. Deportes ligeros } \\
\text { (bolos) }\end{array}$ & $\square 0$ & $\square 1$ & $\square 2$ & $\square 3$ & $\square 4$ & $\square 1$ & $\square 2$ & $\square 3$ \\
\hline $\begin{array}{l}\text { 3. Deportes moderados } \\
\text { (bailar) }\end{array}$ & $\square 0$ & $\square 1$ & $\square 2$ & $\square 3$ & $\square 4$ & $\square 1$ & $\square 2$ & $\square 3$ \\
\hline $\begin{array}{l}\text { 4. Deportes vigorosos } \\
\text { (nadar, cazar, } \\
\text { montañismo, pescar) }\end{array}$ & $\square 0$ & $\square 1$ & $\square 2$ & $\square 3$ & $\square 4$ & $\square 1$ & $\square 2$ & $\square 3$ \\
\hline 5. Trabajo de casa ligero & $\square 0$ & $\square 1$ & $\square 2$ & $\square 3$ & $\square 4$ & $\square 1$ & $\square 2$ & $\square 3$ \\
\hline 6. Trabajo de casa pesado & $\square 0$ & $\square 1$ & $\square 2$ & $\square 3$ & $\square 4$ & $\square 1$ & $\square 2$ & $\square 3$ \\
\hline
\end{tabular}




\begin{tabular}{|c|c|c|c|c|c|c|c|c|}
\hline & Nunca & $\begin{array}{l}<1 \\
\text { por } \\
\text { sem }\end{array}$ & $\begin{array}{l}1-2 \\
\text { por } \\
\text { sem }\end{array}$ & $\begin{array}{l}\text { 3-4 } \\
\text { por } \\
\text { sem }\end{array}$ & $\begin{array}{l}5-7 \\
\text { por } \\
\text { sem }\end{array}$ & $\begin{array}{c}<30 \\
\text { min. } \\
\text { cada vez }\end{array}$ & $\begin{array}{c}\text { 30-60 } \\
\text { min. } \\
\text { cada vez }\end{array}$ & $\begin{array}{l}>60 \mathrm{~min} . \\
\text { cada vez }\end{array}$ \\
\hline $\begin{array}{l}\text { 7. Estar al cuidado del } \\
\text { jardín o el huerto }\end{array}$ & $\square 0$ & $\square 1$ & $\square 2$ & $\square 3$ & $\square 4$ & $\square 1$ & $\square 2$ & $\square 3$ \\
\hline $\begin{array}{l}\text { 8. Estar al cuidado de } \\
\text { personas enfermas }\end{array}$ & $\square 0$ & $\square 1$ & $\square 2$ & $\square 3$ & $\square 4$ & $\square 1$ & $\square 2$ & $\square 3$ \\
\hline $\begin{array}{l}\text { 9. Estar al cuidado de } \\
\text { niños }\end{array}$ & $\square 0$ & $\square 1$ & $\square 2$ & $\square 3$ & $\square 4$ & $\square 1$ & $\square 2$ & $\square 3$ \\
\hline
\end{tabular}

\section{8.- CAÍDAS 2a Parte}

\section{2.- ¿Ha restringido sus actividades por miedo a volver a caer?}
๑1. Sí
$\square$ 2. No 


\section{ANEXO 2.}

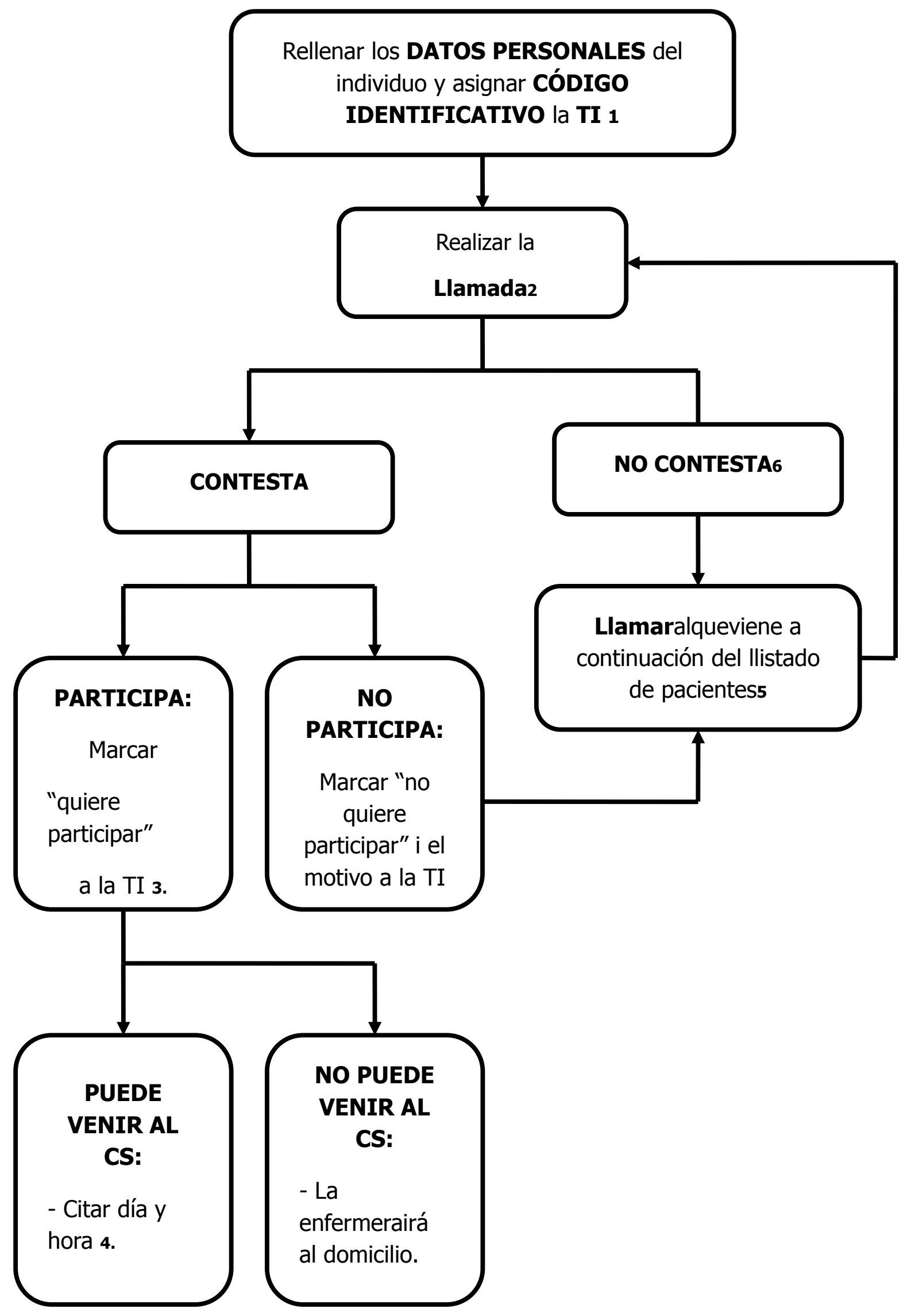




\section{ANEXO 3}

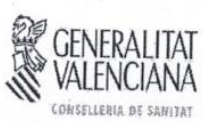

\section{INFORME COMITÉ ÉTICO DE INVESTIGACIÓN CLÍNICA HOSPITAL GENERAL UNIVERSITARIO DE CASTELLÓ} Doña Georgina Queral Capdevila, Secretaria del Comité Ético de Investigación Clínica del
Hospital General Universitario de Castelló,

\section{CERTIFICA}

Que el Comité Ético de Investigación Clínica del HOSPITAL GENERAL UNIVERSITARIO DE CASTELLó en su reunión del día 26 de enero de 2015, acta 1/2015, tras la evaluación de la propuesta realizada por: Ma Pilar Molés Julio / Maria Loreto Macia del Proyecto investigación Tesis Doctoral "Estudio de salud de la población tratar la fragilidad".

Servicio: Atención Primaria

Investigador Principal: Ma Pilar Molés Julio / Maria Loreto Macia.

Y teniendo en consideración las siguientes cuestiones:

1. Cuestiones relacionadas con la idoneidad del investigador y sus colaboradores.

2. Cuestiones relacionadas con la idoneidad de las instalaciones.

3. Cuestiones relacionadas con la idoneidad del protocolo en relación con los objetivos del

4. Consideraciones

4. Consideraciones generales del estudio.

\section{EMITE UN INFORME FAVORABLE}

El Comité tanto en su composición como en los PNT cumple con las normas de BPC (CPMP/ICH/135/95) y con el Real Decreto 223/2004, y su composición actual es la siguiente:

\begin{tabular}{|c|c|}
\hline Presidenta & $\begin{array}{l}\text { Da Amparo Barreda Aznar } \\
\text { Farmacéutica Atención Primaria }\end{array}$ \\
\hline Vicepresidente & D. Emilio Ibáñez Benages \\
\hline Secretaria & $\begin{array}{l}\text { Da Georgina Queral Capdevila } \\
\text { Miembro ajeno a la profesión sanitaria }\end{array}$ \\
\hline Vocales & 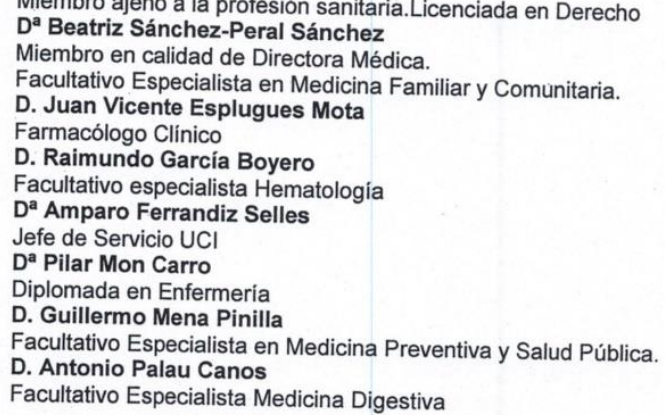 \\
\hline
\end{tabular}


9 GENERALITAT
VALENCIANA
ton
Daria Esther Roselló Sastre

Facultativo Especialista Anatomia Patológica

D. Mario Ferrer Vázquez

Facultativo Especialista Pediatria

Da Neus Rodríguez Bacardit

Facultativo Especialista Medicina Familiar y Comunitaria

Da José Alejandro Díaz Gutiérrez

Miembro lego

D. Ismael García Costa

Facultativo Especialista Traumatologia

$D^{a}$ Berta Claramonte Clausell

Facultativo Especialista Neurología

D. José Vicente Castelló Carrascosa

Facultativo Especialista Alergología

Que en dicha reunión del Comité Ético de Investigación Clínica se cumplió el quórum preceptivo legalmente.

Que en el caso de que se evalúe algún proyecto del que un miembro sea investigador/colaborador, éste se ausentará de la reunión durante la discusión del proyecto.

Lo que firmo en Castellón a 26 de enero de 2015

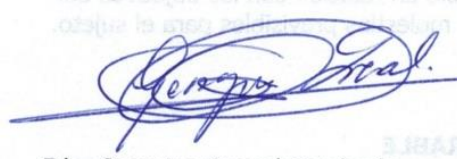

Fdo. Georgina Queral Capdevila Secretaria
HOSPTAL GEUERAL DE CASTELLOR

$$
\text { C. 国。D。C。 }
$$

COMTÉ ETICO DE INVESTIQAOIO: CIMNACA

Avgda. Benicàssim, s/n 12004 Castelló - Tel. (+34) 964726500 - Fax. (+34) 964726645 www.castello.san.gva.es 


\title{
ANEXO 4.
}

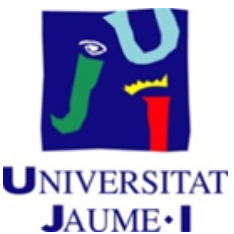

\author{
UNITAT PREDEPARTAMENTAL \\ D'INFERMERIA
}

\section{HOJA DE INFORMACIÓN AL PACIENTE}

TÍTULO DEL ESTUDIO: Evolución del proceso de fragilidad de las personas mayores de Castellón

INVESTIGADOR PRINCIPAL: Pilar Molés Julio. Profesora Ayudante del departamento de Enfermería de la Universidad de Castellón (UJI).

Nos dirigimos a Ud. para informarle sobre un estudio de investigación, aprobado por un comité ético. Nuestra intención es tan sólo que Ud. reciba la información correcta y suficiente para que pueda evaluar y juzgar si quiere o no participar en este estudio. Por ello, le ruego que lea esta hoja informativa con atención, pudiendo consultar con las personas que considere oportunas, y nosotros le aclararemos las dudas que le puedan surgir.

Debe saber que su participación en este estudio es voluntaria, y que puede decidir no participar, o cambiar su decisión y retirar su consentimiento en cualquier momento, sin que por ello se altere la relación su médico ni produzca perjuicio alguno en su tratamiento.

El estudio consiste en analizar los procesos de fragilidad asociados a la edad de las personas mayores de $\mathbf{7 5}$ años que viven en su propio domicilio en la ciudad de Castellón y el efecto que sobre los mismos ejercen los cambios biológicos, psicológicos y sociales.

El número de participantes que se prevé para la realización del estudio será de 1.300 , todos ellos escogidos al azar a partir de su tarjeta sanitaria.

La fragilidad es un conjunto de síntomas y signos que se presentan asociados al envejecimiento y puede producirse por múltiples causas. 
Se le realizará una entrevista que durará aproximadamente cuarenta minutos. Consistirá en hacerle una serie de preguntas que usted deberá contestar lo más fielmente posible. Además, se le medirá la altura, la circunferencia de la pantorrilla, el perímetro del brazo y la altura talón rodilla y se pesará. Todo ello para saber su grado de nutrición. Además, se le medirá la fuerza del apretón de mano y la velocidad al caminar una distancia de unos 5 metros. Todos estos parámetros sirven para saber el grado de fragilidad.

Se recogerán de su historia clínica los últimos datos analíticos y la medicación que toma actualmente. Todos los registros o datos que pudieran identificarlo serán protegidos con acceso estrictamente restringido a su archivo. Sólo el número de participante le identificará en el tratamiento y análisis de esta información.

En ningún caso, el estudio podrá comportar peligro adicional para su salud. Es muy importante identificar las personas mayores frágiles a tiempo para poder intervenir y prevenir efectos adversos. En el caso de que usted no pudiera beneficiarse de los posibles avances que aporte nuestra investigación, sí que podrán ser importantes para otros pacientes en el futuro. En todo caso, si aparecen resultados que puedan ser importantes para usted, le serán dados a conocer.

El tratamiento, la comunicación y la cesión de los datos de carácter personal de todos los sujetos participantes ajustará a lo dispuesto en la Ley Orgánica 15/99 de 13 de diciembre de protección de datos de carácter personal. De acuerdo a lo que establece la legislación mencionada, usted puede ejercer los derechos de acceso, modificación, oposición y cancelación de datos, para lo cual deberá dirigirse a su centro de salud. Los datos recogidos por el estudio estarán identificados mediante un código y solamente el investigador principal podrá relacionar estos datos con Usted y con su historia clínica. Por lo tanto, su identidad no será revelada a ninguna persona.

Se verificará que se ha recibido permiso por parte del entrevistado para guardar sus datos con la finalidad de poder volver a entrevistarle a los dos años en caso de necesidad. 
ANEXO 5.

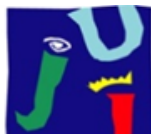

UNITAT PREDEPARTAMENTAL D'INFERMERIA

UNIVERSITAT

JAUME•I

\section{CONSENTIMIENTO INFORMADO}

Yo,

He leído la hoja de información al paciente que se me ha entregado.

He podido hacer preguntas sobre el estudio.

He recibido suficiente información sobre el estudio.

He hablado con:

Comprendo que mi participación es voluntaria.

Comprendo que puedo retirarme del estudio:

- Cuando quiera.

- Sin tener que dar explicaciones.

- Sin que ello repercuta en mis cuidados médicos.

Y, por lo tanto, presto libremente mi conformidad para participar en el estudio.

Fecha:

Firma del participante: 
Firma del investigador:

Firma del cuidador/familiar*:

* Sólo en caso de que el paciente no pueda firmar el consentimiento informado. 